\title{
IV. Die industriellen Beziehungen im Ruhrbergbau unter besonderer Berücksichtigung der Schachtanlagen der Abteilung Bergbau der Vereinigten Stahlwerke
}

\section{Das Unternehmen und seine Vorgänger}

\section{Grundzüge der Unternehmensentwicklung}

Die Gelsenkirchener Bergbau AG (GBAG) war bereits vor dem Ersten Weltkrieg das größte deutsche Steinkohlenunternehmen. 1913 hatte die Belegschaft der Schachtanlagen eine Größe von 37000, die Kohlenförderung betrug 10,35 Millionen Tonnen, was in etwa $10 \%$ der Ruhrgebietsförderung entsprach. ${ }^{1}$ Der Felderbesitz der Gesellschaft, die seit ihrer Gründung 3. 1. 1873) unter der Leitung Emil Kirdorfs stand, konzentrierte sich auf Gelsenkirchen (Rheinelbe/Alma) und Dortmund (Minister Stein/Fürst Hardenberg, Hansa, Zollern, Germania, Monopol und Westhausen). Größte Schachtanlagen vor dem Ersten Weltkrieg waren Rheinelbe/Alma mit einer Jahresförderung von 2,3 Millionen Tonnen und Monopol mit 1,1 Millionen Tonnen. ${ }^{2}$ Die Expansion des Unternehmens vor dem Ersten Weltkrieg verlief durch stürmische Entwicklung der Kohlenförderung und vertikale Konzentration. Die Fusion mit dem Aachener Hütten-Aktienverein und dem Schalker Gruben- und Hüttenverein machte 1907 aus dem Steinkohlenunternehmen einen integrierten schwerindustriellen Konzern, dessen Roheisen- und Stahlbasis linksrheinisch und in Lothringen konzentriert war, so daß im Ergebnis des Ersten Weltkrieges die GBAG ihre Erz- und Eisenbasis verlor. Die Interessengemeinschaft mit Hugo Stinnes' Deutsch-Luxemburgischer Bergwerks- und Hütten AG, die an einer Ausdehnung ihrer Kohlenbasis interessiert war, zur Rheinelbe Union im August 1920 war daher nur folgerichtig. Mit der Ausdehnung des Gemeinschaftsvertrages auf den Bochumer Verein für Gußstahlproduktion (März 1921) entstand in der Inflation einer der größten schwerindustriellen Konzerne, dessen Abteilung Bergbau durch die Zechen von Deutsch-Lux (Bruchstraße, Prinz Regent, Dannenbaum, Friedlicher Nachbar, Friederika, Tremonia, Adolf von Hansemann) und des Bochumer Vereins (Teutoburgia, Carolinenglück, Engelsburg) neben Schwerpunkten in Gelsenkirchen und Dortmund nun auch in Bochum stark vertreten war. Die BV- und Deutsch-Lux-Zechen hatten geringere Fördermengen; ein Teil von ihnen wurde bereits in der zweiten Hälfte der zwan-

I Die Geschichte der Gelsenkirchener Bergwerks AG von ihrer Gründung 1873 bis Anfang 1960, S. 3.

2 Wiel, Wirtschaftsgeschichte des Ruhrgebietes, S. $180 \mathrm{f}$. 
ziger Jahre stillgelegt. Die Fusion der Rheinelbe-Union 1926 mit Thyssen (Schachtanlagen Lohberg, Wehofen, Friedrich Thyssen 1/6, 2/5, 3/7, 4/8), den Rheinischen Stahlwerken (Schachtanlagen wurden nicht eingebracht), der Phoenix AG (Schachtanlagen Westende, Graf Moltke, Nordstern, Zollverein, Holland, Vereinigtes Hörder Kohlenwerk) sowie den Vereinigten Stahlwerken van der Zypen zur Vereinigten Stahlwerke AG brachte im Kohlenbereich einen weiteren Konzentrationsschub. Die in vier Gruppen (Dortmund, Bochum, Gelsenkirchen, Hamborn) organisierte Abteilung Bergbau der Vereinigten Stahlwerke mit Sitz in Essen, die 1934 im Kontext der Reorganisation der Vereinigten Stahlwerke als neue Gelsenkirchener Bergwerks AG (daher im folgenden auch GBAG) fortgeführt wurde ${ }^{3}$, hielt nach Abschluß umfangreicher Rationalisierungsmaßnahmen im September 1934 mit knapp 37 Millionen Tonnen etwa 21,3\% der gesamten Förderkapazität des Ruhrgebiets. Diese Förderkapazität entfiel 1934 auf 25 Schachtanlagen (acht in Dortmund, je sechs in Bochum und Gelsenkirchen, fünf in Hamborn), wobei die Gruppen Dortmund und Gelsenkirchen die größte, Bochum mit 18400 tato die geringste Kapazität aufwies. ${ }^{4}$ Die Belegschaft der Abteilung Bergbau umfaßte bei ihrer Gründung 1926 im Monatsdurchschnitt 84400 Arbeiter und Angestellte, stieg bis 1927/28 auf 93000 und sank von 1928 bis 1932/ 33 kontinuierlich auf schließlich 43132. Während bei der Gründung auf einen Angestellten 16 Arbeiter entfielen, was etwa 6,4\% Anteil der Angestellten an der Belegschaft entsprach, und der Abstand im Zuge der Rationalisierung zunächst noch wuchs, änderte sich die Zusammensetzung der Belegschaft in der Weltwirtschaftskrise; 1931/32 hatten die Angestellten einen Anteil von mehr als $9 \%$ an der Gesamtbelegschaft. ${ }^{5}$

Nach der Fusion begann im Bereich der Abteilung Bergbau der Vereinigten Stahlwerke ein umfangreicher Rationalisierungsproze $\beta^{6}$ mit dem Ziel, die Förderleistungen zu erhöhen und die Förderkosten zu senken. Zu diesem Zweck wurden unrentable Zechen geschlossen, Betriebspunkte zusammengelegt, vorhandene Schachtanlagen modernisiert und schließlich Zollverein 12 und Minister Stein zu Großschachtanlagen ausgebaut. 1938 förderten Zollverein, Friedrich Thyssen und Minister Stein jeweils mehr als zwei Millionen Jahrestonnen; Zollverein war mit knapp 3,6 Millionen Jahrestonnen die größte Zeche des Ruhrgebietes.7 Parallel zu Zusammenfassung und Erweiterung der Schachtanlagen wurden auch die Nebenbetriebe rationalisiert, wobei insbesondere der Bau neuer Groß- bzw. Zentral-

3 Zum Hintergrund Klass, Albert Vögler, S. 220 ff. Ferner Geschichte der Gelsenkirchener Bergwerks AG, S. $10 \mathrm{f}$.

4 BgA 55/1295: GBAG, Betriebs- und Wirtschaftlichkeitsverhältnisse 1926-1933/34, Essen 1935, S. 3.

5 BgA 55/498: Monatsbericht der Vereinigten Stahlwerke 9/1933, S. 50 f.

6 Der Beginn der Rationalisierung im Ruhrbergbau ist umstritten. Die wirtschaftliche Rationalisierung, und von ihr ist im folgenden Rede, begann im Grunde nach der Wiederherstellung geordneter betriebswirtschaftlicher Verhältnisse 1924. Technisch gesehen lassen sich „Rationalisierungsprozesse" schwerlich exakt terminieren. So weist Karin Hartewig zurecht darauf hin, daß jene Techniken, die in der Zeit nach 1924 flächendeckend Verwendung fanden, eine längere Vorgeschichte besaßen. Zur technischen Rationalisierung im einzelnen Burghardt, Die Mechanisierung des Ruhrbergbaus 1890-1930. Hartewig, Das unberechenbare Jahrzehnt, S. 82-119, hier S. 83.

7 Wiel, Wirtschaftsgeschichte des Ruhrgebietes, S. $182 \mathrm{f}$. Betriebs- und Wirtschaftlichkeitsverhältnisse, S. 7-9. 
kokereien das Bild bestimmte. Förderkapazitäten, Schichtleistungen und Leistungsfähigkeit der Nebenbetriebe konnten durch das umfangreiche Investitionsprogramm (1926 bis 1933200 Millionen RM, davon allein 180 Mio. RM in den Jahren 1927 bis 1930/31) so gesteigert werden, daß der Vorstand in einem Wirtschaftlichkeitsbericht 1935 zu dem Ergebnis kam, „daß mit zunehmender Beschäftigung ihre Lage [i.e. der Schachtanlagen und Kokereien der GBAG] schnell günstig wird, weil technisch und lagerstättlich alle Voraussetzungen vorliegen, um die Kohlengewinnung mit den denkbar geringsten Selbstkosten durchzuführen, soweit dieses der Stand der Löhne, der Abgaben und Steuern sowie der Umfang der Beschäftigung im Hinblick auf die Allgemeinkosten praktisch zulassen."

Insbesondere war es gelungen, die Förderleistung je Mann und Schicht derart zu steigern (1934 zwischen 1,8 to in der Gruppe Bochum und über 2 to in der Gruppe Hamborn; im Durchschnitt 1933/34 1,95 to gegenüber 1,18 to 1926/27), daß die Arbeitskosten je Tonne Förderung zwischen 1927/28 und 1933/34 um $41,4 \%$, die gesamten Selbstkosten pro Tonne Förderung im gleichen Zeitraum um $28 \%$ sanken. Zwar gingen die Arbeitskosten je verfahrene Schicht erst 1931/32 zurück, jedoch entfiel auf jeden Beschäftigten, der 1930/31 pro Schicht $20 \%$ mehr kostete als 1926, bis zu 60\% mehr Förderung je Schicht. ${ }^{9}$ Kostenseitig betrachtet hatte sich die Rationalisierung für die Abteilung Bergbau der VSt. also im gewünschten Sinne ausgewirkt, auch wenn das Ausmaß der technischen Rationalisierung der Arbeitsprozesse unter Tage insgesamt nicht überschätzt werden sollte, da ein großer Teil der Mengeneffekte von der Betriebspunktzusammenlegung, der Stillegung unrentabler Zechen und der Zentralisierung von Förderung und Verarbeitung bestimmt gewesen sein dürfte. ${ }^{10} \mathrm{Die}$ Zahl der Betriebspunkte blieb selbst nach der Rationalisierung so groß, daß eine effektive Arbeitskontrolle unter Tage nicht möglich war. Der Bergbau war, wie Trischler zu Recht betont, ein „GroßKlein-Betrieb" geblieben. ${ }^{11}$ Die Kostenseite war indes nur ein Faktor. Auch der Vorstand wußte dies nur zu genau, als er in seinem Wirtschaftlichkeitsbericht bemerkte, daß „die wirtschaftliche Lage der Zechen bekanntlich durch die künftige Erlösgestaltung maßgeblich bestimmt (wird), die wiederum von der Bereinigung der Verhältnisse auf den Weltmärkten ... abhängig ist. " ${ }^{12}$ Die Umsatzerlöse der GBAG hingen nun aber weder von Lohnhöhe noch Kostenstruktur ab, sondern wurden durch verkaufte Mengen und Preise bestimmt, die zumindest teilweise weltmarktvermittelt waren. Auf den Weltmärkten herrschte, von der Phase des englischen Bergarbeiterstreiks abgesehen, starker Preisdruck, den zahlreiche Zechen nur durch die Exportsubventionierung des RWKS bewältigen konnten. Die Rolle des Kohlenexports war daher in der zweiten Hälfte der zwanziger Jahre umstritten, da er über das Umlageverfahren des RWKS kostensteigernd wirkte; andererseits aber benötigten die Zechen ihrer Ansicht nach den Export zur kostendegressiven Anlagenausnutzung. ${ }^{13}$ Für die GBAG war der Kohlenexport

8 Betriebs- und Wirtschaftlichkeitsverhältnisse, S. 13.

9 Betriebs- und Wirtschaftlichkeitsverhältnisse, S. 4.

10 Burghardt, Rationalisierung im Ruhrbergbau, S. 15-42. Tschirbs, Tarifpolitik im Ruhrbergbau, S. 241-258.

11 Trischler, Steiger im deutschen Bergbau, S. 239.

12 Betricbs- und Wirtschaftlichkeitsverhältnisse, S. 14.

13 Ausschuß zur Untersuchung der Erzeugungs- und Absatzbedingungen der deutschen Wirtschaft, 
unbestreitbar von existentieller Bedeutung, da vom Fremdumsatz (Umsatz ohne Lieferungen an VSt.) zwischen 1926 und 1933 zwischen 32 und $40 \%$ im Ausland realisiert wurden. ${ }^{14}$ Die Fixierung auf den Weltkohlenmarkt und seine Preise und damit jene Weltmarktstrategie, die die heimischen Selbstkosten um jeden Preis zu drücken gedachte, waren im Fall der GBAG keine strategische Fehlentscheidung: Angesichts der Marktverhältnisse blieb ihr, wollte man nicht das Unternehmen auf zwei Drittel seiner Größe reduzieren, kaum etwas anderes übrig. ${ }^{15}$ Insbesondere in der Weltwirtschaftskrise erwies sich der Export noch als stabilisierender Faktor, da im Ausland die Umsätze langsamer zurückgingen, die Exportquote am Fremdumsatz der GBAG daher von 32,7\% 1929/30 auf 39,7\% 1932/33 stieg. Auch der gesicherte Absatz an die Vereinigten Stahlwerke war für die GBAG kein Rettungsanker, da dieser noch stärkeren Schwankungen als der Fremdabsatz unterlag. Von 1928/29 auf 1931/32 ging der Absatz an die Vereinigten Stahlwerke um mehr als $62 \%$ zurück. Der gesamte Fremdumsatz betrug demgegenüber 1931/32 immerhin noch $48 \%$ des Standes von 1928/29, der Export sogar 52\%. ${ }^{16}$

Der Umsatz der GBAG folgte nach der Gründung der Vereinigten Stahlwerke insgesamt dem Konjunkturverlauf und war wegen der hohen Konjunkturanfälligkeit des Hauptnachfragers (Eisen- und Stahlindustrie) besonders krisenanfällig. Privater Wärmemarkt und Export stellten Nachfragesegmente geringerer Konjunkturanfälligkeit dar, waren aber heftig umkämpft. In der zweiten Hälfte der zwanziger Jahre gab es kaum noch unbestrittene Märkte; das RWKS konnte auf den revierfernen Märkten des Deutschen Reiches die administrierten Kohlenpreise nicht durchsetzen. In einer derartigen Marktlage (hohe Konjunkturabhängigkeit des Hauptnachfragers, stark umkämpfte Binnen- und Außenmärkte) blieben den Zechenunternehmen, wollten sie die Entwicklung nicht passiv hinnehmen, nur zwei Auswege: Rationalisierung mit Schrumpfung oder Rationalisierung ohne Schrumpfung, wollte man nicht den Bergbau generell zurückfahren. Die GBAG entschied sich für Rationalisierung mit Schrumpfung, wobei allerdings die Schrumpfung, d. h. die Stillegung alter und unrentabler Anlagen in ihrem Kapazitätseffekt durch die moderneren Großanlagen mehr als ausgeglichen wurde, zumal der englische Bergarbeiterstreik 1926 ein frühes Ende des Kapazitätsabbaues brachte. Dieser wirtschaftlich gesehen verhängnisvolle Streik ermöglichte den Ruhrzechen die Aufrechterhaltung eines kapazitären Status quo, der unter Weltmarktgesichtspunkten nicht zu rechtfertigen war, im Inland aber scheinbar die geringsten sozialen Kosten verursachte. Anders ist die Erleichterung über das Ende des Kapazitätsabbaus, die nach Auskunft der Stimmungsberichte des Oberbergamtes im Sommer 1926 allerorten feststellbar war, kaum zu verstehen. ${ }^{17}$ Trotz deutlich steigenden Umsatzes sank daher auch bei der Abteilung

Die deutsche Kohlenwirtschaft. Verhandlungen und Berichte des Unterausschusses für Gewerbe: Industrie, Handel und Handwerk (III. Unterausschuß), Berlin 1929, S. 161-164.

14 Monatsbericht der Vereinigten Stahlwerke 6/1933, S. 40, BgA 55/498.

15 Die Auffassung von Tschirbs, Tarifpolitik im Ruhrbergbau, u. a. S. 446, die falsche Rationalisierungs- und Weltmarktstrategie der Bergbauunternehmen sei für ihre harte Haltung in den Verteilungskämpfen verantwortlich zu machen, unterstellt eine in der Weimarer Zeit realistische Alternative, die zu benennen er freilich schuldig bleibt.

16 Monatsbericht der Vereinigten Stahlwerke 9/1933, S. 40, BgA 55/498.

17 Stimmungsberichte des Oberbergamtes, StAM OBAD 1867, 1868. 
Bergbau der VSt. die Kapazitätsauslastung; die Syndikatsbeteiligungsausnutzungsquoten gingen seit Mitte der zwanziger Jahre zunächst von 75\% 1926 auf $70 \% 1928 / 29$, in der Krise dann auf 36\% 1931/32 zurück, wobei die Abteilung Bergbau im Ruhrgebietsvergleich noch günstig abschnitt. ${ }^{18}$

Die Erlöse je verkaufte Tonne schwankten bei der Abteilung Bergbau der VSt. relativ stark. Der Überschuß über die Selbstkosten je Tonne war 1928/29 mit 1,80 RM am höchsten, in einem Jahr also, in dem die Selbst- und Arbeitskosten nur knapp unter ihrem Spitzenwert von 1927/28 lagen. In jenem Jahr war auch das Bilanzergebnis der gesamten Abteilung Bergbau (incl. Nebenbetriebe) mit 2,80 RM je Tonne Förderung bzw. 76,4 Mio. RM Überschuß das Günstigste in den zwanziger Jahren überhaupt. Die Erlösentwicklung war insofern von der Kostenseite zwar unabhängig, jedoch bestimmte die Kostenentwicklung die Überschußmargen in erheblicher Weise mit. Durch die sinkenden Kosten, insbesondere die stark zurückgehenden Arbeitskosten gelang es der Abteilung Bergbau selbst in der Weltwirtschaftskrise ein positives Bilanzergebnis vor Abschreibungen zu erzielen. Erst durch die außerordentlich hohen Abschreibungen, deren Berechtigung in der zeitgenössischen Debatte stark umstritten war, wies die Abteilung Bergbau seit 1930/31 Bilanzverluste auf. ${ }^{19}$ Aufs Ganze gesehen war die Bergbauabteilung der VSt. aber dazu in der Lage, ihre hohen Neuinvestitionen über Abschreibungen zu finanzieren, zumindest bis 1930, wobei die Abschreibungen insgesamt bis 1930/31 etwa 90\% der Neuanlagen ausmachten, während in der Investitionsfinanzierung das Verhältnis Abschreibungen/Fremdkapital im Schnitt des Ruhrbergbaus vor der Weltwirtschaftskrise bei $60 \mathrm{zu} \mathrm{40 \%} \mathrm{lag.}{ }^{20}$ Erst seit 1931 nahmen Absatzeinbrüche und Kohlenhalden derart zu, daß die Bergbauabteilung in die roten Zahlen rutschte. Während nun aber die Arbeitskosten je Tonne Förderung kontinuierlich sanken und entsprechend das Gewicht der Arbeitskosten an den Gesamtkosten zurückging, stagnierte der Anteil der Löhne an den Umsatzerlösen. Erst in der Weltwirtschaftskrise sank der Lohnanteil an den Umsätzen deutlich ab; im Aufschwung der dreißiger Jahre trat dann genau das ein, was der Vorstand prophezeit hatte: der neuen GBAG gelang es die Umsatzerlöse je Beschäftigten rasch auszudehnen, während sich die Löhne erst nach und nach und vor allem wegen längerer Arbeitszeiten wieder auf Vorkrisenniveau einpendelten. ${ }^{21}$ Selbst sinkende Arbeitskosten führten bis zur Weltwirtschaftskrise daher den Bergbau nicht aus dem Dilemma der Lohnintensität heraus, da betriebswirtschaftlich vor allem der Anteil der Lohnsumme am Umsatz entscheidend war. Dieses Verhältnis aber sank zunächst nicht und nur eine drastische Ausweitung des Umsatzes oder ein durchgreifender Belegschaftsabbau hätten hier Remedur schaffen können, wobei ersteres auf den scharf umkämpften Märkten nur bei niedrigen Preisen zu erreichen war. Die Bergbauunternehmen mußten also betriebswirtschaftlich alternativlos das tun, was sie taten, nämlich Arbeitskostensenkungen und Produktivitätserhöhungen erst dann in Lohnerhöhungen umzusetzen, wenn dies ihre Liqui-

18 Betriebs- und Wirtschaftlichkeitsverhältnisse, S. 2.

19 Betriebs- und Wirtschaftlichkeitsverhältnisse, S. 10, 12.

20 Der Ruhrbergbau im Wandel der Zeiten. Festschrift zum 75jährigen Bestehen des Vereins für die bergbaulichen Interessen im Oberbergamtsbezirk Dortmund, Essen 1933, S. 165.

21 Angaben nach Monatsberichten der Vereinigten Stahlwerke, laufend. 
dität nicht gefährdete, was indes von Umsatzzuwächsen abhing. In der Weltwirtschaftskrise nach 1929 trat allerdings das Gegenteil ein, so daß an eine Ausdehnung der Lohnsumme trotz steigender Leistungsziffern nicht ernsthaft gedacht werden konnte.

Die Abteilung Bergbau der VSt. überstand die Weltwirtschaftskrise zwar insgesamt als ein hochmodernes Kohlenunternehmen, der Zusammenbruch ihrer Kreditwürdigkeit im Kontext der Gelsenberg-Affäre und die „roten Zahlen“ seit 1931, die sich bei maßvolleren Abschreibungssätzen u.U. hätten vermeiden lassen, trübten das Bild in erheblicher Weise und verschleierten die Tatsache, daß man auf die Herausforderungen der Strukturkrise seit Mitte der zwanziger Jahre im Ganzen betriebswirtschaftlich erfolgreich reagiert hatte. Daß ihre betriebswirtschaftlichen Strategien zur Festschreibung von volkswirtschaftlich bedenklichen Überkapazitäten führten, war zwar bedauerlich, aber zumindest aus der Sicht des Unternehmens nicht zu verhindern, zumal man sich dort zu Recht sagte, daß unter den Bedingungen der Strukturkrise lediglich der modernste Anbieter überleben würde, auch wenn die Syndizierung der Branche durch die damit verbundene Hochpreispolitik auch minder rentable Unternehmen am Markt hielt. Die Bergbauabteilung der VSt. hatte auf die Herausforderung der Strukturkrise mit Modernisierung reagiert und wäre bei einem nicht syndizierten Markt ohne Frage als eines der wenigen Unternehmen übriggeblieben, das seine Marktstellung nicht nur hätte behaupten, sondern erweitern können. Damit ist auch die verbreitete Kritik zurückzuweisen, daß die Syndizierung die Marktanpassung verhindert habe. Dies gilt für die gesamte Branche ohne Frage, nicht aber für einzelne Unternehmen wie die Abteilung Bergbau der VSt., die unter dem extremen Kostendruck von Seiten der Märkte, der Stahlunternehmen und der Löhne, Steuern und Abgaben konsequent die Modernisierung und damit die Marktanpassung ihrer Anlagen betrieb. Hier herrschte auch keine Dominanz des technischen über das ökonomische Denken, wie Hans Mommsen dem Ruhrbergbau generell unterstellt. $^{22}$ Bei der Bergbauabteilung der VSt. ging es um betriebswirtschaftliche Kennziffern, die nach 1918 einen starken Rückgang der Leistung und der Gewinne indizierten, und zwar einerseits wegen geringerer Leistungsbereitschaft, schlechter Ernährung und kürzerer Arbeitszeiten, andererseits wegen sinkender bzw. stagnierender Umsätze bei gleichzeitig zunehmenden Kosten (Löhne, Abgaben etc.). Angesichts der Weltmarktorientierung der Abteilung Bergbau bzw. jener Unternehmen, die ihren Kohlenbesitz in die Vereinigten Stahlwerke einbrachten, wäre Mitte der zwanziger Jahre ein Abkoppeln vom Weltmarkt nachgerade selbstmörderisch gewesen. Der englische Bergarbeiterstreik 1926 wertete den Weltmarkt noch zusätzlich auf. Bei der Abteilung Bergbau der VSt. versuchte man unter dieser Konstellation wieder zu einer "gesunden“ Betriebswirtschaft zu gelangen. Der Widerstand gegen die Weimarer Sozialpolitik hatte vor allem materielle, weniger ideologische Gründe, namentlich als man Ende der zwanziger Jahre zu der Auffassung kam, alle Modernisierungsanstrengungen der Unternehmen würden von den Lohnkosten und Sozialabgaben zunichtegemacht: „Ge-

22 Mommsen, Der Ruhrbergbau im Spannungsfeld, S. 162 f. Mommsen, Soziale Kämpfe, in: Mommsen/Borsdorf (Hg.), Glück auf, Kameraden!, S. 252-254. 
winne hat die Rationalisierung den Werken nicht eingebracht. Alle darauf verwandten Mühen und Mittel haben schließlich nur dazu gedient, die Unkosten des staatlichen und sozialen Oberbaus und die erhöhten Löhne zu tragen. "23 Strenggenommen war dies Urteil falsch, da es - wie gezeigt - der GBAG durchaus gelungen war, die Arbeitskosten je Tonne Förderung entscheidend zu senken. Solange aber Förderung und Umsätze nicht wuchsen, blieb die effektive Lohnsummenbelastung der Erlöse unabhängig von der Stückkostenentwicklung in einer Weise hoch, daß sie die Liquidität des Unternehmens gefährdete, da die Lohnkosten ja aus den Erlösen zu zahlen waren. Hohe Löhne stellten daher in gewisser Weise unabhängig vom jeweils erreichten Niveau der Produktivität eine Belastung der Liquidität dar, solange es nicht gelang, die Produktivitätszuwächse durch steigenden Umsatz und wachsende Überschüsse auch zu realisieren. Dieses Dilemma kennzeichnete die Rationalisierungsbewegung in der Weimarer Republik. Produktivitäts- und Rationalisierungsschübe sichern nur das Überleben, nicht die Expansion und können u.U. sogar in einer „Fixkostenfalle“ enden, deren Bedeutung für die späten zwanziger Jahre Schmalenbach behauptet hat ${ }^{24}$, die aber bis heute empirisch nicht bestätigt ist. Sicher ist, daß vor diesem Hintergrund betriebliche Konflikte vorprogrammiert waren. Die Überwindung der geringen Produktivität der Betriebe nach 1923/24 erfolgte auf schrumpfenden bzw. stagnierenden Weltmärkten. Die von den Bergleuten subjektiv erfahrenen Leistungssteigerungen erfuhren keinen in ihren Augen adäquaten Lohnausgleich, im Gegenteil: der Akkord- bzw. Gedingedruck wuchs, während sich die materiellen Lebensbedingungen der Bergleute nicht entscheidend besserten. Die betriebliche Struktur dieses unvermeidlichen Konfliktes hing von zwei entscheidenden Determinanten ab. Einerseits spielte die Unternehmensorganisation eine wesentliche Rolle, andererseits der Arbeitsprozess und die mit ihm verbundenen Kontroll- und Aufsichtsmöglichkeiten.

\section{Grundzüge der Unternehmensorganisation}

Die Entwicklung der GBAG war insgesamt durch mehrere Konzentrationsschübe gekennzeichnet, die stets zu einer Ausdehnung des Unternehmens, zu einer Vergrößerung der Anlagen und zu einer stärkeren Anbindung an die Stahlindustrie geführt hatten. Dies blieb für die Unternehmensorganisation nicht ohne Folgen. Entscheidend war aber zunächst, daß die Zechenunternehmen ohnehin eine spezifische Organisationsstruktur aufwiesen, da die Unternehmensverwaltung von den eigentlichen Zechenbetrieben getrennt blieb. Bis zu den Fusionen der frühen Nachkriegszeit existierte in Gelsenkirchen eine Zentraldirektion, die keine gesonderten Abteilungen zu Fragen der Arbeiterpolitik oder Arbeitsorganisation vorsah. ${ }^{25}$ Im November und Dezember 1918 dachte man im GBAG-Vorstand zwar kurzfristig über die Einrichtung einer sozialpolitischen Abteilung nach, die insbesondere Direktor Burgers vom Schalker Verein forderte ${ }^{26}$, nahm

23 Der Ruhrbergbau im Wandel der Zeiten, S. 162.

24 Schmalenbach, Selbstkostenrechnung und Preispolitik, S. $57 \mathrm{ff}$.

25 Geschäftsordnung der Direktion der GBAG, 11.11. 1912, BgA 55/1227.

26 Beim Schalker Verein entwickelte C. Arnhold das Dinta-Konzept; Arnhold, Menschenorganisa- 
wegen „der unübersichtlichen politischen Verhältnisse“ hiervon aber vorläufig Abstand. ${ }^{27}$ Nach der Bildung der Rheinelbe-Union wurde eine neue Zentraldirektion bei der alten GBAG gebildet mit je einem technischen, kaufmännischen und juristischen Vorstandsmitglied und Emil Kirdorf als Generaldirektor bzw. Vorstandsvorsitzender und einer allgemeinen Verwaltung als Vorstandsstab. Unterhalb dieser Ebene existierten Abteilungen, die in gewisser Weise die späteren Regionalgruppen der VSt. vorwegnahmen und die an die alten Zechenverwaltungen der GBAG und von Deutsch-Lux anknüpften. ${ }^{28}$ Auch jetzt wurde keine sozialpolitische Abteilung eingerichtet. Nach der Gründung der Vereinigten Stahlwerke wurden die wesentlichen Verwaltungsfunktionen der GBAG in der neuen Hauptverwaltung der Abteilung Bergbau in Essen zusammengezogen, wo unter dem Vorstand zwölf Stabsabteilungen in Funktion traten, die spiegelbildlich und in kleinerer Größe auch bei den jeweiligen Gruppenverwaltungen in Hamborn, Gelsenkirchen, Bochum und Dortmund existierten. Eine Abteilung Arbeit und/ oder Arbeitsorganisation bzw. eine sozialpolitische Abteilung existierte weder in Essen noch bei den Regionalgruppen; die „sozialwirtschaftlichen Funktionen“ waren Teil der Abt.A: Allgemeine Verwaltung (Personal, Tarif, Versicherungswesen, sozialwirtschaftliche Angelegenheiten). Auch diese Abteilung beschäftigte sich nicht mit Fragen der Arbeitsorganisation. Sie war wiederum in sieben Unterabteilungen aufgegliedert (Personal-, Gehalts- und Lohnwesen, Versicherung, Revision, Belegschafts- und Lohnstatistik, Briefordnung, Bücherei, Fernsprechamt). Der Aufbau der Stabsabteilungen folgte technisch-betriebswirtschaftlichen Überlegungen, denen auch die Arbeitsorganisation als Anhängsel unterworfen blieb. ${ }^{29}$ Alle formalen Fragen des Betriebsrätegesetzes, des Arbeitsrechtes und der Prozeßvertretung waren im übrigen in der Rechtsabteilung der Abteilung Bergbau der Vereinigten Stahlwerke angesiedelt. ${ }^{30}$ Die organisatorische Entwicklung des Phoenix-Konzerns, der erheblichen Grubenbesitz in die Vereinigten Stahlwerke einbrachte, entsprach dem Muster der GBAG bzw. der Rheinelbe-Union. Nach der Organisationsreform 1921 unterstanden dem Hauptvorstand/Hauptverwaltung in Hoerde, wo eine Zentralstelle für Arbeiterangelegenheiten eingerichtet wurde, verschiedene Abteilungen. Die Hauptverwaltung Bergbau des Phoenix befand sich in Gelsenkirchen, also in der Nähe der großen Phoenix-Gruben in Gladbeck, Wattenscheid und Essen/Gelsenkirchen. Die Hauptverwaltung Bergbau besaß keine eigenständige Verwaltungseinheit für Arbeiterfragen oder Fragen der Arbeitsorganisation. ${ }^{31}$

Mit dem Aufbau der Vereinigten Stahlwerke und der Bildung einer Konzernverwaltung in Düsseldorf wurden dort wichtige Verwaltungsaufgaben konzen-

tion im Bergbau, in: Wirtschaftliche Nachrichten aus dem Ruhrbezirk 1925, H.16. Vgl. insgesamt Schwenger, Die betriebliche Sozialpolitik im Ruhrbergbau, S. 69.

27 Vorstandsprotokoll der GBAG, 6. 12. 1918, BgA 55/115.

28 Geschäftsordnung des Vorstandes, 16. 2. 1920, BgA 55/1227.

29 Organisation, Geschäftsgang und Abrechnungswesen in der Abteilung Bergbau der Vereinigten Stahlwerke. Bericht erstattet vom Unterausschuß, der von der VSt.-Studiengesellschaft zur Vorbereitung der Neuorganisation der VSt. eingesetzt worden ist, Essen 23. 8. 1926, BgA 55/1233. Siehe auch Telephonbuch der Vereinigten Stahlwerke 1938, S. 6-9, ThA, Duisburg.

30 Organisationsplan der Rechtsabteilung der Abteilung Bergbau der VSt., 19. 5. 1926, BgA 55/580.

31 Phoenix-Statuten, beschlossen vom Präsidium des Aufsichtsrates im Dezember 1921, Anschreiben Fahrenhorst/Flaccus 14. 12. 1921, BgA 41/80. 
triert. Am Rhein entstand im Laufe der Zeit eine kleine und zunächst wenig effiziente sozialpolitische Abteilung als Stabsstelle des Gesamtvorstandes, die ein zuvor bestehendes sozialpolitisches Referat ablöste, das sich mit Lohn- und Tarifsowie Arbeitsrechtsfragen befasst hatte. ${ }^{32}$ Sozialreferat bzw. später die sozialpolitische Abteilung arbeiteten dem Vorstand bzw. dem von Helmuth Poensgen geleiteten Sozialausschuß zu. Poensgen und der Leiter der Sozialpolitischen Abteilung Busse bemühten sich, in die Sozial- und Arbeitspolitik der Konzernwerke eine einheitliche Linie zu bringen, da zunächst die einzelnen Konzernwerke ihre traditionelle Arbeiterpolitik weiter fortgesetzt hatten und daher in den Vereinigten Stahlwerken eine in Lohn-, Tarif- und Sozialfragen uneinheitliche Situation herrschte. Im August 1927 forderte Poensgen die Konzernwerke auf, sich vor sozialpolitisch relevanten Entscheidungen mit Düsseldorf ins Benehmen zu setzen. ${ }^{33}$ Die Aufforderung mußte mehrfach wiederholt werden; auch war es nötig, den zuständigen Arbeitgeberverband aufzufordern, unbeschadet des Kontaktes mit den Konzernwerken sich jeweils auch mit der Düsseldorfer sozialpolitischen Abteilung in Verbindung zu setzen. ${ }^{34}$ Die offensichtlich angestrebte Aufwertung der Düsseldorfer Abteilung, die 1930 trotz umfangreicher nomineller Kompetenzen nur drei qualifizierte Mitarbeiter hatte ${ }^{35}$, störte hingegen die unter dem Namen Rechtsabteilung Dortmund/Zentralstelle für Arbeiterangelegenheiten weiterhin bestehende ehemalige Stabsabteilung der Phoenix-Hauptverwaltung, die sich eine Einmischung der Düsseldorfer Stelle in ihre Kompetenzen verbat. ${ }^{36}$ Man schloß einen Formelkompromiß: Dortmund übernahm die Gerichtsvertretung, Düsseldorf die Bearbeitung der grundsätzlichen Fragen, ohne daß dadurch der schwelende Streit beigelegt worden wäre. ${ }^{37}$ Nominell hatte die Düsseldorfer Stelle zwar die größere Kompetenz; der Ende 1929 vorgelegte erste Jahresbericht dokumentierte in seiner Kargheit freilich die geringe Bedeutung der Abteilung. ${ }^{38}$

Im Kontext der Neuorganisation der Vereinigten Stahlwerke versuchte der Leiter der Abteilung Busse Anfang 1933 noch einmal, eine auch stellenmäßige Aufwertung seiner Abteilung zu erreichen, indem er die Zusammenziehung aller sozialpolitischen Kompetenzen in Düsseldorf vorschlug. ${ }^{39}$ Die erneuerte sozialpolitische Abteilung sollte alles umfassen, vom Arbeits- und Tarifrecht über die Rechtsvertretung und die berufsgenossenschaftlichen Fragen bis hin zu Sozialstatistik und Lohnprüfwesen. Stattdessen aber war die Existenz der sozialpolitischen Abteilung im Kontext der Reorganisation 1933/34, die ja auch eine Verwaltungsvereinfachung und -dezentralisation anstrebte, erneut bedroht, zumal in der Zwischenzeit das kollektive Arbeitsrecht beseitigt worden war. Ein Vorstoß des zuständigen Vorstandsmitgliedes Helmuth Poensgen verhallte aber nicht ganz ungehört. Poensgen hatte einer Aufwertung der sozialpolitischen Abteilung das

32 Aktennotiz 6. 12. 1926, ThA VSt/4.

33 Schreiben Dr. Busse/Poensgen, 19. 8. 1927, ThA VSt/4.

34 Ernst Poensgen an Ludwig Grauert, 11. 7. 1928, ThA VSt/4.

35 Bericht Dr. Busse: Organisation der sozialpolitischen Abteilung, für H. Poensgen, 28.6. 1930, ThA VSt/4.

36 19. 2. 1929, ThA VSt/4.

37 Aktennotiz H. Poensgen, 25. 4. 1929, ThA VSt/4.

38 Bericht vom 12.11. 1929, ThA VSt/4.

39 1.2. 1933, ThA VSt/4. 
Wort geredet, da nach Auflösung der Arbeitgeberverbände „die Werke selbständiger werden als bisher. Es muß überall nach den gleichen Grundsätzen vorgegangen werden. Wir können deshalb auf eine derartige Stelle nicht verzichten, weil nur durch Zusammenfassung an einer Stelle die erforderliche Orientierung und der notwendige Erfahrungsaustausch hergestellt werden. ${ }^{40} \mathrm{Im}$ Ergebnis blieb die sozialpolitische Abteilung im alten Umfang erhalten, nur änderte sie 1934 nach Erlaß des Arbeitsordnungsgesetzes ihren Namen in "Sozialwirtschaftliche Abteilung". ${ }^{41}$

In der Organisation der Vereinigten Stahlwerke spielte zunächst der Aufsichtsrat eine ähnlich wichtige Rolle wie der Vorstand. Der Aufsichtsrat war 1926 paritätisch aus den Aufsichtsräten der Gründergesellschaften gebildet worden und war derart groß, daß von Anfang an die Bildung gesonderter Aufsichtsratskommissionen zur Erledigung der laufenden Geschäfte vorgesehen wurde. Eine zentrale Rolle fiel dabei der bereits 1926 eingerichteten Industriellen Kommission zu, die den eigentlichen Kern des Aufsichtsrates bildete und in der alle für das Unternehmen wesentlichen Entscheidungen getroffen wurden. Im Zuge erster Umorganisationsmaßnahmen wurde 1928 auch die Bildung weiterer Kommissionen vorangetrieben, namentlich wurde nun die Errichtung einer Kohlen-, einer Handels- und einer Sozialkommission ins Auge gefaßt. ${ }^{42}$ Gegen letztere wurden rasch Bedenken laut, weil damit die Mitwirkungsmöglichkeiten der Betriebsratsmitglieder im Aufsichtsrat, die im arbeitsunfähigen Aufsichtsratsplenum bislang nicht existiert hatten, ausgeweitet würden. Der Vorstand hatte bereits in seiner Vorlage zur Aufsichtsratssitzung von einer Sozialkommission mit der Bemerkung abgeraten, daß „die Erledigung der sozialen Angelegenheiten im allgemeinen Sache des Vorstandes (sei) und ... der größte Teil der sozialen Aufgaben heute bereits gesetzlich“ festliege. Sollten soziale Fragen auftauchen, die über den Zuständigkeitsbereich des Vorstandes hinausreichten, könnten immer noch gesonderte Aufsichtsratssitzungen unter Hinzuziehung der Betriebsratsmitglieder durchgeführt werden. ${ }^{43}$ Man einigte sich daher, von einer Sozialkommission abzusehen und nahm damit, da man wegen der Gründungsvereinbarungen nicht schlecht eine Sozialkommission ablehnen, andere Kommissionen aber einrichten konnte, erhebliche Konflikte mit anderen Aufsichtsratsmitgliedern in Kauf, die über die Kohlen- und Handelskommission ihren Einfluß in den Führungsgremien der Gesellschaft hatten vergrößern wollen. ${ }^{44}$ Als Kompromiß beschloß man schließlich, die industrielle Kommission gegebenenfalls auch mit den Aufgaben der Handels- und Kohlenkommission zu betrauen und die betreffenden Aufsichtsratsmitglieder dann jeweils hinzuzuziehen. ${ }^{45}$

40 Undatiert, nach der Auflösung der Arbeitgeberverbände, also wahrscheinlich im Frühsommer 1933, ThA VSt/4.

41 Busse an H.Poensgen, 27. 5. 1934, ThA VSt/4.

42 Niederschrift über die Besprechung wegen der Aufsichtsrats-Kommissionen, 19.9. 1928, ThA RSW $170.00 / 4 b$.

43 Vorlage Dr. Poensgen für die Besprechung wegen der Aufsichtsrats-Kommissionen, 19. 9. 1928, ThA RSW 170.00/4b.

44 Auszug aus der Aufsichtsratssitzung Essen, 19.9. 1928, ThA RSW 170.00/4b. Huber, Abt. Bergbau an Albert Vögler, 13. 10. 1928, ThA RSW 170.00/4b.

45 Stellv. Aufsichtsratsvors. Hasslacher an H.Poensgen, 16. 10. 1928, ThA RSW 170.00/4b. 
Diese Politik, die Unternehmensorganisation um jeden Preis so zu gestalten, daß die Betriebsräte im Aufsichtsrat einflußlos blieben, übernahmen die Vereinigten Stahlwerke von ihren Gründungsgesellschaften. Als Reaktion auf das Gesetz über die Vertretung der Betriebsräte im Aufsichtsrat vom 15. Februar 1922 hatte die alte GBAG eine Defunktionalisierung der Aufsichtsratsgeneralversammlungen zu Gunsten von AR-Ausschüssen, an denen die Betriebsräte nicht beteiligt waren, vorgenommen. Durch Satzungsänderungen erhielten diese Ausschüsse Beschlußkompetenzen. Selbst die weitgehend funktionslosen Generalversammlungen der Aufsichtsräte spaltete die GBAG noch einmal in offizielle Sitzungen mit Arbeitnehmervertretern sowie informelle Vorbesprechungen auf. ${ }^{46}$ Bei den Rheinischen Stahlwerken erfolgte eine Anpassung der Aufsichtsratsgeschäftsordnung am 3. April 1922, die die Bildung beschließender Ausschüsse ermöglichte. Man begründete dies zwar allgemein damit, nur die ohnehin üblichen Verfahrensweisen schriftlich fixieren zu wollen, doch war die Tendenz eindeutig. Auf diese Weise konnten die Betriebsräte aus dem für die Aufsichtsratspolitik wesentlichen Personalausschuß ferngehalten werden. ${ }^{47}$

$\mathrm{Zu}$ einer einheitlichen Regelung der Sozialpolitik auf der Vorstandsebene der Vereinigten Stahlwerke kam es daher in der Weimarer Republik nicht. Die Tätigkeit der Arbeitgeberverbände (Arbeitgeberverband für die Nordwestliche Gruppe des VDEStI, Zechenverband), ihrer Gremien und Ausschüsse sowie bei verschiedenen Konzernwerken weiterhin bestehende Einrichtungen und sich daraus ergebendes Kompetenzgerangel ließen Zentralisierung und Ausbau der Sozial- und Arbeitspolitik überflüssig bzw. undurchsetzbar erscheinen. Der Wunsch, aus administrativen und finanziellen Gründen die aufgeblähte Verwaltung zu verkleinern, tat ein Zusätzliches. Auf der Ebene des Aufsichtsrates verhinderte die Animosität gegen eine Beteiligung der Betriebsräte die Bildung einer Sozialkommission. Die betriebliche Sozialpolitik war daher willkürlich von Werk zu Werk organisiert. Lediglich die Eisen- und Stahlwerke hatten eigene Sozialund arbeitspolitische Abteilungen. ${ }^{48} \mathrm{Im}$ übrigen stützte sich die Regelung der industriellen Beziehungen auf die Arbeit von Arbeitnordwest und Zechenverband, in deren Gremien Vertreter der Vereinigten Stahlwerke bzw. der Gelsenkirchener Bergwerks AG an führender Stelle tätig waren. Daß die führenden Herren der Vereinigten Stahlwerke über die sozial- und arbeitspolitischen Verhältnisse in ihren Werken präzise unterrichtet waren, kann also durchaus bezweifelt werden. Mit den einzelnen Schachtanlagen und deren Betriebsräten kam der Vorstand selbst kaum in Kontakt; nur bis 1926 gab es eine direkte Betriebsratsvertretung im Aufsichtsrat der GBAG. Unterhalb des Essener Vorstandes der Abteilung Bergbau der Vereinigten Stahlwerke bestanden als nächste Instanzen die Leitungsgre-

46 Siehe Briefwechsel des Justitiars der GBAG Fusban mit dem Aufsichtsratsvorsitzenden Salomonsohn April/Mai 1922, BgA 55/1227. Die Aufsichtsratsprotokolle der GBAG bis 1926 in: BgA 55/ 20-21. Vgl. auch die Aufsichtsratsprotokolle von Deutsch-Lux, Th A FWH 123/19.

47 Protokoll der Aufsichtsratssitzung der Rheinischen Stahlwerke vom 3. 4. 1922, ThA RSW 123.00/ $19 / 237$.

48 Es besteht dabei der begründete Eindruck, daß in der Schwerindustrie sozialpolitische Einrichtungen zudem stärker von der Eisen- und Stahlseite gefördert und eingerichtet wurden, während der Bergbau offensichtlich glaubte, auf diese Institutionen verzichten zu können. Vgl. Schwenger, Die betriebliche Sozialpolitik im Ruhrbergbau. 
mien der vier Gruppen, danach schließlich als unterste Einheiten die einzelnen Schachtanlagen, auf denen die jeweiligen Betriebsräte gewählt wurden und für die sie zuständig waren. Angesichts des Fehlens von Verwaltungsstäben für Fragen der Arbeits- und Sozialpolitik auf diesen Ebenen muß davon ausgegangen werden, daß der größere Teil der Stabsarbeiten auch hier durch den Zechenverband und seine Bezirksgruppen wenn schon nicht erledigt, so doch zur Entscheidung vorbereitet wurde.

Auf der Ebene der einzelnen (insgesamt 25) Schachtanlagen wurde keine Organisationsausdifferenzierung vorgenommen. Das kaufmännische Personal hier war gering (Materialverwaltung, Lohnwesen etc.), eine eigenständige Arbeitspolitik nicht vorgesehen. Ähnlich wie bei den Stahlwerken, die 1916 in Reaktion auf die zunehmenden sozialen Spannungen im Betrieb dazu übergegangen waren, für die einzelnen Werke Sozialsekretäre als kommunikative Anlaufstellen für die neugebildeten Arbeiterausschüsse einzustellen ${ }^{49}$, gab es bei den verschiedenen Zechen zwar Wohlfahrts- und Sozialbeamte, die aber von ihrem Auftrag her vor allem die wirtschaftsfriedliche Arbeiterbewegung fördern sollten und ansonsten sozialpflegerisch tätig wurden, mit der Arbeitsorganisation also nichts zu tun hatten. ${ }^{50}$ In dieser Beziehung existierte auf den einzelnen Schachtanlagen eine klare Linienorganisation vom Bergwerksdirektor über den Grubeninspektor, Fahrsteiger, Revier- und technische Steiger bis hinunter zu den Kameradschaften. Die bereits seit 1905 bestehenden obligatorischen Arbeiterausschüsse auf den einzelnen Schachtanlagen besaßen ihre Gesprächspartner „vor Ort" in Grubeninspektor und Bergwerksdirektor, die die Sitzungen einberiefen und leiteten, selbst aber keine Entscheidungskompetenz hatten, sondern die offenen Punkte an die Gruppen- bzw. Zentraldirektion zur Entscheidung weiterleiteten. Schon aus diesem Grunde waren Verhandlungen im eigentlichen Sinne unmöglich, direkte Kommunikation zwischen Belegschaftsvertretern und Direktion ausgeschlossen. ${ }^{51}$ Damit ergab sich zwangsläufig eine organisatorische Zweiteilung in stabsförmig strukturierte Verwaltungen und linienförmig organisierte Produktionsprozesse, die nicht miteinander rückgekoppelt waren. Diese Organisationsform präformierte in hohem Maße die betrieblichen Kommunikationsstrukturen, die im Prinzip nur in der direkten Linie erfolgen konnten. Eine nicht zugleich hierarchisch angelegte Kommunikation über Probleme des Arbeitsprozesses war innerbetrieblich ausgeschlossen. Wollten Bergarbeiter „ihre“ Direktion sprechen, blieb ihnen kaum etwas anderes als der Weg an die Öffentlichkeit. Dieser Sprachlosigkeit entsprachen auch die kommunikativen Möglichkeiten der Belegschaften untereinander. Ein Spezifikum der Bergarbeit, insbesondere der Unter-Tage-Arbeit war, daß die Arbeiter während der Arbeit untereinander nicht oder doch nur sehr eingeschränkt kommunikationsfähig waren.Im Gegensatz zu anderen Industriezweigen gab es keine gemeinsamen Pausen ${ }^{52}$ und Aufenthaltsräume, in denen eine Verständigung

49 Besprechung bei Arbeitnordwest im Düsseldorfer Industrieclub, 21.7. 1916, ThA FWH 850/03. Die Rheinischen Stahlwerke stellten entsprechend im Sommer 1917 einen Sozialsekretär (Oberleutnant Roth) ein, Vorstandssitzung 25. 6. 1917, Th A RSW 120/00/5/9.

50 Protokoll der 5. Vorstandssitzung der GBAG, 22. 3. 1917, BgA 55/113.

51 Zum Aufbau der innerbetrieblichen Kommunikationsstrukturen Schwenger, Betriebliche Sozialpolitik im Ruhrkohlenbergbau, S. $37 \mathrm{ff}$.

52 Die „Butterpause“ unter Tage, die im Kontext der Arbeitsintensivierung 1925 in Wegfall kam, er- 
zwischen den verschiedenen Arbeitergruppen über ihre Probleme möglich gewesen wäre. Der einzige innerbetriebliche Kommunikationsort für größere Belegschaften war der Raum vor der Hängebank zu Beginn der Seilfahrt. Diesen für Kommunikation zu nutzen, war indes prekär, da die Zeit begrenzt war, die Kommunikation zudem vor und unter den Augen der Vorgesetzten erfolgte. Beides scheint offensichtlich spontanes Konfliktverhalten stark gefördert zu haben. Ein großer Teil der offenen Konflikte der Zeit nach 1918 sollte hier seinen Ausgangspunkt nehmen.

\section{Grundzüge der Arbeitsorganisation}

Bergarbeit unter Tage war im formalen Sinne angelernte Facharbeit vor allem von Vollhauern (Kohlen-, Gesteins- und Reparaturhauer). Sie arbeiteten mit Lehrhauern und Schleppern gemeinsam in sog. Kameradschaften an je speziellen Betriebspunkten. Die Arbeit war komplex, d.h. die Kameradschaften waren nicht nur für den Kohlenabbau und -transport, sondern auch für den Grubenausbau verantwortlich. Die Förderung erfolgte zunächst mit dem traditionellen "Gezähe“, in den zwanziger Jahren wurden Hammer und Eisen durch den hydraulisch betriebenen Abbauhammer weitgehend verdrängt. ${ }^{53}$ Eine formalisierte Ausbildung zum Bergmann bzw. Hauer existierte erst seit Mitte der 20er Jahre, doch selbst jetzt wurde die Mehrzahl der Jungbergleute durch die Kameradschaften selbst „ausgebildet“, wobei sie vom Hilfsarbeiter über Tage (am Leseband) eine „Karriere" über Schlepper und Lehrhauer bis hin zum Vollhauer durchlaufen konnten. Seit Beginn der zwanziger Jahre hatte der Hauermangel zahlreiche, vor allem fiskalische Zechen zur Einrichtung von Lehrkameradschaften ${ }^{54}$ veranlaßt, um die Nachwuchsrekrutierung zu verbessern, doch nahm die Bedeutung der Nachwuchsförderung mit Ausbruch der Strukturkrise 1924 drastisch ab. Nach einer knappen theoretischen Ausbildung konnte beim Bergamt die Hauerprüfung absolviert und der Hauerschein erworben werden..$^{55}$ Der weitere „Aufstieg“ zum technischen Angestellten (Steiger, Fahrhauer) war nicht ausgeschlossen, angesichts der Zahlenverhältnisse aber mehr als unwahrscheinlich. ${ }^{56}$ Die Zahl der technischen Angestellten nahm zwar in den zwanziger Jahren zu, doch kamen noch 1928 nur gut vier Angehörige dieser Gruppe auf 100 Arbeiter, nachdem es zu Beginn der zwanziger Jahre gemessen an den Arbeitern sogar nur 3,5\% technische Angestellte gegeben hatte. ${ }^{57}$ Bei den Arbeiterbelegschaften der Zechen dominierten die Untertagebeschäftigten, die im Ruhrbergbau etwa drei Viertel der Arbeiter stellten. Unter den Beschäftigten insgesamt überwog die Gruppe der Hauer, die zwar während des Ersten Weltkrieges schrumpfte, seit1922 aber wieder von $38 \%$

möglichte lediglich der engeren Kameradschaft bzw. nahe zusammen arbeitenden Gruppen und Kameradschaften die gemeinsame Aussprache, Tschirbs, Tarifpolitik im Ruhrbergbau, S. 253.

53 Trischler, Steiger im Deutschen Bergbau, S. 230. Zum bergmännischen Arbeitsprozeß siehe auch Brüggemeier, Leben vor Ort.

54 Hartewig, Das unberechenbare Jahrzehnt, S. $99 \mathrm{f}$.

55 Vgl. Schwenger, Betriebliche Sozialpolitik im Ruhrbergbau, S. $49 \mathrm{f}$.

56 Vgl. Rudolf Schwenger, Betriebliche Sozialpolitik im Ruhrbergbau, S. 43 ff., der die Karrieremöglichkeiten sehr positiv beurteilt, da es kein Akademikermonopol bei der Gruppe der „Zechenbeamten" gebe.

57 Trischler, Steiger im deutschen Bergbau, S. 238. 
auf knapp 45\% 1927 anwuchs, womit die Vorkriegsparitäten wiederhergestellt waren. ${ }^{58}$ Die nachlassende Attraktivität des Bergbaus für jugendliche Arbeitskräfte sowie die in der guten Konjunktur 1927 bis 1929 wieder wachsende Fluktuation und die „Flucht“ gerade guter Hauer aus dem Bergbau in andere Branchen schuf allerdings in der zweiten Hälfte der zwanziger Jahre ein Defizit an qualifizierten Arbeitskräften. Hauerkurse und die Einrichtung von Berglehrwerkstätten auf den Zechen der Vereinigten Stahlwerke sollten dieser Entwicklung gegensteuern, doch vermochten sie angesichts des schlechten Images des Bergbaus, vor allem aber der hohen Konjunkturanfälligkeit der Betriebe keine Trendwende einzuleiten. ${ }^{59}$

Die Arbeitsgruppen (Kameradschaften) waren mit einem Gedingeältesten als Sprecher autonom organisiert. Eine Kontrolle der Arbeit unter Tage unterblieb zwar nicht völlig, war aber vor der Rationalisierung wegen der Vielzahl der Abbaupunkte und der Größe der Steigerreviere im strengen Sinne nicht möglich. Auch nach der Rationalisierung war dies kaum anders. Die Kontrollmöglichkeiten hatten sich fraglos punktuell gebessert, auch hatte der Schüttelrutschenbetrieb am Großstoß zum Teil die alte Gruppenarbeit „aufgeweicht“, doch noch im Herbst 1929 wehrte sich der Vorstand der Abteilung Bergbau in Übereinstimmung mit dem Zechenverband erfolgreich gegen Belegschaftswünsche, die „Mindermaßkontrolle“ der gefüllten Kohlenwagen unter Tage und nicht an der Hängebank auszuführen mit der Bemerkung, daß „bei der großen Zahl der Betriebspunkte ... es ganz unmöglich (ist), eine Kontrolle in der Grube selbst ausüben zu

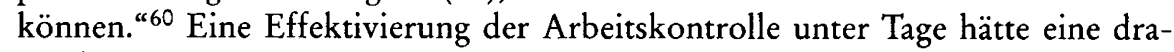
stische Heraufsetzung des technischen Aufsichtspersonals verlangt, die aber aus Kostengründen unterblieb, zumal sich die Arbeitskontrolle auch über das Lohnsystem gestalten ließ. Die gleichwohl erfolgenden Versuche, über eine Mechanisierung des Untertagebetriebes (Schüttelrutschen) eine bessere Leistungskontrolle durchzuführen und mit neuen Arbeitszeitsystemen (systematische Seilfahrt) eine bessere Ausnutzung der Arbeitszeit zu erreichen ${ }^{61}$, waren angesichts der bisherigen Autonomie der Kameradschaften zudem in hohem Maße konfliktträchtig. ${ }^{62}$

Bergarbeit unter Tage erfolgte im Gedinge, war also Akkordarbeit, die nach der effektiv geförderten Menge abgerechnet wurde. Es herrschte der Stückakkord ${ }^{63}$ vor, der zwischen Gedingeältestem und Fahrsteiger über Tage je nach Gebirgslage und Flözmächtigkeit ausgehandelt wurde. Das Kameradschafts- und Gruppenedinge wurde durch die Rationalisierung zugunsten des Einzelgedinges zurück-

58 Tschirbs, Tarifpolitik im Ruhrbergbau, S. 244. Vgl. auch Schwenger, Sozialpolitik im Ruhrbergbau, S. $45 \mathrm{ff}$.

59 Hierzu im einzelnen die Stimmungsberichte des Preußischen Oberbergamtes Dortmund und der einzelnen Bergreviere, StAM, OBAD 1864-1871.

${ }^{60}$ Notiz Bergwerksdirektor Fuldner, Gruppe Bochum, für den Vorstand, 11. 9. 1929; Zechenverband an Bergwerksdirektor Fuldner, 11. 9. 1929, BgA 40/481.

61 Hartewig, Das unberechenbare Jahrzehnt, S. $97 \mathrm{f}$.

62 Burghardt, Die Mechanisierung des Ruhrbergbaus, S. $289 \mathrm{ff}$., beschreibt zwar die Steigerungen der Förderleistung und die technische Rationalisierung; die Änderung der Arbeitsprozesse wird bei $\mathrm{ihm}$ freilich nur angedeutet. So brachte die Rationalisierung eindeutig Autonomieverluste für die Belegschaften: wie weit diese aber gingen, muß beim derzeitigen Forschungsstand als offen gelten.

${ }_{63} \mathrm{Zu}$ den Gedingearten vgl. Schwenger, Betriebliche Sozialpolitik im Ruhrkohlenbergbau, S. 124. 
gedrängt, jedoch blieb diese Akkordform an günstige Voraussetzungen, nämlich insbesondere an Schüttelrutschenbetrieb in flacher Lagerung gebunden, so daß nur einzelne Schachtanlagen sehr hohe Einzelgedingequoten erzielten. Noch nach dem Zweiten Weltkrieg arbeiteten auf der Schachtanlage Zollverein 38\% der Untertagebelegschaft im Kameradschafts- und $56 \%$ im Gruppen-, hingegen nur $5,8 \%$ im Einzelgedinge. Die Zahlen variierten von Zeche zu Zeche - auf der Schachtanlage Holland etwa waren $30 \%$ im Kameradschafts- und $70 \%$ im Einzelgedinge beschäftigt -, Kameradschafts- und Gruppengedinge überwogen trotz der Rationalisierung weiterhin deutlich. ${ }^{64}$ Dort, wo sich der Großrutschenbetrieb durchsetzte, war allerdings auch im Gruppengedinge eine individuelle Leistungskontrolle möglich. ${ }^{65}$ Überall, wo sich neue Arbeitssysteme durchsetzten, verlor die Arbeitsgruppe unter ihrem Ortsältesten ihre Bedeutung. An ihre Stelle trat das Steigerrevier, in dem die Autonomie der Bergleute vor allem technisch deutlich eingeschränkter war.

Garantierte Mindestverdienste existierten vor 1918 nicht. Auch die Einführung fester Mindestlöhne nach 1918 änderte an der Akkordstruktur und den damit verbundenen Problemen nichts. Das technische und Aufsichtspersonal wurde in Grundgehalt und fördermengenabhängigen Prämien bezahlt, mußte also selbst ein Interesse am möglichst großen Umfang der Förderung besitzen. Die Abrechnung erfolgte entsprechend der geförderten Wagen über Tage an der Hängebank, wo die Wagen auf Bergezusatz kontrolliert und registriert wurden. Ein zu großer Bergeanteil am Fördergut konnte zu dem berüchtigten „Wagennullen“ führen, also zur Nichtanerkennung bestimmter Fördermengen und damit zu entsprechendem Lohnverlust. Nach der Rationalisierung wurde ein anderer Teil des Gedinges in der Grube durch den Steiger kontrolliert, indem er das vom einzelnen Bergmann bewältigte Arbeitsquantum nach Metern oder verbautem Holz feststellte. Entscheidende Konfliktpunkte lagen einerseits darin, daß mit dem über Tage ansässigen, nicht revierzuständigen Fahrsteiger das Gedinge, also der Akkordlohn verhandelt werden mußte. Die Fahrsteiger kannten die Unter-Tage-Reviere schlechter als die Reviersteiger, ihre Nähe zur Bergwerksdirektion und ihre eigene Leistungsbezahlung brachten sie zu rigorosen Versuchen, über niedrig angesetzte Gedinge ein betriebswirtschaftlich günstiges Förderergebnis durchzusetzen. Der andere Konfliktpunkt hing damit zusammen, daß die Kontrolle der Wagen unabhängig von den Kameradschaften über Tage und damit in ihren Augen häufig willkürlich erfolgte. Neben Gedingefestsetzung und Fördergutabrechnung kamen weitere kleinere Konfliktpunkte hinzu, die sich aus der alltäglichen Arbeit ergaben. Das Bergwerk stellte z. B. zwar grundsätzlich Gezähe und Lampen, war zu kostenlosem Ersatz aber nur dann bereit, wenn die Beschädigung oder Zerstörung von Werkzeug nicht mutwillig erfolgt war. Gerade letzteres war allerdings in der Regel umstritten. ${ }^{66}$ Die Kontrolle der Bergarbeit durch Stückakkord und eher oberflächliche Arbeitsplatzinspektionen wurde

64 Aktennotiz Zentrallohnbüro der Gruppe Gelsenkirchen der GBAG, 1. 8. 1946, BgA 41/757.

65 Tschirbs, Tarifpolitik im Ruhrbergbau, S. 253. Vgl. auch Hartewig, Das unberechenbare Jahrzehnt, S. $97 \mathrm{f}$. 66 Zu möglichen Gedingekonflikten Schwenger, Betriebliche Sozialpolitik im Ruhrkohlenbergbau,
S. $115 \mathrm{ff}$. 
durch Arbeitsordnungen kodifiziert, die die Bergleute bei Anlegung als verpflichtend akzeptieren mußten. Die Arbeitsordnungen der Vorkriegszeit, obwohl bereits seit 1905 der Arbeiterausschuß hierzu gehört werden mußte, waren die Grundlage für das rigorose Strafsystem im Bergbau. Unerlaubtes Fernbleiben, Alkohol, Widerstand gegen Vorgesetzte, Diebstahl, mutwillige Beschädigungen etc. wurden mit Geldstrafen, unter Umständen mit Entlassungen sanktioniert. Die Arbeitsordnungen der Vorkriegszeit, aber auch der Weimarer Republik waren direkter Ausdruck des auf den Zechen vorherrschenden Linienorganisationssystems autoritären Zuschnitts. ${ }^{67}$

Folgte die Linienorganisation im Bergwerk bei Auslagerung der Stabs- und Verwaltungsfunktionen zunächst rein organisatorischen und betriebswirtschaftlichen Nützlichkeitsüberlegungen, so erwies sich die militärisch strikt exekutierte Linienorganisation, die eine freie Kommunikation von Problemen der Bergarbeit nicht kannte, im Laufe der Zeit auch als die scheinbar angemessene Lösung zur Integration der zahlreichen neuen Arbeitskräfte sowie zur Regelung der Arbeitsprozesse und sich hieraus ergebender Konflikte. Dabei entwickelte sich schließlich insofern ein interessanter Widerspruch, als ein autoritärer und auf Allmacht der Bergwerksdirektion verpflichteter Führungsstil mit einem Arbeitsprozeß korrespondierte, der faktisch nicht kontrollierbar war. Im konkreten Arbeitsvollzug waren die Bergwerksleitungen völlig auf die Kompetenz und Berufserfahrung jener Arbeiter angewiesen, denen sie andererseits grundsätzlich nicht nur jedes Mitspracherecht, sondern überhaupt jede Kommunikationsmöglichkeit über die Probleme der Bergarbeit verweigerten. Aus dieser Konstellation ergaben sich vor 1914 Heftigkeit und Intensität von Streiks und Konflikten einerseits, die hohe Belegschaftsfluktuation andererseits. Die Reaktionen der Bergwerksunternehmen auf die drei großen Streiks vor dem 1 . Weltkrieg ${ }^{68}$ bestanden jeweils in Aussperrungen und Kommunikationsverweigerung. Fast zwangsläufig wurde dadurch der Staat auf den Plan gerufen, der, um den sozialen Konfliktdruck zu mindern, sich um eine Verbesserung der betrieblichen Kommunikation allerdings wiederum nur so halbherzig bemühte, daß der Konfliktdruck kurzfristig gemildert wurde. Die 1905 eingerichteten Arbeiterausschüsse blieben ohne größere Wirkung. $\mathrm{Da}$ freilich die betriebswirtschaftlichen Daten bis 1914, wenn auch bei stagnierenden Förderleistungen je Kopf und Schicht, günstig waren und über Arbeitszeit und Mehrbeschäftigung die Förderung zügig gesteigert werden konnte, gerieten die Zechenleitungen nicht unter Anpassungsdruck. Gedinge, Mengenkontrolle, Arbeitszeitregelungen und Beschäftigungspolitik im Kontext eines rigorosen Strafsystems waren die Grundzüge der betrieblichen Arbeitspolitik der Bergwerksleitungen vor 1914 und damit neben der autonomen, kameradschaftlich organisierten Bergarbeit selbst die Grunddeterminanten der industriellen Beziehungen. Das Fehlen legitimer Interessenartikulations- und Kommunikationsmöglichkeiten der Bergarbeiter führte zu unreguliertem Konfliktverhalten (Fluktuation, willkürliches Feiern), dessen negative Konsequenzen die Bergwerke wie-

67 Vgl. die Sammlung der Vorkriegsarbeitsordnungen der GBAG in: BgA 55/1232. Die GBAG hatte auf allen Schachtanlagen die gleichen Arbeitsordnungen.

68 Brüggemeier, Leben vor Ort. 
derum durch eine Verschärfung des autoritären Führungsstils bekämpften. Positive Ansätze einer differenzierten betrieblichen Sozialpolitik traten dahinter zurück.

\section{Die Entwicklung der industriellen Beziehungen 1916 bis 1934}

\section{6 bis 1918}

In der zweiten Kriegshälfte nahmen die materiellen Probleme der Bergleute rasch zu. ${ }^{69}$ Die ersten Unruhen und Teilstreiks im Ruhrbergbau gab es im Sommer 1916 wegen der Teuerung und Problemen bei der Lebensmittelversorgung, insbesondere der unzureichenden Zuteilung von Fleisch, Fett und Kartoffeln. Ausgehend von Zechen im Essener Norden breiteten sich die Streiks und Arbeitsniederlegungen zunächst im östlichen und dann auch im nördlichen Revier aus. ${ }^{70}$ Die Zechenleitungen hatten sich zwar, um Unruhen zu vermeiden, in der Lohnfrage flexibel gezeigt, angesichts von Leistungsrückgang und Arbeitskräftemangel aber an individueller Lohnpolitik und Mehrarbeit festgehalten. Dieser Politik lag der starke Rückgang der Förderung zu Grunde, die im Ruhrgebiet 1915 insgesamt um 25\% unter den Stand von 1913 gesunken war. Dies hing vor allem mit der Abnahme der Belegschaften von 4000001913 auf 2800001915 zusammen, die durch einen leichten Anstieg der Pro-Kopf-Förderung nicht ausgeglichen werden konnte. ${ }^{71}$ Betrug die Zahl verfahrener Schichten je Bergmann 1913 302, so lag sie 1915 bei 332. Der durchschnittliche Schichtverdienst blieb allerdings unter dem Stand von 1913; lediglich wegen der Vielzahl verfahrener Schichten erzielte der Bergmann 1915 einen nominell höheren Jahresverdienst als 1913 bei allerdings zugleich deutlich gestiegenem Kalorienverbrauch und sich beschleunigender Inflation. ${ }^{72}$ Die Förderung im Ruhrgebiet stieg 1916 gegenüber 1915 zwar um knapp 7\% auf 94,2 Mio.t, jedoch nahm im gleichen Zeitraum die Belegschaft um mehr als $25 \%$ zu. Die Förderung pro Belegschaftsmitglied insgesamt sank damit um mehr als 10\% im Jahre 1916 mit weiter fallender Tendenz ab. ${ }^{73}$ Angesichts steigender Kohlenpreise nahm zwar der Umsatz rascher zu; die GBAG konnte 1916 und 1917 auch wieder an die Dividendenhöhe der Vorkriegszeit anknüpfen, doch entwikkelten sich Mengen und Kosten sehr unvorteilhaft. Das Zechenmanagement vor Ort stand mithin unter einer doppelten Anforderung: Leistungssteigerung einerseits, Entgegenkommen gegenüber den Bergleuten andererseits, zwei Forderungen, die angesichts der sich zuspitzenden Ernährungslage immer unvereinbarer wurden, da alle Lohnzugeständnisse den Bergleuten nicht ausreichten, um

69 Zur allgemeinen Sozialgeschichte der Bergarbeiterschaft an der Ruhr Hartewig, Das unberechenbare Jahrzehnt, insbes. Kap. $5 \mathrm{ff}$. Hartewig gibt auch einige allgemeine Angaben zur Entwicklung der materiellen Lage der Arbeiterschaft. So lagen die Löhne der Bergarbeiter bis 1922 nicht unter dem Vorkriegsstand, sondern wurden, wenn häufig auch erst nachträglich, kontinuierlich angepaßt. Erst die beschleunigte Inflation brachte eine Trendwende. Die Probleme zuvor hatten weniger mit der Höhe der Löhne als dem Zusammenbruch der Versorgung zu tun.

70 Ebenda, S. 20.

71 Wiel, Wirtschaftsgeschichte des Ruhrgebietes, S. 131.

72 Daten nach Günter Hegermann, Zahlentafel 1.

73 Wiel, Wirtschaftsgeschichte des Ruhrgebietes, S. 131. 
den mit den Leistungsanforderungen wachsenden Bedarf an Lebensmitteln zu decken. ${ }^{74}$ Die Möglichkeiten der Bergwerke im Bereich der Lebensmittelversorgung waren beschränkt; die betriebliche Sozialpolitik der Zechen war traditionell derart gering, daß eine sozialfürsorgerische Infrastruktur mit Kaufhaus, Betriebsküchen, eigener Landwirtschaft, Erholungsheimen etc., wie sie im Leverkusener Fall existierten, und auf die man jetzt hätte zurückgreifen können, fehlte. ${ }^{75}$

Daß sich im Sommer 1916 die Konflikte zuspitzten und es auf zahlreichen Zechen an der Ruhr, u. a. auch auf den GBAG-Zechen Pluto und Ver. Hamburg und Franziska, zu mehr oder weniger spontanen Arbeitsniederlegungen kam, hatte daher vor allem materielle Gründe. Entsprechend waren die Reaktionen der $\mathrm{Ze}$ chenleitungen bzw. des Vorstandes der GBAG. Hatte man zunächst die Einführung von Teuerungszulagen noch abgelehnt, da sie nivellierend wirkten, erklärte man sich nach einer Arbeiterausschußsitzung auf Pluto, auf der der Arbeiterausschußorsitzende derartige Zulagen zumindest für kinderreiche Familien gefordert hatte, zu einer derartigen Neuerung bereit, da sie, so Bergwerksdirektor Brandi, im Moment einer allgemeinen Lohnerhöhung vorzuziehen seien. ${ }^{76}$ In den Arbeiterausschußsitzungen des Sommers 1916 hatte sich die Ausstandsbewegung im übrigen nicht abgezeichnet. Dies lag vor allem an der eigentümlichen Kommunikationsstruktur in den Ausschüssen, in denen die Arbeitervertreter ihre Forderungen vorlegten, ohne daß über sie verhandelt werden konnte. ${ }^{77} \mathrm{Da}$ die Zechenleitungen zugleich jede Kommunikation mit den Verbänden ablehnten, mußten sie über die Lage in ihren eigenen Betrieben zwangsläufig schlecht informiert sein, zumal sie die Gewerkschaftspresse als tendenziös zurückwiesen. Hätte man sich auf eine volle Auseinandersetzung eingelassen, so hätte man das herrschende Dilemma begreifen müssen: solange nicht eine durchgreifende Besserung der Ernährung erfolgte, war eine durchgreifende Leistungssteigerung nicht möglich. Die bessere Ernährung war aber an höhere Löhne gebunden, die man nur bei erhöhter Leistung gewähren wollte. Die Reaktion der Zechenleitungen auf die unvorhergesehenen Arbeitsniederlegungen bestand nun aber keineswegs in einer Verbesserung der betrieblichen Kommunikation und einer entsprechenden Anpassung von Lohn- und betrieblicher Sozialpolitik. Im Gegenteil: Im Kontext der Sommerstreiks meldete die GBAG alle Vorfälle sorgfältig an das stellvertretende Generalkommando in Münster. Kirdorf betonte bei der Diskussion dieser Meldungen, „daß unter allen Umständen ein Verhandeln mit den Organisationen unterbleiben müsse."78 Gerade der „alte Verband" war es in der Sicht der Zechenleitungen, der die Konflikte geschürt und damit den Anlaß zu den Unruhen und Arbeitsniederlegungen gegeben hatte. Konsequenterweise plädierte der Vorstand der GBAG daher für eine Unterdrückung des gewerkschaftlichen Einflusses und eine Stärkung der wirtschaftsfriedlichen Organisationsalternativen. Als im Wittener Revier die Bergarbeitergewerkschaften bestimmte Forderungen der Arbeiteraus-

74 Laut Hartewig, Das unberechenbare Jahrzehnt, S. 159, wurde 1916 der Kalorienbedarf der Bergleute trotz ihrer Privilegierung bei der Lebensmittelversorgung nur noch zu $72 \%$ gedeckt.

75 Typisch hierfür auch der Verlauf der Arbeiterausschußsitzungen der Phoenix-Zeche Holland in Wattenscheid,; BgA 41/323. Generell Hartewig, Das unberechenbare Jahrzehnt, S. 161.

76 Vorstandsprotokoll der GBAG, 3. 10. 1916, BgA 55/111.

77 Protokolle der Arbeiterausschußsitzungen Schächte Franziska, BgA 40/39.

78 Vorstandsprotokoll der GBAG, 25. 8. 1916, BgA 55/111. 
schüsse, die von den örtlichen Zechenleitungen der Vereinigten FranziskaSchächte zurückgewiesen worden waren ${ }^{79}$, aufgriffen und direkt bei der Zechenleitung intervenierten, blieb der GBAG-Vorstand bei seiner Haltung, mit den Organisationen der Bergarbeiter nicht einmal zu reden. Während die Wittener Zechenleitung zumindest für eine Antwort an die Verbände plädierte und am 8. Dezember 1916 einen entsprechenden Beschluß faßte, war der Vorstand anderer Auffassung. Auf Initiative Kirdorfs wurde der Wittener Beschluß nicht akzeptiert; Ende Dezember entschied man sich, die Eingabe der Bergarbeiterverbände nicht zu beantworten.$^{80}$ Stattdessen begann man, u. a. auch in expliziter Reaktion auf das Vaterländische Hilfsdienstgesetz und seine Vorschriften über die Neuwahl von Arbeiterausschüssen und die Einsetzung paritätischer Schlichtungsausschüsse, mit noch massiverer Unterstützung der gelben Werkvereine; insbesondere unterstützte man die Bildung von sog. „Verständigungsausschüssen für den rheinisch-westfälischen Industriebezirk" zwischen Arbeitgebern und Arbeitnehmern. ${ }^{81}$ Unter prominenter Beteiligung der GBAG hielt dieser Verständigungsausschuß am 17. März 1917 eine Sitzung ab, auf der sich Arbeitgeber und Arbeitnehmer über Arbeitsrichtlinien einigten. ${ }^{82}$ „Der Verständigungsausschuß hat den Zweck, Mittel und Wege zu finden zur Förderung der wirtschaftsfriedlichen Lehre und Bewegung sowie zur Geltendmachung der gemeinsamen Interessen der Arbeiter und der Unternehmer... Der Verständigungsausschuß tritt im allgemeinen nach außen hin nicht selbst in Erscheinung, sondern überläßt die praktische Durchführung der bei dem Gedankenaustausch festgestellten Gesichtspunkte den Vertretungen der beteiligten Gruppen." Nach dieser Festlegung diskutierten die Teilnehmer des Treffens die Ursachen der seit Februar 1917 - von Krupp ausgehend - feststellbaren Streikbewegungen auf zahlreichen Zechen des Ruhrgebietes. Ein Essener Sozialsekretär meinte, die Arbeiter seien unzufrieden, doch hätten erst die Gewerkschaften durch das Hineintragen der Lohnfrage die Belegschaften politisiert. Dem stimmten die anwesenden Arbeiter"vertreter" der gelben Vereine zu, betonten aber, daß die Lebensmittelnot wirklich groß sei. Sie verwiesen ferner auf die immer größere Spannung zwischen Gedinge- und Schichtlöhnen. Erstere zögen immer stärker davon. Die anwesenden Bergwerksvertreter griffen diese Anregung "dankbar" auf und sagten zu, im Bereich der Schichtlöhne in Zukunft mehr zu tun. Daraufhin wandte sich die Runde den bevorstehenden Arbeiterratswahlen zu. Verschiedene Berichterstatter sprachen über die bislang gemachten Erfahrungen und empfahlen, „die Wahlen so weit wie irgend möglich hinaus zu schieben, im übrigen aber während der Wahlhandlung sehr streng auf den geheimen Charakter der Wahl zu achten, da die Gewerkschaftsvertreter bei diesen Wahlen versuchen, zu ihren Gunsten die Geheimhaltung der Wahl durch Ausgabe eigener Stimmzettel und Einstecken derselben in den Umschlag schon vor Betreten der Wahlzelle zu verhindern. ${ }^{\text {"83 }}$ Die schlechten Lebensbedingungen und die hohen Leistungsanforderungen hatten mithin seit

79 BgA 40/39.

80 Vorstandsprotokolle der GBAG, 11. 12. 1916, 28. 12. 1916, BgA 55/111.

81 Vorstandsprotokoll der GBAG, 22. 2. 1917, BgA 55/113.

82 Anhang zum Vorstandsprotokoll der GBAG, 22. 3. 1917, BgA 55/113.

83 Ebenda. 
dem Jahr 1915 zu Problemen geführt, die sich in mehr oder weniger spontanen Streiks niederschlugen. Die Zechen, die durch eine in ihren Augen angemessene Politik der Lohnerhöhungen auf die wachsenden Probleme reagiert hatten, wurden von diesen Ausständen überrascht; in der defekten Kommunikation der Arbeiterausschüsse, für die die Zechenleitungen verantwortlich waren, hatten sich die Konflikte nicht abgezeichnet. Da die Zechenleitungen aus der vordergründigen Ruhe auf eine grundsätzlich friedliche Stimmung der Bergleute schlossen, konnten in ihren Augen die Ausstände nur das Ergebnis sozialdemokratischer Verhetzung sein, die sich der Arbeiterausschüsse bzw. eines Teiles ihrer Mitglieder bediente. Die hierauf sinnvollste Reaktion schien einerseits materielles Entgegenkommen gegenüber den Belegschaften, andererseits Unterdrückung der sozialdemokratischen Bewegung bzw. Förderung ihrer wirtschaftsfriedlichen Konkurrenz zu sein. Der Vorstand der GBAG war nicht bereit, sich in einer veränderten Kommunikationsstruktur der Wirklichkeit der Bergarbeit und der Stimmung unter den Bergarbeitern zu stellen und daraus Konsequenzen zu ziehen.

Zunächst war man mit dieser Haltung erfolgreich. Die Streikwelle verebbte Ende August 1916, ohne daß grundsätzliche Zugeständnisse hätten gemacht werden müssen, doch war hierfür vor allem die Besserung der Lebensmittelversorgung nach der Ernte verantwortlich. Im Herbst 1916 kam es nur zu gelegentlichen Arbeitsniederlegungen bei der $\mathrm{GBAG}^{84}$, im Januar 1917 brachen allerdings erneut Streiks, diesmal zunächst in den westlichen Revieren aus. Im Februar des Jahres erreichten die Streiks auch das mittlere und östliche Ruhrgebiet. Bei der GBAG kam es zu einem ersten Teilausstand auf der Essener Zeche Bonifacius, dessen Motive für die innerbetriebliche Kommunikation des Kohlenkonzerns bezeichnend waren. Auf der Arbeiterausschußsitzung am 20. Februar 1917 erklärten die Arbeitervertreter: „Der Streik, in den ein Teil der Belegschaft eingetreten sei, solle nur eine kurze Demonstration sein, um die Aufmerksamkeit der Öffentlichkeit und der Regierung darauf zu lenken, daß es so nicht mehr weitergehe und besondere Maßnahmen getroffen werden müßten, um die Leistungsfähigkeit der Arbeiter zu halten. Die Ausschußmitglieder hätten zwar von einem Streik abgeraten, um im Inlande keine Unruhe und im Auslande keine Aufmerksamkeit zu erregen, doch sei die Erregung innerhalb der Belegschaft so groß, daß sie sich in einer derartigen Demonstration habe Luft machen müssen. Die Hauptunruhe sei dadurch entstanden, daß den Leuten in der Ernährungsfrage immer wieder Versprechungen gemacht würden ohne Erfolg und daß die Gleichmäßigkeit der Lebensmittelversorgung noch viel zu wünschen übrig lasse. ${ }^{85}$ Die Ernährungsfrage, vor allem aber die starken Versorgungsunterschiede zwischen den einzelnen Schachtanlagen gäben dabei Anlaß für zahlreiche Gerüchte. Auf den Streikausbruch, der zunächst mit der schlechten Lebensmittelversorgung, sodann mit Lohnforderungen begründet wurde, reagierte die Zechenleitung vor Ort mit Beschwichtigungen und Zugeständnissen, um die Arbeiter zur Anfahrt zu bewegen, was „in sofort aufgenommenen Verhandlungen" auch erreicht wurde. Dabei sicherte der Bergwerks-

84 Anfang Oktober 1916 legten die Belegschaften der Dortmunder Germania-Schächte im Kontext der Umstellung der Sommer- auf dic Winterzeit und der Änderung der Seilfahrtzeiten die Arbeit nieder. Spethmann, Zwölf Jahre Ruhrbergbau, Bd. I, S. 26.

85 Arbeiterausschuß der Zeche Bonifacius, 20. 2. 1917, BgA 41/529. 
direktor im Arbeiterausschuß „eine Nachprüfung der Gedinge und deren angemessene Regelung so wie eine Erhöhung der Schichtlöhne bis zu weiteren 40 Pfg." $\mathrm{zu}^{86}$ Parallel hierzu verhandelte Kirdorf im Zechenverband über eine allgemeine Reaktion auf die Streikbewegung, die man, so Spethmann 1928 im Nachhinein ${ }^{87}$, vor allem auf das Hilfsdienstgesetz und den gewerkschaftlichen Versuch, eine de facto Tarifierung der Löhne durchzusetzen, zurückführte. Die häufig gleichen Forderungen nach 10,50 Mk. Mindestlohn, die auf der Mehrzahl der bestreikten Zechen vom Arbeiterausschuß verlangt wurden, deuteten in der Tat auf eine Abstimmung der Ausschußforderungen durch die Gewerkschaften hin, doch überschätzten die Zechenleitungen die Gewerkschaften, wenn sie glaubten, diesen gelinge es ohne weiteres, friedliche Belegschaften zum Streik zu bringen. Das Problem war vielmehr, daß die Gewerkschaften sich zu Sprechern des bergmännischen Protestes und der Forderungen der Bergarbeiter machen konnten, da diesen ansonsten jede Artikulations- und Verhandlungsmöglichkeit fehlte, wenn sie nicht direkt streiken und demonstrieren wollten. Beim Zechenverband erkannte man rasch "die Notwendigkeit eines Nachgebens ..., da in heutiger Zeit keinesfalls ein längerer Stillstand eintreten dürfe." Zugleich hielt man aber daran fest, „unter allen Umständen nur mit den gesetzlichen Arbeiterausschüssen - nicht mit den Gewerkschaften - zu verhandeln, auch Mindestlöhne und Sondervergütungen für Über- und Nebenschichten abzulehnen." 88

Mitte April 1917 lief eine erneute Streikwelle durch das Ruhrgebiet, bei der von den Arbeitern in zunehmendem Maße spontan gehandelt und auch die Arbeiterausschüsse übergangen wurden; die Gewerkschaften behaupteten, diese Aktionen seien im wesentlichen von Unorganisierten durchgeführt worden. ${ }^{89}$ Militär und Staat waren gezwungen, in vermittelnder Weise einzugreifen, doch führte gerade diese Vermittlung zu Ergebnissen, die den Vorstand der GBAG in erheblicher Weise störten. Bei einer vom Gelsenkirchener Oberbürgermeister einberufenen Arbeiterausschußkonferenz stellte sich heraus, daß im Gegensatz zu anderen $\mathrm{Ze}-$ chen die GBAG ihre Arbeiterausschüsse nicht an der Lebensmittelbeschaffung bzw. an deren Kontrolle und Verteilung beteiligte. Zunächst beschloß der Vorstand der GBAG auf diesen Vorfall hin, sich bei anderen Zechen über deren Verfahren zu erkundigen. ${ }^{90}$ Initiativen des Generalkommandos in Münster, die Arbeiterausschüsse zu beteiligen, lehnte die GBAG schroff ab. Im Vorfeld einer Sitzung mit Militärvertretern beschloß der Vorstand, „daß eine Kontrolle der Ausschußmitglieder beim Lebensmitteleinkauf, die Zuziehung anderer Belegschaftsmitglieder oder gar der Vertreter der Organisationen zu den Ausschußsitzungen, abzulehnen, im übrigen aber zu betonen ist, daß die erneute Erörterung gerade des letzten Punktes zu neuen Bewegungen und Erregungen unter der Arbeiterschaft führen würde, was einen Rückgang der Kohlenförderung zur Folge haben

86 Vorstandsprotokoll der GBAG, 22. 2. 1917, BgA 55/111.

87 Spethmann, Zwölf Jahre Ruhrbergbau, Bd. I, S. 33.

88 Vorstandsprotokoll der GBAG, 22. 2. 1917, BgA 55/111.

89 Spethmann, Zwölf Jahre Ruhrbergbau, Bd. I, S. 37f. Stenographischer Bericht über die Verhandlungen der Belegschafts-Versammlung der Zechen Minister Stein und Hardenberg, 29.4. 1917, StAM OBAD 1791, Bll.84ff.

90 Vorstandsprotokoll der GBAG, 2. 5. 1917, BgA 55/113. 
würde. “91 Das gerade Gegenteil war freilich der Fall. Auf der Dortmunder Zeche Minister Stein hatte der Arbeiter-Ausschuß seit dem September 1916 verlangt, ihm „Einsicht in die Lebensmittelbeschaffung zwecks Feststellung der Herkunft und der Preise zu gestatten." Diese Forderung war scharf zurückgewiesen worden; mit der Drohung, daß man unter Umständen die Lebensmittelbeschaffung einstellen werde, hatte die Zechenleitung in Dortmund den Arbeiter-Ausschuß sogar zur Rückziehung des Antrages gezwungen. ${ }^{92} \mathrm{Da}$ jedoch die Lebensmittelversorgung der Bergleute in Dortmund weiterhin schlecht blieb, häuften sich die Gerüchte über Sondergeschäftemacherei der Zeche. Insbesondere wurde auf diese Weise keine Ruhe in die Belegschaft getragen; im Gegenteil wurde ihr Mißtrauen zusätzlich angeheizt, das sich zudem aus dem Wissen speiste, daß die GBAG anders etwa als Hoesch die Lebensmittelversorgung kaum subventionierte. ${ }^{93}$

Daß es auf den Dortmunder GBAG-Zechen nicht zu größeren Streiks und Arbeitsniederlegungen kam, war daher keineswegs ein Verdienst der Politik der Zechenleitungen, sondern ein Erfolg der gewerkschaftlichen Agitation. Die Stimmung unter den Bergleuten war wegen der schlechten Lebensmittelversorgung und der hohen Leistungsanforderungen gereizt. Auch die im März 1917 zugesagte Anhebung der Durchschnittslöhne auf 10,50 M vermochte die Stimmung nicht zu beruhigen, da es sich bei dieser Summe nicht um einen Mindestlohn handelte. Mindestlöhne lehnte die GBAG wegen ihrer leistungssenkenden Folgen strikt ab. Folgende Arbeiterstimme, von den Bergleuten der Schachtanlagen Minister Stein und Hardenberg mit Bravo-Rufen aufgenommen, war daher durchaus repräsentativ: „Wir bleiben solange am arbeiten, bis wir überhaupt nicht mehr beförderungsfähig (!) sind. Wer weiß, wie lange der Krieg noch dauert. Die Regierung verlangt, daß die Arbeitsfähigkeit erhalten bleiben soll. Die Antreiberei muß aufhören. Eine höhere Lohnzulage ist notwendig. Die Herren Kapitalisten mögen einmal auf jede Dividende verzichten. In den Jahren von 1870 bis jetzt haben sie ein Kapital angehäuft, das ein Nationalvermögen darstellt. Das haben sie uns zu verdanken. Jetzt mögen sie aber auch dafür sorgen, daß unsere Arbeitsfähigkeit erhalten bleibt. Tun sie das nicht, so werden auch wir eines Tages stehen bleiben müssen. “94 Der auf der ersten großen Belegschaftsversammlung im April 1917 anwesende Gewerkschaftssekretär unterstützte die Forderungen der Arbeiter nach höheren, vor allem aber gleichmäßigeren Löhnen und einer Verbesserung der Lebensmittelversorgung, verwies zur Durchsetzung der Forderungen allerdings auf den Weg über den Arbeiterausschuß und die Organisationen: „Wir hoffen, daß die Zukunft uns bessere Zustände bringen wird. Kameraden, das besagt auf der anderen Seite, daß unsere Kameraden hier in den Munitions-Fabriken und Bergwerken heute nicht die Arbeit wegen dieser Frage [Lebensmittel] niederlegen dürfen. Das müßte aufs schwerste verurteilt werden, wenn Kameraden da sind, die glauben, wegen jeder Kleinigkeit die Arbeit niederlegen zu müssen. Unsere Kameraden an den Fronten haben heute größere Opfer zu bringen als wir in der Heimat. ... Ich

91 Vorstandsprotokoll der GBAG, 15. 5. 1917, BgA 55/113.

92 Bericht des Arbeiterausschußvorsitzenden auf der Belegschaftsversammlung der Zechen Minister Stein und Hardenberg am Sonntag, dem 29. 4. 1917, StAM OBAD 1791, Bll.85.

93 Diskussionsbeiträge auf der Belegschaftsversammlung am 29.4. 1917, a.a.O..

94 Ebenda, Bl. $92 \mathrm{f}$. 
möchte bemerken, die organisierten Kameraden tragen die Schuld nicht daran, wenn so etwas vorkommt, sondern in der Hauptsache sind es die unorganisierten Kameraden. Ich hoffe, daß auf Minister Stein so etwas nicht eintreten wird. “95

Der Verweis auf die Tätigkeit von Arbeiterausschüssen und Gewerkschaften, Behörden und Schlichtungsausschüssen konnte im April 1917 die Belegschaften der Dortmunder GBAG-Zechen noch von spontanen Streikaktionen abhalten. Obwohl den Zechenleitungen und dem Zechenverband diese letztlich konfliktmoderierende Haltung der Gewerkschaften bewußt war, gaben sie ihre ablehnende Haltung ihnen gegenüber nicht auf, sondern verschärften sie im Sommer 1917 weiter. Hintergrund waren dabei einerseits die Auftritte von Gewerkschaftssekretären auf den sich häufenden Belegschaftsversammlungen, andererseits gewerkschaftliche Forderungen nach Verkürzung der Arbeitszeit, die mit einer zunehmenden Agitation gegen die Über- und Mehrarbeit verbunden waren. ${ }^{96} \mathrm{Be}-$ sonders erbost zeigte sich der Zechenverband über die Behauptung, Arbeitszeitverkürzungen hätten positive Auswirkungen auf die Leistungsfähigkeit der Belegschaften, sowie die Versuche gewerkschaftlicher Vertrauensleute, das reale Ausmaß der Über- und Mehrarbeit durch Belegschaftsbefragungen festzustellen. Anstatt in einen Dialog mit den Gewerkschaften einzutreten, beschwerte sich der Zechenverband beim Generalkommando in Münster. Die Gewerkschaften, so seine Argumentation, würden den Leistungswillen der Belegschaften untergraben und unrealistische Hoffnungen wecken. Überdies bestritt man die Vorwürfe zu zahlreicher Überschichten. Man beobachte vielmehr seit Anfang 1917 „eine stetige Zunahme der willkürlichen und mit Urlaub eingelegten Feierschichten..., so daß im April die Zahl der Über- und Nebenschichten diejenige der Feierschichten nur um ein ganz geringes überstieg. Tatsächlich bilden ja auch die Über- und Nebenschichten nur den Ausgleich für die durch Betriebsstörungen und Wagenmangel oder durch freiwillige Entschließung und andere Gründe entstandenen Feierschichten." Ein Verbot der Mehrarbeit liege nicht einmal im Interesse der Arbeiter: „Dem Interesse der Arbeiterschaft würde mit einem Verbot der Überschichten nur gedient sein, wenn ihnen eine volle Vergütung für nicht verfahrene Schichten zugestanden würde." Dies sei allerdings ausgeschlossen. Der Zechenverband beließ es nicht bei dieser allgemeinen Argumentation, die zumindest insofern stimmig war, als Arbeitszeitforderungen bei den Belegschaften hinter dem Wunsch nach verbesserter Lebensmittelversorgung noch zurückstanden. Man forderte den kommandierenden General von Gayl indirekt auf, die Bergarbeiterpresse zu zensieren: „Ganz abgesehen davon, daß auf diese Weise [durch die Veröffentlichung von Gewerkschaftseingaben] im vorliegenden Fall die Öffentlichkeit und damit auch das feindliche Ausland von den Arbeitsniederlegungen ... erfährt, ist insbesondere die in ihr [der Eingabe] ausgesprochene gesperrt gedruckte Drohung, die ununterbrochene Kohlenförderung werde sich nicht aufrechterhalten lassen, wenn nicht schnell und durchgreifend in der Lebensmittelversorgung gehandelt werde, geeignet, bei vielen Leuten das Gefühl zu erwecken, als ob sie zu

95 Ebenda, Bl. 107.

96 Verkürzung der Arbeitszeit und Arbeitsleistung, in: Der Bergknappe, Nr. 28 vom 14. 7.1917 , StAM OBAD 1791, Bl. 211. 
den bisherigen Arbeitsleistungen körperlich nicht mehr in der Lage und deshalb berechtigt seien, mit einer größeren Kräfteanspannung zurückzuhalten. ${ }^{“ 97}$

Hier zeigten sich zentrale Merkmale und Argumentationslinien des Verteilungskonfliktes, der für die nächsten Jahre beherrschend werden sollte und den der Bergbau verfahrensmäßig nicht in den Griff bekam. Während die Zechenleitungen Lohnerhöhungen erst für erkennbare Leistungssteigerungen zugestehen wollten, verlangten die Belegschaften die Lohnerhöhungen als Voraussetzung, angesichts der schlechten Rahmenbedingungen die Leistung halten bzw. steigern zu können. Da hierüber eine Einigung nicht möglich war, hätte im Prinzip die Einsicht folgen müssen, einen derartigen, nicht lösbaren Konflikt durch eine von beiden Seiten akzeptierbare Verfahrensstruktur zumindest zu regulieren, um jeweils für einen bestimmten Zeitraum legitime Entscheidungen treffen zu können, was indes die Anerkennung der Gewerkschaften oder anderer Arbeitervertretungen als Verhandlungspartner auf Seiten der Belegschaften implizierte. Doch genau diese Umsetzung eines Konfliktes in ein reguliertes Verfahren mit jeweils zeitlich begrenzten, revidierbaren Entscheidungen verweigerten die Zechenleitungen mit dem Argument, gäbe es die gewerkschaftlichen Forderungen nicht, gäbe es den Konflikt nicht. Damit zwang man die Gegenseite nachgerade zur Radikalität bzw. zur Unterwerfung, solange es nicht gelang, diese zu spalten. Wegen der technischen Struktur der Produktionsprozesse war die Differenzierung der Belegschaft im Bergbau schwierig, die Zechenleitungen hätten daher um so mehr ein Interesse an Kooperation haben müssen, um den zerstörerischen Alternativen von Unterwerfung oder Radikalität zu entgehen. Denn Unterwerfung der Belegschaften führte ja nicht zu Ruhe, sondern lediglich zu willkürlichen und damit unberechenbareren Formen der Konfliktaustragung, wie die Streikwelle vom April 1917 zeigte. Doch hielt man mit einer Verkrampfung ohnegleichen an der Ablehnung der Gewerkschaften fest. Noch im Januar 1918 versah der GBAG-Vorstand Verbandsaufforderungen von Zechenverband und Arbeitnordwest, auf keinen Fall mit den Gew'erkschaften auch nur zu korrespondieren, mit dem gehörigen Nachdruck, um sie im ganzen Konzern verbindlich durchzusetzen. ${ }^{98}$

Daß für dieses Verhalten unter Umständen sogar zutreffende ökonomische Gründe ins Feld geführt wurden, änderte nichts daran, daß in den Belegschaften die Unruhe und Unzufriedenheit wuchs. Ein reines Zurückweisen der Belegschaftsforderungen, mit welchen Argumenten auch immer, änderte nichts an der ja durchaus kostenträchtigen Konfliktträchtigkeit der Situation. Die Verweigerung von Verhandlungen mit den Gewerkschaften führte zudem nicht einmal zu den gewünschten Ergebnissen, weil die Gewerkschaften dazu übergingen, die Arbeiterausschüsse als ihre Sprachrohre zu nutzen. Auf diese Weise nahm der Verhandlungsbedarf überproportional $\mathrm{zu}$, da die Auseinandersetzungen um die Lohnforderungen der Belegschaft auf jeder Zeche einzeln zu führen waren. Im August 1917 entschloß sich eine Konferenz der vier großen Bergarbeiterverbände (Alter Verband, Christliche Bergarbeiterschaft, Hirsch-Dunckerscher Werkver-

97 Verein für die bergbaulichen Interessen/Zechenverband an den kommandierenden General, 21.7. 1917, StAM OBAD 1871, Bll.209f.

98 Vorstandsprotokoll der GBAG, 8. 1. 1918, BgA 55/115. 
ein, Polnische Vereinigung) nach zahlreichen Eingaben von Arbeiterausschüssen und Belegschaftsversammlungen, die von den jeweiligen Zechenverwaltungen abgewiesen worden waren ${ }^{99}$, eine konzertierte Aktion aller Arbeiterausschüsse auf den Weg zu bringen. „Sämtliche Arbeiterausschüsse auf den Ruhrzechen mögen bei ihren Werksverwaltungen eine alsbaldige Lohnerhöhung beantragen, welche zur Folge hat, daß ... der Lohn für Hauer und Lehrhauer pro Schicht nicht unter 12 Mark ... beträgt. “ ${ }^{100}$ Trotz der Obstruktionshaltung der Zechenleitungen plädierten die Gewerkschaften aber auch jetzt noch für ruhiges Verhandeln und lehnten eigenständigen Aktionen der Belegschaften ab. Für den Fall eines Scheiterns der Verhandlungen verwies man auf die Möglichkeit, den Konflikt vor den Schlichtungsausschuß zu bringen. ${ }^{101}$

Anstatt sich diesem Verfahren zu unterwerfen, eröffnete der Zechenverband eine umfassende Polemik nicht nur gegen die Gewerkschaften, sondern auch gegen die Schlichtungsausschüsse. Hintergrund war die Defensive, in der sich die Zechenbesitzer befanden, $d a$ in zunehmendem Maße auch die staatlichen und Schlichtungsbehörden bereit waren, auf Forderungen der Bergarbeiterschaft einzugehen. ${ }^{102}$ War bereits die Anfang des Jahres aufgestellte Forderung nach einer Erhöhung des Hauerdurchschnittslohnes auf 10,50 Mark vom Generalkommando unterstützt worden, so zeichnete sich im Sommer $1917 \mathrm{ab}$, daß zahlreiche Schlichtungsausschüsse den Forderungen der Arbeiterausschüsse teilweise entsprechen würden. Ende Juli 1917 hatte auf der Krupp-Zeche ver. Sälzer-Neuack die Belegschaft kurzfristig die Arbeit niedergelegt, nachdem die Forderung des Arbeiterausschusses nach Erhöhung des Durchschnittslohnes auf 12 Mark von der Zechenleitung abgelehnt worden war. Der mit der Sache befaßte Schlichtungsausschuß einigte sich auf einen Kompromiß, mit dem sich schließlich auch der Arbeiterausschuß einverstanden erklärte. ${ }^{103}$ Der Zechenverband befürchtete daher der Essener Schiedsspruch sprach sich selbst grundlegende Bedeutung zu -, daß nicht nur reihenweise Schlichtungsverfahren verloren würden, sondern überdies die Belegschaften glaubten, durch Streiks die Arbeit der Schlichtungsausschüsse in ihrem Sinne zu Entscheidungen veranlassen zu können: „Unseres Erachtens kann es nur dazu führen, die Erkenntnis unter der Arbeiterschaft zu fördern, jedwede Forderung zu erzwingen, sich jede Übertretung gesetzlicher Bestimmungen gestatten zu können, da sie durch das einfache Mittel der Streikandrohung oder einer Arbeitseinstellung von nur wenigen Tagen auf den vollen Schutz der verantwortlichen Behörde rechnen kann. “104 Folgerichtig zog man das gesamte Schlichtungsverfahren in Zweifel: „In dem durch das Hilfsdienstgesetz eingeführten

99 Polizeibericht über eine Belegschaftsversammlung der Schachtanlagen Minister Stein und Hardenberg, 23. 8. 1917, StAM OBAD 1791, Bll.272-274.

${ }^{100}$ An die Arbeiterausschüsse der Ruhrzechen, in: Bergarbeiter-Zeitung, Nr. 33 vom 18. 8. 1917, StAM OBAD 1791, Bl. 249.

${ }^{101}$ Ebenda.

102 Redebeitrag eines Vertreters des Alten Verbandes, Belegschaftsversammlung der Zeche Sachsen, 7. 10. 1917, StAM OBAD 1792, Bl. 31.

${ }^{103}$ Begründung des Schiedsspruches durch den Schlichtungsausschußvorsitzenden; Abschrift in einem Brief des Zechenverbandes an den kommandierenden General, 22. 8. 1917, StAM OBAD 1791 , Bll.254f.

${ }^{104}$ Schreiben des Zechenverbandes an den kommandierenden General, 22. 8. 1917, StAM OBAD 1791, Bll.252-259, hier 258f. 
Schlichtungsverfahren steht aber der Vorsitzende auf dem schwankenden Boden des Wirtschaftslebens ..., inmitten des Streits sozialpolitischer Anschauungen, die zugleich stark in das politische Gebiet hinüberspielen. Es ist eine höchst schwierige Aufgabe, auf diesen unsicheren Faktoren fußend, Forderung und Gegenstandpunkt so abzuwägen, daß sich daraus das wirtschaftlich Richtige bei gleichzeitiger Befriedigung beider Parteien ergibt." Konnte man das gesamte Schlichtungssystem nicht beseitigen, so drang man beim Generalkommando darauf, daß die richtigen Grundsätze im Schlichtungsverfahren stärker berücksichtigt würden. Vor allem wollte der Zechenverband verhindern, daß der Essener Schlichtungsspruch Schule machte: „Wohin man sich auf dem uferlosen Gebiet der durch das Hilfsdienstgesetz schnell geschaffenen einigungsamtlichen Tätigkeit verlieren kann, wenn an den angedeuteten Grundsätzen [Kopplung von Lobn und Leistung] nicht festgehalten wird, zeigt die letzte Entscheidung des Essener Schlichtungsausschusses." 105

Das Generalkommando in Münster ließ keinen Zweifel daran, daß man im Interesse der Aufrechterhaltung des Arbeitsfriedens Lohnerhöhungen in einem von den Gewerkschaften vorgeschlagenen Maße, wenn auch nicht derart schnell wie gefordert, für notwendig hielt. Nicht zuletzt die sprunghaft angestiegene Teuerungsrate lasse „eine weitere Steigerung der Löhne im Bergbau als absolut notwendig erscheinen. " 106 Der kommandierende General bat den bergbaulichen Verein/Zechenverband, „sogleich und ohne Zögern diese Verhältnisse [Teuerung] zu erwägen und einen allgemeinen Entschluß der Zechen ... herbeizuführen, wonach in wenigen Monaten der jetzige Lohn von 10,50 M auf $12 \mathrm{M}$ für die Hauer steigen soll." ${ }^{107}$ Lediglich in der Ablehnung der Forderung nach Mindestlöhnen waren Generalkommando und Zechenverband noch gemeinsamer Auffassung. Der Zechenverband und die angeschlossenen Schachtanlagen beharrten aber darauf, Lohnverbesserungen nur gegen erkennbare Leistungssteigerungen zu gewähren und kritisierten, daß Zugeständnisse nur die ohnehin geringe Leistungsbereitschaft senken würden. Dem Generalkommando gegenüber erklärte man, die nötigen Lohnanpassungen seien bereits erfolgt: „Darüber hinaus hat der Bergbauverein oder Zechenverband nicht das Recht und die Macht, die Zechen zu einer bindenden Erklärung zu veranlassen, daß in wenigen Monaten der Schichtlohn für die Hauer von M 10,50 auf die von den Arbeiterverbänden verlangte Höhe von M 12,- steigt. Ganz abgesehen davon muß befürchtet werden, daß, wie die Erfahrungen gerade dieses Jahres gezeigt haben, die Zusicherung eines derartig bestimmten Hauer-Durchschnittslohnes zu einem weiteren Rückgang der durchschnittlichen Arbeitsleistung führt. “108 Wegen der Kohlenpreiserhöhung, die das Generalkommando u. a. wegen der minderleistungsfähigen Zechen angeregt hatte, habe das RWKS die erforderlichen Schritte eingeleitet, doch sei eine kurzfristige Entscheidung wegen des Urlaubs des Handelsministers nicht zu erwarten.

${ }^{105}$ Ebenda, B1. 254.

${ }^{106}$ Der kommandierende General an den Verein für die bergbaulichen Interessen, 28. 8. 1917, StAM OBAD 1791, Bll.266-270, hier Bl. 268.

107 Ebenda.

${ }^{108}$ Bergbauverein an den kommandierenden General, 3. 9. 1917, StAM OBAD 1791, Bll. 338-339, hier 339. 
Erst nach dessen Entscheidung könne daher neu beraten werden. Bis dahin müsse man den Wunsch des Generalkommandos „vertagen“. ${ }^{109}$ Der Vorstand des Zechenverbandes tagte Mitte September 1917. Dem kommandierenden General teilte man danach zwar die Bereitschaft mit, bis zum Jahresende den Hauerdurchschnittslohn sukzessive auf $12 \mathrm{M}$ steigen zu lassen, doch seien bereits Forderungen nach $15 \mathrm{M}$ aufgetaucht; auch die alte Mindestlohnforderung würde weiterhin vertreten. Durch Nachgeben sei der Betriebsfrieden auf den Zechen nicht zu garantieren. Im Gegenteil trügen die Behörden zu dieser Forderungswelle durch ihr nachgiebiges Verhalten bei: „Wir befürchten, daß die amtliche Politik, die sich über die Wirkung dessen, was sie tut, nicht klar ist, daß an diesem Punkte unser Wirtschaftsleben einen Riß bekommen wird, dessen Folgen zum Verlust des Krieges führen werden. " ${ }^{110}$ Letztlich beschuldigte der Zechenverband die Behörden, „der zielbewußten Tätigkeit des sozialdemokratischen Bergarbeiterverbandes den Weg zu bahnen. "111

Die GBAG zählte im Zechenverband zu den kompromißlosen Unternehmen und setzte auch nach dem Sommer 1917 ihre bisherige Politik fort, durch einseitige Anpassungen der Löhne an die Inflation zwar eine kontinuierliche Lohnsteigerung zu garantieren, ein grundlegendes Eingehen auf die Belegschaftsforderungen, ja jede ernsthafte Verhandlung hierüber abzulehnen. Auf der Unternehmensebene aber war man direkt mit den Folgen möglicher Schlichtungsausschußentscheidungen konfrontiert. Trotz der politischen Ablehnung des Hilfsdienstgesetzes mußte man sich mit der Realität arrangieren. Daher zeigte, nachdem klar war, daß von behördlicher Seite kaum noch Schützenhilfe zu erwarten war, die Drohung der Arbeitervertreter mit dem Schlichtungsausschuß auch bei der GBAG Wirkungen, insofern sich eine gewisse Kompromißbereitschaft gegenüber den Lohnforderungen einstellte, um Schlichtungsverfahren aus dem Weg zu gehen. ${ }^{112}$ Die Verhandlungen auf den einzelnen Zechen, sofern man von Verhandlungen überhaupt sprechen will, verliefen allerdings weiterhin nach dem alten Muster. Auf Belegschaftsversammlungen wurden Forderungen nach Lohnerhöhungen und Lebensmittellieferungen aufgestellt, die der Arbeiterausschuß der Zechenleitung vortrug, die die Forderungen mit dem Hinweis auf ihre Bereitschaft, die Löhne kontinuierlich anzuheben und in der Lebensmittelbeschaffung das Mögliche zu tun, nur sehr bedingt bewilligte. Die dabei stets geforderten Mindestlöhne wurden mit dem Leistungsargument immer wieder zurückgewiesen. ${ }^{113}$ So reagierten die GBAG-Zechen auch auf die Forderung der Arbeiterausschüsse nach dem 12 M-Durchschnittslohn abweisend: „Die Zechenverwaltungen“ schrieb der Bergaufsichtsbeamte für das 3. Dortmunder Bergrevier am 8. September 1917, "haben [auf die Arbeiterforderungen] durchweg in dem Sinne geantwortet, daß die Löhne der Hauer bereits jetzt annähernd $11 \mathrm{M}$ betrügen und eine weitere Steigerung bei gleichbleibender Leistung stattfinden würde. ... Die Erhöhung des

${ }^{109}$ Ebenda.

110 Bergbauverband an den kommandierenden General, 19. 9. 1917, StAM OBAD 1791, Bll.402-407, hier 404.

111 Ebenda, Bl. 407.

112 Vorstandsprotokoll der GBAG, 3. 8. 1917, BgA 55/113.

${ }^{113}$ Arbeiterausschuß der Franziska-Schächte, 24. 9. 1917, 27. 12. 1917, 31. 1. 1918, BgA 40/39. Arbeiterausschußsitzungen Zeche Graf Moltke, BgA 41/324. 
Kindergeldes ist durchweg abgelehnt, mit der Begründung, daß unter der Belegschaft selbst eine Gegnerschaft gegen die Kinderzulage bestände."

Anfang September 1917 hatten fast alle Arbeiterausschüsse die Gewerkschaftsforderungen, z.T. im Rahmen von Belegschaftsversammlungen übernommen und sie den Zechenleitungen gegenüber vorgetragen. Ähnlich wie in Dortmund weigerten sich die Zechenleitungen auch in anderen Orten, den Bergarbeitern grundsätzlich entgegenzukommen, bekundeten aber ihre Bereitschaft zu leistungsbezogenen Lohnanpassungen. ${ }^{115}$ Die fortdauernde Weigerung, zu einer generellen Regelung zu kommen, bedingte sehr unterschiedliche Lohnhöhen. Die zugestandenen Erhöhungen der Hauerdurchschnittsverdienste reichten von 20 bis 50 Pfennig; auf einzelnen Zechen wurden Kinderzulagen gewährt und auch die Lebensmittelbeihilfen u. a. zur Kartoffeleinkellerung fielen von Schachtanlage zu Schachtanlage unterschiedlich aus. Die Schlichtungsausschüsse wurden ebenfalls unterschiedlich, aber doch in wachsendem Maße bemüht. Die fortdauernde Weigerung der Zechenverwaltungen, zu einer grundsätzlichen Regelung der Lohnfrage zu kommen, die angesichts der Vielzahl der Zechen nur durch Tarifverhandlungen erreichbar gewesen wäre, bei gleichzeitiger Bereitschaft zu Lohnanpassungen und Lebensmittelbeihilfen bedingte auf diese Weise eine Zersplitterung der Lebenslagen und gab erheblichen Nährstoff für Schlichtungsverfahren, Gerüchte und nachfolgende Fluktuation. Vor allem aber ließ sich so kaum der Arbeitsfrieden gewährleisten. Dabei hätte die sich ohnehin durchsetzende Orientierung an Durchschnittslöhnen einen Einstieg in die Tarifierung des Lohnsystems ohne weiteres zugelassen.

Die eigentliche Befürchtung der Zechenbesitzer bezog sich darauf, durch Lohntarifierung und vor allem die Fixierung von Mindestlöhnen das in ihren Augen einzig wirksame Instrument zur Leistungssteigerung zu verlieren, woraus sie auch gegenüber den Belegschaften keinerlei Hehl machten. ${ }^{116}$ Die Zechenbesitzer bestanden bei allen Zugeständnissen auf Handlungsautonomie in dieser Frage. ${ }^{117}$ Diese harte Haltung trug in der zweiten Jahreshälfte 1917 zur Politisierung der Auseinandersetzungen bei, da die Zechenbesitzer in den Augen der Belegschaften grundsätzlich kompromißunwillig erschienen, obwohl sie selbst ganz offensichtlich zu den "Kriegsgewinnlern“ gehörten. Vor einer Versammlung der Arbeiter der GBAG-Zeche Sachsen erklärte der zuständige Gewerkschaftssekretär: „Die Gesamtsumme der ausgezahlten Löhne an die Bergarbeiter im Rheinisch-Westfälischen Kohlenrevier betrug im Jahr 1916649 Mill. Mark, der Betriebsgewinn im gleichen Jahr betrug allein für 48 Gewerkschaften 523 Millionen, 175 Millionen mehr wie(!) im Jahre 1914. Durch die neue Kohlenpreiserhöhung vom 1. 10. 1917 werden dem deutschen Volke allein 153 Millionen Mark abgeknöpft. Herr Kirdorf sitzt da in Gelsenkirchen mit 4 Mann, diese stimmen durch Handerheben und schon stecken die Bergherrn 153 Millionen mehr ein. "118 Die Bergarbeiter-

114 Bergrevier Dortmund III, 8. 9. 1917, StAM OBAD 1792, Bl. 159.

115 Berichte der Bergreviere Anfang September 1917, StAM OBAD 1792.

${ }^{116}$ Siehe Polizeibericht über die Belegschaftsversammlung der Zeche Sachsen in Hamm, 7. 10. 1917, StAM OBAD 1792, Bll.31-32.

117 Arbeiterausschuß Bonifacius, 28. 9. 1917, BgA 41/529.

${ }_{118}$ Polizeibericht über die Belegschaftsversammlung der Zeche Sachsen in Hamm, 7.10. 1917, StAM OBAD 1792, Bl. 32. Die „vier Mann“ bezogen sich offensichtlich auf den Vorstand des RWKS. 
gewerkschaften, mehr aber noch die Belegschaften gelangten so nach und nach zu der Auffassung, die Zechenbesitzer könnten nur politisch zur Aufgabe ihres Standpunktes gezwungen werden, solange Streik als Mittel nicht in Frage kam. ${ }^{119}$ Offensichtlich wurde aber auch den Gewerkschaften klar, daß sich die Belegschaften kaum noch ruhig halten ließen. Bereits am 30. September 1917 hatte ein Vertreter des Alten Verbandes vor einer Belegschaftsversammlung der Zeche Auguste Victoria erklärt, es sei der „Herrenstandpunkt, der ... schon manchen bösen Streit angerichtet (habe), und es scheint als ob die Herren durch diesen Krieg nichts gelernt hätten.... Aber eins müssen sich diese Herren gesagt sein lassen, wenn dieser Herrenstandpunkt nicht aufhört, dann läuft das Maß über. ... Wenn ... Zustände herrschen, die unerträglich werden, so braucht man sich nicht zu wundern, wenn der Sumpf eines Tages zusammenschlägt. ${ }^{\text {"120 }}$ Einen Ausweg aus dicser Situation schienen nur politische Maßnahmen zu weisen. Die Gewerkschaften betonten als Alternative zu Kampfmaßnahmen folgerichtig den Kampf um politische Änderungen (Berggesetz, Wahlrecht, Tarifordnung) und forderten die Bergleute auf, die Organisationen zu stärken, um den Bergbaubesitzern gegenüber straff organisiert auftreten zu können. ${ }^{121}$ Die neuen Gesetze und die „Beseitigung des Arbeitsvertrages wie er heute ist" müßten zu effektiver Mitbestimmung der Bergarbeiter führen, wovon sich Husemann zugleich eine Hebung der Leistung versprach: "Nicht nur der Herrenmensch, sondern auch der Bergmann soll im Bergbau mitbestimmen. Hierdurch wird Arbeitsfreudigkeit erzielt." ${ }^{122}$ Ende 1917 war der Spielraum, den das Hilfsdienstgesetz einräumte, im Bergbau erschöpft. Angesichts der Blockadehaltung der Zechen und ihres Verbandes ließen sich Arbeiterausschüsse und Schlichtungsverfahren, auch wenn letztere zu Gunsten der Arbeiterschaft entschieden, nur sehr bedingt zur Artikulation und Durchsetzung der sich im Rahmen der Inflation ständig neu ergebenden Forderungen nutzen. Das Fehlen von kollektiven Verhandlungsstrukturen bedingte folgerichtig eine Aufwertung der politischen Institutionen, zumal diese wie das Generalkommando in Münster von sich aus ein Interesse daran hatten, den Bergleuten im Interesse des Arbeitsfriedens entgegenzukommen.

Anfang 1918 verschärften sich im Ruhrgebiet erneut die Lohnauseinandersetzungen, da sich die Lohnanhebung auf einen Durchschnittslohn von $12 \mathrm{M}$ als unzureichend erwies. Bereits im Herbst 1917 waren gelegentlich $15 \mathrm{M}$ gefordert worden; im Januar 1918 wurden von den Arbeiterausschüssen wiederum mit gewerkschaftlicher Unterstützung 13,50 M verlangt. Parallel zu den Lohnforderungen verschlechterte sich die Nahrungsmittelversorgung weiter; die bevorstehenden Regierungsmaßnahmen zur Bekämpfung des Schleichhandels, die auch die Lebensmitteleinkäufe verschiedener Zechengesellschaften empfindlich treffen mußten, ließen zudem eine weitere Verschlechterung der Versorgung der Bergarbeiter befürchten. ${ }^{123}$ Anders als im Herbst 1917 waren jetzt die Belegschaften

\footnotetext{
119 Ebenda, B1. 32.

120 Zitiert nach Spethmann, Zwölf Jahre Ruhrbergbau, Bd. I, S. 48.

$121 \mathrm{Vgl}$. Reden von Fritz Husemann und Albert Martmöller vom Alten Verband auf einer Bergarbeiterversammlung in Witten-Annen, 2. 12. 1917, StAM OBAD 1792, Bll. 242-246.

122 Ebenda, Bl. 244.

${ }^{123}$ Oberbergamt an pr. Handelsminister, 11. 2. 1918, StAM OBAD 1792, Bll.297f.
} 
nicht mehr durch Appelle ruhig zu halten, zumal aus Berlin Gerüchte über politische Streiks in den Westen drangen und sich Kriegsmüdigkeit breit machte. Am 20. Januar brachen nach der Ablehnung von Arbeiterausschußforderungen auf verschiedenen nordöstlichen Zechen des Reviers die ersten Streiks aus, die sich am 28. Januar $1918 \mathrm{zu}$ einer Art Generalstreik ausweiteten. ${ }^{124}$ Bei der Gelsenkirchener Bergwerks AG wurden die Schachtanlagen Hansa, Hamburg, Minister Stein, Zollern II und Germania von der Ausstandsbewegung ergriffen. Durch das zeitliche Zusammentreffen mit den Berliner Streiks ergab sich eine Politisierung der Auseinandersetzungen, doch waren auch an der Ruhr Friedensforderungen mehr und mehr Allgemeingut geworden. Von Emil Kirdorf, dem Generaldirektor der GBAG, wurde überdies eine gewisse Nähe zum Berliner Machtzentrum vermutet; seine Zugehörigkeit zum „Unabhängigen Ausschuß für einen Deutschen Frieden", den die GBAG auch finanziell unterstützte ${ }^{125}$, war allgemein bekannt. ${ }^{126}$ Ein Zusammenwirken von Not und Kriegsmüdigkeit sowie die offenkundige Erfolglosigkeit aller bisherigen Verhandlungen bedingten mithin die Streikbewegung, die jedoch von den Zechenbesitzern und der oberen Bergbehörde ausschließlich als politische Bewegung begriffen wurde. Die obere Bergbehörde führte die Arbeitsniederlegungen auf die Politik der Gewerkschaften zurück: „Wenn jetzt von dem alten Verbande behauptet wird, daß vorwiegend die unzureichenden Löhne und die mangelhafte Lebensmittelversorgung Veranlassung zu dem Ausstande gegeben hätten, so muß demgegenüber darauf hingewiesen werden, daß auf vielen Zechen überhaupt keine Lohnforderungen oder Forderungen nach mehr Lebensmitteln gestellt worden sind, sondern daß das gleiche Wahlrecht, Freiheit und sofortiger Friede gefordert wurde." Für das Dortmunder Oberbergamt war klar: „Es kann daher kaum zweifelhaft sein, daß die Ausstandsbewegung in der Hauptsache wohl nur aus politischen Gründen von sozialdemokratischer Seite aus in die Belegschaften hineingetragen worden ist. ${ }^{\text {"127 }}$ Diese Auffassung verkürzte die Vorgeschichte des Streikes, der im übrigen nach dem Eingreifen des Generalkommandos relativ rasch beendet werden konnte ${ }^{128}$, vollständig. Die "Politisierung“ stand nicht am Anfang des Konfliktes, sondern markierte das Ende aller Versuche, zu einer gegenseitig akzeptablen Verhandlungslösung zu kommen. Die Reaktion der GBAG auf den Streik wurde indes vor allem durch seine geringe Dauer bestimmt. Grundsätzlich waren auch für den Vorstand der GBAG die Streiks, die bis auf Rheinelbe/Alma alle großen Schachtanlagen des Konzerns erfaßt hatten, ein Ergebnis politischer Verhetzung, auf das die verantwortlichen Bergwerksdirektoren zunächst scharf reagierten. Einerseits kündigte Bergwerksdirektor Eichler den auf den Dortmunder Anlagen Streikenden Geldstrafen wegen Kontraktbruchs an, andererseits weigerte er sich, zwei der bekanntesten „Rädelsführer“ wiedereinzustellen. Nachdem sich ein Ende des Ausstandes allerdings schon nach wenigen Tagen, Anfang Februar 1918, abzeichnete, bean-

${ }^{124}$ Spethmann, Zwölf Jahre Ruhrbergbau, Bd. I, S. 52 ff.

125 Vorstandsprotokoll der GBAG, 6. 8. 1918, BgA 55/115.

${ }^{126} \mathrm{Zu}$ Emil Kirdorf fehlt bislang eine gute biographische Darstellung. Vgl. zu seiner politischen Bedeutung Ende der Weimarer Republik Turner jr., Die Großunternehmer, S. $114 \mathrm{ff}$.

${ }_{127}$ Bericht des Oberbergamtes, 11. 2. 1918, StAM OBAD 1792, Bll.295-298, hier Bl. 296.

${ }^{128}$ Ebenda, Bl. 296. 
tragten die betreffenden Arbeiterausschüsse den Verzicht auf Maßregelungen, einem Wunsch, dem der Vorstand der GBAG auch nachkam, da „im vaterländischen Belange es sich empfiehlt, Nachsicht zu üben, um auch nicht einen Arbeiter von der Arbeit zurückzuhalten. Daher soll“, so wurde dem für die Zechen des Dortmunder Gebietes zuständigen Bergwerksdirektor Eichler aufgegeben, „in einer alsbald abzuhaltenden Ausschußsitzung verhandelt und unter gewissen Bedingungen Zurücknahme der obigen Anordnungen [Bestrafungen, Entlassungen] zugestanden werden." ${ }^{129}$

Den Streikenden waren keine materiellen Zugeständnisse gemacht worden. Daher kam den noch ausstehenden Schlichtungsausschußentscheidungen, die nach betrieblicher Nichteinigung von verschiedenen Arbeiterausschüssen angerufen worden waren, große Bedeutung zu. Am 8. Februar 1918 erfolgte die erste Entscheidung auf eine Eingabe des Arbeiterausschusses von Stein/Hardenberg. Es kam zu keinem Schiedsspruch, doch drückte der Schlichtungsausschuß seine Erwartung aus, daß „die Lohnverhältnisse in nächster Zeit auf beiden Schachtanlagen sich so gestalten, daß bei normalen Arbeitsleistungen und normalen Arbeitsverhältnissen für den Monat Februar ein Hauerdurchschnittslohn von 13,- Mk. erreicht wird und daß auch bei den anderen Arbeiterkategorien eine Lohnsteigerung in demselben prozentualen Verhältnis stattfindet." Der Schlichtungsausschuß ging weiter davon aus, daß „ür die Monate bis Mai bei normalen Arbeitsleistungen und normalen Arbeitsverhältnissen eine weitere Lohnentwicklung bei allen Arbeiterkategorien in demselben Verhältnis eintritt wie in den Monaten Oktober bis Februar einschließlich. ${ }^{\text {"130 }}$

Die Verweigerung von Lohnverhandlungen auf regionaler Ebene brachte mithin zusätzliche Sitzungen, Konflikte und schließlich Schlichtungsausschußentscheidungen, die zusammengenommen die vermeintlichen Nachteile eines geregelten Verkehrs mit den Gewerkschaften weit übertroffen haben dürften. Zudem hatte bereits seit 1917 die Praxis zumindest indirekter Verhandlungen in folgender Weise Platz gegriffen: Die Bergarbeitergewerkschaften wurden mit Eingaben beim stellvertretenden Generalkommando in Münster vorstellig, welches die Eingaben zur Stellungnahme an den Zechenverband weitergab. Auf die Vorhaltungen und Wünsche des Generalkommandos hin machte der Zechenverband gewisse Zugeständnisse, die die Münsteraner Behörde den Gewerkschaften mitteilte. Diese Kryptoverhandlungen waren ein Ergebnis der Bereitschaft des Generalkommandos, die Gewerkschaften zu akzeptieren. Der Zechenverband hingegen verband seine Antworten auf Münsteraner Anfragen stets mit dem Hinweis, die Gewerkschaften würden lediglich aus Machtdünkel handeln. De facto befand sich der Zechenverband auf diese Weise schließlich in einer Situation vollständiger "Sprachlosigkeit“. Selbst die "guten“ Argumente, die man etwa in der Über- und Mehrarbeitsfrage hatte ${ }^{131}$, konnten so nicht zum Zuge kommen, da als Reaktion auf die Verweigerungshaltung der Zechen auch die Arbeiterschaft nichts mehr von Verhandlungen hielt. Strenggenommen verprellte der Zechenverband durch seine

129) Vorstandsprotokoll der GBAG, 2. 2. 1918, BgA 55/115.

130 Vorstandsprotokoll der GBAG, 23. 2. 1918, BgA 55/115.

${ }^{131}$ Siehe die Ausarbeitung des Zechenvcrbandes zur Mehrarbeitsfrage, 6. 3. 1918, StAM OBAD 1792, Bll.317-326. 
starre Haltung im Jahre 1918 die einzigen Verbündeten, die er angesichts der Zeitverhältnisse realistisch hatte. Eine Auseinandersetzung mit den Gewerkschaften hätte zwar materielle Zugeständnisse verlangt, aber den Handlungsspielraum der Zechen gegenüber den Belegschaften erheblich vergrößert. Mit ihrer Verweigerungshaltung aber trieben sie die Bergleute faktisch in den Streik, so daß folgerichtig nur noch Repression als Handlungsalternative übrigblieb. Das Versagen der Zechenbesitzer drückte sich darin am deutlichsten aus, daß ihnen letztlich nur der Ruf nach dem Militär blieb, um die eigenen Belegschaften disziplinieren zu können. ${ }^{132} \mathrm{Zwar}$ handelte das Militär in der Regel rasch und zog „aufsässige“ Leute zum Felddienst ein, jedoch war absehbar, daß derartige Disziplinierungsinstrumente dauerhaft kaum zur Verfügung stehen würden. Im April 1918 zeichnete sich zudem ab, daß auch die Strategie einseitiger Lohnerhöhungen nur begrenzt anwendbar war, da erwartete Kohlenpreiserhöhungen nicht vorgenommen wurden, die bisherige Politik der Zechenleitungen, die erhöhten Löhne aus den steigenden Kohlenpreisen zu finanzieren, also in Frage gestellt wurde. Kohlenpreiserhöhungen und militärischer Druck auf die Belegschaften waren die zwei zentralen Handlungsressourcen der Zechen, über die sie aber autonom überhaupt nicht verfügen konnten. Spätestens jetzt hätte deutlich werden müssen, daß man sich in verhängnisvoller Weise eigener Handlungsmöglichkeiten begeben hatte: Der Preis der Verweigerung war die eigene Handlungsunfähigkeit.

Der GBAG-Vorstand beschloß Anfang April 1918, zwar an der Politik kontinuierlicher Lohnsteigerungen festhalten zu wollen, bezweifelte aber, „daß diese Steigerung in dem bisherigen Umfang fortgesetzt werden kann. " ${ }^{133}$ Im Juni 1918 mußte die örtliche Zechenleitung dem Arbeiterausschuß der Franziska-Schächte auf dessen Vorhaltung, seit dem ersten Quartal seien die Löhne nicht mehr gestiegen, dies mit dem Hinweis auf die nicht erfolgte Kohlenpreisanpassung bestätigen. ${ }^{134}$ Forderungen der Arbeiterausschüsse nach Erhöhung der Hauerlöhne auf 15 M., die während des Frühsommers mit gewerkschaftlicher Unterstützung faktisch auf allen Schachtanlagen des Ruhrgebietes gestellt wurden, wiesen die Zechenleitungen flächendeckend mit dem Hinweis zurück, ohne eine Erhöhung der Kohlenpreise könnten weitere Lohnzusagen nicht gemacht werden. Die Arbeiterausschüsse wandten sich daraufhin an die Schlichtungsausschüsse, die Bergarbeiterverbände an den Minister für Handel und Gewerbe, der seinerseits betonte, daß eine Kohlenpreiserhöhung nur bei entsprechenden Lohnzusagen durch den Zechenverband erfolgen würde. Ein Schiedsspruch des Dortmunder Schlichtungsausschusses, der eine Eingabe des Arbeiterausschusses der Zeche Westhausen zurückwies und die kontinuierliche Lohnsteigerungspolitik der GBAG ausdrücklich anerkannte, half nichts mehr. ${ }^{135}$ Im August 1918 kam es zu umfangreichen Streikaktionen, die sich vor allem auf den Duisburger und Essener Raum konzentrierten. Die GBAG war vom Streik diesmal nur mit ihrer Schachtanlage Bonifacius betroffen. ${ }^{136}$ Erst der Streik brachte Bewegung in die festgefahrene Situation.

\footnotetext{
${ }^{132}$ Kriegsamtsstelle Münster an den Bergbauverein, 6. 7. 1918, StAM OBAD 1793, Bl. 211.

${ }^{133}$ Vorstandsprotokoll der GBAG, 4. 4. 1918, BgA 55/115.

${ }^{134}$ Sitzung des Arbeiterausschusses der Franziska-Schächte, 27. 6. 1918, BgA 40/39.

135 Vorstandsprotokoll der GBAG, 19. 4. 1918, BgA 55/115.

136 Arbeiterausschuß der Schachtanlage Bonifacius, 14. 8. 1918, BgA 41/529.
} 
In jeweils zweiseitigen Verhandlungen zwischen Bergarbeiterverbänden, Zechenverband und Handelsministerium machten die Zechen nach der Zusage von weiteren Kohlenpreiserhöhungen schließlich gewisse Lohnzugeständnisse, so daß eine Art indirekte Tarifvereinbarung zustandekam. Wenngleich sie mit den erreichten Zusagen weiterer kontinuierlicher Lohnerhöhungen auf $15 \mathrm{M}$. Hauerdurchschnittslohn, Anhebung der Schichtlöhne und des Kindergeldes nicht völlig zufrieden waren, nahmen die Belegschaften doch relativ rasch die Arbeit wieder auf. ${ }^{137}$ Die Drohung seitens der Militärbehörden, drastisch gegen Streikende vorzugehen, dürfte hierfür ebenso eine Rolle gespielt haben, wie die Haltung der Gewerkschaften, die Kampfmaßnahmen weiterhin ablehnten, auch wenn sich das Generalkommando in Münster erstmals über die nicht ausreichend streikfeindliche Haltung der Verbände beschwerte. ${ }^{138}$

Mit den Lohnzugeständnissen des August 1918 trat keine Beruhigung ein. Die GBAG übernahm zwar die Zusagen des Zechenverbandes und konnte im September 1918 ihren Arbeiterausschüssen gegenüber auf die wieder aufgenommene Politik der kontinuierlichen Lohnsteigerungen hinweisen, mußte aber Probleme bei der Lebensmittelversorgung eingestehen; man bemühe sich nach Kräften, zusätzliche Lebensmittel zu beschaffen, sei allerdings an die Bewirtschaftungsvorschriften gebunden. ${ }^{139}$ Im September aufflackernde Forderungen nach Zulassung der Gewerkschaften wiesen die GBAG-Zechenleitungen zurück. ${ }^{140}$ Auf der regulären Arbeiterausschußsitzung der Franziska-Schächte in Witten Ende Oktober 1918, auf der die Belegschaftsvertreter ihre Forderungen nach Anerkennung der Gewerkschaften vorbrachten und zusätzliche Lieferungen von Lebens- und Waschmitteln verlangten, erklärte der zuständige Bergwerksdirektor, durch die kontinuierliche Lohnanpassungspolitik seien die Forderungen längst überholt, bei der Lebensmittelversorgung würden die Handlungsspielräume immer geringer. ${ }^{141}$ Es war klar, daß auch die nächste „Lohnrunde“ wieder den gewohnten Verlauf nehmen würde, vom Schlichtungsausschuß zum Streik, von der politischen Intervention des Generalkommandos und des Handelsministers zu indirekten Tarifverhandlungen und schließlich zu einem neuen Lohnkompromiß. Kriegsende und Novemberrevolution setzten dieser Konstellation indes ein abruptes Ende.

Die sich in der ersten Jahreshälfte und im Sommer 1918 kumulierenden Probleme führten beim Vorstand der GBAG nicht zu Überlegungen, durch Kooperation mit den Belegschaften und ihren Vertretungen die Konfliktaustragung zu regulieren und Eskalationen zu verhindern. Ganz im Gegenteil forcierte man im Mai 1918 erneut die Unterstützung der gelben Werkvereine und plädierte nachdrücklich für die Bildung lokaler Verständigungskomitees in der Hoffnung, hierdurch den Einfluß der Gewerkschaften begrenzen und die innerbetrieblichen Konflikte gering halten zu können. ${ }^{142}$ Handlungsbedarf im eigenen Hause sah man nicht; das Drängen der Eisen- und Stahlmanager, insbes. von Direktor Bur-

${ }^{137}$ Bericht des stellv. Generalkommandos über die Aufstandsbewegung, StAM OBAD 1793, Bll. 212-215. Vgl. auch Spethmann, Zwölf Jahre Ruhrbergbau, Bd. I, S. $64 \mathrm{ff}$.

${ }_{138}$ Bericht des stellv. Generalkommandos über die Aufstandsbewegung, StAM OBAD 1793, Bl. 213.

139 Arbeiterausschuß der Franziska-Schächte, 5. 9. 1918, BgA 40/39.

${ }_{141}^{1+0}$ Eingabe vom 21. 9.1918 des Arbeiterausschusses der Franziska-Schächte, BgA 40/39.

${ }^{141}$ Arbeiterausschuß der Franziska-Schächte, 30. 10. 1918, BgA 40/39.

142 Vorstandsprotokoll der GBAG, 10. 5. 1918, BgA 55/115. 
gers vom Schalker Verein auf Einrichtung einer Sozialabteilung beschied der GBAG-Vorstand wegen der „unübersichtlichen politischen Verhältnisse“ noch Anfang Dezember 1918 abschlägig. ${ }^{143}$ Der Ausbruch der Revolution traf die GBAG im November 1918 daher nicht unbedingt unerwartet, aber doch unvorbereitet, da alle während des Krieges ergriffenen Maßnahmen zur Gestaltung des Verhältnisses zu den Belegschaften plötzlich über Nacht entwertet wurden. Der Vorstand tagte in Gelsenkirchen am 23.Oktober 1918 das letzte Mal vor der Revolution, als man einen Bericht Emil Kirdorfs über die zwei Tage zuvor geführten Gespräche zwischen Zechenverband und Gewerkschaften entgegennahm. ${ }^{144}$ Zwar fanden im November zwei reguläre Vorstandssitzungen statt - der GBAGVorstand tagte in einem vierzehntägigen Rhythmus -, doch beschäftigten sie sich nicht mit „Arbeiterfragen“. ${ }^{145}$ Die GBAG nahm die Revolution tatenlos und abwartend hin.

Zwei Aspekte fallen ins Auge, will man die innerbetrieblichen Kommunikationsstrukturen im Ruhrbergbau nach 1916 charakterisieren. Zunächst ist unübersehbar, daß die Zechenleitungen auf die Leistungseinbrüche der ersten Kriegshälfte durch ein Festhalten am individuellen Leistungslohn und zumindest eine Aufrechterhaltung der Arbeitszeiten zu reagieren suchten. Die sich verschlechternden betriebswirtschaftlichen Strukturen (geringere Produktivität) schienen eine derartige Strategie zwingend zu machen. Lohnerhöhungen gestand man daher theoretisch nur als Gegenleistung für eine zumindest gleichbleibende Leistungsbereitschaft zu, praktisch machte man sie allerdings von Kohlenpreiserhöhungen abhängig, so daß sich schließlich de facto Produktivität und Löhne unabhängig von einander entwickelten. Für die Belegschaften hingegen war der Leistungseinbruch eine logische Folge des Krieges und der sich verschlechternden Lebensmittelversorgung; die Löhne wurden im übrigen naheliegenderweise nicht nach der Arbeitsleistung, sondern nach der Teuerungsentwicklung beurteilt. Für die Bergarbeiter war daher klar, daß ein Aufrechterhalten der Arbeitsleistung nur bei steigenden Löhnen und ausreichender Nahrungsmittelversorgung erreicht werden konnte. Der Leistungsdruck namentlich über das System der Leistungslöhne wurde daher von ihnen in immer stärkerem Maße in Frage gestellt, so lange keine adäquaten Lohnerhöhungen und eine angemessene Nahrungsmittelversorgung sichergestellt waren. Die Standpunkte der Zechenbesitzer und der Arbeiterschaft waren, und dies ist das erste Ergebnis, keineswegs unvereinbar. Trotzdem entwickelten sich die jeweiligen Positionen und Handlungsstrategien zunehmend auseinander, die Konfliktformen eskalierten und schließlich beherrschten abgrundtiefes Mißtrauen und die Hoffnung, durch die „Politik“ die Gegenseite zu Zugeständnissen zwingen oder disziplinieren zu können, die Szene. Die sich etablierenden Konfliktstrukturen waren schließlich so simpel wie katastrophal. Die Arbeiterausschüsse stellten Forderungen einer immer unruhigeren Belegschaft; die Zechen lehnten die Forderungen ab. Die Gewerkschaften griffen die Forderungen auf, doch weigerte sich der Zechenverband mit ihnen überhaupt zu reden.

\footnotetext{
${ }^{143}$ Vorstandsprotokoll der GBAG, 6. 12. 1918, BgA 55/115.

144 Vorstandsprotokoll 23. 10. 1918 der GBAG, BgA 55/115.

145 Ebenda.
} 
Die Arbeiterorganisationen nutzten daraufhin gezielt das Hilfsdienstgesetz, veranlaßten gleichlautende Anträge der Arbeiterausschüsse bei den Zechenleitungen und empfahlen im Fall der Ablehnung den Weg zum Schlichtungsausschuß. Zugleich intervenierten sie bei den zuständigen Behörden, die ihrerseits im Interesse des Arbeitsfriedens auf den Zechenverband einzuwirken suchten. Gegenüber den Belegschaften plädierten die Gewerkschaften für Ruhe und verwiesen auf politische Änderungen, etwa beim Wahl- oder Arbeitsrecht. Schlichtungs- und indirekte Tarifverhandlungen benötigten indes Zeit, so daß die Belegschaften immer öfter zu Arbeitsniederlegungen griffen, die dann sehr rasch die Behörden auf den Plan riefen. Diese reagierten einerseits gegenüber den Streikenden repressiv, andererseits suchten sie die Zechenbesitzer zu Zugeständnissen zu bewegen, die diese aber jeweils erst nach Kohlenpreiserhöhungen machten. Das Ausmaß der Zugeständnisse reichte in der Regel den Belegschaften nicht aus, so daß in kurzen Abständen neue Forderungen vorgebracht wurden, mit denen die gesamte Prozedur von vorne begann.

Auf diese Weise erhielt der Staat eine Schlüsselrolle bei der Regulierung sozialer Konflikte im Bergbau, die das fast zwangsläufige Ergebnis der Weigerung der Zechenleitungen war, zu freiwilligen Absprachen zu kommen. Da die Zechenleitungen auf der "Kostenneutralität" aller Zugeständnisse bestanden, zwangen sie den Staat zugleich dazu, das Mittel der Kohlenpreiserhöhung als Voraussetzung für Kompromisse zu nutzen. ${ }^{146}$ Angesichts der zentralen Rolle der Kohlenförderung für die deutsche Wirtschaft war der Staat zu Preisanpassungen auch deshalb bereit, weil sich die Leistungen der Bergarbeiter allein durch Repression kaum auf das gewünschte Niveau bringen ließen. Kohlenpreiserhöhungen wurden damit zum entscheidenden "Schmiermittel“ der industriellen Beziehungen im Ruhrbergbau schon vor der Novemberrevolution. Da der Staat zu derartigen Interventionen allerdings in der Regel erst dann bereit war, wenn sich Arbeiterunruhen abzeichneten, waren Kohlenpreiserhöhungen kaum ein Mittel, um die Beziehungen zwischen den sozialen Kontrahenten im Bergbau grundsätzlich zu verbessern. Im Kern trugen sie nur dazu bei, daß die an sich unbefriedigende Konstellation nicht völlig aus dem Ruder lief. Überdies war dieses Verfahren umständlicher, zeitaufwendiger und kostenträchtiger als Tarifverhandlungen und brachte kaum befriedigende Ergebnisse. Im Gegenteil führte es zu allgemeiner Unzufriedenheit bei allen beteiligten Gruppen. Diese Unzufriedenheit wurde im Laufe der Zeit zudem immer stärker moralisch; auf Seiten der Bergarbeiterschaft und ihrer Gewerkschaften erschienen die Zechenbesitzer schließlich nicht mehr nur als Vertragsgegner, sondern als habgierige Spekulanten, Schmarotzer und Sklaventreiber, während für den Zechenverband und die Zechengesellschaften die unzufriedenen Arbeiter verhetzt und die Gewerkschaften von Machtdünkel befallen waren. Da klar war, daß über Kohlenpreiserhöhungen dieses letztlich völlig ineffektive System der industriellen Beziehungen nicht aufrechterhalten werden konnte, spekulierten beide Seiten im übrigen zunehmend auch auf politische Hilfe: die Zechenbesitzer

${ }^{146}$ Ein "Lohn-Preis-Junktim“ gab es im Ruhrbergbau daher nicht erst seit den ersten Kollektivverhandlungen Ende 1918/Anfang 1919, de facto bestand es seit 1916; vgl. Tschirbs, Tarifpolitik im Ruhrbergbau, S. 59. 
im Sinne einer Unterdrückung der Gewerkschaften und einer repressiven Disziplinierung der Arbeiter, die Gewerkschaften und immer größere Teile der Belegschaften im Sinne politischer Strukturreformen bis hin zur Sozialisierung der Bergwerke. Während die Gewerkschaften zu der Konstellation gegenseitiger Blockade allerdings das Tarifsystem als Alternative besaßen und damit zumindest im Prinzip für konsensuelle Lösungen offen waren, besaßen die Zechenleitungen außer der Repression keinerlei Konzept, sieht man von der Förderung der „wirtschaftsfriedlichen“ Verbände ab. Das Mittel der Repression allerdings konnte man nicht autonom verwenden, sondern war auf die Hilfe der staatlichen Behörden angewiesen. Hierin kam letztlich eine selbstgeschaffene Handlungsunfähigkeit zum Ausdruck, aus der auszubrechen ein neues Konzept der industriellen Beziehungen verlangt und damit eine Aufgabe der bisherigen Gewißheiten bedeutet hätte. Hierzu waren die Bergbauunternehmen aber selbst unter den Bedingungen der zweiten Kriegshälfte nicht bereit.

\section{8 bis 1920}

Auf die Herausforderung der Revolution hatte der Vorstand der GBAG nicht reagiert. Er überließ das Aushandeln der zukünftigen Beziehungen zu den Gewerkschaften dem Zechenverband und wartete zunächst die weitere Entwicklung ab, zumal die Revolutionstage selbst vergleichsweise ruhig verliefen. Lediglich auf Rheinelbe und Alma versuchten bewaffnete Arbeiter und heimgekehrte Soldaten die Bergarbeiter mit Erfolg von der Arbeit abzuhalten. ${ }^{147}$ Beim Zechenverband hatte sich bereits im Oktober 1918 die Überzeugung durchgesetzt, daß mit den Gewerkschaften verhandelt werden mußte. ${ }^{148}$ Die am 18. Oktober 1918 aufgenommenen Verhandlungen brachten zunächst keine Ergebnisse. ${ }^{149}$ Erst nach längeren Verhandlungen einigte man sich am 14. November 1918 auf die Einführung der Achtstundenschicht (incl. Ein- und Ausfahrt), auf Überstunden- und Überschichtzuschläge, auf Mindestlöhne (4/5 des Durchschnittslohnes) und feste Berechnung des Kindergeldes. Der Zechenverband gab unter dem Eindruck der Unruhen im Revier überdies seine bisherigen „schwarzen Listen“ auf. Im Gegenzug sagten die Bergarbeiterverbände zu, daß mit der Arbeitszeitverkürzung keine weiteren Leistungsrückgänge einträten. „Übereinstimmung“ bestand darin, daß Eingriffe in die Zechenleitung, Absetzungen von Beamten und Arbeiterausschußmitgliedern oder die „Fortführung von Autos und Pferden“ unterbleiben sollten. ${ }^{150}$ Eine Tarifierung der Löhne erfolgte nicht; stattdessen begannen unter dem Druck verschiedener Belegschaften Lohnsonderbewegungen, die schließlich in eine allgemeine, über Preiserhöhungen finanzierte Lohnbewegung mündeten. ${ }^{151}$ Damit war im Verlaufe eines Monates eine branchenspezifische Umsetzung der ZAG-

${ }^{147}$ Spethmann, Zwölf Jahre Ruhrbergbau, Bd. I, S. $85 \mathrm{f}$.

${ }^{148}$ Mommsen, Die Bergarbeiterbewegung an der Ruhr, in: Reulecke ( $\mathrm{Hg}$.), Arbeiterbewegung an Rhein und Ruhr, S. 282-289.

${ }^{149}$ Tschirbs, Tarifpolitik im Ruhrbergbau, S. $37 \mathrm{ff}$.

${ }^{150}$ Rundschreiben Nr. 9 des Zechenverbandes, 15. 11. 1918, abgedruckt bei Spethmann, Zwölf Jahre Ruhrbergbau, Bd. I, S. 361 f. Vgl. auch Tschirbs, Tarifpolitik im Ruhrbergbau, S. 47, der die Terminierung bei Spethmann korrigiert, Anm. 33.

151 Tschirbs, Tarifpolitik im Ruhrbergbau, S. $50 \mathrm{ff}$. 
Beschlüsse erreicht, die allerdings von der Mehrzahl der Bergarbeiter in ihrem materiellen Teil abgelehnt wurde. ${ }^{152} \mathrm{Da}$ zugleich eine Intensivierung der innerbetrieblichen Gesprächskontakte und Verhandlungen zumindest bei den Zechen und Anlagen der GBAG unterblieb ${ }^{153}$, der Zechenverband weiterhin bestrebt war, die Gewerkschaften aus den Schachtanlagen herauszuhalten und die Handlungsspielräume der Arbeiterausschüsse zu begrenzen, und überdies verschiedene Zechen im Essener und Gelsenkirchener Raum versuchten, die Schichtzeitverkürzung zu umgehen ${ }^{154}$, aber auch wegen des Zusammenbruchs der „öffentliche Ordnung" waren die Bedingungen für eine Eskalation der betrieblichen Konfliktformen, wie sie typisch für die sozialen Auseinandersetzungen der letzten beiden Kriegsjahre gewesen waren, günstig.

Die Änderungen in den betrieblichen Kommunikationsstrukturen gingen daher nicht auf ein konfliktantizipierendes Verhalten der Werksleitungen zurück, sondern folgten Initiativen aus den Kreisen der Bergarbeiter, ihrer Gewerkschaften und schließlich neuentstehender bzw. plötzlich an Gewicht zunehmender politischer Gruppierungen insbesondere unionistischer und syndikalistischer Provenienz. ${ }^{155}$ Die Arbeiterausschüsse veränderten ihr Gesicht noch im November 1918; wirtschaftsfriedliche Mitglieder traten häufig unter Belegschaftsdruck zurück. ${ }^{156}$ Widerstände gegen derartige Änderungen wurden von den allerorten entstehenden, im übrigen in der Regel mehrheitssozialdemokratisch dominierten Arbeiter- und Soldatenräten barsch zurückgewiesen. Der Gelsenkirchener Arbeiterund Soldatenrat drohte mit Streik, sollte das Oberbergamt die spontanen Arbeiterausschußwahlen nicht akzeptieren. ${ }^{157}$ Auf einzelnen Zechen bildeten sich parallel zu den Arbeiterausschüssen auch Arbeiter- und Soldatenräte, die mit weitreichenden Forderungen nach Einführung der Sechsstundenschicht sowie nach deutlichen Lohnerhöhungen an die Zechenleitungen herantraten. ${ }^{158}$ Bereits jetzt wurde deutlich, daß sich die Belegschaften sehr viel anders verhielten, als es die Gewerkschaften wünschten. ${ }^{159}$ Solange die Gewerkschaften auf tarifliche Vereinbarungen setzten, diese allerdings erst nach langwierigen Verhandlungen zustandekamen und die Zechen sie nur widerwillig in die Praxis umsetzten, schien es geradezu folgerichtig, daß sich auf den Schachtanlagen Bewegungen breit machten, die über die Tarifforderungen hinausgingen. Das Fehlen greifbarer Erfolge bedingte mithin eine zunehmende Radikalisierung der Belegschaften, zumal diesen aus den letzten Kriegsjahren klar war, daß nur die Drohung mit dem Streik oder

152 Bergarbeiterverband an Preußisches Handelsministerium, 22.11. 1918, StAM OBAD 1793, Bl. 239.

${ }^{153} \mathrm{Ob}$ sich die von Tschirbs, Tarifpolitik im Ruhrbergbau, S. $43 \mathrm{f}$, angegebene Taktik von Paul Reusch, auf intensivere Kontakte zu den Arbeiterausschüssen zu setzen, verallgemeinern läßt, ist daher fraglich. ${ }^{154}$ Bergarbeiterverband an Preußisches Handelsministerium, 22.11. 1918, StAM OBAD 1793,
Bl. 239.

${ }^{155}$ Siehe vor allem Lucas, Ursachen und Verlauf, in: Duisburger Forschungen 15 (1971), S. 1-119. Generell zum Syndikalismus/Unionismus Bock, Syndikalismus und Linkskommunismus.

156 Ein Beispiel: Arbeiterausschuß der Zeche Nordstern, 10.12. 1918, BgA 41/320a. ${ }^{157}$ Arbeiter- und Soldatenrat Gelsenkirchen an Oberbergamt, 25.11. 1918, StAM OBAD 1854,
Bl. 18.

${ }^{158}$ Der Minister für Handel und Gewerbe an die Bergarbeitergewerkschaften, 14.11. 1918, StAM OBAD 1793, Bll.224/3.

159 Bergarbeiterverband an den Minister für Handel und Gewerbe, StAM OBAD 1793, Bl. 239. 
die Arbeitsniederlegung selbst Bewegung in die festgefahrenen Fronten bringen konnte. ${ }^{160}$ Die Politik der Tarifgewerkschaften, namentlich des Alten Verbandes geriet auf diese Weise in eine defensive, taktisch ungünstige Position, da man auf das Tarifsystem setzte, die Belegschaften aber nicht bereit waren, die Durchsetzung des Tarifsystems allein schon als Erfolg der Revolution zu akzeptieren. Das ohnehin bereits während des Krieges schwierige Verhältnis von Gewerkschaften und Belegschaften wurde auf diese Weise zusehends gespannter. ${ }^{161}$

\section{Das Hamborner Beispiel}

Ein Blick auf die Konflikte bei den Schachtanlagen der Gewerkschaft Deutscher Kaiser (GDK) in Hamborn ${ }^{162}$ soll diese Entwicklung verdeutlichen. ${ }^{163} \mathrm{Zu}$ einem ersten Konflikt kam es noch im November 1918 wegen des Achtstundentages und der mit ihm verbundenen Seilfahrtregelung, mit der sich die Belegschaft nicht zufrieden zeigte. Im Gegenzug erzwang sie „unter Führung einer kleinen Minderheit“, so die Grubendirektion, die 7,5-stündige Arbeitszeit, der der Hamborner Arbeiter- und Soldatenrat unter dem Eindruck der aktionsbereiten Belegschaft seine Zustimmung gab. Zudem sanktionierte er die Regelung aller offenen Lohnund Arbeitsfragen durch Belegschaftsversammlungen, wogegen die Werksleitung unter Hinweis auf die Gespräche zwischen Zechenverband und Gewerkschaften energisch protestierte. Die Belegschaft hatte inzwischen aber an den mehrheitlich tarifgewerkschaftlich orientierten Arbeiterausschüssen vorbei eigene Kommissionen zur Verhandlungsführung gebildet. Der neugebildete Arbeiterrat der GDKZeche Lohberg stellte sechs zentrale Forderungen auf, darunter nicht nur Hauerdurchschnittslöhne von 19,50 M und Hauermindestlöhne von $17 \mathrm{M}$, er verlangte zudem die Anerkennung der 7,5-Stundenschicht, ab dem 1. Januar 1919 die Sechsstundenschicht, verbilligte Deputatkohlen, die unentgeltliche Instandsetzung der Wohnungen sowie einmalige Teuerungszulagen bis zu $400 \mathrm{M} \cdot{ }^{164}$ Die Werksleitung beharrte auf tariflichen Regelungen. Verhandlungen unter Einbeziehung von Gewerkschaftsvertretern konnten den Eskalationsprozeß nicht aufhalten. Nachdem bereits am 6. Dezember auf zwei Schachtanlagen gestreikt wurde, kam es am 8. Dezember 1918 zu einer Massenversammlung von Bergleuten in Hamborn, die - aufgehetzt u. a. durch Zeitungsberichte über einen angeblichen Landesverrat August Thyssens, der eine Besetzung des Ruhrgebietes durch die Entente gefordert hätte - die Ausweitung des Streiks beschloß. Rufe wurden laut, daß „nicht eher Ruhe einkehren (könne), bis daß die Forderungen bewilligt seien und ein

${ }^{160}$ Zur Situation der Tarifgewerkschaften vgl. Tschirbs, Tarifpolitik im Ruhrbergbau, S. $50 \mathrm{ff}$.

${ }^{161}$ Mommsen, Bergarbeiterbewegung an der Ruhr, S. $290 \mathrm{ff}$. Vgl. auch Lucas, Ursachen und Verlauf, passim.

${ }^{162}$ Die Hamborner Entwicklung ist ausführlich bei Lucas, Ursachen und Verlauf, dargestellt. Vgl. auch Mommsen, Bergarbeiterbewegung an der Ruhr, S. 289 ff.; Winkler, Von der Revolution zur Stabilisierung, S. 164-166. In diesen Ausführungen geht es daher weniger um den Verlauf der Auseinandersetzungen als vielmehr um die Art der Konfliktaustragung und die sich daraus ergebenden Konsequenzen für die betriebliche Kommunikation der zwanziger Jahre.

${ }^{163}$ Betrifft: Arbeiterunruhen auf den Schachtanlagen der Gewerkschaft Deutscher Kaiser, ohne Datum, StAM OBAD 1793, Bll.242-251. Der Bericht enthält keinen Verfasserhinweis. Aus dem Tenor der Darstellung geht hervor, daß er von der Leitung der GDK verfaßt wurde.

${ }^{164}$ An die Direktion der Zeche Lohberg, ohne Datum, StAM OBAD 1793, Bl. 265. 
Dutzend von der Spitze am Galgen hingen. “165 In den darauffolgenden Tagen fanden wiederholt scharfe Auseinandersetzungen zwischen arbeitswilligen und streikbereiten Bergarbeitern sowie zwischen Streikenden und Zechenvertretern statt. Mehrere GDK-Zechen, darunter Friedrich Thyssen 1/6, sowie die Nachbarzechen Neumühl und Westende standen schließlich im Streik.

Zur entscheidenden Verhandlung kam es am Abend des 9. Dezember 1918 bei GDK-Bergwerksdirektor Jacob, nachdem sich die GDK zu Verhandlungen mit der "wilden Streikleitung " bereitgefunden hatte. Die streikenden Bergleute unter Führung der Kommissionen und des Arbeiter- und Soldatenrates erklärten, „die Belegschaft sei gesonnen unter Anwendung aller Mittel und Wege ihre Forderungen durchzudrücken und schrecke auch nicht vor Anwendung brutaler Gewalt zurück, nehme keine Rücksicht auf Personen und Eigentum und werde auch zu Zerstörungen der Zechen übergehen, das Verwaltungsgebäude und die Wohnung des Generaldirektors stürmen, wenn nicht bis zum 10. Dezember vormittags 10 Uhr, auf welche Zeit eine weitere Belegschaftsversammlung auf dem Neumarkt anberaumt sei, die Entscheidung in ihrem Sinne gefallen sei. " 166 Die Leitung der GDK lehnte die Forderungen auch dann noch ab, als Vertreter der Arbeiterschaft zusicherten, sich in Berlin für eine Kohlenpreiserhöhung stark zu machen. ${ }^{167}$ Über Lohnerhöhungen, so Jacob, könne nur zwischen den Organisationen verhandelt werden. Da Fritz und August Thyssen zur Zeit in Berlin seien, könne er ohnehin keine bindenden Zusagen machen. Den Arbeiter- und Soldatenrat forderte er auf, die öffentliche Sicherheit zu garantieren, „da dieser ja im Besitze der Regierungsgewalt sei. Die Mitglieder des Arbeiter- und Soldatenrates erklärten hierzu, daß sie unter den jetzigen Verhältnissen keine Bürgschaft für Leben und Eigentum übernehmen könnten. "168 $\mathrm{Als}$ auch das Generalkommando in Münster $^{169}$ sowie die Stadtverwaltung Hamborn ihre Machtlosigkeit gegenüber den Gewaltdrohungen der Bergarbeiterschaft eingestehen mußten, gab nach mehrstündigen Verhandlungen schließlich Bergwerksdirektor Jacob folgende öffentliche Erklärung ab: „Nachdem die Belegschaft der Gewerkschaft Deutscher Kaiser in der schärfsten Weise angedroht hat, ohne Rücksicht auf Personen und Eigentum (Sabotage der Zechenanlagen) ihre Forderungen zu erzwingen und nachdem der Arbeiter- und Soldatenrat erklärt hat, daß er keine Verantwortung für die Sicherheit der Anlage übernehmen kann, falls die Forderung abgelehnt wird, erkläre ich, daß ich die Forderungen unter Protest annehme, um weiteres Unheil von der Zeche und der Stadt Hamborn abzuwehren. " 170 Am nächsten Morgen ging der Streik weiter, ja spitzte sich noch zu, als Streikposten die Hängebank der Schachtanlage Wehofen stürmten und drohten, die Fördermaschinen zu beschädigen, sollte die Einfahrt arbeitswilliger Bergleute nicht sofort eingestellt werden. Erst

\footnotetext{
165 Ebenda, Bl. 246.

166 Ebenda, Bl. 248.

167 Ebenda, B1. 249.

${ }^{168}$ Ebenda, Bl. 250.

169 Aus Münster kam laut Winkler, Von der Revolution zur Stabilisierung, S. 165, die Antwort, vor dem 20. 12. 1918 stünden keine Truppen zur Verfügung.

170 Ebenda, Bl. 250.
} 
eine erneute Versammlung der Bergleute auf dem Hamborner Neumarkt brachte mit der Bekanntgabe der durchgesetzten Forderungen ein Ende des Streikes. ${ }^{171}$

Bei dieser Versammlung betonten die Kommissionsmitglieder und die Vertreter des Hamborner Arbeiterrates die großen Erfolge des Streikes (19,50 HauerDurchschnittslohn, Mindestlohn hiervon 5/6 oder 16,25, verbilligte Hausbrandkohle), der zudem mit einer de-facto-Anerkennung der auf den Schachtanlagen spontan gebildeten Verhandlungskommissionen geendet habe. Nachdem nun alles erreicht sei, was man sich vorgenommen habe, forderten die Arbeiterratsvertreter die Arbeiter zur Wiederaufnahme der Arbeit auf. „Keiner dürfe dem Arbeiter nachsagen, daß er ein Bummelant sei, sondern jeder müsse von dem Arbeiter mit Achtung sprechen. Es sei daher Ehrenpflicht eines jeden Arbeiters jetzt, nachdem alles erreicht sei, ohne Demonstration bereits heute Nachmittag um 2 Uhr die Arbeit wiederaufzunehmen und es sei weitere Ehrenpflicht, den Verfügungen des Arbeiterrates aufs genaueste Folge zu leisten. Deshalb müssen die Arbeiter zeigen, daß sie arbeiten können. "172 In ihren Streikauswertungen betonten die Hamborner Streikführer darüber hinaus nachdrücklich, daß es nicht die Gewerkschaften, sondern der örtliche Arbeiterrat und die Kommissionen gewesen seien, die den Erfolg der Streikenden bewirkt hätten. „Langwierige Verhandlungen und Vertröstungen hätten, wie es in den letzten 25 Jahren der Fall war, zu nichts geführt. Eine kühn vollbrachte Tat ist mehr wert als tausend schöne Reden. Und so hat man sich entschlossen, durch einen Handstreich die Forderungen durchzudrücken, was auch geschehen ist. "173 Der Streikführer Heiling ${ }^{174}$ forderte daher die Bergleute auf, sich den Organisationen anzuschließen, die wirklich etwas für sie tun würden. „Früher hätten die meisten der Arbeiterverbände sich hohe Beiträge von den Arbeitern zahlen lasen, ohne für sie etwas erwirkt zu haben. Deshalb ist es Pflicht eines jeden Arbeiters, sich genau zu überlegen und zu prüfen, welcher Organisation er beitritt. Er empfehle die freie Vereinigung deutscher Gewerkschaften ${ }^{175}$, deren Bestreben es seit jeher gewesen sei, jede berechtigte Forderung mit Nachdruck durchzusetzen. Dieser Vereinigung höchster Grundsatz ist, sich nicht auf langwierige, vertröstende Verhandlungen einzulassen, sondern mit der ihr zu Gebote stehenden stärksten Kraft, nämlich Arbeitsverweigerung, ihre Forderungen durchzudrücken, und ihr Wahlspruch ist: Solidarität und wieder Solidarität!"176

Der Ausstand auf den Thyssen-Zechen brach sofort wieder aus, als Bergwerksdirektor Jacob seine Zugeständnisse widerrief und statt dessen ein am 13. Dezember 1918 in Essen abgeschlossenes Lohnerhöhungsabkommen der Tarifparteien ${ }^{177}$

${ }^{171}$ Bericht über die Massenversammlung des heutigen Tages der Schachtanlagen der G.D.K. Neumühl und Westende, Hamborn, den 10. 12. 1918, StAM OBAD 1793, Bll.257-262.

172 Ebenda, Bl. 258.

${ }^{173}$ Ebenda, Bl. 259.

${ }^{174}$ Lucas, Ursachen und Verlauf, S. $40 \mathrm{f}$.

${ }_{175}$ Zur freien Vereinigung vgl. Lucas, Ursachen und Verlauf, S. 41-44.

${ }^{176}$ Bericht über die Massenversammlung des heutigen Tages der Schachtanlagen der G.D.K. Neumühl und Westende, Hamborn, den 10. 12. 1918, StAM OBAD 1793, Bl. 260.

177 Zum Essener Abkommen vom 13. 12. 1918 vgl. Winkler, Von der Revolution zur Stabilisierung, S. 165. Danach sollten die Löhne ab dem 1.1.1919 um 15\% erhöht werden. Im Gegenzug sagten die Gewerkschaften cine Unterstützung entsprechender Preiserhöhungsforderungen der Zechenbesitzer zu. 
für die Thyssen-Schächte übernahm. ${ }^{178}$ Auch war weder in den Zugeständnissen der GDK noch in der Essener Vereinbarung die Forderung nach einer Teuerungszulage erfüllt worden, an der die Bergarbeiter mit Nachdruck festhielten. ${ }^{179}$ Die Lage war, obwohl nicht alle Schachtanlagen am Ausstand teilnahmen, so kritisch, daß zur Herbeiführung eines Verhandlungskompromisses zwischen Zechenleitung und Kommissionen Otto Hue als Regierungsvertreter, der ohnehin im Ruhrgebiet vermittelnd tätig war ${ }^{180}$, hinzugezogen wurde. In einer gemeinsamen Sitzung mit Otto Hue und Vertretern der Schachtkommissionen der GDK wurde beschlossen, am 16. Dezember 1918 den Streik zu beenden. Am 15. Dezember 1918 traf sich die Belegschaft der Schachtanlage Friedrich Thyssen 1/6, aus der der Syndikalistenanführer Heiling stammte. Heiling berichtete den Sachstand, namentlich von dem Beschluß zur Wiederaufnahme der Arbeit. Die Kommissionen aller Thyssen-Schachtanlagen hätten gemeinsam beraten und würden weder zum Streik noch von ihm abraten, sondern die Entscheidung den Belegschaften überlassen. Während sich ein Kommissionsmitglied gegen einen weiteren Streik aussprach, andere auf zusätzliche soziale Leistungen der Zechen hinwiesen, forderten verschiedene Sprecher die Fortsetzung des Streikes zur Durchsetzung aller Ziele, namentlich auch der einmaligen Teuerungszahlung, die von der Belegschaftsversammlung kurzerhand auf $1000 \mathrm{M}$ festgesetzt wurde. Daß bei einer derartigen Konstellation sich eine Mehrheit für die Fortführung des Streiks aussprach, war nicht weiter verwunderlich. ${ }^{181}$ Der Versammlungsleiter Heiling konstatierte indes nicht nur die Zustimmung zum Streik; er betonte auch, daß „es nicht wieder vorkommen (dürfe) wie in den letzten Tagen, daß ein Schacht streikt und die anderen arbeiten." Auch hier solle ein Majoritätsbeschluß herbeigeführt werden, dessen Ergebnis in einer gemeinsamen Sitzung der Kommissionen festzustellen sei. Damit war auch klar, daß arbeitswillige Mehrheiten einzelner Schachtanlagen unter Umständen mit Gewalt an der Fortführung der Arbeit gehindert werden sollten. ${ }^{182}$ Neben der Schachtanlage Friedrich Thyssen $1 / 6$ beschloß allerdings nur die Schachtanlage $2 / 5$ den Streik ${ }^{183}$, so daß die übrigen fünf GDK-Schächte mit Gewalt stillgelegt werden mußten. Am 16. Dezember wurden alle sieben GDKSchächte bestreikt.

Die Fortsetzung des Streikes wurde jetzt nur noch zum Teil mit der Durchsetzung der Arbeitszeitforderung und der einmaligen Teuerungszulage begründet. Ein zusätzliches Motiv lag in der Konkurrenz verschiedener Gewerkschaftsorganisationen „vor Ort", die ihre jeweilige Durchschlagskraft unter Beweis stellen wollten. Die Gewerkschaft Deutscher Kaiser sah sich zu Recht als Forum des Kampfes zwischen kommunistischen und syndikalistischen Gruppierungen ${ }^{184}$ und Tarifgewerkschaftern: „Wir haben aus den Belegschaftsversammlungen und

\footnotetext{
${ }^{178}$ Winkler, Von der Revolution zur Stabilisierung, S. 166.

179 An die Direktion der Zeche Lohberg, ohnc Datum, StAM OBAD 1793, Bl. 265.

180 Tschirbs, Tarifpolitik im Ruhrbergbau, S. $52 \mathrm{f}$.

${ }^{181}$ Abschrift: Belegschaftsversammlung der Schachtanlage 1/6, 15.12. 1918, StAM OBAD 1793, Bll.282-284.

${ }^{182}$ Ebenda, Bl. 284.

${ }^{183}$ Bericht über die Belegschaftsversammlung der Schachtanlage 2/5 der G.D.K., 16.12. 1918, StAM OBAD 1793, Bll.288-290.

${ }^{184}$ Zum Hintergrund Lucas, Ursachen und Verlauf der Bergarbeiterbewegung, S. 41-44.
} 
Äußerungen der Seele der Bewegung, des Kommissionsmitgliedes Heiling und auswärtiger Redner der Sinnesrichtung Heiling die Überzeugung gewonnen, daß es sich um einen Kampf handelt der freien Vereinigung deutscher Gewerkschaften gegen die Organisationen, bei welchem unsere Schachtanlagen zum Kriegsschauplatz geworden sind, auf dem die mit großem Terrorismus vorgehende Gruppe einen Sieg erfechten will, durch Erzwingung der maßlosen Forderungen. Das in Hamborn statuierte Exempel soll dann als Agitationsmittel zur Weiterarbeit verwandt werden und als Empfehlung zum Beitritt in die freie Vereinigung werden der Belegschaft genannt als Grundsätze der Vereinigung: nicht langwierige vertröstende Verhandlungen, sondern Anwendung von Nachdruck auf berechtigte Forderungen der Arbeiter durch Anwendung aller zu Gebote stehenden Kräfte, direkte Aktion und Arbeitsniederlegung und wenn dadurch nichts erreicht werden kann, Sabotage. ${ }^{185}$ Die Beobachtung der Zechengesellschaft war nicht aus der Luft gegriffen. Hatte die nur schleppende Übernahme der ZAG- und anderer zentraler Abmachungen auf den Zechen das Vorpreschen einzelner Belegschaften und die Bildung spontaner Vertretungsgremien begünstigt und war die „direkte Aktion" auch nach den Weltkriegserfahrungen das wahrscheinlich wirksamste Mittel, um materielle Forderungen durchzusetzen, so erhielten diese Bewegungen nunmehr politisch-programmatische Züge, insofern die syndikalistischen Vertreter der Schachtkommissionen diese Konfliktformen an sich positiv beurteilten und in ihnen keineswegs nur das Ergebnis defekter Kommunikationsprozesse der Kriegszeit sahen, sondern Alternativen zum Tarifsystem. Diese Alternativsetzung fand auch deshalb bei zahlreichen Bergleuten Zuspruch, weil sie zumindest unter den Bedingungen im November und Dezember 1918 direkt greifbare materielle Ergebnisse brachte, während die Tarifregelungen nicht nur langwieriger Verhandlungen bedurften, sondern auch geringere materielle Vorteile beinhalteten.

Im Anschluß an die gewaltsame Streikdurchsetzung fand am 18.Dezember 1918 eine große Streikversammlung auf einem Sportplatz in Hamborn statt, auf der bekanntgegeben wurde, die vereinigten Belegschaftskommissionen der GDK hätten eine Kommission nach Berlin gesandt, „damit sie die Regierung von der Berechtigung ihrer Forderung überzeugten und diese veranlaßten, ihre Forderungen durchzudrücken. “ ${ }^{186}$ Gemessen an den Forderungen anderer Schachtanlagen, so das Kommissionsmitglied von 1/6 Dellmich, seien „die Deutschen KaiserSchächte die reinsten Waisenknaben mit ihren Forderungen “. ${ }^{187}$ Die Belegschaftsversammlung beharrte daher auf ihren Forderungen, insbesondere auch der Zahlung einer nun Weihnachtsgeld genannten Teuerungszulage: „Es dürfe nicht eher angefahren werden", verlangte Kommissionsmitglied Dellmich, bis alle Forderungen durchgesetzt seien, „und wenn man mit der ganzen Familie verrecken müsse. " ${ }^{188}$ Diese Belegschaftsversammlung war ein Beweis für das selbstbewußte Auftreten der Bergleute, das vor allem aus dem Wissen um ihre betriebliche

${ }^{185}$ Gewerkschaft Deutscher Kaiser an das Oberbergamt, 18.12. 1918, StAM OBAD 1793, Bll.281, Hervorhebung im Original.

186 Bericht über die öffentliche Bergarbeiterversammlung der Gewerkschaft Deutscher KaiserSchächte auf dem Sportplatz an der Buschstr., 18. 12. 1918, 10 Uhr vormittags, StAM OBAD 1793, Bll.293-295.

187 Ebenda, Bl. 293.

${ }^{188}$ Ebenda, Bl. 294. 
Machtstellung beruhte. ${ }^{189}$ Man rechnete nicht einmal mit einem langen Streik, da die Regierung sich einen langen Arbeitskampf wegen der Kohlenknappheit nicht leisten könne. ${ }^{190}$ Auch nahm die Radikalität des Streikverhaltens weiter zu, nachdem klar war, daß die örtlichen Zahlstellen der Tarifgewerkschaften die Streikenden unterstützen würden. Diese Zahlstellen müßten dazu genutzt werden, die Hauptvorstände der Tarifgewerkschaften zu einer Änderung ihrer bisherigen Politik zu bewegen. Gegenteiliges Argumentieren oder etwa Arbeitsbereitschaft verschiedener Belegschaften wollte man von jetzt ab nicht mehr dulden. Der Versammlungsleiter „erklärte weiter, daß die Streikposten in viel zu geringer Zahl ausgestellt seien und daß diese viel zu spät aufzögen. Man glaube wohl jetzt würde gestreikt und man könne sich ausschlafen. Das sei aber total falsch. Die geringe Zahl der Streikposten könne von Arbeitswilligen überrumpelt werden und müsse daher in genügender Stärke vorhanden sein. Wenn dann Arbeitswillige erschienen, dann sei die Parole für die Streikposten: Gummischläuche raus und gründliches Verhauen der Arbeitswilligen. Für diesen Fall könne es immer nur heißen: Feste druff!"191 Parallel zu diesem verschärften Vorgehen gegenüber Belegschaftsangehörigen der GDK-Schachtanlagen nahmen die Streikenden die Nachbarzechen in Hamborn, Neumühl und Westende ins Visier, auf denen noch gearbeitet wurde. Auch wenn sich nur etwa 500 der 3000 Versammlungsteilnehmer an der Besetzung der Zeche Neumühl beteiligten ${ }^{192}$, legte man die beiden Nachbarzechen still. Gewaltsam wurden Verwaltung und Hängebank besetzt, die Förderung eingestellt und die sofortige Ausfahrt der Belegschaft verlangt. Ein Fahrsteiger von Neumühl, der die Ausfahrt aus der Grube organisieren wollte, „wurde zurückgehalten und bedroht, in den Schacht geworfen zu werden, weil die Menge behauptete, er wolle die Leute in der Grube nur zum Widerstand auffordern. Eine Anzahl Leute von G.D.K. fuhr daraufhin mit brennenden Zigarren und Pfeifen in die Grube zu den Füllörtern der einzelnen Sohlen und zwang die dort beschäftigten Arbeiter, sofort auszufahren. “193 Die in der Grube arbeitenden „Zechenbeamten“ wurden bei der Ausfahrt auf der Hängebank beschimpft und bedroht; ähnlich erging es den arbeitswilligen Bergleuten verschiedener Schächte. Die Schachtanlage $1 / 2$ von Neumühl konnte rechtzeitig vor Eintreffen der GDK-Arbeiter geschlossen werden. Die bewaffnete Grubenwehr wurde jedoch überwältigt, die Schachtanlage nach Weigerung des Grubeninspektors, die Ausfahrt zu veranlassen, ebenfalls besetzt. Danach erzwangen die GDK-Arbeiter nicht nur die Ausfahrt der Morgenschicht, sondern hinderten auch die arbeitswillige Mittagsschicht daran, anzufahren. ${ }^{194}$ Die Besetzung der Nachbarzechen war kein Zufall. Streikende GDK-Arbeiter zogen auch nach Oberhausen, Bottrop und Gladbeck, um weitere Schachtanlagen stillzulegen. Wegen der Bereitschaft der streikenden GDK-Arbei-

\footnotetext{
189 Lucas, Ursachen und Verlauf der Bergarbeiterbewegung, S. 66.

190 Bericht über die öffentliche Bergarbeiterversammlung der Gewerkschaft Deutscher KaiserSchächte auf dem Sportplatz an der Buschstr., 18. 12. 1918, 10 Uhr vormittags, StAM OBAD 1793, Bl. 295.

191 Ebenda, Bl. 294.

192 Ebenda, Bl. 295.

${ }^{193}$ Steinkohlenbergwerk Neumühl, Unbetitelter Bericht über die Ausstandsbewegung vom 18.-20. 12. 1918, 20. 12. 1918, StAM OBAD 1793, Bll.319-322, hier B1. 319.

194 Ebenda, Bll.321 f.
} 
ter, Nachbarzechen im Zweifelsfall auch gegen deren Willen zum Streik zu bringen, bahnten sich Konflikte mit dem Berzirkssoldatenrat in Recklinghausen an, der arbeitswillige Gruben durch den Einsatz freikorpsähnlicher Truppenverbände schützen wollte. In Gladbeck kam es zu einem blutigen Zusammenstoß; größere Konfrontationen konnten durch den Einsatz des Essener Arbeiter- und Soldatenrates aber vermieden werden. ${ }^{195} \mathrm{Zu}$ größeren Streiks kam es daher in der Umgebung Hamborns zunächst nicht, da sich die Mehrzahl der Belegschaften mit den Ergebnissen der Vereinbarung vom 13. Dezember 1918 zufriedengab. ${ }^{196}$

Da offensichtlich eine Mehrheit der Bergarbeiter bereit war zu arbeiten, setzte der Hamborner Arbeiter- und Soldatenrat für Sonntag, den 22. Dezember 1923 eine geheime Abstimmung über die Fortsetzung des Streikes an. Bereits am Sonnabend sprach sich die Belegschaft von Neumühl mit überwältigender Mehrheit dafür aus, am Montag, dem 23. Dezember 1918 die Arbeit wiederaufzunehmen. Auch für die Zechen des Thyssen-Konzerns erwartete die Zechenleitung eine Mehrheit für die Beendigung des Streikes. Die Abstimmung wurde auf der Zeche Lohberg jedoch von den Streikposten verhindert; in Hamborn selbst „vereitelte die terrorisierende Minderheit die durch den Arbeiterrat Hamborn eingeleitete Abstimmung durch eine Bekanntmachung, daß die Wahl nicht stattfinde und eine vom Streik-Komitee nach Berlin entsandte Abordnung zur selben Zeit, in der die Wahl stattfinden sollte, ihren Bericht der Belegschaft erstatten würde. "197 In der Tat fand am 22. Dezember 1918 eine Versammlung von etwa 5000 Thyssen-Bergarbeitern statt, auf der die aus Berlin zurückgekehrte Delegation berichtete, der Volksbeauftragte Barth ${ }^{198}$ habe die Erklärung abgegeben, die Bergwerke würden noch vor Weihnachten „enteignet und verstaatlicht. ${ }^{\text {"199 }}$ Zugleich behaupteten die Delegationsmitglieder, "daß sich Volksbeauftragter Barth mit seiner Person dafür einsetzen werde, daß den Bergarbeitern sofort eine Teuerungszulage gewährt werde. ${ }^{200}$ Mehr noch, berichtete die GDK nach Berlin, sei auf der Versammlung behauptet worden: „Volksbeauftragter Barth soll dabei das Versprechen abgegeben haben, daß er mit dieser Sache stehe oder falle und fest entschlossen sei, gegebenenfalls aus der Regierung auszutreten und den Generalstreik für ganz Deutschland zu proklamieren." 201 Vor diesem Hintergrund drängten die Streikleitung und die Vertretung der Schachtkommissionen die anwesenden Bergarbeiter, zunächst den Streik aufrechtzuerhalten. Die Bergarbeiter stimmten zu und beschlossen, in einem Telegramm nach Berlin vor Wiederaufnahme der Arbeit

195 Lucas, Ursachen und Verlauf, S. $69 \mathrm{ff}$.

196 Winkler, Von der Revolution zur Stabilisierung, S. 165.

197 Gewerkschaft Deutscher Kaiser an Oberbergamt, 23. 12. 1918, StAM OBAD 1793, B1. 302.

198 1879-1941, Führender Kopf der Berliner Revolutionären Obleute, linkes USP-Mitglied, Angehöriger des Rates der Volksbeauftragten bis zum 29.12.1918, sprach sich im Januar 1919 gegen die immer weiter um sich greifenden politischen Streiks aus, vgl. Geschichte der deutschen Arbeiterbewegung, Bd. 3, S. 104, 150, 166, 169. Vgl. auch Winkler, Von der Revolution zur Stabilisierung, insbesondere S. 74 zum Skandal um russische Gelder, in den Emil Barth verwickelt war.

199 Abschrift eines Telegramms der GDK an den Rat der Volksbeauftragten und das Handelsministerium in Berlin, 23. 12. 1918, StAM OBAD 1793, Bll.303-304. Winkler, Von der Revolution zur Stabilisierung, S. 104.

200 GDK an den Rat der Volksbeauftragten und das Handelsministerium, 23. 12. 1918, StAM OBAD $1793, \mathrm{Bl} .303$.

201 Ebenda, B1. 303. Der Rücktritt Barths vom Rat der Volksbeauftragten am 29. 12. 1918 mußte für viele Hamborner Arbeiter daher wic ein regelrechtes Streikfanal wirken. 
eine schriftliche Bestätigung der Ausführungen Barths durch die Regierung zu verlangen. „Weiter wurde in der Bergarbeiterversammlung beschlossen, bis zum Erhalt einer bindenden Zusage im Streik zu verharren und die Arbeit nicht eher

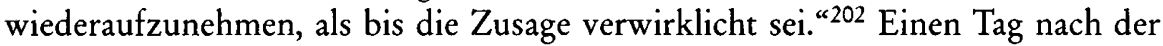
Belegschaftsversammlung wurde erneut die Zeche Neumühl gestürmt. Wiederum wurden die Zechenwehren entwaffnet, die „Beamten“ bedroht und verprügelt, die Leute gewaltsam „aus der Grube geholt.“ Wie bereits die Gewerkschaft Deutscher Kaiser in einem Telegramm nach Berlin am Vortag, so forderten jetzt Zechenverwaltung und Arbeiterausschuß von Neumühl gemeinsam, die Entsendung eines Regierungsvertreters und die Garantierung von Sicherheit und Eigentum durch die Regierung. ${ }^{203}$

Der Streik zog sich über die Weihnachtstage hin; die Konfliktformen eskalierten: Geschäfte wurden geplündert, leitende Angestellte des Thyssen-Konzerns „verhaftet“ ${ }^{204}$ Kern der Streikmotivation der Arbeiterschaft war ganz offensichtlich die bislang unerfüllte Forderung nach einer Weihnachtsgratifikation oder Teuerungszulage. Angesichts dieser sich bereits Weihnachten abzeichnenden Situation wurde ein erneuter Schlichtungsversuch mit dem preußischen Minister Ströbel (USPD) unternommen, der am 28. Dezember 1918 in Mülheim mit dem Ergebnis endete, daß als Streikausfallentschädigung eine einmalige Zahlung erfolgen sollte. ${ }^{205}$ In den Verhandlungen, namentlich in den Stellungnahmen Heilings wurde deutlich, daß die Bergarbeiterschaft schnell erkennbare materielle Zusagen und wirksame Maßnahmen gegen die Hinhaltetaktik der Zechenleitungen verlangten. Aus diesen Erfahrungen mit der Zechenleitung resultiere, so Heiling, auch die Empörung über die Widerrufung der Zugeständnisse vom 10. Dezember 1918. Daß Terror ausgeübt worden sei, bestritt er im übrigen ebenso energisch, wie der GDK-Direktor Jacob dies behauptete. Der Vermittler Ströbel erfaßte relativ rasch den Kern der Sache. Auch die Regierung sei für den Verhandlungsweg, doch helfe dies angesichts der Notlage der Arbeiterschaft zur Zeit nichts. Er gestand auch zu, daß die Arbeiterschaft aus „Mangel an Übersicht sowie Überschätzung der lokalen Verhältnisse“ zu spontanen, unüberlegten Handlungen neige. Man lebe eben in revolutionären Zeiten. Bleibe ein Entgegenkommen der Zechen aus, drohe eine endlose Konflikteskalation. Nach längeren Verhandlungen gestand Thyssen schließlich einmalige Zahlungen unter der Bedingung $\mathrm{zu}, \mathrm{daß} \mathrm{ab}$ dem 1. Februar 1919 die von den Organisationen vereinbarte Achtstundenschicht voll verfahren werde.

Nach Bekanntgabe des Verhandlungsergebnisses flaute der Streik ab, brach jedoch Anfang Januar 1919 wegen der ausbleibenden Teuerungszulage erneut aus und wurde jetzt durch die Ereignisse in Berlin zusätzlich verschärft. In dieser Situation ergriff der Essener Arbeiter- und Soldatenrat die Initiative, bildete eine Neunerkommission zur Sozialisierung des Bergbaus und begann gleichzeitig,

202 Ebenda, Bl. 303.

${ }^{203}$ Telegramm Zechenverwaltung und Arbeiterausschuß von Neumühl. 23. 12. 1918, StAM OBAD 1793, Bl. 313.

${ }^{204}$ Lucas, Ursachen und Verlauf, S. $80 \mathrm{ff}$.

${ }^{205}$ Protokoll der Konferenz zur Beilegung der Streikbewegung im Ruhrbergbau, abgedruckt bei Lucas, Ursachen und Verlauf, S. 107-113. 
über die Wahl von Steigerrevier- und Zechenräten eine neue organisatorische Infrastruktur auf den Zechen zu errichten, die als Basis einer betriebsnahen Produktionskontrolle dienen konnten. Die Regierung ging auf diese Initiativen halbherzig ein, insbesondere akzeptierte sie die neuen betrieblichen Gremien, wenn auch in verwässerter Form. Die Neunerkommission aber wollte sie nicht akzeptieren. Noch während in Weimar zwischen Neunerkommission und Regierung verhandelt wurde, eskalierten indes die Konflikte an der Ruhr militärisch. Reguläre Truppen zogen im Ruhrgebiet ein, im Gegenzug riefen Syndikalisten und Kommunisten zum Generalstreik auf, der allerdings Ende Februar 1919 zusammenbrach. $^{206}$ Nach dem Abflauen der Auseinandersetzungen zeigte sich, daß die Bergarbeiterschaft weniger an politischen Gesten als an materiellen Verbesserungen interessiert war, namentlich an einer Verbesserung der Löhne und einer Verkürzung der Arbeitszeit. Verhandlungen zwischen Zechenverband und Tarifgewerkschaften brachten zwar im März das Ergebnis einer halbstündigen Arbeitszeitverkürzung ohne Lohnausfall, jedoch waren die Bergarbeiter wiederum vorgeprescht und hatten auf zahlreichen Zechen eigenhändig die Sechsstundenschicht durchgesetzt. Erneute blutige Zusammenstöße, diesmal in Witten, leiteten eine weitere Konflikteskalation ein, die eine von USPD und KPD beherrschte Schachtdelegiertenkonferenz zu einem erneuten Generalstreikaufruf brachten. In diesem Zusammenhang wurde zudem eine neue Organisation, die Allgemeine Bergarbeiterunion gebildet. ${ }^{207}$ Der Aprilstreik war wiederum außerordentlich heftig. Als Reaktion entsandte die Reichsregierung Carl Severing als Staatskommissar für das Ruhrgebiet in das Streikgebiet, unter dessen Vermittlung ein Arbeitszeitkompromiß zwischen den Tarifparteien (Siebenstundenschicht) zustandekam, in dessen Gefolge Anfang Mai 1919 schließlich der Streik zusammenbrach, nicht ohne durch das Eingreifen von Freikorps verursachte weitere Verbitterungen. ${ }^{208}$

Die Ereignisse in Hamborn und die sich anschließenden Auseinandersetzungen zeigten einen aus der Kriegszeit bekannten typischen Verlauf. Neu war jetzt vor allem die Radikalität der betrieblichen Lohn- und Arbeitszeitbewegungen. Ähnlich wie im Kriege entwickelten sich zwei unterschiedliche Konfliktebenen, die schließlich nicht mehr miteinander abgestimmt waren. Auf der einen Seite handelte es sich um die Ebene von Branchenverhandlungen und -vereinbarungen, auf der der Zechenverband, die Gewerkschaften und der Staat als Akteure auftraten. Mit den Novembervereinbarungen war hier ein qualitativer Durchbruch zumindest auf der Verfahrensebene erreicht worden. Die neuen tarifären Verfahren beanspruchten indes Zeit und brachten in der Regel nur materielle Kompromisse. Auf der anderen Seite handelte es sich um betriebliche Bewegungen, in denen zunächst Belegschaften und Zechenleitungen als Akteure auftraten. Die Zeitdauer und die nur begrenzten materiellen Ergebnisse der Branchenverhandlungen wirkten sich auf die betriebliche Ebene direkt aus, insofern den Bergarbeitern die Verhandlungen zu lange dauerten und die materiellen Ergebnisse zu schlecht waren.

${ }^{206}$ Vgl. Winkler, Von der Revolution zur Stabilisierung, S. 167 ff., hier S. 169.

${ }^{207}$ Winkler, Von der Revolution zur Stabilisierung, S. 172.

${ }^{208}$ Ebenda, S. 174. 
Da zudem eine prinzipielle Akzeptanz des Tarifsystems bei den Bergleuten nicht vorhanden war, erinnerte man sich an die Kriegszeit, in der in der Regel erst Aktionen der Belegschaften Bewegung in die übergeordneten Verhandlungen gebracht hatten. Anders als freilich im Krieg setzte nach dem November 1918 jetzt ein unregulierter Eskalationsprozeß ein, da die staatliche Autorität faktisch nicht mehr existierte, sondern jedesmal neu durchgesetzt werden mußte. Zunächst bedingte dies eine relative Stärke aktionsbereiter Belegschaften, die mit nur geringer Gegenwehr glaubten rechnen zu müssen. Und in der Tat bestand die regelmäßige Reaktion auf direktes Belegschaftshandeln faktisch nur im Verweis auf neue Tarifverhandlungen, deren Ergebnisse jeweils nur kurzfristig die Ruhe wiederherstellen konnten. Zudem schien offensichtlich, daß durch direkte Aktionen größere materielle Vorteile erzielt werder konnten. Es entspann sich mithin ein Prozeß der spiralförmigen Eskalation über Streik, Verhandlung, Streik, Verhandlung, an dessen Ende die militärische Konfrontation stand. In diesem Eskalationsprozeß ging jedes Vertrauen in geregelte Konfliktverfahren verloren.

Im Unterschied zur Kriegszeit trat jetzt allerdings ein Moment der Politisierung der Forderungen hinzu, das nicht unbedingt von den an unmittelbaren materiellen Verbesserungen interessierten Belegschaften ausging. Die Politisierung trat vielmehr erst im Verlauf der Eskalationsprozesse auf, und zwar primär als Ergebnis des scheinbaren bzw. wirklichen Versagens der Verhandlungen auf Branchenebene. Dieses Versagen bedingte einerseits einen sukzessiven Vertrauensschwund der Belegschaften zu den Gewerkschaften und zweitens eine starke, moralische aufgeladene Protesthaltung gegenüber der Intransigenz der Zechenbesitzer. Beides zusammen erhöhte die Wirksamkeit syndikalistischer und kommunistischer Parolen, die versprachen, genau jene Fehler zu vermeiden, die den Branchenverhandlungen vorgeworfen wurden. Ein drittes Moment der Politisierung ergab sich schließlich daraus, die primär materiell motivierte Streikbereitschaft der Belegschaften gleichsam politisch auf das Feld der Sozialisierung umzuleiten. Angesichts der Tatsache, daß die Sozialisierung selbst wiederum Gegenstand zeitaufwendiger und betriebsferner Verhandlungen sein mußte, war das Scheitern dieses „Umweges“ vorherzusehen. Die Politisierung bedingte zudem ein weiteres Moment in der Spirale der Konflikteskalation, nämlich die naheliegende Neigung der Zechenbesitzer, sich durch Hinweis auf den linksradikalen Charakter der Bergarbeiterbewegung Verbündete im politischen und militärischen Bereich zu suchen, womit sie nicht erfolglos blieben. Insbesondere das Eingreifen militärischer Verbände brachte indes nur einen weiteren Eskalationsschub. Der Verlauf der sich an die Novemberrevolution anschließenden sozialen Konflikte im Ruhrbergbau war daher das Ergebnis eines interaktiven Eskalationsprozesses, in dem die Politik erst vergleichsweise spät eine Rolle spielte. Daß es hierzu überhaupt hatte kommen können, war nicht zuletzt Folge der Halbherzigkeit und der Verzögerungstaktik, mit der der Zechenverband auf die "revolutionären“ Herausforderungen reagierte ${ }^{209}$ Diese Halbherzigkeit war zu nicht geringem Maße dadurch bedingt, daß die Zechenbesitzer die Aktionsbereitschaft ihrer Belegschaften unterschätzten

${ }^{209}$ Kritisch zur Taktik der freien Gewerkschaften in diesem Rahmen Mommsen, Bergarbeiterbewegung an der Ruhr, S. $289 \mathrm{ff}$. 
und glaubten, durch Zugeständnisse gegenüber den Gewerkschaften ließe sich Ruhe in die Betriebe bringen. Unterstützt in dieser Auffassung wurde der Zechenverband zweifellos von der Erfahrung, daß sich die Belegschaften der Ruhrzechen nicht homogen verhielten, vielmehr "friedliche“ und "radikale“ Belegschaften nebeneinander in bunter Gemengelage auftraten. Der Eskalationsprozeß wäre durch eine offenere und intensivere betriebliche Kommunikation zumindest in der Weise verändert worden, daß die Zechenbesitzer früher und flexibler auf die Aktionsbereitschaft der Belegschaften hätten reagieren können.

Der betriebliche Kommunikationsprozeß war im Gefolge der geschilderten Eskalation dauerhaft schwerstens belastet, weil jene Gremien, die die Kommunikation hätten verbessern können, zugleich auch jeweils als Ansatzpunkt zur Organisierung basisnaher Aktionsbereitschaft verstanden werden konnten. Insbesondere die Steigerrevier- und Zechenräte standen von Anfang unter dem Odium, ein Ergebnis der Politik linksradikaler Organisationen zu sein. Waren die Arbeiterausschüsse nach dem November 1918 im westlichen Ruhrgebiet rasch überspielt worden, so zeichnete sich Anfang 1919 keine neue betriebliche Kommunikationsinfrastruktur ab, die das Vertrauen beider Konfliktparteien auch nur ansatzweise hätte erreichen können.

\section{Die Neustrukturierung der betrieblichen Kommunikationsprozesse im Frühjahr 1919}

Das Hamborner Beispiel machte Schule, insbesondere auf den Großzechen des nordwestlichen Ruhrgebietes. Von hier ausgehend bildeten sich mit den Zechenund Steigerrevierräten neue innerbetriebliche Gremien, die sich Kontrollfunktionen gegenüber dem Produktionsprozeß und den Zechenleitungen anmaßten und nicht selten durch Absetzung mißliebiger Vorgesetzter Schlagzeilen machten. ${ }^{210}$ Derartige Vorkommnisse erreichten während der Streiks im Januar und Februar 1919 ein Ausmaß, daß ein geordneter Zechenbetrieb kaum noch möglich war; $\mathrm{Ge}$ walttätigkeiten waren an der Tagesordnung. Ausgehend von Hamborner und Mühlheimer Zechen griffen zudem quasi militärische Zechenbesetzungen um sich, mit denen arbeitsbereite Belegschaften ebenfalls zum Streik gezwungen wurden. Erst der massive Militäreinsatz brachte im März 1919 eine oberflächliche Ruhe in die Reviere zurück, doch noch im Mai 1919 beklagte sich die Fachgruppe Bergbau im RDI beim Minister für Handel und Gewerbe über die häufig mit Streikdrohungen und Gewalttätigkeiten verbundenen Absetzungen von Vorgesetzten. ${ }^{211}$

Die auf Hamborn konzentrierten Streiks jedenfalls griffen um sich und dehnten sich auch ins mittlere Ruhrgebiet aus. Zu Beginn des Jahres 1919 bekamen sie einen explizit politischen Zug. ${ }^{212}$ Unter diesem Druck einigten sich Zechenverband und Bergarbeiterverbände am 9. Januar 1919 auf rückwirkende Sonderzah-

${ }^{210}$ Ausführliche Berichte hierzu in: StAM OBAD 1794.

${ }^{211}$ Fachgruppe Bergbau an Minister für Handel und Gewerbe, 7. 5. 1919, StAM OBAD 1795, Bl. 48. Fischbeck hatte allerdings bereits am 29.4. 1919 den Reichskommissar Severing angewiesen, derartige Vorkommnisse auf jeden Fall zu unterbinden, ebenda, Bl. 45.

${ }^{212}$ Spethmann, Zwölf Jahre Ruhrgebiet, Bd. 1, S. 142 ff. 
lungen, ${ }^{213}$ die durch Zahlungen des Reiches bzw. durch Kohlenpreiserhöhungen aufgefangen wurden. ${ }^{214}$ Damit wurden tariffeindliches Verhalten und direkte Aktionen der Bergleute regelrecht prämiiert. ${ }^{215} \mathrm{Zwar}$ waren zu derartigem Vorgehen im Dezember 1918 und Januar 1919 noch nicht alle Belegschaften bereit, namentlich in den östlichen Revieren gab es gegenüber dem Hamborner Beispiel Vorbehalte. Der Betriebsführer Ufer auf Zollern II berichtete dem GBAG-Vorstand, „daß die Belegschaft dieses Schachtes entschieden Stellung genommen (habe) gegen Unruhen, wie sie in Hamborn vorgekommen, und hat beschlossen, den Arbeiter- und Soldatenrat in Bövinghausen zu ermächtigen, alle Vorkehrungen zur Unterdrückung etwaiger Ausschreitungen zu treffen. Wie Herr Eichler hierzu berichtet, vertreten die Belegschaften von Germania den gleichen Standpunkt. “216 Es war allerdings absehbar, daß auch in diesen Revieren die Stimmung umschlagen würde, sollten sich die Erfolge der Hamborner Bergleute erst herumgesprochen haben. Die Erfahrungen aus den ersten Dezembertagen, als die erzwungenen $\mathrm{Zu}$ geständnisse in Hamborn zu Folgestreiks faktisch im gesamten westlichen Revier geführt hatten, sprachen eine deutliche Sprache. ${ }^{217}$ Die politische Streikbewegung der ersten Januarhälfte führte aber nicht nur das gerade erst eingeführte System kollektiver Lohnregelungen ad absurdum und brachte faktisch ein Zurück in die letzte Weltkriegsphase. Durch die im Januar 1919 für den gesamten streikenden Ruhrbergbau gebildete Streikleitung, insbesondere die Essener Neunerkommission von SPD, USPD und Kommunisten, wurde zugleich die Sozialisierung des Bergbaus proklamiert, der Zechenverband und das RWKS besetzt und schließlich auf den Zechen die direkte Demokratie verkündet. Eine Konferenz der Arbeiterund Soldatenräte des Ruhrreviers am 13. Januar 1919 bestätigte diese Beschlüsse, setzte einen Sozialisierungskommissar ein und forderte alle Belegschaften auf, Steigerrevier- und Zechenräte zu wählen, um die Sozialisierungsmaßnahmen vor Ort kontrollieren zu können. ${ }^{218}$

Die Arbeiterausschußwahlen des Jahres 1919, die nach der Verordnung der Reichsregierung vom 18. Januar $1919^{219}$ durchgeführt werden sollten, verliefen daher nicht regulär, da sie sich mit "wilden“ Steigerrevier- und Zechenratswahlen überschnitten. Zunächst verzögerten sich die Wahlen bis in den März hinein, da nicht selten die Zechenräte versuchten, Neuwahlen von Arbeiterausschüssen zu verhindern. ${ }^{220}$ Angesichts dieser Situation machte Anfang Februar 1919 auch der Handels- und Gewerbeminister einen Rückzieher, indem er zugestand, wo sie bestehen würden, könnten "aushilfsweise“ auch die Zechen- und Steigerrevierräte als Belegschaftsvertreter akzeptiert werden. ${ }^{221} \mathrm{Da}$ bei den zugleich ins Auge ge-

${ }^{213}$ Ebenda, S. $143 \mathrm{f}$.

${ }^{21+}$ Ebenda, S. $123 \mathrm{ff}$. Tschirbs, Tarifpolitik im Ruhrbergbau, S. $51 \mathrm{ff}$.

215 Zum Umfang der Streiks in den westlichen Revieren Spethmann, Zwölf Jahre Ruhrbergbau, Bd. 1, S. 131.

216 Vorstandsprotokoll der GBAG, 7. 1. 1919, BgA 55/117.

217 Winkler, Von der Revolution zur Stabilisierung, S. 165.

${ }_{218}$ Ebenda, S. $154 \mathrm{f}$.

$219 \mathrm{BgA} 41 / 328$.

220 Bei den Schachtanlagen der Gewerkschaft Deutscher Kaiser (Thyssen) kam es hierüber zu massiven Auscinandersetzungen, dic mit einem vorläufigen Sieg der Zechenräte endeten, Gewerkschaft Deutscher Kaiser an Oberbergamt, 1.2. 1919 und 3. 2. 1919, StAM OBAD 1854, Bll.37-39.

221 1. 2. 1919, StAM OBAD 1854, Bl. 36. 
faßten Weimarer Verhandlungen zwischen der Essener Neunerkommission, der Vertretung der streikenden Ruhrbergarbeiter, und der Reichsregierung auch über die Zukunft der innerbetrieblichen Kommunikation zu verhandeln war, riet der Handelsminister wenige Tage später dem Oberbergamt von einer „gewaltsamen Beseitigung“ der Zechenräte als „nicht ratsam“ ab. Es müsse in den Weimarer Verhandlungen versucht werden, diese Gremien in legale Institutionen zu überführen. ${ }^{22}$ Die Weimarer Verhandlungen brachten mit den Dienstanweisungen für Steigerrevier- bzw. Betriebsräte in der Tat einen Durchbruch, der zu einer faktischen Anerkennung der Zechen- als Betriebsräte führte, der auch der Zechenverband zustimmte. 223

Die Preußische Regierung ordnete daraufhin zunächst eine weitere Verschiebung der Ausschußwahlen an. ${ }^{224}$ Als die Wahlen im März 1919 endlich durchgeführt werden konnten, waren sie von heftigen Konflikten um Durchführung und Wahlmodus begleitet, auch wenn schließlich bis auf den Hamborner Zechen fast durchweg Vertreter der Tarifgewerkschaften mit großen Mehrheiten in die Ausschüsse gewählt wurden. ${ }^{225}$ Das Nebeneinander von Zechen- bzw. jetzt Betriebsräten und Arbeiterausschüssen war damit aber keineswegs beseitigt. Im Gegenteil wies das Handelsministerium die Bergbehörden am 18. März 1919 an: „Bis zur bevorstehenden reichsgesetzlichen Regelung muß unter stillschweigender Duldung des bestehenden Zustandes mit den verschiedenen, die Rechte und Pflichten der Sicherheitsmänner ausübenden Organe möglichst reibungslos zusammengearbeitet werden. "226 Damit war auf den Zechen eine doppelte Belegschaftsvertretung institutionalisiert, die sich aus in der Regel gemäßigten Arbeiterausschüssen und z.T. radikalen Betriebsräten zusammensetzte. Das Ausmaß der Radikalität der Belegschaftsvertretungen variierte stark. Auf den GBAG-Zechen kam es zu einer Spaltung der Situation zwischen Dortmunder und Gelsenkirchener Revier, wobei in letzterem die Radikalität der Arbeiterausschußmitglieder ausgeprägter war. Bochum, Schwerpunkt der Deutsch-Lux-Zechen, hatte nicht nur geographisch eine mittlere Position. Die Mehrzahl der Phoenix-Zechen befand sich ebenfalls im Essen-Gelsenkirchener Raum, so daß auch hier von einer ausgeprägteren Radikalität der Betriebsvertretungen auszugehen ist. Sicher ist auf jeden Fall die vergleichsweise gemäßigte Entwicklung im Dortmunder und Wittener Raum. Bei den Arbeiterausschußwahlen der Franziska-Schächte in Witten Anfang 1919 wurden nur Mitglieder des Alten Verbandes gewählt, die bis auf eine Person als Hauer beschäftigt waren. ${ }^{227}$

Ungeachtet des unterschiedlichen Radikalisierungsgrades der Belegschaften und ihrer Vertretungen änderte sich aber insgesamt das Auftreten der Belegschaftsvertreter. Organisationszwang war an der Tagesordnung, auch wenn die

222 6. 2. 1919, StAM OBAD 1854, Bl. 40.

${ }^{223}$ Rheinisch-Westfälische Zcitung, 18. 2. 1919; Minister für Handel und Gewerbe an Oberbergamt, 22. 2. 1919, StAM OBAD 1854, Bl. 55.

$22+$ 27. 2. 1919, StAM OBAD 1854, Bl. 60.

225 Berichte der Bergrevicrbeamten über Verlauf und Ergebnis der Arbeiterausschußwahlen, StAM OBAD 1854, Bll. $67 \mathrm{ff}$.

${ }^{226}$ Minister für Handel und Gewerbe an Oberbergamt, StAM OBAD 1854, Bl. 212.

$227 \mathrm{BgA} \mathrm{40/44.} \mathrm{Siehe} \mathrm{auch} \mathrm{über} \mathrm{die} \mathrm{Wahlvorbereitungen} \mathrm{Vorstandsprotokoll} \mathrm{der} \mathrm{GBAG,} \mathrm{21.} \mathrm{1.} \mathrm{1919,}$ BgA 55/117. 
Zechenleitungen auf Anweisung des Zechenverbandes ihn zu verhindern suchten. ${ }^{228}$ Das Miteinanderumgehen wurde zusehends rüde. Der spätere Leiter der Abteilung Bergbau der Vereinigten Stahlwerke bzw. der neuen GBAG, Gustav Knepper, der zuvor die Abteilung Bergbau von Deutsch-Lux geleitet hatte, wurde Ende Januar 1919 kurz hintereinander das Opfer von zwei politisch motivierten Anschlägen. Nach einem Streik war es auf der Dortmunder Zeche Adolf von Hansemann zur spontanen Bildung eines Zechenrates gekommen, dessen Illegalität Knepper auf einer Sitzung am 21. Januar 1919 nachdrücklich betonte. Lohnforderungen der Belegschaft lehnte er ab. Beide Male berief er sich dabei auf die Abmachungen, die zwischen dem Zechenverband und den Bergarbeitergewerkschaften getroffen worden waren. Als Knepper nach der Sitzung die Zeche verlassen wollte, wurde er im Auto aufgehalten und mit dem Tode bedroht, sollte er den Zechenrat nicht akzeptieren und die Forderungen bewilligen. In neuen Verhandlungen gab er schließlich nach und gestand die Lohnerhöhungen $\mathrm{zu}^{229}$ Wenige Tage später, Anfang Februar 1919, kam es zu einer Auseinandersetzung auf der Deutsch-Lux-Schachtanlage Dannenbaum in Bochum-Laer. Die Belegschaft hatte auf einer Versammlung ultimativ die Entlassung eines Betriebsinspektors verlangt und war zur Durchsetzung ihrer Forderung in den Streik getreten. Nachdem sich die Direktion lediglich bereitfand, den Betriebsinspektor zum 1. April $1919 \mathrm{zu}$ versetzen, dehnte sich der Streik aus. Die Nachbarzeche Prinzregent trat in einen Sympathiestreik ein. Der Arbeiterausschußvorsitzende Jacob und der Vorsitzende des Alten Verbandes Husemann bemühten sich auf einer eilig einberufenen Belegschaftsversammlung am 5. Februar 1919, eine Beilegung des Konfliktes zu erreichen, indem sie die Versetzung des Inspektors als ausreichend hinstellten. Die Belegschaft inszenierte aber völlig unbeeindruckt hiervon im Anschluß an die Versammlung einen Demonstrationszug zum Hause Kneppers, wo man niemanden antraf. Daraufhin besetzte man das nahegelegene Verwaltungsgebäude der Schachtanlage Friederika und verprügelte den Betriebsführer. Im Anschluß hieran stürmten verschiedene Belegschaftsmitglieder zunächst die Wohnung des Betriebsführers Schleicher und kehrten anschließend zur Villa Kneppers am Steinring in Bochum zurück. Dort kam es erneut zu einer, von der Polizei nur kurzfristig unterbrochenen Plünderung, der nach Angaben Kneppers unter anderem auch 100 Flaschen Wein zum Opfer fielen. Der Gesamtschaden betrug gut $21000,-$ Mark. ${ }^{230}$ Auch wenn der Arbeiterausschuß der Zeche Dannenbaum sich bei Knepper entschuldigte ${ }^{231}$ und der Vorsitzende des Bochumer Arbeiter- und Soldatenrates Fritz Husemann unorganisierte „Radikalinskis“ für den Überfall verantwortlich machte ${ }^{232}$, war die Sprache eindeutig. Ganz ähnlich war die Entwicklung in Gelsenkirchen. Zunächst wurden hier von der Belegschaft bzw. Teilen der Belegschaft über den Arbeiterausschuß bzw. die Zechenräte Forderungen

228 Sitzung des Arbeiterausschusses, 26.11. 1918, BgA 40/39.

${ }^{229}$ Spethmann, Zwölf Jahre Ruhrbergbau, Bd. 1, S. $185 \mathrm{f}$.

${ }^{230}$ Schreiben Bergwerksverwaltung Deutsch-Lux an Zechenverband, 6. 2. 1919, BgA 55/1447. Dort auch undatierte Schadensliste.

${ }^{231}$ Anschreiben an Knepper, ohne Datum, Eingangsstempel vom 8. 2. 1919, BgA 55/1447.

${ }^{232}$ Spethmann, Zwölf Jahre Ruhrbergbau, Bd. I, S. 187. Die schließlich vom Bochumer Amtsgericht am 16.5. 1919 zu Gefängnisstrafen zwischen 15 und vier Monaten Verurteilten waren jugendliche Bergarbeiter, Volksblatt 17.5. 1919, BgA 55/1447. 
gestellt. Im Anschluß hieran ergaben sich umfangreiche Verhandlungen, in denen sich die Zechenleitungen in der Regel zu Lohnzugeständnissen, aber nicht zu weiteren Kompromissen bereiterklärten. Insbesondere lehnte die GBAG jeden Bruch der Kollektivvereinbarungen entschieden $a b .{ }^{233}$ In einem nächsten Schritt berieten dann Belegschaftsversammlungen über weitere Aktionen. Nach einer Ablehnung der Forderung der Tages- und Kokereiarbeiter auf ver. Rheinelbe und Alma kam es am 30. Januar 1919 zum Streik dieser Arbeitergruppe. Die Zechenleitung versuchte mit Hilfe der Angestellten die Tagesanlagen so weit in Betrieb zu halten, daß die Kohlenförderung fortgesetzt werden konnte, was jedoch nicht gelang. Die Untertagebelegschaft weigerte sich, Streikbrecherarbeiten zu leisten. Die Streikenden selbst hinderten schließlich auch die Angestellten an der Arbeit und erklärten den zuständigen Bergwerksdirektor, nachdem dieser sich weiterhin weigerte, die Lohnerhöhungsforderung zu bewilligen, für abgesetzt. Dieser verließ unter Protest die Zeche, woraufhin die anwesenden Revolutionäre den Keller der Zechenverwaltung plünderten, wovon nach Angaben der Zechenleitung unter anderem 24 Flaschen Schnaps und 130 Flaschen Wein betroffen waren. Erst nach Intervention der Essener Sozialisierungskommission, die die überzogenen Forderungen der Tagesarbeiter ebenfalls zurückwies, konnte der Betrieb wiederaufgenommen werden. ${ }^{234}$

Die Radikalisierung der betrieblichen Konflikte erfaßte nicht alle Zechen, doch wurden schließlich auch im Dortmunder und Wittener Revier die Töne schärfer. Nachdem der Arbeiterausschuß der Franziska-Schächte sich noch im Dezember 1918 mit der Lohnentwicklung zufrieden gezeigt hatte ${ }^{235}$, forderte man im Januar nicht nur Lohnerhöhungen, sondern auch die Möglichkeit zur laufenden Kontrolle der Lohnlisten und die Überprüfung der Gewerkschaftsbücher im Betrieb. Überdies verlangte man die Gleichstellung im Lohn mit den übrigen Zechen des Wittener und Dortmunder Reviers. Die Zechenleitung lehnte alle Erweiterungen der Rechte des Arbeiterausschusses ab, zeigte sich in der Lohnfrage aber zuvorkommend, wenngleich eine Gleichstellung mit den anderen Zechen wegen der schlechten Lage der Südrandzechen nicht in Frage komme. Der Arbeiterausschuß erklärte sich mit den angekündigten Lohnerhöhungen einverstanden. Die Taktik des GBAG-Vorstandes, Lohnzugeständnisse in moderater Höhe zu machen und ansonsten genau auf der Einhaltung der Kollektivvereinbarungen zu bestehen, schien hier zunächst noch aufzugehen. ${ }^{236}$ Die folgenden Monate brachten dann mit den beiden großen Streiks im Februar und April auch hier schwere Erschütterungen, die durch die in der Regel im März neugewählten Arbeiterausschüsse in keiner Weise reguliert werden konnten. Die Eskalation über Generalstreik, gewaltsame Eingriffe in die Zechenleitungen und - in der Reaktion - massives Eingreifen der Staatsgewalt mit einem zivilen Staatskommissar Severing und der Entsendung regulärer Truppen in das Ruhrgebiet nahm ihren Lauf. Die Bergleute hatten mit den Streikmaßnahmen ihre Machtposition derart ausgenutzt, daß ange-

${ }^{233}$ Kurzer Bericht zur Streikbewegung auf der Kokerei Bonifacius, Rheinelbe, 23. 1. 1919, BgA 41/ 529.

${ }^{234}$ Spethmann, Zwölf Jahre Ruhrbergbau, Bd. I, S. $181 \mathrm{ff}$.

${ }^{235}$ Arbeiterausschußsitzung 30.12.1918, BgA 40/39.

${ }^{236}$ Arbeiterausschußsitzung, 20.1.1919, BgA 40/39. 
sichts des Kohlenmangels dem Staat zur direkten Intervention keine Alternative blieb. Die Eskalation endete keineswegs mit einer Niederlage der Streikenden, auch wenn die Sozialisierung des Kohlenbergbaus schließlich nicht im gewünschten Umfang, sondern nur in einer harmlosen „Gemeinwirtschaftsform “ realisiert wurde. ${ }^{237}$ Im Gegenteil konnten erhebliche Lohnerhöhungen mit den Aprilstreiks ebenso durchgesetzt werden wie eine weitere Verkürzung der Schichtzeit auf sieben Stunden. ${ }^{238}$ Analog zum mitteldeutschen Streikgebiet ${ }^{239}$ einigten sich Zechenverband und Bergarbeitergewerkschaften schließlich auf die freiwillige Einführung von Betriebsräten, die als geschäftsführende Ausschüsse von den bereits bestehenden und im März 1919 neu gewählten Arbeiter- und Angestelltenausschüssen gebildet werden sollten. ${ }^{240}$ Die mit der Forderung nach Zechenräten verbundenen Vorstellungen wurden mit den Betriebsräten zwar nicht erfüllt, doch erhielten diese nicht nur das Recht in die Unterlagen der Zechen Einsicht zu nehmen, sondern auch über die Grubensicherheit zu wachen. Ihre Tätigkeit hatte sich freilich im Rahmen der Kollektivvereinbarungen zu bewegen; auch waren sie verpflichtet, für einen möglichst hohen Stand der Produktion zu sorgen. In gewisser Weise stellten die Betriebsräte, die paritätisch aus Arbeitern und Angestellten zu bilden waren, eine Vorwegnahme der späteren Betriebsausschüsse dar, abgesehen davon, daß über diese Vereinbarungen der Gesetzgebungsprozeß in Gang kam und den Betriebsvertretungen ein prestigeträchtiger Name verliehen wurde. ${ }^{241}$

Die verschiedenen Zechenleitungen und Vorstände hatten die Entwicklung keineswegs passiv hingenommen, sondern über ihre Vertretung im Zechenverband aktiv auf die Entwicklung Einfluß genommen. ${ }^{242}$ Jedoch waren mit diesen Engagements auf der Verbandsebene weiterhin keinerlei betriebliche Maßnahmen verbunden. Die GBAG förderte die Bildung freiwilliger Zechenwehren, die auf Rheinelbe während des Februarstreiks auch eine Besetzung der Anlage verhinderten, im Gegensatz zu Alma, wo die freiwillige Grubenwehr, „infolge zeitweiligen Versagens der vom Soldatenrat gestellten Sicherungsmannschaften durch eine größere Zahl von Aufrührern entwaffnet und die Stillegung des Betriebes erzwungen" wurde. ${ }^{243}$ Zugleich finanzierte man die Sicherheitswehr in Gelsenkirchen und beteiligte sich an den Kosten der Polizei und der Freikorps. Auch den Regierungstruppen wurden Zuwendungen gemacht. ${ }^{244}$ Versuche allerdings, in den ruhigeren Momenten mit der Belegschaft neue und effektivere Kommunikationsstrukturen aufzubauen, unterblieben. Die Zusammenarbeit mit den Arbei-

237 Wulf, Regierung, Parteien, Wirtschaftsverbände, in: Mommsen, Petzina. Weisbrod (Hg.), Industrielles System, S. 647-657. Wulf, Die Auseinandersetzungen um die Sozialisierung der Kohle, in: VfZ 25 (1977), S. 46-98.

${ }^{238}$ Feldman, Arbeitskonflikte im Ruhrbergbau, S. $169 \mathrm{f}$.

${ }^{239}$ Siehe Richtlinien für die Bestellung von Betriebsräten für die Braunkohlen- und die chemische Industrie, 8. 3. 1919, BAL 214/11. Grundsätze für die Errichtung von Betriebsräten, ohne Datum, BAL 214/10.

${ }^{240}$ Severing setzte die gemeinsamen Beschlüsse in eine Verordnung um, 26. 5. 1919, die dem Zechenverband allerdings zu weit ging, weil damit scheinbar die Freistellung der Betriebsratsmitglieder vorgeschrieben sei, Rundschreiben Nr. 55 vom 31. 5. 1919.Severing dementierte dies auf Anfrage einer Zeche im Juni 1919 allerdings, Rundschreiben Nr. 63 vom 28. 6. 1919, BgA 41/328.

241 Vgl. zum politischen Zusammenhang Oertzen, Betriebsräte in der Novemberrevolution.

${ }^{242}$ Vorstandsprotokoll der GBAG, 30.5. 1919, BgA 55/117.

${ }^{243}$ Vorstandsprotokoll der GBAG, 5. 3. 1919, BgA 55/117.

244 Ebenda. 
terausschüssen auf den nichtstreikenden Schachtanlagen wurde zwar fortgesetzt, doch blieb diese im Rahmen der bisherigen, bereits aus der Kriegszeit eingespielten Strukturen. Weder wurde die Zahl der Sitzungen erhöht noch änderte sich das Feld der Teilnehmer. ${ }^{245}$ Verschiedene "leitende Herren" nahmen zwar gelegentlich ad hoc an Belegschaftsversammlungen teil, doch geschah dies in der Regel erst in einem Stadium der Eskalation, in dem kaum noch geschlichtet werden konnte. Die GBAG finanzierte die Unterdrückung der Bergarbeiterbewegung, soweit dies ihr möglich war und hielt sich ansonsten an die im November 1918 vereinbarten Kollektivregelungen. Zu Lohnzugeständnissen war man weiterhin bereit, auch wenn sich die Finanzlage des Unternehmens wegen der Förderausfälle und der gestiegenen Lohnkosten verschlechtert hatte. Da allerdings die Kohlenpreise stiegen, gab es einen Ausweg, der der GBAG im Gegensatz zu den Hüttenzechen auch offenstand. ${ }^{246}$ Die Leitungen der Verbundkonzerne waren als Kohlen- und Koksverbraucher an niedrigen Energiekosten interessiert und plädierten daher stärker gegen Lohn- und damit Kostenerhöhungen. Anders als die „reinen“ $\mathrm{Ze}$ chen waren hier die betriebswirtschaftlichen Spielräume für Lohnzugeständnisse zunächst geringer. Gleichwohl war auch bei der GBAG absehbar, daß die Finanzierung von immer stärker steigenden Kosten bei sinkender Produktion über Preiserhöhungen kein dauerhafter Ausweg aus der Krise der Kohlenwirtschaft war. Nur ein beständiger Leistungsanstieg der Zechen konnte hier einen Ausweg und auch eine betriebswirtschaftlich sichere Basis für höhere Löhne und kürzere Arbeitszeiten sein. Wie der Leistungsanstieg in einer auch für die Bergleute akzeptablen Weise zu erreichen sein könnte, wie unter Umständen betriebliche Kommunikations- und Entscheidungsstrukturen den veränderten Verhältnissen angepaßt werden könnten, darüber machte man sich bei der GBAG allerdings überhaupt keine Gedanken.

Hier wie bei der Abteilung Bergbau von Deutsch-Lux in Bochum und bei der Gewerkschaft Deutscher Kaiser in Hamborn führten die Januarereignisse zu einem tiefen Bruch in den industriellen Beziehungen, der auch durch die vorhandenen betrieblichen Kommunikationsmöglichkeiten nicht mehr überbrückt werden konnte. Denn die Arbeiterausschüsse hatten sich angesichts des Vorgehens der Belegschaften bzw. einzelner Belegschaftsteile als völlig hilflos erwiesen. Die Politisierung der Konflikte und ihre Eskalation, die auf die Beseitigung der Gegenseite als Verhandlungsmacht setzte, wurde von den linken politischen Parteien und Belegschaftsteilen so massiv betrieben, daß offensichtlich nur noch die Alternative zwischen Unterwerfung und Bürgerkrieg zu bestehen schien. Jedenfalls betonte Gustav Knepper im Anschluß an den Überfall, daß er alles Vertrauen zu den Belegschaften, für die er sich neben dem Wohl der Zechen auch immer eingesetzt hätte, verloren habe. Es werde lange dauern, bis das alte Vertrauen wiederhergestellt sei. ${ }^{247}$ So existierte im Mai 1919 zwar eine im Grundsatz von allen Beteiligten

${ }^{245}$ Arbeiterausschußsitzungen der Franziska-Schächte, Ifd., BgA 40/39. Vgl. auch Arbeiterausschuß der Zeche Bonifacius, 10. 3. 1919, BgA 41/529.

${ }^{246}$ Vgl. zum Konflikt „,reine“ gegen Hüttenzechen in der Lohn- und Preisfrage Tschirbs, Tarifpolitik im Ruhrbergbau, S. $55 \mathrm{ff}$.

${ }^{247}$ Knepper an den Vorsitzenden des Arbeiterausschusses von Dannenbaum, Jakob, 14. 2. 1919, BgA $55 / 1447$. 
akzeptierte neue betriebliche Kommunikationsstruktur; in ihrem Rahmen aber herrschten Mißtrauen, Angst und wenig Kooperationsbereitschaft.

\section{Konfliktalltag 1919}

Eine produktive Nutzung der neuen Institution der Betriebsräte war unwahrscheinlich. Im Gegenteil wurden bald Klagen laut, die Verwaltungen würden die Konstituierung der Betriebsräte verhindern. Zwar sicherte die Zechenleitung der Franziska-Schächte die Einberufung der Betriebsräte bereits im April zu, doch mußte der Arbeiterausschuß im Juni noch einmal nachsetzen und mit der Anrufung des Reichskommissars Severing drohen, bis endlich eine Betriebsratssitzung einberufen wurde. ${ }^{248}$ Dies war kein Zufall, hatte der Vorstand der GBAG doch beschlossen, mit den Betriebsräten nicht zu kooperieren, ihnen vor allem keine Akteneinsicht zu geben: „Aus Anlaß eines besonderen Falles ...hält Herr Brandi es für notwendig, daß die Bürovorsteher unserer Hauptverwaltung angewiesen werden, an Betriebsratsmitglieder unserer Zechen keinerlei Auskunft zu geben, es sei denn, daß in besonderen Fällen die Betriebsverwaltung bzw. der zuständige Direktor die Hauptverwaltung vorher einwilligend in Kenntnis gesetzt hat. ${ }^{\text {249 }}$ Die Betriebsrat-Boykottierung durch die Zechenleitungen ging schließlich derart weit, daß der preußische Handelsminister Konsequenzen androhte, scheiterte mit diesem Ansinnen aber an den Bergbehörden, die ein Eingreifen ablehnten. ${ }^{250}$ Neben der Kommunikations- und Akteneinsichtsverweigerung bestand das wirksamste Mittel der Zechenleitungen gegen die Betriebsräte darin, diesen die Revierbefahrungen zu erschweren. Verbieten konnten sie die Befahrungen nicht, doch die Zahl der Befahrungen so gering halten, daß angesichts der Größe der Steigerreviere eine wirkungsvolle Betriebsratsarbeit ausgeschlossen war. Nach langen Auseinandersetzungen einigten sich Zechenverband und Bergarbeiterverbände unter Vermittlung Severings am 14. Juli 1919 im Falle der Krupp-Zeche Ver. Sälzer-Neueck auf zwei Fahrschichten pro Betriebsratsmitglied im Monat. Dies müßte angesichts der Größe der Reviere ausreichen, was jedoch nur in Ausnahmefällen zutraf. ${ }^{251}$ Bei der Deutsch-Lux-Zeche Dannenbaum, wo der Betriebsrat sich erstmalig am 19. Juni 1919 traf, wurden drei Befahrungen im Monat zugestanden. Ebenso durften die Betriebsratsmitglieder an den Tagen ihrer Revierbefahrungen eine halbe Stunde früher ausfahren, um über Tage rechtzeitig für Sprechstunden zur Verfügung zu stehen. ${ }^{252}$ Später wurde ihm auch eine beschränkte Einsicht in die Lohnlisten zugestanden, jede gewerkschaftliche Tätigkeit aber strikt untersagt. ${ }^{253}$

Die Obstruktionspolitik der Zechenleitungen blieb freilich nicht ohne Antwort. Die Phoenix-Bergwerksverwaltung sammelte im Herbst 1919 derartige Vorfälle, um sie in Berlin zur Vorlage bringen zu können. ${ }^{254}$ Die Meldungen der

\footnotetext{
${ }^{248}$ Arbeiterausschußsitzungen 5. 4. 1919, 4. 6. 1919, BgA 40/39.

249 Vorstandsprotokoll der GBAG, 30. 5. 1919, BgA 55/117.

${ }^{250}$ Schreiben des Zechenverbandes an die Verbandszechen, 26. 6. 1919, BgA 41/328.

$251 \mathrm{BgA} \mathrm{41/328.}$

252 Direktion Deutsch-Lux an Betriebsinspektor Mehring, 22. 8. 1919, BgA 40/224.

${ }^{25.3}$ Betriebsratssitzungen Dannenbaum 16. 8. 1919, 4. 10. 1919, BgA 40/224.

254 Anschreiben an die cinzelnen Schachtanlagen, 25. 10. 1919, BgA 41/328.
} 
einzelnen Phoenix-Zechen vermittelten nicht nur die Weltsicht der jeweiligen Zechenleitung, sondern zugleich einen Einblick, wie weit der Betriebsalltag von Kampf und Auseinandersetzungen geprägt war. Die Zusammenstellung der Phoenix-Bergwerksverwaltung war eindrucksvoll: „Zeche Holland: Unausgesetzte Hetze gegen den Betriebsführer Thielemeier, dem Lügen und Fälschungen der Kohlentafel vorgeworfen werden. Wegen dieser Angelegenheit ist von uns gegen das Betriebsratsmitglied W. Strafantrag wegen Beleidigung gestellt... Zeche Nordstern 3/4: Der Betriebsrat unter Führung des Steigers H. trifft über den Kopf der Betriebsleitung hinweg und ohne die Direktion zu fragen betriebliche Anordnungen, u. a. daß an bestimmten heißen Stellen nur 5,1/2 Stunden gearbeitet werden soll. Er fährt ohne Genehmigung des Betriebsführers und unter Verletzung der Seilfahrtsordnung aus der Grube. Weiter hat der Betriebsrat die Ausfertigung der für Abschlagszahlungen angeordneten seit Jahren üblichen Abschlagsscheine verweigert. Dieserhalb hat der Reichskommissar den Führer des Betriebsrates ... schon zur Rede gestellt. Weiter bekümmert sich der Betriebsrat unter Führung des ... Steigers A. um Dinge, die ihn gar nichts angehen: so auf Graf Moltke, wo es sich um die Beurlaubungssache eines Steigers ... handelte,... und der Zeche Welheim, wo ein Steiger angeblich wegen Diebstahls entlassen worden ist: hier hat der Betriebsrat von Nordstern zum Ausdruck gebracht, wenn der Steiger St. von Welheim nicht wieder eingestellt würde, würden sie mit der Belegschaft von Nordstern in den Streik treten. In gleicher Weise wurde wegen des Steigers G. von unserer Zeche Graf Moltke gedroht, wenn die Betriebsdirektion nicht nachgeben würde." 255 Wenige Tage zuvor hatte sich auf einer Zeche des ebenfalls zum Phoenix zählenden Hoerder Kohlenwerkes folgendes ereignet: „Die Mitglieder des Betriebsrates der Zeche Holstein haben gestern einen Anschlag am schwarzen Brett gemacht, demzufolge am 24 ds. Mts. eine Organisationskontrolle auf der Zeche vorgenommen werden soll. Die Leute haben mir [dem berichtenden Bergwerksdirektor] seit Wochen gleichlautende Anträge zum Aushang vorgelegt. Ich habe den Aushang aber verweigert, so daß sie den gestrigen Aushang ohne Genehmigung gemacht hatten. Ich habe den Aushang entfernt. Darauf haben die Betriebsratsmitglieder die Belegschaft heute früh nicht anfahren lassen, sondern in der Kaue eine Belegschaftsversammlung abgehalten, in der ich gesprochen und den Versuch unternommen habe, die Leute davon zu überzeugen, daß die Zeche zu diesen Bestrebungen nicht die Hand bieten könnte; daß sie aber außerhalb des Zechenplatzes machen könnten, was sie wollten. Die Versammlung bestand aber darauf, die Kontrolle auf der Zeche vorzunehmen. Ich habe erklärt, daß ich der Gewalt natürlich weichen würde. Die Kontrolle wird am nächsten Samstag stattfinden. “256

Die Betriebsräte nutzten so in der zweiten Jahreshälfte 1919 zum Teil recht geschickt die hohe Mobilisierbarkeit der Belegschaften und schränkten auf diese Weise den Handlungsspielraum der Zechenleitungen ein. Die Behinderung der Betriebsräte durch die Zechenleitungen schlug mithin auf deren Handlungsfähig-

255 25. 10. 1919, BgA 41/328.

${ }^{256}$ Hoerder Kohlenwerk an Phoenix Bergwerksverwaltung, 22. 10. 1919, BgA 41/328. Zum Problem des Organisationszwangs vgl. auch Tschirbs, Tarifpolitik im Ruhrbergbau, S. $83 \mathrm{ff}$. 
keit direkt zurück. Ein signifikanter Fall ereignete sich Ende des Jahres auf den Wittener Franziska-Schächten. Hier - wie auf zahlreichen anderen Anlagen - versuchten die Zechenleitungen durch Überschichten die Kohlenförderung zu steigern. Einerseits hatte die Kohlennot im Lande dramatische Züge angenommen, andererseits litt die GBAG stark unter der niedrigen Förderung und konnte die günstige Konjunktur kaum ausnutzen. Diese Konstellation gab der Belegschaft eine bedeutende Machtstellung. Auf eine Anfrage des Bergwerksdirektors erklärte der Betriebsrat unter folgenden Bedingungen, Überschichten zu akzeptieren: „a) Einräumung des Mitbestimmungsrechtes an den Betriebsrat über die gesamte Förderung, Abführung der Mehrförderung nur an das Gußstahlwerk, b) Einstellung des Landabsatzes durch einen bestimmten Unternehmer, c) Erhöhung des Überschichtenaufschlages von 25 auf $50 \%$, d) Bewilligung einer Teuerungszulage von $1000,-$ Mk., e) Befreiung der Überschichteneinkommen von der Steuer, f) sofortige Einführung der Sechsstundenschicht." Dem Vorstand der GBAG blieb keine andere Wahl als zu beschließen: „Unter Berücksichtigung dieser Bedingungen muß also auf das Verfahren von Überschichten verzichtet werden. “257

Die Blockade der Betriebsräte durch die Unternehmen erreichte also zumindest solange eher das Gegenteil, wie die Belegschaften bereit waren, aus geringen Anlässen zu demonstrieren, zu protestieren und zu streiken. Dabei spielte auch kaum eine Rolle, daß die im Frühjahr vereinbarten Richtlinien über die Tätigkeit der Betriebsräte eigentlich das Belegschaftsverhalten im Sinne einer rationaleren Konfliktregulierung kanalisieren sollten. Viele Belegschaften kümmerten sich um papierene Vorschriften wenig, zumal sich ja ganz offensichtlich die Gegenseite hieran auch nur sehr formal gebunden fühlte. Daß die Zechenleitungen den $\mathrm{Ge}$ setzentwurf über die Betriebsräte vom Frühsommer 1919 nicht begrüßten, war daher nur zu verständlich, würde er doch keinerlei Entlastung bringen. Angesichts der Verhältnisse war vielmehr zu befürchten, daß die gesetzliche Verankerung der Betriebsräte dem Betriebsradikalismus noch Auftrieb geben würde. Abhilfe hätte in dieser Sicht, wenn überhaupt, so nur ein Gesetz gebracht, daß die Betriebsräte eng an die Kandare gelegt und wirksame Mittel zur Bekämpfung der Arbeiterradikalität geboten hätte. Gerade dies aber schien das Gesetz nicht zu leisten, im Gegenteil stärkte es die betriebliche Stellung der Räte noch, auch wenn es ihre Rechte eher restriktiv faßte. Gleichwohl hielt sich der Vorstand der GBAG in der Kommentierung des Gesetzentwurfes zurück: „Mit Rücksicht auf die dem Bergbau-Verein vorbehaltene Vertretung in dieser Angelegenheit erscheint Abgabe besonderer Anregungen unsererseits nicht angängig. "258 Der Zechenverband hatte bereits im August gegenüber dem preußischen Handelsminister grundsätzlich zum Gesetzentwurf Stellung genommen. Dabei verlangte man eine Berücksichtigung jener Erfahrungen, die der Ruhrbergbau mit den Betriebsräten bereits gemacht habe. ${ }^{259}$ Vor allem müsse das passive Wahlalter hochgesetzt, die Beteiligung an der Gedingefestsetzung auf Streitfälle beschränkt, die Freiheit der Ze-

${ }^{257}$ Vorstandsprotokoll der GBAG, 30. 12. 1919, BgA 55/117.

${ }^{258}$ Vorstandsprotokoll der GBAG, 26.11. 1919, BgA 55/117.

${ }^{259}$ Zechenverband an Preuß. Handelsminister, 11.8. 1919, GStA Merseburg Rep 120 BB VII 1 Br. 9 adh. 5, Bd. 1, Bll.191-197. 
chenleitung bei Einstellungen betont und den Betriebsräten jeder selbständige Eingriff in die Zechenleitung untersagt werden. Freistellungen dürften generell nicht zugelassen werden, da ansonsten ein jährlicher Förderausfall von 460000 to eintrete. Schließlich müßte die Möglichkeit für gemeinsame Arbeitsordnungen aller Ruhrzechen erhalten bleiben. Diese noch moderate Kritik, die im übrigen in fast allen Punkten schließlich durchgesetzt werden konnte, wich im Zuge der späteren Auseinandersetzungen einer allgemeinen Hysterie über das neue Gesetz, die teilweise sogar der GBAG zu weit ging, wenn etwa ernsthaft überlegt wurde, mit der Schließung der Zechen zu drohen, wenn das Gesetz durchkomme. ${ }^{260}$

Konnte man sich mit den Betriebsräten und ihren Kontroll- und Mitbestimmungsansprüchen nicht arrangieren, so blieb aber auch die Tätigkeit der weiterhin bestehenden Arbeiterausschüsse nur ein Schatten dessen, was etwa im Bayerwerk in Leverkusen vor sich ging. Die in der ersten Jahreshälfte 1919 dominanten politischen Fragen verschwanden aus der Tätigkeit der Arbeiterausschüsse. Sie wurden entweder wie die Sozialisierungsfrage direkt im politischen Raum debattiert oder zwischen den Zechenleitungen und den neugebildeten Betriebsräten verhandelt. Die Arbeiterausschüsse beschäftigten sich durchweg mit den alltäglichen, drückenden Sorgen der Bergleute und ihrer Familien, die ja trotz der durch die Streiks erzielten Lohnerhöhungen nicht entscheidend zurückgegangen waren. Im Sommer $1919 \mathrm{kam}$ auch die Lebensmittelfrage wieder auf die Tagesordnungen. ${ }^{261}$ In all diesen Punkten zeigten die Bergwerksdirektionen der GBAG, so weit die noch vorhandenen Unterlagen ein Bild zulassen, durchaus eine flexible Haltung und waren dort, wo sie konnten, durchaus entgegenkommend. ${ }^{262}$ Daß hier indes Ansätze entwickelt wurden, über die starre Konfrontationshaltung hinauszukommen, war nicht zu erkennen; der Rahmen dessen, was bereits unter dem Hilfsdienstgesetz Praxis gewesen war, wurde nicht überschritten.

Resümiert man die Entwicklung in den entscheidenden Jahren 1918 bis 1920, so ergibt sich folgendes Bild. Die alltägliche Praxis der betrieblichen Kommunikation zeigte, daß GBAG, GDK, Phoenix und Deutsch-Lux auf die Ausdifferenzierung ihrer innerbetrieblichen industriellen Beziehungen kaum Gedanken verschwendet hatten, sondern sich eigentümlich defensiv verhielten. Von sich aus wurden sie in keinem einzigen Fall aktiv. Sie nahmen zwar jeweils die gegen ihren Willen neu geschaffenen Einrichtungen und Vereinbarungen hin, versuchten dann aber, diese praktisch ins Leere laufen zu lassen, da man sich von ihnen nichts versprach als eine weitere Förderung der Arbeiterradikalität. Verweigerungshaltung und Belegschaftsradikalität schaukelten sich auf diese Weise selbst auf jenen Schachtanlagen gegenseitig hoch, deren Belegschaften an sich nicht radikal auftraten wie etwa beim Hoerder Kohlenwerk. Neben zahlreichen anderen Gründen, der Struktur der Produktionsprozesse, der Zusammensetzung der Belegschaften und ihres Verhaltens erwies sich als ein hemmender Faktor für die Entwicklung funktionierender innerbetrieblicher industrieller Beziehungen die Tatsache, daß die sozial- und arbeitspolitischen Entscheidungen in der überwie-

${ }^{260}$ Vorstandsprotokoll der GBAG, 30. 12. 1919, BgA 55/117.

${ }^{261}$ Arbeiterausschußsitzungen der Franziska-Schächte, Ifd., BgA 40/39.

262 Vorstandsprotokoll der GBAG, 23.9. 1919, BgA 55/117, mit Anträgen von Minister Stein, ver. Bonifacius und Hamburg. 
genden Zahl der Fälle nicht auf den Zechen selbst, sondern durch die Gremien des Zechenverbandes oder seiner Bezirksorganisationen getroffen wurden. Dies entlastete die Bergwerksverwaltungen, hinderte sie aber auch daran, eigene Überlegungen zu entwickeln und ggf. unorthodoxe Maßnahmen zu ergreifen. Die Tatsache, daß die Bergwerksgesellschaften nicht über eigene sozialpolitische Stäbe verfügten, sondern diese Arbeit dem Zechenverband übertragen hatten, machte sie in ihren eigenen Angelegenheiten entscheidungsunfähig. Immer häufiger wurde in den kommenden Jahren selbst wegen banaler Kleinigkeiten in Essen angefragt. Der Zechenverband aber entschied, wie er es im größeren (sozial)politischen Rahmen für richtig befand, nicht wie es unter Umständen betrieblich angemessen gewesen wäre. Die letztlich gewerkschaftsfeindliche Haltung, die auf diese Weise konserviert wurde, obwohl gerade die Gewerkschaften einen wichtigen Beitrug zur betrieblichen Deradikalisierung hätten leisten können, wirkte zweifellos für die Entwicklung der industriellen Beziehungen in den einzelnen Betrieben kontraproduktiv, auch wenn keineswegs sicher war, daß eine gewerkschaftsfreundlichere Politik von den Belegschaften mit friedlicherem Verhalten beantwortet worden wäre. Zumindest die Möglichkeit hierzu hätte bestanden, doch geriet sie nicht in den Blickwinkel der Zechen, da diese wegen des Fehlens geeigneter Institutionen und Organisationsstrukturen sozialpolitisch „blind“ waren. Die Bergwerksgesellschaften, die durch ihre gewerkschafts- und betriebsratsfeindliche Blockadepolitik die eigene Handlungsautonomie gegen Mitbestimmung sichern wollten, erreichten damit allerdings etwa in der Arbeitszeit- und Überschichtenfrage das gerade Gegenteil. Je unversöhnlicher man war, um so geringer waren die eigenen Handlungsspielräume, um so mehr zwang man sich auch selbst, in Repression und Unterdrückung der Bergarbeiterbewegung den Ausweg aus der sozial und wirtschaftlich verfahrenen Lage zu suchen. Im Bergbau zeichnete sich eine Situation ab, in der alle Beteiligten einen Zustand des Unfriedens mit Mitteln bekämpfen wollten, mit denen sie ihn gemeinsam herbeigeführt hatten.

Die Einführung des Tarifsystems erwies sich in diesem Zusammenhang sogar als ein weiterer Krisenpunkt, da es den Belegschaften die legale Möglichkeit direkter Aktionen nahm und sie auf den Verhandlungsweg zwischen den Organisationen verwies. Schon während des Krieges aber hatten die zentralen Verhandlungen vielen Belegschaften zu lange gedauert und nur unzureichende Ergebnisse gebracht. Das Auseinanderklaffen von Belegschaftserwartungen und Ergebnissen des Tarifsystems wurde zum zentralen Ansatzpunkt syndikalistischer und unionistischer Politik. Abhilfe hätte in diesem Bereich nur eine flexiblere, betriebs- und belegschaftsbezogene Politik der Zechenverwaltungen bringen können, die diese aber wegen der damit verbundenen Kosten ablehnte. Sie trugen daher im Gegenteil zur immer weiteren Entfremdung von den Belegschaften zu ihren Gewerkschaften bei und förderten indirekt das Ausgreifen radikaler Arbeiterverbände, gegen die wiederum nur Repression zu helfen schien. Ende 1919 befand sich der Ruhrbergbau daher in einer Blockadesituation, aus der auszubrechen kaum noch möglich erschien. 
1920 bis 1923

Die betriebliche Bedeutung des Betriebsrätegesetzes im Ruhrbergbau

Die Einführung des Betriebsrätegesetzes brachte im Ruhrbergbau eine Beschränkung der Handlungsmöglichkeiten der Betriebsvertreter, obwohl sich die Bergarbeiterschaft an der Ruhr auf verschiedenen Kundgebungen für die Verwirklichung des Betriebsrätegesetzes stark gemacht hatte. Das Ergebnis der Gesetzgebung war für die Bergarbeiter enttäuschend. ${ }^{263}$ Die Ereignisse vor dem Reichstag im Kontext der Verabschiedung des Gesetzes und die Befürchtung von Unruhen brachten dem Ruhrgebiet seit dem 17. Januar 1920 den verschärften Belagerungszustand. ${ }^{264}$ Die ersten Betriebsratswahlen an der Ruhr wurden zusätzlich von den sich an den Kapp-Putsch anschließenden März-Kämpfen überschattet, da sie häufig unmittelbar im Anschluß an die Kämpfe stattfanden. ${ }^{265}$ Die Wahlergebnisse fielen für die Tarifgewerkschaften trotz ihrer scharfen Stellungnahme gegen die Märzrevolution nicht ungünstig aus: „Selbst im Ruhrrevier, wo die Kappunruhen am schlimmsten tobten und der Kampf gegen den Bergarbeiterverband von Unionisten, Syndikalisten und Kommunisten mit allen Mitteln geführt wurde, ist das Wahlergebnis befriedigend. Wir erhielten rund 1250, die Unionisten und Syndikalisten 700, der Gewerkverein christlicher Bergarbeiter 500, die Polen 190 und der Gewerkverein H.D. 9 Mandate. ${ }^{\text {266 }}$ Bei den GBAG-Zechen (incl. Phoenix und Deutsch-Lux) wiesen die Wahlergebnisse, soweit sie erhalten sind, große Unterschiede auf. Während Rheinelbe und Alma, die Anfang Mai 1920 wählten, von Anfang an unionistische Mehrheiten hatten, gab es auf den Zechen im Bochumer und Dortmunder Raum tarifgewerkschaftliche Mehrheiten. Auf Rheinelbe hatten Alter Verband (4 Sitze) und "Christen" (2) zusammen 6 Mandate, Unionisten (7) und Syndikalisten (1) mit 8 Sitzen die Mehrheit; auf Alma brachte es die Union auf elf Mandate, "Christen“ und „Freie“ je auf drei. ${ }^{267}$ Die Dannenbaum-Schächte in Bochum entsandten acht Angehörige des Alten Verbandes in den Arbeiterrat, vier „Christen“ und je einen Polen und Unionisten. ${ }^{268}$ Bei der Wittener Zeche ver. Hamburg und Franziska schließlich errangen die Angehörigen des Alten Verbandes bis auf einen Sitz (Christen) alle Mandate im Arbeiterrat. ${ }^{269}$ Diese Tendenz blieb auch bei den kommenden Wahlen erhalten: Je größer und je nordwestlicher die Zeche, um so extremer das Wahlverhalten. ${ }^{270}$ Die soziale Zusammensetzung

${ }^{263}$ Einige allgemeine Hinweise bei Hartewig, Das unberechenbare Jahrzehnt, S. 260ff. In ihrer Wahrnehmung des BRG im Bergbau bleibt die interaktive Dynamik von Zechenleitungen, Belegschaften und Betriebsräten am Rande; die Bergwerksdirektoren erscheinen so stärker, als sie tatsächlich waren.

${ }^{26+}$ Spethmann, Zwölf Jahre Ruhrbergbau, Bd. II, S. 58.

${ }^{265}$ Zuweilen konnte es vorkommen, daß Angehörige der Roten Ruhrarmee sogar in Abwesenheit in den Betriebsrat gewählt wurden, so auf der Schachtanlage Recklinghausen 2, die am 7.4. 1920 wählte, vgl. Zimmermann, Schachtanlage und Zechenkolonie, S. 103.

266 Jahrbuch des Verbandes der Bergarbeiter Deutschlands 1920, S. 110.

$267 \mathrm{BgA} \mathrm{41/531.}$

${ }^{268}$ BgA 40/224.

${ }^{269} \mathrm{BgA} \mathrm{40/44.}$

${ }^{270}$ Der Zusammenhang zwischen sozialstrukturellen Daten und Arbeiterradikalismus ist nachdrücklich von Lucas, Ursachen und Verlauf der Bergarbeiterbewegung, S. 1 ff., herausgestellt worden. Vgl. auch Brüggemeier, Leben vor Ort. Niethammer, Umständliche Erläuterung. Murphy, Gastarbeiter im Deutschen Reich. Crew, Bochum. 
der Betriebsräte variierte nach der Größe des Übertagebetriebes. So waren auf Rheinelbe mit bedeutendem Übertagebetrieb von 14 Arbeiterratsmitgliedern lediglich neun Hauer, während bei der Wittener Zeche lediglich ein Arbeiterratsmitglied (von 12) kein Hauer war. Ein Zusammenhang zwischen politischer Orientierung und beruflicher Stellung im Betrieb ist nicht erkennbar.

Es dauerte lange, bis auf allen Zechen reguläre Betriebsräte ihre Arbeit aufgenommen hatten. ${ }^{271}$ Danach begann erneut ein Kleinkrieg um die betriebliche Regelung der Handlungsmöglichkeiten der neuen Arbeitervertretungen. Die Zechenleitungen nutzten die Tatsache, daß das neue Betriebsrätegesetz die Revierbefahrungen nicht erwähnte, den Aktionsradius der Betriebsräte einzugrenzen. Bei der Phoenix-Bergwerksverwaltung in Gelsenkirchen ging man im Mai 1920 zwar davon aus, daß die Vorschriften der Severing-Verordnung durch das Gesetz nicht außer Kraft gesetzt worden seien, gestattete aber nur noch drei monatliche Revierbefahrungen durch Angehörige des Betriebsausschusses, obwohl die Rechtslage unklar war. ${ }^{272}$ Auch die Gelsenkirchener Zentrale wußte keinen Rat; sie empfahl den Zechen, sich auf jeweils den Passus der Verordnung bzw. des Betriebsrätegesetzes zu beziehen, der für die Zeche der günstigere sei. ${ }^{273}$ Auch bei der GBAG und Deutsch-Lux favorisierte man eine restriktive Handhabung des BRG in dieser Frage. So häuften sich sehr rasch die Klagen, daß die Zechen die neugewählten Betriebsräte an der Arbeit hinderten. Anfang Mai 1920 wurde der Alte Verband beim Reichsarbeitsministerium vorstellig: „Auf einer Anzahl Zechen des Ruhrreviers versuchen die Verwaltungen, den Betriebsräten bei der Ausübung ihrer Tätigkeit Schwierigkeiten zu bereiten, indem sie den Mitgliedern des Betriebsausschusses vorschreiben, wieviel Schichten sie im Monat vergütet bekommen." Auf diese Weise verhindere man ausreichende Revierbefahrungen durch die Betriebsratsmitglieder, wobei man sich auf das Gesetz berufe, nach dem das Betriebsratsamt ehrenamtlich sei. „Als notwendige Versäumnis von Arbeitszeit lassen sie nur die im Gesetz vorgesehenen Fälle gelten“, zu denen aber die Betriebsinspektion nicht gehörte. Dies behindere nicht nur die Arbeit der Räte, sondern "dieses Vorgehen einer Vielzahl von Werksverwaltungen (bedeutet) eine gewaltige Einschränkung der bisherigen Rechte der Betriebsräte im Ruhrrevier.“ Während der Beratungen des Betriebsrätegesetzes habe der Vertreter des preußischen Handelsministers erklärt, eine Einschränkung bisheriger Rechte finde durch das $\mathrm{Ge}$ setz nicht statt. Der Betriebsausschuß könne seiner Arbeit nur nachkommen, wenn er völlig von der Arbeit befreit sei: „Das war auch bereits bei den Betriebsräten früher der Fall.“ Nun würden die Aktionen der Zechenverwaltungen erneut „Erschütterungen im Ruhrkohlenbergbau“ heraufbeschwören, „die für unsere Volkswirtschaft katastrophal wären und unter allen Umständen verhütet werden müssen." Eine Ausführungsverordnung zum Betriebsrätegesetz für den Bergbau wäre daher sehr wünschenswert, zumindest aber ein behördliches Einwirken auf die Zechenverwaltungen, den Betriebsausschüssen jene Schichten zu bezahlen, die

${ }^{271}$ Jahrbuch des Verbandes der Bergarbeiter, 1920, S. $109 \mathrm{f}$.

272 Phoenix-Bergwerksverwaltung an Ver. Hoerder Kohlenwerk, 30. 4. 1920, BgA 41/328.

${ }^{273}$ Phoenix Bergwerksverwaltung an die Zechen, 4. 6. 1920, BgA 41/328. 


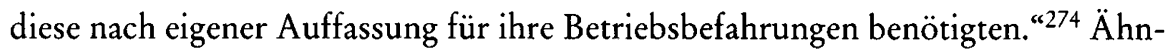
lich argumentierte der Gewerkverein christlicher Bergarbeiter: „Statt, wie die Bergarbeiter gehofft haben, durch das Betriebsrätegesetz eine Erweiterung ihrer Rechte zu erhalten, zeigt sich jetzt, daß versucht wird, wesentliche Verschlechterungen einzuführen." Wenn sie ihre gesetzlichen Aufgaben erfüllen sollen, so bedürften sie einer "größeren Bewegungsfreiheit. Diese Bewegungsfreiheit wird ihnen jetzt verweigert. Die Zechenverwaltungen wollen teilweise nur eine dreimalige Befahrung im Monat zulassen. Teilweise weigern (!) sie jede Befahrung des Betriebes durch die Betriebsräte." Führen die Betriebsvertreter trotzdem ein, würde ihnen die Lohnzahlung für die Ausfallschicht verweigert. Auf diese Weise verhinderten die Zechenverwaltungen, daß die Betriebsräte zu nützlichen Einrichtungen würden: „Sollen die Betriebsräte die Verwaltung unterstützen, zur Hebung der Förderung beitragen, bei Lohn-und Gedingestreitigkeiten mitwirken, die Unfallgefahren bekämpfen, so müssen sie Gelegenheit haben, den Betrieb durch und durch kennenzulernen." Wolle man also den Bergbau vor weiteren schweren Konflikten bewahren, sei eine einschlägige Durchführungsverordnung zwingend. „Eile tut not!”275 Der Reichs- und Staatskommissar für den Bereich des früheren VII. Armeekorps in Münster, Mehlich, bestätigte die Beobachtungen des Alten Verbandes und drang mit einer detaillierten Beschreibung der Erregung im Ruhrgebiet auf eine rasche politische Aktion: „Wie mir berichtet wird, plant die syndikalistische Bergarbeiter-Union die Einberufung einer Betriebsräte-Konferenz, um zu dem Vorgehen der Zechenverwaltungen Stellung zu nehmen. Auch den übrigen Verbänden nahestehende Betriebsräte sind aufs äußerste erregt und ein Vertreter des deutschen Bergarbeiterverbandes [Alter Verband] hat mir heute versichert, daß bestimmt mit einem allgemeinen Streik zu rechnen sei, wenn nicht bald eine Regelung herbeigeführt würde, die eine Kürzung der bisherigen Rechte der Betriebsräte ausschließt." Wenn es schon rechtlich nicht möglich sei, die alte Severing-Verordnung erneut in Kraft zu setzen, „so würde ich bitten“, schrieb Mehlich dem preußischen Handelsminister, „zu erwägen, ob nicht durch eine Übergangsverordnung die bisherigen Rechte der Betriebsräte im Bergbau sichergestellt werden sollen. " 276 Der Reichsarbeitsminister wollte keine Sonderverordnungen für einzelne Industriezweige erlassen. Statt dessen forderte er die Bezirksarbeitsgemeinschaft Bergbau in Essen auf, Grundsätze für die Tätigkeit der Betriebsräte zu verabschieden. Ähnlich äußerte sich der preußische Handelsminister, der die Verabschiedung einer gemeinsamen Geschäftsordnung für alle Betriebsräte der Ruhrzechen schon aus Gründen der wünschenswerten Einheitlichkeit der Verfahren vorschlug. Zwar sei die Festlegung von Geschäftsordnungsregeln Aufgabe der Betriebsausschüsse, doch sei eine gemeinsam in der Arbeitsgemeinschaft verabschiedete Geschäftsordnung geeignet, Streitigkeiten zu verhindern. ${ }^{277}$

${ }^{274}$ Verband der Bergarbeiter Deutschlands an Reichsarbeitsminister, 7. 5. 1920, BAP RAM 400, Bll. 1-2.

${ }^{275}$ Gewerkverein christlicher Bergarbeiter Deutschlands an Reichsarbeitsministerium, 18.5. 1920, BAP RAM 400, Bl. 33.

276 Der Reichs- und Staatskommissar an den Minister für Handel und Gewerbe, 12.5. 1920, BAP RAM 400, Bl. 8.

${ }^{277}$ Minister für Handel und Gewerbe an Bezirksarbeitsgemeinschaft Bergbau/Ruhr, 17. 5. 1920, BAP RAM, Bl. 31. 
Die Verhandlungen in der Bezirksarbeitsgemeinschaft wurden rasch aufgenommen und führten noch im Juni $1920 \mathrm{zu}$ einem ersten Ergebnis, dem die beteiligten Organisationen vorbehaltlich der Zustimmung ihrer Mitgliedschaft das Placet erteilten. ${ }^{278}$ Bei diesem Entwurf hatte sich der Zechenverband durchgesetzt, auch wenn er behauptete, ,in den Richtlinien den Arbeitnehmern auf das äußerste entgegengekommen " zu sein. ${ }^{279}$ Der Erfolg der Zechenvertreter bestand in der Begrenzung der Revierbefahrungen auf drei; die Reviereinteilung blieb zudem Sache der Zechenleitung. Lediglich Reviere mit zwei Steigern galten auch als zwei Reviere und bildeten mithin zwei Fahrabteilungen. Der Betriebsausschuß wurde für eine Schicht pro Woche zur Erledigung der laufenden Arbeiten freigestellt. Sprechstunden sollten während des Schichtwechsels abgehalten werden; das betreffende Betriebsratsmitglied hatte dann das Recht, eine halbe Stunde früher auszufahren. Lohnlisten waren dem Betriebsrat ebenso vorzulegen wie im beschränkten Umfang Gehaltslisten und betriebswirtschaftliche Unterlagen über die Selbstkostenentwicklung, soweit hierdurch keine Betriebsgeheimnisse verletzt wurden. Eine Mitwirkung bei der Gedingefestsetzung wurde verneint. Lediglich im Beschwerdefall war der Betriebsrat hinzuzuziehen, der allerdings bei der Einführung neuer Gedingeformen mitwirken durfte. Bei Straffestsetzungen war die Rolle der Betriebsvertretung auf das Mitwirken beim Erlaß allgemeiner Strafgrundsätze und eine nachherige Einsicht von Straflisten beschränkt. Der Betriebsausschuß hatte schließlich das Recht, ein Mitglied für betriebliche Unfalluntersuchungen zu benennen; die Funktion der Sicherheitsmänner wurde damit nach Auffassung der Arbeitsgemeinschaft überflüssig.

Die Mitgliedschaft und die Betriebsräte des Alten Verbandes lehnten den Entwurf ab. Die Zechenverwaltungen versuchten daraufhin in einer Doppelstrategie, die Richtlinien doch noch durchzusetzen. Der Zechenverband drängte den Reichsarbeitsminister, für eine Verabschiedung des Entwurfes zu sorgen. ${ }^{280} \mathrm{Zu}$ gleich setzten die Zechenverwaltungen die Richtlinien von sich aus einseitig in Kraft. So beschloß der Vorstand der Bergwerksabteilung der Rheinelbe-Union, „daß die Betriebsverwaltung sich ihrerseits an die Richtlinien gebunden erklärt und bei etwaigen Überschreitungen der Richtlinien von den gesetzlichen Mitteln Gebrauch macht, insbesondere von dem Recht der Nichtbezahlung unnötigerweise für Betriebsratszwecke verwendeter Arbeitszeit." Hiervon wollte man auch Reichskommissar Mehlich unverzüglich in Kenntnis setzen. ${ }^{281}$ Ein erneuter Konflikt zeichnete sich ab. Reichskommissar Mehlich griff vermittelnd ein und erreichte, daß die Verbände sich am 10. Juli 1920 endgültig auf einen neuen Entwurf verständigten. ${ }^{282}$ Die Änderungen betrafen lediglich das Befahrungsrecht. Statt drei wurde die Anzahl der monatlichen Revierbefahrungen auf vier erhöht; die Befahrung sollte im Regelfalle mit dem bergpolizeilich verantwortlichen „Beam-

\footnotetext{
${ }^{278}$ Richtlinien vom Juni 1920, BAP RAM 400, Bll.39-43.

${ }^{279}$ Schreiben Zechenverband an Reichsarbeitsministerium, 3.7. 1920, BAP RAM 400, Bl. 37 . Vgl. auch Protokoll der Vorstandssitzung der Bergwerksabteilung, 23. 6. 1920, BgA 55/121.

${ }^{280}$ Schreiben vom 3. 7. 1920, BAP RAM 400, Bll.37f.

281 Protokoll der Sitzung der Bergwerksabteilung der Rheinelbe-Union, 29. 7. 1920, BgA 55/119.

282 Mehlich an den Reichsarbeitsminister, 15. 7. 1920, BAP RAM 400, Bl. 103; Mchlich an den Minister für Handel und Gewerbe, 11. 8. 1920, BAP RAM 400, Bll.109-111.
} 
ten" gemeinsam erfolgen, mußte es aber nicht. ${ }^{283}$ Diese geringfügig revidierten Richtlinien stießen weiterhin auf den Widerstand vieler Betriebsräte, zumal jener, die keiner Tarifgewerkschaft nahestanden. Die Reviereinteilung und die Befahrungsrechte vor Ort blieben umstritten, zumal die Zechenverwaltungen durch das Recht, eigenständig die Größe der Steigerreviere bestimmen zu können, immer noch willkürlich die Befahrungsrechte begrenzen konnten. ${ }^{284}$ Die Proteste brachen daher nicht ab, auch wenn Mehlich sie schließlich für unberechtigt hielt. Mit den Richtlinien, so sein Urteil im Oktober 1920, „hat sich fast ganz allgemein auf den Zechen ein nahezu reibungsloses Zusammenarbeiten der Verwaltungen mit den Betriebsräten herausgebildet. Es ist richtig, daß die Bergarbeiterschaft mit den bestehenden Richtlinien nicht restlos zufrieden ist. Indessen besteht kein Bedürfnis im Augenblick, eine abermalige Änderung der Richtlinien herbeizuführen. "285 $\mathrm{Zu}$ einer Änderung dieser Richtlinien kam es auch später nicht mehr; zum 1.September 1922 wurde lediglich eine redaktionell überarbeitete Fassung in Kraft gesetzt. ${ }^{286}$ Die Tätigkeit der Betriebsräte im Ruhrbergbau war damit verbindlich geregelt. In ähnlichen Verhandlungen wurden 1921 auch neue Arbeitsordnungen durch die Bezirksarbeitsgemeinschaft verabschiedet, die an die Stelle der alten „Kasernenhofordnungen“ traten, allerdings lediglich das Nötigste festlegten. ${ }^{287}$ Die Kommunikationsstrukturen von Zechenleitungen und Betriebsvertretungen wurde auf diese Weise nicht in den Betrieben, sondern durch die Verbände bestimmt. Dabei war klar, daß der Zechenverband für das abmachungskonforme Verhalten der Zechenleitungen eher eine Garantie übernehmen konnte, als die Bergarbeiterverbände für die Tariftreue und die Regelakzeptanz der Belegschaften. Im Prinzip wußten dies auch die Zechenverwaltungen, da die Tarifgewerkschaften bei den Betriebsratswahlen nicht immer und überall Mehrheiten hatten erreichen können. Eine betriebliche Untermauerung der überbetrieblichen Vereinbarungen zur Verbesserung der innerbetrieblichen Kommunikation hätte sich daher unter Umständen durchaus angeboten, unterblieb aber weiterhin. ${ }^{288}$

Damit war die formalisierte betriebliche Kommunikation, wie sie sich am Beispiel der Bochumer Deutsch-Lux-Zeche Dannenbaum ${ }^{289}$ darstellt, etwa folgendermaßen strukturiert. In der Tradition der Arbeiterausschüsse hielt man in der Regel an gemeinsamen, zunächst monatlich, später vierteljährlich stattfindenden Betriebsausschuß- bzw. Betriebsratssitzungen fest. Dort trafen sich der zuständige Grubeninspektor und die Betriebsräte und besprachen Probleme des techni-

${ }^{283}$ Richtlinien sowie Protokollarische Zusätze zu den Richtlinien vom 10.7. 1920, BAP RAM 400, Bll.104-108.

${ }^{284} \mathrm{Vgl}$. den Konflikt beim Hoerder Kohlenwerk/Phoenix-Konzern im Juli und August 1920, BgA $41 / 328$.

${ }^{285}$ Der Reichs- und Staatskommissar an den Reichsarbeitsminister, 1. 10. 1920, BAP RAM 400, Bl. 127.

${ }^{286}$ Zechenverband an Verbandszechen, 17. 8. 1922, BgA 41/328; Fassung der crneuerten Richtlinien in: ThA VSt 72.

${ }^{287}$ Vgl. Arbeitsordnung Zeche Dannenbaum, beschlossen am 11.6. 1921 von Zechenverband und "Viererbande“. Sie umfaßte fünf Abschnitte: Einstellung, Entlassung, Dienstvorschriften, Strafen, Hierarchie, BgA 40/226. Alle Zechen zumindest im Rahmen der späteren Abteilung Bergbau der VSt. hatten die gleichen Arbeitsordnungen, $\mathrm{BgA} 41 / 752$.

${ }^{288}$ Mommsen, Bergarbeiterbewegung an der Ruhr, S. $298 \mathrm{f}$.

2891922 etwa 2500 Beschäftigte, Jahresförderung unter 900000 to, also eine mittclgroße Zeche. 
schen Grubenbetriebes. Die Betriebsräte versuchten, Forderungen und Wünsche der Belegschaft gegenüber der Direktion zu formulieren. Da der Grubeninspektor indes keinerlei Entscheidungsrechte hatte, konnte er die Forderungen des $\mathrm{Be}$ triebsrates nur weiterleiten. ${ }^{290}$ Die Betriebsratsmitglieder führten ihre Befahrungen durch, sprachen mit den Bergleuten und hielten ihre Sprechstunden ab. ${ }^{291}$ Bei konkreten Vorfällen waren die Bergleute laut Arbeitsordnung verpflichtet, sich zunächst an den Steiger und dann an den Grubeninspektor zu wenden. ${ }^{292}$ Eine arbeitsplatznahe Interessenvertretung im Sinne der Vertrauensmänner des Leverkusener Chemiewerkes existierte nicht. Allein schon aufgrund technischer Probleme konnten Betriebsvertreter bei aktuellen Problemen, wenn überhaupt, so nur zufällig "vor Ort“ sein. Die Kommunikationsstruktur der Bergleute blieb auf die Kameradschaft fast monadenhaft beschränkt, wollte man sich nicht direkt an den Vorgesetzten wenden. Die Betriebsvertretung konnte fast immer nur im Nachhinein eingreifen. Aus dieser Situation hätte lediglich die Bereitschaft der Zechenleitungen herausgeholfen, den Betriebsvertretungen Diskussionsforen einzuräumen, in denen auch generell und unter Umständen antizipativ über Probleme der Bergarbeit hätte geredet werden können. Diese Räume aber blieben den Organisationen vorbehalten; die GBAG bemühte sich ihrerseits sogar nachhaltig darum, das Zustandekommen eines Gesamtbetriebsrates, der immerhin auf der Ebene des Vorstandes ein Gesprächspartner hätte sein und also die Vielzahl der Zechen kommunikativ hätte bündeln können, zu verhindern. Einem rechtlich möglichen, freiwilligen Betriebsratszusammenschluß verweigerte die GBAG jedes $\mathrm{Ge}$ spräch. ${ }^{293}$

So war es auch nicht überraschend, daß eine Reaktion auf die Verabschiedung des Betriebsrätegesetzes bei der GBAG in institutioneller Hinsicht nicht erfolgte. ${ }^{294}$ Hausintern wurde zwar über das Gesetz kurz informiert, alle Streit- und offenen Fragen verwies man hingegen an die zuständigen Stellen des Zechenverbandes bzw. seine Unterorganisationen. Typisch für den Umgang mit dem Betriebsrätegesetz war die Frage der Weitergabe von Zahlen an die Betriebsräte in den Quartalsberichten, deren Gestaltung in der Tat ein Problem darstellte. Die GBAG wollte Richtlinien hierzu auf der Basis von Zechenverbands-Vorschlägen erarbeiten. ${ }^{295}$ Die Überlegung, durch eine gemeinsame Diskussion der wirtschaftlichen Verhältnisse der Zechen, das wirtschaftliche „Verständnis“ der Betriebsräte, dessen Fehlen in der Debatte um das Betriebsrätegesetz häufig beklagt worden war, zu erhöhen, wurde aber gar nicht erst angestellt. Stattdessen griff man begierig abschreckende Meldungen auf, die August Heinrichsbauer in seinem

${ }^{290}$ Arbeiterausschuß- bzw. Betriebsratsprotokolle der Schachtanlage Dannenbaum/Bochum BgA 40/ $224,40 / 225$.

291 Phoenix-Bergwerksverwaltung an Zechenverband, 2. 9. 1921, BgA 41/328 mit detaillierter Beschreibung des Betriebsratsalltags.

${ }^{292} \mathrm{BgA} 40 / 226$.

${ }^{293}$ Vorstandsprotokoll der GBAG, 1. 12. 1920, BgA 55/119. Zum vorherigen vgl. Vorstandsprotokoll der GBAG, 14. 5. 1920, BgA 55/119.

${ }^{294}$ Die 1920 eintretenden Organisationsänderungen hatten ausschließlich mit der Bildung der Rheinelbe-Union zu tun. Der Gesamtvorstand der Rheinelbe-Union wurde nunmehr aufgesplittert; es gab in Zukunft eigenständige Bergwerksabteilungssitzungen, auf denen die Arbeit der Schachtanlagen der alten GBAG und von Deutsch-Lux geleitet wurde.

${ }^{295}$ Vorstandsprotokoll der GBAG, 12.8. 1920, BgA 55/119. 
Rheinisch-Westfälischen Wirtschaftsdienst kolportierte. ${ }^{296}$ Im Oktober 1920 wurde dort unter der Überschrift „Betriebsräte, wie sie nicht sein sollen“ an einem Fall aus dem Siegerland den Gewerkschaften vorgeworfen, die Betriebsräte zur Werksspionage zu nutzen. Die Bezirksgruppe Siegerland des Alten Verbands hatte nach Heinrichbauers Informationen die Betriebsräte gebeten, die Organisation jeweils schriftlich über die Quartalsberichte zu informieren. „Auch aus diesem Aufruf geht hervor, daß die Betriebsräte von gewissen Drahtziehern als Organisationen zur geschäftlichen Spionage ausgebaut werden sollen. Gegen solche Bestrebungen, die mit den auch jetzt noch gültigen Anschauungen von Moral und Recht in schärfstem Widerspruch stehen, und die auch sowohl gegen den Sinn wie gegen den Buchstaben des Betriebsrätegesetzes verstoßen, kann nicht entschieden genug Verwahrung eingelegt werden. “297 Als der Betriebsrat der Zeche Dannenbaum in Ergänzung zum mündlichen Quartalsbericht auch um schriftliche Angaben von nichtvertraulichen Zahlen bat, reagierte der zuständige Bergwerksdirektor Fuldner zögerlich und ablehnend. Mit derartigen Angaben, meinte er unter explizitem Hinweis auf Heinrichsbauers Artikel, würde ja doch nur "Agitation“ betrieben. Fuldner wollte deshalb grundsätzlich beim Zechenverband nachfragen, beauftragte aber den Betriebsdirektor Müller, den Dannenbaum-Betriebsrat unter Hinweis auf Heinrichsbauers Artikel abschlägig zu bescheiden. ${ }^{298}$ Ähnlich erging es dem Betriebsrat ver. Hamburg und Franziska. Auch seine Bitte um Zahlen zu Förderung, Versand und Verlusten lehnte der Vorstand der Bergwerksabteilung der Rheinelbe-Union ab. ${ }^{299}$ Man stritt sich faktisch über alles: von der Saalmiete über das Porto bis hin zu der Ausstattung der Betriebsratsbüros und ihre Versorgung mit Büromaterial. Die Betriebsräte suchten dabei auch von sich aus den Konflikt, indem sie weitreichende Ansprüche stellten. Wohlwollen oder auch nur der Versuch, miteinander zu reden, waren selten. Ein Beispiel war der Wunsch der Betriebsvertretung der Zeche ver. Hamburg und Franziska, die Zechenleitung möchte doch für den Betriebsrat das Reichsgesetzblatt bestellen. Bei anderen Zechen, etwa dem Aplerbecker Actien-Verein für Bergbau, würde dies bereits geschehen. Dessen Leitung bestritt derartiges ganz entschieden und fügte in einem Anschreiben an die Zeche ver.Hamburg hinzu: „Auf Wunsch unseres Betriebsrates stellten wir diesem aber für ein Vierteljahr versuchsweise die Deutsche Bergwerkszeitung zur Verfügung. Wie zu erwarten, haben wir dabei die Wahrnehmung gemacht, daß leider der Inhalt rechtsgerichteter Blätter ihn nicht belehrt. “300

Das Kommunikationsklima war, wurde überhaupt miteinander geredet, schlecht. ${ }^{301}$ Dies war unter anderem auch eine Folge der extremen Politisierung der Region durch den Bürgerkrieg, der sich an den Kapp-Putsch angeschlossen hatte. Die März-Revolution zählt dabei bis heute zu den stark umstrittenen Ereig-

${ }^{296} \mathrm{Zu}$ August Heinrichsbauer, insbesondere auch zu seiner späteren Funktion als „Verbindungsmann zwischen Ruhrindustrie und NSDAP" vgl. Turner jr., Die Großunternehmer, S. $171 \mathrm{f}$.

${ }^{297}$ Rheinisch-Westfälischer Wirtschaftsdienst, 7. 10. 1920, BgA 40/224.

${ }^{298}$ Aktennotiz Fuldner, 9. 10. 1920, BgA 40/224.

${ }^{299}$ Vorstandsprotokoll, 4. 1. 1921, BgA 55/121.

300 24. 11. 1821, BgA 40/44.

${ }^{301}$ Ein Indiz hierfür war auch die Überhäufung der Bergrevierbeamten mit Streitfragen aus dem Betriebsrätegesetz, z. B. Bergrevier Essen III an Oberbergamt, 8. 3. 1921, StAM OBAD 372, Bl. 89f. 
nissen. Eindeutig ist ohne Frage die Tatsache, daß die Wochen zwischen dem 15. März und dem 7. April 1920 für das Ruhrgebiet einen tiefen politisch-moralischen Einschnitt brachten, der nicht mehr zu kitten war. Für die einen ein Aufstand des "roten Mobs“, der brandschatzte, plünderte, die Ordnung in Frage stellte und die lebenswichtige Kohlenförderung lahmlegte ${ }^{302}$, war es für andere Beobachter der Überlebenskampf des Ruhrgebietsproletariates gegen Staat, Zechenbesitzer und Militär, die schließlich den Märzaufstand im Blutbad des „Weißen Terrors “ ertränkten. ${ }^{303}$ Zwischen diesen Positionen war eine Verständigung nicht möglich. Gleichwohl saßen sich Exponenten beider Seiten in den Betriebsräten gegenüber; man hielt die jeweilige Gegenseite daher nicht nur für einen betrieblichen Konfliktpartner, sondern zugleich für einen politischen und militärischen Feind. ${ }^{304}$

\section{„Mitbestimmungsalltag“ 1920 bis 1922}

Für die je aktuellen Forderungen der Belegschaften wie für die Politik der Werksleitungen waren Konjunktur- und Inflationsverlauf entscheidend. Die Position der Bergleute verbesserte sich dabei 1920 kontinuierlich. Während die Hauerschichtlöhne zum Jahresende 1919 real nur etwa drei Viertel des Niveaus von 1913 betragen hatten, lagen sie Ende des Jahres bei etwa 95\% des Vorkriegsstandes. ${ }^{305}$ Die Schichtleistungen der Untertagebelegschaften lagen mit 806 Kilogramm aber immer noch deutlich unter dem Niveau von 1913, als sie 1161 Kilogramm betragen hatten. Selbst 1918 waren die Leistungen mit 1068 deutlich höher. ${ }^{306}$ Nur durch Ausdehnung der Belegschaften (Belegschaftsstand an der Ruhr 1919: 400000, 1920: 470000) gelang es gegenüber 1919, als die Gesamtförderung des Ruhrgebietes bei 71 Millionen Tonnen gelegen hatte, zu einer Fördersteigerung von etwa 17 Millionen Tonnen zu kommen. Damit blieb man freilich immer noch um mehr als $20 \%$ unter dem Vorkriegsstand. ${ }^{307}$ Die Zahl der verfahrenen Schichten je Bergmann war gegenüber 1919 noch einmal leicht zurückgegangen; da jedoch die Leistung langsam wieder anstieg, u.a. auch wegen einer Verlängerung der Schichtzeiten durch Überstunden, konnte der Schichtenausfall kompensiert werden. ${ }^{308}$ Die betriebswirtschaftlichen Kennziffern der Bergbauunternehmen gerieten durch diese Entwicklung nur deshalb nicht in eine katastrophale Lage, da wegen der Inflation und der Bereitschaft von Zechenverband und Gewerkschaften, im Reichskohlenrat kräftig die Preise zu erhöhen, der Umsatz stärker expandierte als die Kosten. Die entscheidende Liquiditätskennziffer des Bergbaus (Verhältnis Lohnsumme/Umsatz) entwickelte sich 1920 wegen der preisinduzierten Umsatzexplosion sogar ausgesprochen günstig. ${ }^{309}$ Faktisch wurden die Zechen über die Preise subventioniert und ein Teil dieser Subvention wurde in Form von

\footnotetext{
302 Diese Darstellung bei Spethmann, Zwölf Jahre Ruhrbergbau, Bd. II, S. 74-275.

303 Vgl. Lucas, März-Revolution 1920.

304 Diese Aussagen betreffen nicht das Verhältnis der Tarifparteien zueinander.

${ }^{305}$ Vgl. die Angaben bei Abelshauser, Himmelmann, Revolution in Rheinland und Westfalen, S. 180.

306 Wiel, Wirtschaftsgeschichte des Ruhrgebietes, S. 137.

307 Ebenda, S. 131.

308 Zahlen hicrzu nach Günter Hegermann, Dic Entwicklung des Montansektors, Ms., Bochum 1991, Zahlentafel 1.

${ }^{309}$ Ebenda, Zahlentafel 2.
} 
Lohnerhöhungen an die Bergleute weitergegeben. Ein Ende der Subventionierung, ja nur ein langsameres Steigen der Kohlenpreise mußte die verzerrten Kostenstrukturen aufdecken und damit zu massiven Verteilungskonflikten im Ruhrbergbau führen. ${ }^{310}$

Angesichts großer Kohlennachfrage hatten die Bergwerke schon 1919 ein starkes Interesse an einer Ausdehnung der Schichtarbeitszeit, um die günstige Kohlenkonjunktur ausnutzen zu können. Das Plädoyer für die Schichtzeitverlängerung folgte dabei, so Tschirbs, dem doppelten Interesse an Leistungssteigerungen und Arbeitszeitverlängerungen an sich. ${ }^{311}$ Der in Deutschland allerorten zu spürende Energiemangel schuf für die Forderungen nach Überschichten ein günstiges öffentliches Klima, dem sich selbst die Tarifgewerkschaften nicht entziehen konnten. ${ }^{312}$ Vor diesem Hintergrund kam es zunächst zur Verordnung Severings vom 2. Februar 1920, "nach der aus Gründen des allgemeinen Wohls die einzelnen $\mathrm{Ze}$ chen zusammen mit den Betriebsräten ein Übereinkommen über die Einlegung von Überstunden oder Überschichten herbeizuführen hatten. ${ }^{\text {"313 }}$ Am 18. Februar 1920 wurde schließlich ein förmliches Überschichtenabkommen zwischen Zechenverband und Tarifgewerkschaften geschlossen, nach dem zusätzlich zur normalen Siebenstundenschicht zweimal pro Woche je eine halbe Überschicht zu arbeiten war. Den Bergarbeitern wurden hierfür Lohnzugeständnisse in Form von Überarbeitszuschlägen und zusätzlichen Lebensmittellieferungen gemacht. ${ }^{314} \mathrm{Bis}$ 1922 wurde dieses Überschichtenabkommen beibehalten, wodurch zur tariflichen Arbeitszeit von sieben Stunden stets unterschiedliche Überarbeitsverpflichtungen hinzutraten. Für ihre Bereitschaft zur Mehrarbeit erhielten die Bergarbeiter jeweils erhebliche materielle Gratifikationen. ${ }^{315}$ Zahlreiche Bergarbeiter waren zunächst zum Ableisten der Mehrarbeit bereit. ${ }^{316}$ Im Sommer 1920 ging angesichts gravierender Versorgungsprobleme diese Bereitschaft zurück. Die schlechte physische Verfassung vieler Bergleute war Wasser auf die Mühlen von Unionisten und Syndikalisten, die seit Jahresbeginn ihre Agitation für die Einführung der Sechsstundenschicht verschärft hatten. ${ }^{317}$ Ihr konsequentes Eintreten für Arbeitszeitverkürzungen und Lohnerhöhungen dürfte auch ihre Wahlerfolge auf Kosten der Tarifgewerkschaften gerade auf den Großzechen, wo der Leistungs- und Förderdruck am stärksten war, bedingt haben.

Damit sind wesentliche Rahmenbedingungen alltäglicher Betriebsratsarbeit skizziert, die am Beispiel des Betriebsrates der Zeche Dannenbaum in BochumLaer im einzelnen betrachtet werden soll. Der Betriebsrat hatte den letzten größeren Konflikt mit der Zechenleitung wegen des Tarifvertrages im November 1919 ausgefochten. Er hatte sich dabei zum Sprachrohr der mit dem Manteltarif unzufriedenen Belegschaft gemacht, letztlich aber nichts erreicht. Anfang 1920 setzte sich das beim Tarifkonflikt gezeigte Spiel weiter fort. Der Betriebsrat vertrat un-

${ }^{310}$ Zum Mechanismus dieser Politik ausführlich Tschirbs, Tarifpolitik im Ruhrbergbau, S. 50 ff.

311 Tschirbs, Tarifpolitik im Ruhrbergbau, S. 95.

${ }^{312}$ Ebenda, S. 93.

${ }^{313}$ Ebenda, S. 96.

${ }^{314}$ Feldman, Arbeitskonflikte im Ruhrbergbau, in: VfZ 28 (1980), S. 168-223, S. $190 \mathrm{f}$.

315 Tschirbs, Tarifpolitik im Ruhrbergbau, S. 104.

${ }^{316}$ Feldman, Arbeitskonflikte im Ruhrbergbau, S. 187. Zum folgenden ebenda, S. 195.

317 Vgl. Spethmann, Zwölf Jahre Ruhrbergbau, Bd. II, S. 51 ff. 
gefiltert die zum Teil weitgehenden Belegschaftsforderungen. Diese hatte sich am 11. Januar 1920 zu einer Versammlung getroffen und dabei folgende Forderungen an die Zechenleitung beschlossen: Zunächst verlangte man die Einführung der Sechsstundenschicht. Für Überstunden unter der Woche solle ein Zuschlag von $50 \%$, an Sonn- und Feiertagen 100\%, an den hohen Festtagen schließlich 150\% gezahlt werden. Der Grundlohn sei von 14,- auf 30,- Mark mehr als zu verdoppeln. Die Schichtlöhner über Tage müßten mindestens 16,- Mark erhalten. Ebenfalls wurde ein Kindergeld in Höhe von 1,- Mark sowie eine Teuerungszulage verlangt. Hiermit nicht genug forderte die Belegschaft auch die sofortige Beseitigung der Arbeitsordnung: „Die Belegschaft ist der Ansicht, daß die einseitigen Bestimmungen, welche in der Arbeitsordnung enthalten sind, nur Verärgerungen unter der Arbeiterschaft erzeugen und in die heutige Zeit nicht mehr hineinpassen. “"318 Die Direktion verweigerte zu diesen Forderungen jedes Gespräch; man könne dazu gar nicht Stellung nehmen, da man an den Tarifvertrag gebunden sei. Auch eine einseitige Aufkündigung der Arbeitsordnung sei nicht angängig. Man empfahl dem Betriebsrat, die Wünsche und Anregungen den Gewerkschaften vorzulegen. Die Arbeiterorganisationen könnten diese Positionen ja in die nächsten Tarifverhandlungen einbringen. ${ }^{319}$ In der Frage der Mehrarbeit lehnte der Dannenbaum-Betriebsrat Überstunden ab und war lediglich bereit, Überschichten am Sonnabend einzuräumen. An der ersten dieser Überschichten beteiligten sich allerdings nur oder - je nach Standpunkt - immerhin $54 \%$ der Belegschaft. ${ }^{320}$ Die Betriebsratssitzung Anfang März 1920 verlief trotz der Belegschaftsforderungen ausgesprochen ruhig, obwohl Ende Februar eine Betriebsräte-Konferenz der Freien Arbeiter-Union stattgefunden hatte und der verschärfte Kampf gegen die Überschichten aufgenommen worden war. ${ }^{321}$ Die Sitzung stand ganz im Zeichen des beginnenden Frühjahres. Der Betriebsrat wünschte Ammoniak-Lieferungen als Düngemittel, brachte Probleme der „Lampenwirtschaft" zur Sprache und verlangte schließlich eine Heraufsetzung jener Pauschale von 30,- auf 50,- Mark, die die Zeche Dannenbaum freiwillig für die außerhalb der Arbeitszeit liegende Betriebsratstätigkeit zahlte. ${ }^{322}$ Die Agitation gegen die Überschichten und die schleichende Arbeitszeitverlängerung war zwar bei der Belegschaft der DannenbaumSchächte nicht ohne jeden Erfolg, doch war man vor dem Kapp-Putsch zu betrieblichen Verabredungen, die einigermaßen funktionierten, durchaus in der Lage. Dies hing fraglos auch mit der Stimmung der Bergarbeiterschaft der Zeche zusammen, die noch nach dem Kapp-Putsch mit großer Mehrheit einen tarifgewerkschaftlichen Betriebsrat wählte.

Dessen erste Sitzung fand am 21. April 1920 statt. Hauptpunkte waren die Überarbeit, die Rechte des Betriebsrates, die Folgen des Ruhrkampfes und der Organisationszwang. ${ }^{323}$ Der Betriebsrat gestand nicht nur die zwei dreieinhalbstündigen Schichtverlängerungen pro Woche zu, sondern schlug zusätzliche

\footnotetext{
${ }^{318}$ Resolution der Belegschaftsversammlung vom 11.1. 1920, vom Betriebsrat an die Direktion weitergereicht am 12.1.1920, BgA 40/224.

${ }^{319}$ Zechenleitung an Betriebsrat, 20.1.1920, BgA 40/224.

320 Notiz Betriebsinspektor Mehring, 11.2. 1920, BgA 40/224.

${ }^{321}$ Spethmann, Zwölf Jahre Ruhrbergbau, S. $71 \mathrm{f}$.

322 Protokoll der Betriebsratssitzung, 6. 3. 1920, BgA 40/224.

${ }^{323}$ Protokoll der Sitzung, BgA 40/224.
} 
Sonnabendschichten vor, verlangte dafür aber insgesamt $100 \%$ ige Zuschläge, was zumindest für die Überschicht von der Zechenleitung nicht bewilligt wurde, so daß man den Betriebsratsvorschlag ablehnte. ${ }^{324}$ In den anderen Punkten erzielte man lediglich dahin Einigkeit, daß die Befahrung der Steigerreviere wie bisher erfolgen sollte. Auch sollten wegen des Märzkrieges flüchtige Bergleute wieder eingestellt werden, wenn sie keine „ehrenrührigen“ Handlungen begangen hätten. Übereinstimmung herrschte auch in dem Ansinnen, die weibliche Beschäftigung in den Nebenbetrieben abzubauen. Die Forderung des Betriebsrates, in Zukunft nur noch Gewerkschaftsmitglieder einzustellen und nichtorganisierte Bergleute nicht in den Genuß des Tarifvertrages kommen zu lassen, wies der Grubeninspektor Mehring zurück. Die Direktion machte ihm hierin wenige Tage später noch einmal den Rücken stark; Organisationszwang widerspreche dem Betriebsrätegesetz und sei ganz entschieden abzulehnen. ${ }^{325}$

Die Forderungen des Betriebsrates zeigten, daß er weiterhin ein Sprachrohr der Belegschaft sein würde, ähnlich wie der Grubeninspektor Mehring auf der anderen Seite nichts weiter als das Sprachrohr der Direktion war. Im strengen Sinne erfüllten Grubeninspektor und Betriebsausschuß Briefträgerfunktionen zwischen Direktion und Belegschaft, zwei Polen also, die nicht direkt miteinander kommunizieren wollten, dafür aber unter Umständen immer zu direkten Aktionen bereit waren. Als der Betriebsrat das Scheitern seines Überschichtenmodells bekanntgab, beschloß eine Belegschaftsversammlung postwendend solange keine Überstunden mehr zu machen, bis das Betriebsrats-Modell akzeptiert sei. Einwände des Grubeninspektors, die Forderung nach $100 \%$ iger Überschichtzulage verstoße gegen den Tarif, nahm man dabei offensichtlich kaum zur Kenntnis. ${ }^{326}$ Die Überarbeit kam damit zum Erliegen. Stattdessen herrschte Kleinkrieg. Der Betriebsrat beantragte ohne Rücksprache mit dem Grubeninspektor beim Oberbergamt eine Untersuchung der Unfallgefahren auf der Zeche, die daraufhin vom Oberbergamt verlangte, in ähnlichen Fällen zunächst gehört zu werden. ${ }^{327}$ Zugleich häuften sich die Klagen des Grubeninspektors Mehring über das Auftreten der Betriebsvertretung. Mitte Mai 1920 meldete er der Direktion, daß der Obmann des Betriebsrates sich "mehrerer Eingriffe in die Betriebsleitung schuldig“ gemacht habe. Er mache Aushänge ohne Wissen und Zustimmung der Zechenleitung; auch kommentiere er Aushänge der Zechenleitung. Der letzte Schichtenplan sei mit einem ablehnenden Vermerk versehen worden. Mehring habe das sofort entfernen lassen, zumal es sich um eine Eigenmächtigkeit des Obmannes ohne vorherigen Betriebsratsbeschluß gehandelt habe. Er bat die Direktion, den Betriebsrat zur Unterlassung derartiger Handlungen aufzufordern. Ihm müsse klar gemacht werden, daß nach dem Gesetz beide Seiten Forderungen zu unterlassen hätten, die das Betriebswohl störten. ${ }^{328}$

Mitte Juni 1920 legte der Dannenbaum-Betriebsrat eine lange Liste von Punkten vor, die er mit der Zechenleitung zu besprechen wünschte. ${ }^{329}$ An der Betriebs-

\footnotetext{
${ }^{324}$ Notiz Grubeninspektor Mehring, 27. 4. 1920, BgA 40/224.

${ }^{325}$ Knepper an Mehring, 28. 4. 1920, BgA 40/224.

326 Notizen Mehrings vom 3. und 4. 5. 1920, BgA 40/224.

327 Notiz Mehring, 6. 5. 1920; Schreiben Direktion, 12. 5. 1920, BgA 40/224.

${ }^{328}$ Mehring an Direktion, 17. 5. 1920, BgA 40/224.

${ }^{329}$ Aufforderung zur Einberufung einer Betriebsratssitzung, 17.6. 1920, BgA 40/224.
} 
ratssitzung am 23. Juni 1920 nahm mit Bergwerksdirektor Fuldner diesmal auch das zuständige Direktoriumsmitglied der Deutsch-Lux-Bergwerksverwaltung teil. ${ }^{330}$ Am Sitzungsverlauf änderte sich dadurch nichts. Die Direktion gestand zu, wozu sie das Gesetz verpflichtete, und lehnte alle anderen Wünsche des Betriebsrates ab. So war man bereit, die Lohnlisten und die täglichen Betriebsberichte vorzulegen, verweigerte aber die Bezahlung eines Raumes für die Belegschaftsversammlung und bot statt dessen - wie es der Zechenverband generell empfohlen hatte - Betriebsräume an, die der Betriebsrat nicht akzeptierte. Er wollte deswegen ebenso den Schlichtungsausschuß anrufen wie wegen des Lohnabzuges anläßlich einer außerordentlichen Betriebsratssitzung. Auch hier handelte Fuldner entsprechend der Empfehlungen des Zechenverbandes, der parallel in den Verhandlungen um die Richtlinien für die Betriebsratstätigkeit im Bergbau immer wieder die Ehrenamtlichkeit des Betriebsratsamtes hervorstrich. Daß ein Teil der Tätigkeit notwendigerweise in die Arbeitszeit fiel und auch nur dann erledigt werden konnte, war nur akzeptiert, wenn es wie etwa bei der Lebensmittelbeschaffung und -verteilung der Zeche direkt nutzte.

So entstand auch auf dieser Sitzung kaum gegenseitiges Vertrauen. Im Gegenteil wurden Vorurteile verfestigt. Hierzu trug paradoxerweise ein Zugeständnis Fuldners bei. Er erklärte sich bereit, den Betriebsrat, der gebeten hatte, Mieterhöhungen für die Koloniehäuser erst nach der Entscheidung des Mieteinigungsamtes vom Lohn abzuhalten, an der Wohnungsbewertung zu beteiligen und diese nicht allein durch den Kolonieverwalter vornehmen zu lassen. ${ }^{331}$ Auf der nächsten Betriebsratssitzung Anfang August 1920 beklagte sich der Betriebsratsobmann, daß man in der Wohnungsfrage nicht zugezogen worden sei, was Fuldner für ein Mißverständnis erklärte, woraufhin man sich auf ein gemeinsames Wohnungsinspektionsverfahren einigte. ${ }^{332}$ Anders als der Betriebsrat, der zumindest nach den ersten Zusagen damit auch eine Mitbestimmung bei der Mietpreishöhe verband, bestritt die Direktion vor dem Mieteinigungsamt der Betriebsvertretung aber alle Rechte, was in der Belegschaft erhebliche Unruhe auslöste. Auf einer eigens zur Lösung dieser Frage angesetzten Sitzung machte die Direktion erst unter massiven Streikandrohungen für den Fall, daß die Mieterhöhungen ohne weiteres von den Löhnen abgezogen würden, gewisse Zugeständnisse. Einige Mieter sollten noch einmal stellvertretend das Einigungsamt anrufen; Reparaturen würden in Zukunft schneller ausgeführt. Schließlich erhielt in der Wohnungsfrage der Betriebsrat einen direkten Zugang zur zuständigen Verwaltungsabteilung. ${ }^{333}$

Ansonsten standen im Dannenbaum-Betriebsrat im Sommer 1920 Fragen im Vordergrund, die sich auf die Dauer der Lohnzahlung - die Bergleute mußten bis zu zwei Stunden warten - oder Probleme bei der Materialausgabe bezogen, Punkte, für die der Grubeninspektor zumindest zu einem großen Teil zuständig war. Das Verhältnis zwischen Mehring und dem Betriebsrat war von Anfang an schlecht; am 1. September 1920 weigerte sich der Betriebsrat endgültig und ein-

\footnotetext{
${ }^{330}$ Betriebsratssitzung, 23.6. 1920, BgA 40/224.

331 Betriebsratssitzung, 23.6. 1920, BgA 40/224.

332 Betriebsratssitzung, 5. 8. 1920, BgA 40/224.

${ }^{333}$ Notiz über Treffen, 18. 8. 1920, BgA 40/224.
} 
stimmig, weiterhin mit Mehring zu verhandeln, woraufhin sich auch der ebenfalls anwesende Bergwerksdirektor Fuldner von der Sitzung zurückzog. ${ }^{334}$ Im übrigen war es auf der Zeche wie im gesamten Ruhrgebiet in diesem Sommer ruhig. Die Einführung des Lohnabzuges von der Steuer wollten die Unionisten zwar zu einer größeren Kampagne nutzen ${ }^{335}$, doch faßte die Lohnsteuerbewegung, die ja etwa bei Daimler-Benz oder in der Großchemie größere Streikaktionen, Aussperrungen, in Untertürckheim gar bürgerkriegsähnliche Szenen nach sich zog, im Ruhrbergbau kaum Fuß. Der GBAG-Vorstand verzeichnete lediglich die Forderung eines Betriebsrates nach Einstellung des Steuerabzuges und Rückzahlung der einbehaltenen Beträge, was er unter Hinweis auf die gesetzliche Lage ablehnte. ${ }^{336}$

Trotz dieser Ruhe blieb das Verhältnis, zumal nach dem folgenlosen Konflikt um Grubeninspektor Mehring, frostig. Im Oktober 1920 schloß sich die bereits geschilderte Auseinandersetzung um die Überlassung schriftlicher Zahlen an, die die Direktion ablehnte. Ende des Monats verlangte der Betriebsrat die Neueinstellung von Arbeitern und die Errichtung eines Ledigenheimes; dann müßten auch keinerlei Unternehmerarbeiter mehr auf der Zeche beschäftigt werden. Die Novembersitzung war völlig belanglos. Im Februar 1921 traf man sich dann endlich wieder im größeren Kreise mit Bergwerksdirektor Fuldner, Betriebsdirektor Müller und Grubeninspektor Mehring. Auf Seiten der Belegschaft konstituierte sich mit dieser Sitzung auch der neue Betriebsrat, von dessen 12 Mitgliedern nunmehr nur noch sechs den freien Gewerkschaften, zwei der Christlichen Gewerkschaft und einer der Polnischen Vereinigung angehörten. Statt bisher einem Mandat hatte die Union nunmehr drei, womit sich eine freilich noch moderate Linksverschiebung in der Belegschaftsvertretung ergeben hatte. ${ }^{337}$ Dies lag ungefähr im Trend. Reichsweit hatten die freien Gewerkschaften 1921 67\% der Mandate (1920 $68,6 \%$ ) und damit nur leichte Verluste hinnehmen müssen. Ähnlich sah es bei den christlichen Organisationen aus. Die Union konnte nur geringe Zuwächse feiern. ${ }^{338}$ Die Behauptung der freigewerkschaftlichen Position mochte dabei auch damit zusammenhängen, daß namentlich der Alte Verband die Wahlen sehr ernst und auf die Auswahl der Kandidaten direkt Einfluß genommen hatte. ${ }^{339} \mathrm{Im}$ Ruhrbergbau mußten die freien Gewerkschaften allerdings trotz dieser Bemühungen Verluste von etwa 4\% der Stimmen (Anteil 41,2\%) hinnehmen, die der Union und den Syndikalisten zu gute kamen, die es zusammen auf $30,7 \%$ der Stimmen brachten. Auf Rheinelbe konnten die freien Gewerkschafter der Union indes den Rang ablaufen. Die Tarifgewerkschaften hatten hier jetzt eine Mehrheit von neun Mandaten gegenüber sieben von Arbeiterunion und Syndikalisten. ${ }^{340}$

\footnotetext{
${ }^{334}$ Protokoll der Betriebsratssitzung, 1. 9. 1920, BgA 40/224.

335 Spethmann, Zwölf Jahre Ruhrbergbau, Bd. II, S. $276 \mathrm{f}$.

${ }^{336}$ Vorstandsprotokoll der GBAG, 12. 8. 1920, BgA 55/119.

${ }^{337} \mathrm{BgA}$ 40/224. Im Arbeiterrat war das Verhältnis folgendermaßen: 7 Alter Verband, 3 „Christen“, 3 Union, 1 Pole.

${ }^{338}$ Jahrbuch des Bergarbeiterverbandes 1921, S. 68, 1931, S. $326 \mathrm{f}$.

339 Jahrbuch des Bergarbeiterverbandes 1921, S. 67: „Die Betriebsräte sind Funktionäre der Gewerkschaften. Die Organisation leitet somit die Auswahl und nimmt die Aufstellung der Kandidaten vor."

${ }^{340}$ Martiny, Arbeiterbewegung an Rhein und Ruhr, S. 252.
} 
Auf Dannenbaum jedenfalls gab es weiterhin eine tarifgewerkschaftliche Mehrheit. Direktor Fuldner hielt zur Eröffnung der Sitzung eine kurze Ansprache. „Er begrüßt die neu gewählten Betriebsratsmitglieder und spricht die Hoffnung aus, daß auch in Zukunft ein gedeihliches Zusammenarbeiten möglich sein wird. Ferner bittet er zu erwägen, ob ein wechselseitiger Vorsitz in den Sitzungen nicht eingeführt werden könnte. ${ }^{\text {“311 }}$ Der Betriebsrat wich aus, wurde aber in einigen anderen Punkten sehr schnell energisch. Die Zechenleitung hatte nicht nur den Quartalsbericht für das letzte Quartal 1920 bisher nicht erstattet, sie zögerte auch die Beantwortung von offiziellen Anfragen hinaus bzw. beschied sie im persönlichen Gespräch mit Betriebsausschußmitgliedern mündlich. Der Betriebsausschuß hatte aber bereits mehrfach um rasche und schriftliche Entscheidungen gebeten. Während Fuldner hier Zugeständnisse machte und auch den Quartalsbericht auf der nächsten Sitzung nachholen wollte ("keine böswillige Verzögerungsabsicht"), lehnte er eine Einsicht in die Steigerjournale strikt ab. Der Betriebsrat hatte argumentiert, es gäbe Scheingedinge und wollte dies überprüfen. Anstatt aber dem Betriebsrat entgegenzukommen und sich klar zu der Frage einer unterstellten künstlich herbeigeführten Akkordanhebung zu äußern, verweigerte die Direktion das Gespräch. Auch ansonsten hatte sich nicht viel geändert. Die Zechenleitung war zu materiellen Zugeständnissen an die Belegschaft nicht bereit. Man lehnte die verbilligte Abgabe von Ammoniak ebenso ab wie eine allgemeine Unterstützung von Familien mit gerade schulentlassenen Kindern. Ausgefallene Pflichtüberschichten wurden nicht bezahlt, einen verschließbaren Kasten für Aushänge könne der Betriebsrat nur bekommen, wenn er alle Aushänge vorher abzeichnen lasse und der Betriebsdirektor den Schlüssel erhalte. Entgegenkommen wurde lediglich bei der Forderung signalisiert, den Betriebsrat bei Geldstrafenverhängungen, die bisher einseitig durch die Zechenleitung erfolgten, hinzuziehen. ${ }^{342}$

Die schlechte Stimmung auf den Dannenbaum-Schächten war kein Sonderfall. Die Kleinlichkeit der Zechenleitung war eine Folge der Empfehlungen des Zechenverbandes. Es war zweifellos auch ein Ergebnis der Anfang 1921 sich verschärfenden politischen Auseinandersetzung im Bergbau. Ähnlich wie in Leverkusen versuchten auch im Ruhrgebiet die Kommunisten, vor allem nachdem die Unruhen in Mitteldeutschland ausgebrochen waren, Bewegungen zur Verteidigung des Achtstundentages, schließlich einen Generalstreik herbeizuführen. ${ }^{343}$ Dies führte auf der Schachtanlage Alma zu schweren Konflikten, da Betriebsratsmitglieder die Bergleute zur Ausfahrt zwingen wollten. Da aber keine Resonanz hierauf erfolgte, gelang es Polizei und Zechenleitung rasch, die Bewegung in den Griff zu bekommen. Den Betriebsratsvorsitzenden und zwei weitere Betriebsratsmitglieder kostete dieser Vorfall allerdings Amt und Arbeit. ${ }^{344}$ Die Zechenleitung ging entschieden vor. Der Bergwerksvorstand der Rheinelbe-Union beschloß am 30. März 1921: „Vorstand hält energische Strafmaßnahmen für geboten ohne Rücksicht auf etwa daraus entstehende neue Unruhen in der Belegschaft Alma und stimmt dem von Herrn Hueck beabsichtigten Vorgehen [Entlassungen]

\footnotetext{
${ }^{341}$ Protokoll der Betriebsratssitzung, 28. 2. 1921, BgA 40/224.

${ }^{3+2}$ Protokoll der Betriebsratssitzung, 28. 2. 1921, BgA 40/224.

${ }^{343}$ Winkler, Von der Revolution zur Stabilisierung, S. $514 \mathrm{ff}$.

${ }^{3+4}$ Spethmann, Zwölf Jahre Ruhrbergbau, Bd. II, S. 295.
} 
zu. “345 Auf Dannenbaum spielten politischen Fragen keine vergleichbare Rolle. Es wurde hier klar, daß die Zechenleitungen auch keine unpolitischen Betriebsräte wünschten. Als der Betriebsrat der Dannenbaumschächte am 9. April 1921 um Beschaffung von Stempel, Briefpapier und Schreibmaschine bat, wies die Direktion den Betriebsdirektor an, das Gesuch abzulehnen: „Die Benutzung eines Stempels sowie von Briefpapier mit Kopfdruck ist kein notwendiges Geschäftsbedürfnis, sondern eine überflüssige Ausgabe, die die Verwaltung nicht zu übernehmen beabsichtigt. Wenn der Betriebsrat Wert auf diese Äußerlichkeiten legt, hat er Gelegenheit, hierzu die monatliche Aufwandsentschädigung für den Betriebsrat zu verwenden. Die Beschaffung einer Schreibmaschine für die Schachtanlage

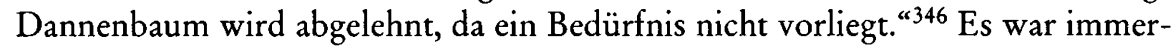
hin die Direktion der Gruppe Bochum der Zechen der Rheinelbe-Union, die sich mit derartigen Fragen selbst befaßte und dies keineswegs dem Betriebsdirektor oder Grubeninspektor überließ. Der Bergwerksvorstand der Rheinelbe-Union, immerhin des mit Abstand größten Kohlenunternehmens des Ruhrgebietes, der zugleich die Gelsenkirchener Zechen mitbetreute, wollte den Bochumer Kollegen von ehemals Deutsch-Lux nicht nachstehen und beschäftigte sich u.a. mit Fragen, ob den Betriebsräten Thermometer zur Messung der Grubentemperatur zur Verfügung gestellt werden konnten, was man selbstverständlich abschlägig beschied. ${ }^{347}$ Zechenverband und einzelne Zechen lehnten die Betriebsräte grundsätzlich ab. Die aus der Politisierung resultierenden Zwischenfälle wie auf Alma, die bei den Bergarbeiterbewegungen im übrigen stets das Ende und nie den Anfang eines Eskalationsprozesses bildeten, waren in gewisser Weise sogar ein dankbarer, nicht selten selbstprovozierter Anlaß, um das, was man ohnehin von den Betriebsräten dachte, nun auch praktisch bewiesen zu sehen. ${ }^{348}$ In dieses Bild zum Teil bewußter politischer Provokationen durch die Zechenleitungen paßte auch ein kleiner Vorfall auf den Zollern-Schächten im Juni 1921. Als Reaktion auf ein Herner Grubenunglück (Mont Cenis) wurde die Zeche zum Ausdruck der Trauer beflaggt - bezeichnenderweise allerdings mit der schwarz-weiß-roten Fahne, was die Belegschaft zu einem eintägigen Streik veranlaßte. ${ }^{349}$

Das Grubenunglück auf Mont Cenis brachte einen weiteren Entfremdungsschub zwischen Zechenleitungen, Bergrevierbeamten und Betriebsräten. Im PreuBischen Landtag und im Reichstag wurde in Interpellationen von Seiten der MSPD und der USPD nachdrücklich darauf hingewiesen, daß die Behinderung der Tätigkeit der Betriebsräte durch die Zechenleitungen und ihre Nichtbeachtung durch die Bergbehörden die Unfallgefahr im Bergbau erhöhe. Der Preußische Handelsminister hatte seine nachgeordneten Behörden zwar bereits mehrfach, zuletzt durch eine Anordnung vom Januar 1921, zu einer engeren Zusammenarbeit mit den Betriebsräten aufgefordert, doch hatten die verschiedenen Anordnungen in den Augen von Gewerkschaften und Arbeiterparteien wenig Er-

\footnotetext{
${ }^{345}$ Protokoll des engeren Bergwerksvorstandes der Rheinelbe-Union, 30. 3. 1921, BgA 55/121.

${ }^{3+6}$ Direktion an Betriebsdirektor, 23. 4. 1921, BgA 40/225.

${ }^{3+7}$ 2. 2. $1922, \mathrm{BgA} 55 / 122$.

${ }^{3+8}$ Prototypisch hierfür der Artikel „Erfahrungen mit dem Betriebsrätegesetz“, in: Deutsche Bergwerkszeitung, Nr. 166, 19.7. 1921.

${ }^{349}$ Spethmann, Zwölf Jahre Ruhrbergbau, Bd. II, S. 305.
} 
gebnisse gebracht. Anfang Juli 1921 verlangte unter dem Eindruck der Parlamentsdebatten der Handelsminister daher ultimativ von den Oberen Bergbehörden, die Zusammenarbeit mit den Betriebsvertretungen zu intensivieren sowie hierüber umgehend Bericht zu erstatten. Fischbeck beließ es nicht bei dieser Anordnung. Er deutete zudem an, daß weitere einschlägige Klagen für die Bergrevierbeamten weitreichende Folgen nach sich ziehen könnten: „Ich verhehle nicht, bei dieser Gelegenheit darauf hinzuweisen, daß dem preußischen Landtag bereits Anträge vorliegen, die die Zuziehung der Betriebsräte zu den Grubenfahrten durch die Bergrevierbeamten sowie die Wahl von Arbeiterkontrolleuren für die Bergreviere vorsehen. ${ }^{\text {“ }} 50$

Das Dortmunder Oberbergamt forderte die einzelnen Bergreviere zur Berichterstattung auf. ${ }^{351}$ Die Antworten der Revierbeamten waren ein Zeugnis ihrer Empörung über die Vorwürfe sowie über die Vorstellung, die Betriebsräte könnten in größerem Umfang im Bereich der Unfallverhütung sinnvoll tätig werden. Zunächst bestritten die zuständigen Beamten die Behauptung, die Betriebsräte würden zur Unfallverhütung nicht gehört. Die Verordnung vom Januar 1921 habe man weisungsgemäß angewandt; in einem vierteljährlichen Rhythmus würden Fragen der Bergsicherheit mit den Betriebsräten erörtert. Dabei zeige sich, daß der Betriebsrat Fragen des Grubenausbaus und der Schießarbeit ungern verhandele, „da er sich dadurch bei seinen Wählern unbeliebt macht und nicht wieder gewählt wird. “352 Bei den Quartalsbesprechungen würden daher Vorschläge zur Unfallverhütung gemacht wie „Einführung der Sechsstundenschicht oder überhaupt ... Einschränkung der Arbeitszeit und ... Beseitigung der Gedinge. “353 Der Bergrevierbeamte von West-Recklinghausen griff auch direkt die persönliche Integrität der Betriebsräte an: „Schon bei diesen beiden Amtshandlungen [Besichtigung des Unfallpunktes unter Tage, Unfallverbandlung über Tage] ist die Erfahrung gemacht worden, daß die Betriebsräte nur dann - nicht immer - erscheinen, wenn sich persönliche Vorteile, vor allem eine Unterbrechung ihrer Arbeitszeit bietet. Selten oder nie erscheinen sie, wenn die Unfalluntersuchung außerhalb der selbstgesetzten Arbeitszeit der Betriebsräte stattfindet. ${ }^{354}$ Der außerordentlich auskunftsfreudige Recklinghäuser Beamte sprach den Betriebsräten auch jede Kompetenz ab: was bei Gelegenheit der Sicherheitskonferenzen vorgetragen würde, „entspricht dem Gesichtskreis der Betriebsräte. Es sind fast nur belanglose Kleinigkeiten." In den letzten Sitzungen seien überhaupt keine Beschwerden mehr geäußert worden. Die Sprunghaftigkeit der Betriebsratsklagen hatte für den Recklinghäuser Berginspektor recht einfache Gründe: „Die vorgebrachten Wünsche sind fast nie das Ergebnis längerer Beobachtung oder praktischer, auf längere Zeit gesammelten (!) Erfahrungen, sondern nur Augenblickseinfälle oder Instruktionen ihrer Parteisekretäre. “355

${ }^{350}$ Der Minister für Handel und Gewerbe an sämtliche Oberbergämter, 9. 7. 1921, StAM OBAD 372, Bll.107f; das Zitat auf Bl. 108.

351 Sammlung der Antworten auf die Verfügung des Oberbergamtes vom 15. 7. 1921 in: StAM OBAD 372 , Bll.116ff.

${ }^{352}$ Bergrevier Dortmund I, 1. 8. 1921, StAM OBAD 372, Bl. 116.

${ }^{353}$ Bergrevier Ost-Recklinghausen, 1. 8. 1921, StAM OBAD 372, Bl. 119.

${ }^{354}$ Bergrevier West-Recklinghausen. 27. 7. 1921, StAM OBAD 372, Bl. 133.

${ }^{355}$ Bergrevier West-Recklinghausen. 27. 7. 1921, StAM OBAD 372, Bl. 133. 
Von einer Erweiterung der Rechte der Betriebsräte im Unfallschutz versprach sich die Bergaufsicht nichts; im Gegenteil befürchtete sie eine Aushöhlung ihrer Kompetenzen und eine Verschlechterung der Bergsicherheit: „Um die Unfallverhütung im Bergbau würde es traurig bestellt sein, wenn man der Mitwirkung der Betriebsräte irgendwie maßgebliche Bedeutung beimessen wollte." Die Begründung dieser schroff ablehnenden Haltung war aufschlußreich und vermittelte einen recht präzisen Eindruck von der Konfrontationsstellung auf den Schachtanlagen: „Wer in der Praxis steht, weiß ganz genau, daß die Betriebsräte ihre Hauptaufgabe keineswegs in der Mitwirkung bei der Verhütung von Unfällen oder bei der Hebung der Produktion erblicken, sondern in der politischen Agitation. Der Unionist ist bei Grubenfahrten für die Union politisch tätig, der Mehrheitssozialist für den alten Verband u.s.w. Da die Betriebsräte nur Rechte und nicht auch Pflichten haben, vor allem nicht die Pflicht der Erledigung eines bestimmten Befahrungspensums wie die Steiger, auch Niemandem, außer vielleicht ihren Parteisekretären, Rechenschaft schulden, ohne über ihre Tätigkeit der Behörde Bericht erstatten zu müssen oder Buch zu führen, so tritt an vielen Arbeitspunkten, die sie befahren, nur ein Aufenthalt im Interesse der politischen Agitation ein. ${ }^{\text {"356 Diese }}$ Behauptung war praktisch kaum überprüfbar, wenngleich für sie gewisse Indizien, etwa die jeweilige Organisationsprogrammatik sprachen. Im Prinzip wußte die Bergbehörde, daß es den Bergleuten vor allem um ihr materielles Wohlergehen ging, wodurch auch die Arbeit der Betriebsräte in der Grubensicherheitsfrage entscheidend beeinflußt wurde: „Völlig versagt haben die Betriebsräte bisher auf dem wichtigsten bergbaulichen Unfallgebiet, dem des Stein- und Kohlenfalles. Mehrfach haben sie schon ganz aufrichtig zugegeben, daß sie auf diesem Gebiete keine Einwirkung ausüben können, denn der Betriebsrat wird natürlich nicht gewählt, um die Leute zum ordnungsmäßigen Verbauen oder überhaupt zur Einhaltung bergpolizeilicher Vorschriften anzuhalten." Bei der Erweiterung der Rechte der Betriebsräte im Bereich des Unfallschutzes befürchtete die Bergaufsicht zudem einen Einfluß- und Ansehensverlust zugunsten "gering gebildeter Leute“. Hinter der Forderung nach Arbeiterkontrolleuren stecke ohnehin nur Parteipolitik: „Man faßt sich an die Stirn und fragt sich erstaunt: ,Wissen denn die Herren, die solche Anträge geduldsam behandeln, wirklich nicht, daß es hierbei auf Unfallverhütung überhaupt nicht ankommt, sondern nur auf parteipolitische Ziele, daß hier lediglich der weitere Ausbau einer Nebenregierung betrieben wird, die dem Gesamtwohl des Volkes durchaus verderblich ist. “ ${ }^{\text {‘37 }}$ Daß den Betriebsräten in der Unfallschutzfrage jedes Entgegenkommen verweigert wurde, war daher klar, auch wenn sich die Bergaufsicht formal an ihre Vorschriften hielt. Angesichts der Kompetenzprobleme vieler Betriebsräte in Fragen der Bergtechnik genügte aber bereits eine Verweigerung von wenigen Informationen, um die gemeinsamen Besprechungen ins Leere laufen zu lassen. Arbeiterkontrolleure als Institution zur Verbesserung der Sicherheit lehnte die Bergaufsicht kategorisch ab: den Mangel an Wissen und Kompetenz der in Frage kommenden Personen „durch Vorträge verbessern zu wollen, ist ein aussichtsloses Beginnen. Die Auffassung, daß durch

${ }^{356}$ Ebenda, Bl. 133, S. 5.

357 Ebenda, Bl. 133, S. 9. 
einige Vorträge dem Mangel abgeholfen werden könnte, verrät eine recht geringe Einschätzung der wissenschaftlichen Voraussetzungen für die Beaufsichtigung des Bergbaus entsprechend der heutigen allgemeinen Geringbewertung geistiger Arbeit. Die Beamten der Bergbehörden und der Werke haben weder Zeit noch auch werden sie den Beruf fühlen, unwissende Leute schulmäßig mit Kenntnissen für ihr Amt zu versorgen. “358

In der zweiten Jahreshälfte 1921 mehrten sich die Anzeichen eines aktiveren Vorgehens der Zechenverwaltungen gegen die Betriebsräte. Man hielt sich zwar streng an die in den Rundschreiben und Bekanntmachungen des Zechenverbandes geforderte restriktiv-legalistische Haltung; bei kleinsten Anlässen aber wurden Amtsenthebungen und Entlassungen betrieben, so im November 1921 auf der Zeche Bonifacius, als man den Betriebsratsvorsitzenden wegen vermeintlichen Organisationszwangs entlassen wollte. ${ }^{359}$ Ähnlich ging man auf Rheinelbe/Alma vor: Dem Betriebsratsvorsitzenden Eckey, der auch die Betriebsrätezentrale im Ruhrgebiet leitete, wurde im Dezember 1921 wegen einer Lappalie gekündigt; der Schlichtungsausschuß stimmte der Entlassung zu. Die Belegschaft von Rheinelbe/ Alma drohte daraufhin mit Streik, falls das Reichsarbeitsministerium nicht zugunsten Eckeys eingreife. Man war der Überzeugung, daß die Zechenleitung die Mitbestimmung schlechthin treffen wollte, wie der Vorsitzende des Angestelltenrates von Alma erklärte: „Das Unternehmertum hätte bereits bei der letzten ArbeiterVertreter-Versammlung erklärt, daß sie - die Unternehmer - nicht mehr in der Defensive, sondern in der Offensive sich befänden. Der Kampf gelte vor allen Dingen den Betriebsräten, Angestellten und Arbeitern. ${ }^{360}$ Die Aktionen der Gelsenkirchener Bergleute zugunsten ihres Betriebsratsvorsitzenden blieben vergeblich. Parallel ließ man die reguläre Betriebsratsarbeit dadurch ins Leere laufen, daß man zu den gemeinsamen Sitzungen mit den Betriebsausschüssen keine entscheidungsberechtigten "Werksbeamten“ entsandte. "Wie uns die Angestellten des Ruhrkohlenbergbaus mitteilen," beschwerte sich der Deutsche Werkmeisterverband im Juli 1921 beim Zechenverband ${ }^{361}$, „versuchen die Arbeitgeber im Bergbau immer und immer mehr das Betriebsrätegesetz zu sabotieren und zwar in der Hauptsache dadurch, daß sie zu den Sitzungen nicht wie üblich einen bevollmächtigten Vertreter der Arbeitgeber entsenden, sondern den Betriebsführer der jedesmaligen Schachtanlage. Der Betriebsführer der Schachtanlage ist aber Angestellter, also Arbeitnehmer und nicht Arbeitgeber. Dadurch, daß der Arbeitgeber oder ein bevollmächtigter Vertreter des Arbeitgebers an den Sitzungen nicht teilnimmt, kann der Zweck des Betriebsrätegesetzes nicht erreicht werden." Die Werkmeister vermuteten hinter den Sabotagemaßnahmen den Zechenverband: „Durch das Vorgehen der genannten Zechen [Mülheimer Stinnes-Zechen] ... ist die Erregung unter der gesamten Arbeitnehmerschaft des Ruhrbergbaus aufs höchste gestiegen, so daß dem Ruhrkohlenbergbau eine ernste Gefahr droht. Naturgemäß wird diese Verärgerung der gesamten Arbeitnehmerschaft von den Unionisten und Syndikalisten noch geschürt und die Gefahr für den Ruhrkohlenbergbau noch dadurch er-

\footnotetext{
${ }^{358}$ Bergrevier West-Recklinghausen an Oberbergamt, 11. 8. 1921, StAM OBAD 372, Bl. 122.

${ }^{359}$ Protokoll der Bergvorstandssitzung der Rheinelbe-Union, 14. 11. 1921, BgA 55/121.

360 BgA 41/531.

361 16. 7. 1921, StAM OBAD 372, Bl. 127.
} 
höht. “" ${ }^{362}$ Die Bergbehörden gingen den Beschwerden nach, bestätigten sie aber nicht. Es komme hin und wieder vor, daß Verhandlungen durch leitende Angestellte geführt würden; dies sei aber nicht die Regel. Die Arbeitgebervertreter würden allerdings an Sitzungen, die während der Arbeitszeit stattfänden, generell nicht teilnehmen, seien hierzu aber auch nicht verpflichtet. ${ }^{363}$ Ein Eingreifen der Behörden war damit ausgeschlossen. Da die Vorwürfe nicht verstummten, blieb die faktische Verhandlungsverweigerung an der Tagesordnung. Sie war zweifellos auch eine Antwort auf die Vielzahl der Sitzungen 1920 und 1921, von denen sich mancher Bergwerksdirektor entlasten wollte. Vor allem aber dienten sie der Paralysierung der Betriebsräte. Eine auch nur einigermaßen zufriedenstellende Mitbestimmungspraxis auf den Schachtanlagen war damit ausgeschlossen.

Die Betriebsratssitzungen der Dannenbaum-Schächte, um das Beispiel dieser Deutsch-Lux-Zeche wieder aufzugreifen, blieben letztlich von Auseinandersetzungen um die Rechte der Betriebsräte beherrscht. Es war ein zäher Prozeß des Ringens um Einsichtsmöglichkeiten in Förderlisten und Steigerjournale, um die Beteiligung bei Strafen, um die Qualität der Deputatkohlen, um die Frage der Lampenkontrolle und ähnliches mehr. Die Zechenleitung und die hinter ihr stehende Bergwerksverwaltung spielte dabei das Spiel, nur das zuzugestehen, was sich nicht umgehen ließ. Und auch hier blieb es häufig bei verbalen Zugeständnissen, wie das Beispiel der Geldstrafen zeigte. Trotz wiederholter Zusagen, den Betriebsausschuß zu beteiligen, verhängte die Dannenbaum-Leitung weiterhin eigenständig Geldstrafen. Auf erneute Proteste hin erklärte Bergwerksdirektor Fuldner im Februar 1922, ohne Strafen gehe es nicht. Da bisher die Frage der Beteiligung des Betriebsausschusses nicht endgültig geregelt sei, behalte sich die Zechenleitung das Bestrafungsrecht vor. Nach langem Hin und Her einigte man sich darauf, daß die ausgesprochenen Bestrafungen dem Betriebsrat zur Kenntnis gebracht und die Betroffenen bei ihm ein Beschwerderecht erhalten sollten. Zechenleitung und Betriebsvertretung sollten sich dann einigen. ${ }^{364}$ Auf der gleichen Sitzung am 8.Februar 1922 setzte man den Streit um die Aushänge der Betriebsvertretung weiter fort. Die Angelegenheit sollte schließlich dem Reichsarbeitsministerium bzw. dem Oberbergamt vorgetragen werden, doch war man nicht einmal dazu in der Lage, sich auf die Instanz zu einigen, die man anrufen wollte. Daß angesichts derartiger Blockaden die Legitimität der Betriebsräte in den Augen der Belegschaft fragwürdig wurde, da sie keine wirklichen Erfolge vorzuweisen hatte, bedarf keiner weiteren Erläuterung. Sie wurden häufig in die Radikalität geradezu hereingedrängt, da sie auf dem ordentlichen Verfahrenswege für eine weiterhin unter schweren materiellen Bedingungen arbeitende und lebende Belegschaft nichts erreichen konnten. Das Urteil des Bergarbeiterverbandes über die industriellen Beziehungen im Ruhrbergbau 1921 traf durchaus den Kern: „Das Zusammenarbeiten von Betriebsräten und Betriebsleitungen läßt vielfach noch zu wünschen übrig. Viele Unternehmer können sich mit dem Gedanken der Betriebsdemokratie noch nicht abfinden. Sie hängen noch allzusehr an dem alten

\footnotetext{
${ }^{362}$ Ebenda.

${ }^{363}$ Bergrevierbeamte Essen III, 28. 7. 1921; Essen II, 3. 8. 1921; Werden, 3. 8. 1921, StAM OBAD 372, Bll.163 ff.

${ }^{364}$ Protokoll der Betriebsratssitzung, 8. 2. 1922, BgA 40/225.
} 
Herrn-im-Hause-Standpunkt. Auf der anderen Seite verstehen es viele Betriebsräte noch nicht, sich auf den Boden des Gesetzes zu stellen. “365 Die Tarifgewerkschaften waren daher durchweg bestrebt, durch Betriebsratsschulung zumindest von der Seite der Betriebsräte her die Voraussetzungen erfolgreicher Mitbestimmung zu verbessern. ${ }^{366} \mathrm{Da}$ die Zechenverwaltungen allerdings an Verhandlungen nicht ernsthaft interessiert waren und das Argument, den Betriebsräten fehle für ernsthafte Zusammenarbeit die Sachkompetenz, im wesentlichen vorgeschoben oder doch zumindest unüberlegt war, blieb auch für "kompetente“ Betriebsräte die offene Frage, wo sie ihr neues Wissen hätten erfolgreich einbringen können.

Die vergleichsweise günstige materielle und Lohnentwicklung des Jahres 1921 die Reallöhne hatten sich in etwa auf dem Vorkriegsniveau gehalten; bei den Übertagearbeitern lagen sie zu Jahresende deutlich darüber ${ }^{367}$ - war ein Ergebnis der Inflationskonjunktur im Bergbau. Unter Förder- und Absatzgesichtspunkten verpaßte der Ruhrbergbau diese Sonderkonjunktur; er nahm an ihr vor allem über die rasch anziehenden Preise teil. Während die Förderung zwischen 1920 und 1922 faktisch bei 90 Mio.t stagnierte, wuchs die Zahl der Beschäftigten im Jahresdurchschnitt 1921 von 470000 auf 540000, um sich während des Jahres 1922 in etwa auf diesem Niveau zu stabilisieren. Arbeitslosigkeit unter den Bergleuten war nicht vorhanden. Da die Förderung nicht zunahm, ging die Leistung der Belegschaften zurück. Die Leistung je Belegschaftsmitglied und Schicht betrug im Schnitt des Jahres $1921173 \mathrm{~kg}$, in etwa soviel wie zuletzt $1865 .{ }^{368}$ Die Kostenverhältnisse auf den Zechen dürften sich entsprechend weiter verschlechtert haben, doch noch immer verdeckte die Preisentwicklung den eigentlichen betriebswirtschaftlichen $\mathrm{Zu}$ stand der Anlagen und ermöglichte ein Fortführen der Situation. ${ }^{369}$ Auf diese Weise erklärte sich auch die relative Ruhe, die im Ruhrgebiet nach den Auseinandersetzungen im März 1921 herrschte. Daß vor diesem Hintergrund die Zechen daran interessiert waren, zu steigenden Leistungsziffern und einer ausgeglicheneren Betriebswirtschaft zu gelangen, ist ohne weiteres nachvollziehbar. Insofern sie für den Leistungseinbruch der Nachkriegszeit das neue Arbeitsrecht, die Gewerkschaften, die Betriebsräte und die politischen Arbeiterparteien verantwortlich machten, zeigten sie freilich nicht nur wenig Phantasie. Sie favorisierten damit auch einen Krisenausweg, der die Konflikte und Probleme nur weiter verschärfen mußte, solange der Bergbau nicht in der Lage war, die Bergarbeiterbewegung endgültig und effektiv zu unterdrücken. Ein derartiger politischer Durchmarsch gegen die Arbeiterschaft aber war, das hatte der Kapp-Putsch gezeigt, zu Beginn der zwanziger Jahre nicht möglich. Anstatt sich mit den neuen Vorschriften zu arrangieren und ihre Vorteile für sich zu nutzen, verharrten die Bergwerksgesellschaften und ihr Verband in einer Pose der Verweigerung und förderten damit nur all jene Probleme, auf die wiederum Verweigerung die angemessene Antwort schien.

${ }^{365}$ Jahrbuch des Bergarbeiterverbandes 1921, S. 68.

366 Vgl. noch einmal „Betriebsrätekonferenz für das Ruhrgebiet“, in: Der Bergknappe, Nr. 40, 1. 10. 1921, StAM OBAD 372, Bl. 187.

${ }^{367}$ Abelshauser, Himmelmann, Revolution in Rheinland und Westfalen, S. 180.

${ }^{368}$ Wiel, Wirtschaftsgeschichte des Ruhrgebietes, S. 131.

${ }^{6} 69$ Dies gaben selbst die christlichen Gewerkschaften zu. Vgl. die Reden auf der „Betriebsrätekonferenz für das Ruhrgebiet“, in: Der Bergknappe, Nr. 40, 1. 10. 1921, StAM OBAD 372, Bl. 187. 


\section{Erneute Eskalation 1922/23}

Bei den Neuwahlen zu den Betriebsräten im Ruhrbergbau im März und April 1922 bestätigten sich im wesentlichen die Ergebnisse des Vorjahres, die freien Gewerkschaften konnten ihren Mandatsanteil auf $41,7 \%$ (reichsweit im Bergbau $68,4 \%$ ) gegenüber $41,2 \%$ sogar leicht ausdehnen; Union und Syndikalisten gemeinsam kamen jetzt auf 32,5\% der abgegebenen Stimmen. ${ }^{370}$ Auf der Dannenbaum-Schachtanlage in Bochum-Laer trug allerdings ein Lebensmittelskandal dazu bei, den Alten Verband in den Augen der Bergleute zu diskreditieren. Bei einer Wahlbeteiligung von $77 \%$ erhielten auf der Bochumer Zeche die Union von 14 Arbeiterratsmandaten sechs, die "Christen“ vier, der Alte Verband drei und der DMV ein Mandat. ${ }^{371}$ In den Betriebsausschuß wurden alle Gruppen mit einem Vertreter und ein Angestellter gewählt, der zunächst dort den Vorsitz übernahm. An seine Stelle trat später der Vertreter der Union. Im Rheinelbe-Union-Konzern insgesamt waren die Ergebnisse je nach regionaler Lage und Größe der Zeche sowie nach der sozialen Zusammensetzung der Belegschaften unterschiedlich ${ }^{372}$; jedoch war auch hier kein durchgreifender Linksrutsch erfolgt. Von den Mehrheitsverhältnissen her blieben die Betriebsräte im Ruhrbergbau berechenbar. Dies galt mit gewissen Abstrichen auch für die Belegschaften zumindest solange, wie sich hohes Beschäftigungsniveau und einigermaßen stabile Lohnsituation gegenseitig ergänzten. Im ersten Halbjahr 1922 war die Lage auf den Schachtanlagen daher noch ruhig. Gegen Ende 1922 änderten sich allerdings die Verhältnisse. Die inflationsbedingte Nachkriegskonjunktur zeigte erste Schwächen; der Dumpingexport mußte eingeschränkt werden, da sich Inlands- und Weltmarktpreise zusehends anglichen. Die Subventionierung des Bergbaus über schnell steigende Kohlenpreise wurde zwar weiter betrieben, ein Ende hierfür war aber ebenfalls abzusehen. Während Belegschaft und Förderung auf Vorjahresniveau stagnierten, beschleunigte sich überdies die Inflation erneut; in ihrem Gefolge brachen die Reallöhne in der zweiten Jahreshälfte 1922 ein. Zum Jahreswechsel 1922/23 lagen sie bei gleicher Förderleistung wie im Vorjahr nur noch bei 50\% des Vorkriegsstandes. ${ }^{373}$

Für die Zechenunternehmen war die Leistungssteigerung der Bergleute bei nur unterproportionaler Steigerung der Lohnkosten ein Ziel, dessen Bedeutung täglich zunahm. Die Überschichtenfrage erhielt ein überragendes Gewicht. Das Überschichtenabkommen vom August 1922, das dreimal in der Woche Überarbeit zuließ, aber mit erheblichen Lohnsteigerungen gekoppelt war und definitiv die Rückkehr zur Achtstundenschicht ausschlo ${ }^{374}$, brachte zwar die gewünschte Mehrarbeit, doch nicht wenige radikale Betriebsräte boykottierten das Abkommen, so daß die Reichsregierung gar Polizeischutz für die arbeitswilligen Bergar-

${ }^{370}$ Jahrbuch des Bergarbeiterverbandes 1922, S. 65. Martiny, Arbeiterbewegung an Rhein und Ruhr, S. 252.

$371 \mathrm{BgA} \mathrm{40/225.}$

${ }^{372}$ Auf Rheinelbe wurde am 3.4. 1922 gewählt. Christen und Freigewerkschaftern konnten ihren Stimmen- und Mandatsmehrheit klar behaupten, $\mathrm{BgA} 41 / 531$.

${ }^{373}$ Tschirbs, Tarifpolitik im Ruhrbergbau, S. 185-187. Abelshauser, Himmelmann, Revolution in Rheinland und Westfalen, S. 180.

${ }^{374}$ Feldman, Arbeitskonflikte im Ruhrbergbau, in: VfZ 28 (1980), S. 219. 
beiter erwog. ${ }^{375}$ Im September 1922 verweigerte auch der Dannenbaum-Betriebsrat die Zustimmung zu Überarbeit nach dem neuen Überschichtenabkommen. Die Bergleute, so sein Argument, sollten im einzelnen selbst entscheiden, ob sie zu Mehrarbeit bereit seien. Anordnungen von Mehrarbeit würde der Betriebsrat nicht zustimmen. Die Zechenleitung warf dem Betriebsrat Vertragsbruch vor. Außerdem sei es unglaubwürdig, dieses Ergebnis der Arbeitsgemeinschaft abzulehnen, andererseits aber die Vorteile der Arbeitsgemeinschaft in Anspruch zu nehmen. Unionisten und "Christen“ blieben aber bei ihrer ablehnenden Haltung auch noch, als Bergwerksdirektor Fuldner die Schwierigkeiten betonte, die entstehen würden, wenn ein Teil der Bergleute nach sieben Stunden ausfahre, der andere aber vor Ort bliebe. ${ }^{376}$ Nicht zuletzt wegen der Bereitschaft zahlreicher Bergleute, Mehrarbeit zu leisten, scheiterten aber die vor allem von der Union initiierten Boykottaktionen.

Als das Überschichtenabkommen zwischen dem 18. Dezember 1922 und dem 15. Januar 1923 offiziell suspendiert wurde ${ }^{377}$, schlug die Stunde der Betriebsräte. Bei der Leistung nunmehr freiwilliger Überarbeit beanspruchten sie eine VetoPosition, der sich ein Teil der Belegschaften unterwarf. Angesichts der Lohneinbußen nach Wegfall der Mehrarbeit und den Befürchtungen im Vorfeld der Ruhrbesetzung ${ }^{378}$ waren andererseits aber auch größere Belegschaftsteile bereit, freiwillige Mehrarbeit zu leisten, so daß es zu einer Belegschaftsspaltung kam. Die Berichte der Bergrevierbeamten insbesondere zur Jahreswende 1922/23 dokumentierten diese Situation. Während der Wattenscheider Bergrevierbeamte, in dessen Revier mit Rheinelbe/Alma eine der größten GBAG-Zechen fiel, notierte, daß „die Zahlen der freiwilligen Überschichten (wahrscheinlich) noch erheblich größer sein (würden), wenn nicht ein Teil der Betriebsräte aus taktischen oder parteipolitischen Gründen dem Verfahren von Überschichten entgegenarbeiteten, “ ${ }^{379}$ meldete das Bergrevier Essen III, in dem verschiedene Phoenix-Zechen lagen: „Es werden zahlreiche wilde Überschichten gemacht. Etwa die Hälfte der

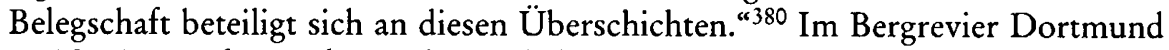
II (GBAG-Anlagen) lagen die Verhältnisse ähnlich; die Betriebsräte und eine kleine Mehrheit der Belegschaften plädierten gegen jede freiwillige Mehrarbeit, während die verheirateten Bergleute zur Ableistung von Überstunden durchweg bereit seien. ${ }^{381} \mathrm{Im}$ Bereich der nördlichen und westlichen Großzechen stimmten die Betriebsräte geschlossen gegen das Verfahren freiwilliger Mehrarbeit ${ }^{382}$, konnten sich damit aber bei den Belegschaften nicht immer durchsetzen. ${ }^{383}$ Deren Verhalten beschrieb das Oberbergamt am 17. Januar 1923, eine Woche, bevor wegen

\footnotetext{
375 Ebenda.

376 Protokoll der Betriebsratssitzung, BgA 40/225.

377 Feldman, Arbeitskonflikte im Ruhrbergbau, in: VfZ 28 (1980), S. 220.

378 Bergrevier Recklinghausen-West, 29. 12. 1922, StAM OBAD 1864, Bl. 15.

379 Bergrevier Wattenscheid, 30. 12. 1922, StAM OBAD 1864, Bl. 23.

380 Bergrevier Essen III, 29. 12. 1922, StAM OBAD 1864, Bl. 26.

381 Bergrevier Dortmund II, 13. 1. 1923, StAM OBAD 1864, Bl. 34.

382 Bergrevier Herne, 13. 1. 1923; Bergrevier Essen I, 13. 1. 1923; Bergrevier Essen II (u. a. GBAG-Zechen Ver. Bonifacius, Phoenix-Zeche Zollverein) 15.1. 1923; Bergrevier Essen III, 15. 1. 1923; Bergrevier Oberhausen 13. 1. 1923, StAM OBAD 1864, Bll. 43-51.

${ }^{383}$ Bergrevier Recklinghausen-Ost, 13. 1. 1923, StAM OBAD 1864, Bl. 36.
} 
der Ruhrbesetzung die Stimmungsberichte eingestellt wurden ${ }^{384}$, als ruhig, zumal in einem Schiedsspruch vom 8. Januar 1923 eine weitere Lohnerhöhung von mehr als $25 \%$ für Gedingearbeiter festgesetzt worden war. ${ }^{385}$ Die Wirkung der Betriebsratsvoten gegen die freiwillige Mehrarbeit sei vor diesem Hintergrund gering geblieben: "Während der Pause, die von den Verbänden in dem Verfahren der Überschichten eingelegt worden ist, sind nach den Berichten unserer Bergrevierbeamten in großem Umfange freiwillige Überschichten verfahren worden, da viele Bergleute bei der herrschenden Teuerung den Ausfall an Lohn nicht ertragen wollten.“ ${ }^{386}$

Die aktuelle Ruhe war freilich, so wußte das Oberbergamt nur zu genau, prekär. Einerseits hing sie von den zügigen Lohnanpassungen ab: „Die Teuerung ist in den letzten Tagen sprunghaft gestiegen. ... Es wird darauf zu achten sein, daß die Löhne und Gehälter dieser Teuerung laufend angepaßt werden und daß notwendig werdende Neuregelungen nicht zu spät kommen." Andererseits waren die Leistungen, die in der zweiten Jahreshälfte 1922 leicht gestiegen waren, über die Weihnachtsfeiertage wieder abgesackt. Eine Aussicht auf Besserung bestand - zumal unter den Bedingungen der französischen Besatzung - zunächst nicht. Damit war klar, daß die Lohnanpassungen kaum über erhöhte Produktionsleistungen, sondern nur durch höhere Kohlenpreise finanziert werden konnten, womit freilich über kurz oder lang die Bedingungen der deutschen Sonderkonjunktur untergraben wurden. Die inflationäre Entwicklung wurde auf dieser Basis zu einem sich selbstverstärkenden Prozeß, den zu durchbrechen nur eine erhöhte Leistung der Schachtanlagen vermocht hätte. Mit der Ruhrbesetzung und der sich daraufhin sprunghaft beschleunigenden Inflation begann das definitive Ende der Inflationskonjunktur. Die Arbeitslosigkeit an der Ruhr wuchs; die Zechen verzeichneten ein ,immer größer werdende(s) Angebot von ungelernten Arbeitern im Bergbau. ${ }^{\text {“ } 387}$ Mit der Arbeitslosigkeit und der teuerungsbedingten Not nahm auch deviantes Verhalten stark zu: „Die industrielle Werke verlassenden Eisenbahnzüge werden förmlich von allerlei Gesindel bestürmt, auf der Weiterfahrt werden Metall- und sonstige Gegenstände abgeworfen, von bereitstehenden Helfern aufgenommen und bei Althändlern abgesetzt. " ${ }^{388}$ Die Bergaufsicht plädierte für drastische Strafen, um der Situation Herr zu werden: „Namentlich gegenüber der durch und durch verrohten Jugend dürfte keinerlei Milde walten; wenn hier nicht mit eisernem Griff zugepackt wird, so wird die Jugend die Achtung vor dem Eigentum, die Achtung vor den richterlichen Behörden und dem Staat immer mehr verlieren. " ${ }^{389}$ Wieder war es in der Argumentation der Bergaufsicht im übrigen nicht die „eigentlich gutwillige Belegschaft“, sondern die verrohte Jugend, die das deviante Verhalten zeigte. Für sie wie für die Zechenleitungen war eindeutig, daß die radikalen Belegschaftsteile und die jugendlichen Radaumacher den eigentlichen Gegner ausmachten, der in den Betriebsräten eine seiner Hochburgen besaß. Mit

${ }^{384}$ Bergamt Dortmund an Minister für Handel und Gewerbe, 23.1. 1923, StAM OBAD 1864, Bl. 55.

${ }^{385}$ Oberbergamt Dortmund, Allgemeine Lage des Bergbaus im Ruhrgebiet, 17.1. 1923, StAM

OBAD 1864, Bll.329-332, hier Bl. 330.

${ }^{386}$ Ebenda, Bl. 331.

${ }^{387}$ Ebenda.

${ }^{388}$ Oberbergamt Dortmund, Stimmungsbericht, 2. 1. 1923, StAM OBAD 1864, Bll.2-6.

${ }^{389}$ Ebenda, Bl. 4. 
dem Bild der eigentlich gutwilligen Belegschaft waren allerdings die Betriebsratswahlergebnisse kaum noch zu vereinbaren. Resignation machte sich breit: „Die Stimmung der Arbeitgeber ist dauernd diejenige starker Resignation. “390

Mitte 1923 spitzte sich wegen der Folgen der Hyperinflation die Situation im Ruhrgebiet zu. ${ }^{391}$ Ähnlich wie in Leverkusen kam es im Juli und August $1923 \mathrm{zu}$ Versuchen, Teuerungszuschläge durchzusetzen, doch verpufften sie mehr oder weniger wirkungslos. ${ }^{392}$ Zwar gelang im August 1923 zwischen Zechenverband und Bergarbeitergewerkschaften noch der Abschluß eines Abkommens über die Zahlung wertbeständiger Löhne sowie die Vereinbarung eines 245\%igen Lohnzuschlages ${ }^{393}$, doch war die Entwicklung in den Zechenrevieren nicht mehr einzudämmen. Lebensmittelknappheit und Probleme bei der Lohnzahlung brachten massive Erregung in der Bergarbeiterschaft und führten zum Wiederaufleben spontaner Vertretungskörperschaften, die die gewählten Betriebsräte verdrängten und eigenständig mit den Zechenleitungen verhandelten. Plünderungen und Felddiebstahl waren an der Tagesordnung. Wie weit die Erregung ging, zeigte die Drohung des Betriebsrates der Duisburger Zeche Westende (Phoenix), „daß er die Grubenpferde abschlachten lasse, wenn die Zeche nicht für Lebensmittel sorge. “" ${ }^{994}$ Im August 1923 befand sich der Bergbau faktisch im Aufruhr: „Auf einem sehr großen Teil der Zechen herrscht teils offener Streik, teils passive Resistenz, teilweise werden nicht einmal die Notstandsarbeiten ausgeführt", meldete das Oberbergamt nach Berlin und bezichtigte die Unionisten, hierfür verantwortlich zu sein: „Die ganze Bewegung ist eine kommunistisch-syndikalistische Mache, welche die zeitige Ohnmacht der Staatsgewalt im besetzten Gebiet nach allen Seiten hin ausnutzt. ${ }^{395}$ Angesichts der Hyperinflation und der Unfähigkeit verschiedener Zechenleitungen und Kommunalverwaltungen, rechtzeitige Lohnzahlungen sicherzustellen, nahm auch der symbolische Protest drastische Formen an: „Sinnlos und beschämend ist die Unvernunft, namentlich bei dem jüngeren Teil der Belegschaften, welche in den letzten Tagen auf einer Anzahl Zechen, z. B. Sälzer Neuack, Erin, Viktor I/II, Germania, Kaiserstuhl und anderen Galgen errichtet haben, an welchen sie die Zechenleiter aufhängen wollen, wenn die Lohngelder nicht pünktlich zur Stelle sind. Bei Viktor I/II steht ein Galgen mit roter Fahne, an welchem eine Puppe aufgehängt ist, die durch häufige Fußtritte hin- und herbewegt wird. Auf Germania steht der Galgen auf dem höchsten Punkte der Halde, damit er möglichst weithin sichtbar ist. An den Kaiserstuhler Galgen soll eine möglichst hochstehende, indessen sonst beliebige Persönlichkeit Dortmunds aufgeknüpft werden, wenn die Lohngelder nicht pünktlich bereitlägen, um auf diese

${ }^{390}$ Bergrevier Recklinghausen-West, StAM OBAD 1864, BI. 37.

${ }^{391}$ Detaillierte Hinweise bei Wentzcke, Ruhrkampf, Bd. 2, S. $444 \mathrm{ff}$. Vgl. auch Ranft, Erwerbslosenfürsorge, S. $190 \mathrm{ff}$. Zahlreiche Hinweise auch bei Hartewig, Das unberechenbare Jahrzehnt, S. $175 \mathrm{ff}$.

${ }^{392}$ Betriebsrat an Bergwerksverwaltung Deutsch-Lux, 13. 8. 1921, Übermittlung der Forderungen der Belegschaftsversammlung vom 9. 8. 1923, BgA 40/225. Allgemein Hartewig, Das unberechenbare Jahrzehnt, S. $225 \mathrm{ff}$.

${ }^{393}$ Kölnische Zeitung, Nr. 550 vom 9. 8. 1923. Westfälische Allgemeine Volkszcitung, Nr. 178 vom 10. 8.1923.

${ }^{394}$ OBAD, Die heutigen Verhältnisse beim Steinkohlenbergbau im Ruhrbezirk, 11.8. 1923, StAM OBAD 1864, Bl. 333.

${ }^{395}$ Ebenda, Bl. 334. 
Weise ein abschreckendes Beispiel zu geben.“396 Parallel zur Verschärfung der symbolischen Proteste häuften sich auch wieder direkte Angriffe auf Vorgesetzte und leitendes Zechenpersonal: „Verschiedentlich ist es auch zu Mißhandlungen von Grubenangestellten gekommen. So auf Zeche Sälzer Neuack und König Ludwig. Auf letzter ist der Generaldirektor Bergrat Hollender der Mißhandlung nur dadurch entgangen, daß sich ein Betriebsratsmitglied zwischen ihn und die Angreifer warf, wobei es erheblich verletzt wurde. Der Bergassessor Kleynmans derselben Zeche wurde mit Grubenlampen und Stöcken geschlagen und trug erhebliche Kopfverletzungen davon.“397

Für die Bergbehörden war klar, daß die Form der Konfliktaustragung von außen in die Bergarbeiterschaft hineingetragen wurde. Während sie zugestand, daß die Lage wegen der Lebensmittelknappheit und der galoppierenden Inflation angespannt war, hielt sie die Konfrontation mit den Zechenleitungen für ein Ergebnis von Fremdsteuerung: „Die Bewegung wird vielfach von auswärtigen Agitatoren betrieben. Für die Art und Weise, wie dies geschieht und für den Fortfall der Autorität der Werksleitungen bezeichnend, ist ein Vorfall, der sich am 10. d.Mts. [August] auf einer großen, sehr gut geleiteten Zeche, die bisher mit ihrer Belegschaft in besonders guten Verhältnissen stand, zugetragen hat. In einer Belegschaftsversammlung, welche anstelle des Betriebsrates eine Zwölferkommission einsetzen wollte, und zu welcher der Betriebsführer mit dem Betriebsrat erschienen war, wurde ersterem, als er sich bei einem Angriff zum Wort melden wollte, von dem betriebsfremden Versammlungsleiter das Wort verboten mit dem Ausdruck „Halts Maul, Du A...loch.“ ${ }^{398}$ Die Behauptungen und Beobachtungen der Bergbehörde über die Formen der Konfliktaustragung waren schwer zu widerlegen, griffen sie doch jeweils tatsächliche Momente auf, die dann freilich mit allgemeinen Wertungen und Meinungen verknüpft wurden, so daß sich ein unentwirrbares Knäuel aus Tatsachenfeststellungen und Vorurteilen ergab. Die eigentliche Bedeutung der Auffassung, für die Formen der Konfliktaustragung seien „zechenfremde Elemente“, jugendliche Arbeiter und Arbeitsscheue verantwortlich, ergab sich daraus, daß sie zum festen Bestandteil der Ursachenanalyse der Bergbehörden und der Zechenverwaltungen wurde, aus denen eine einfache Rezeptur zur Befriedung des Bergbaus abgeleitet wurde. Es mußte darum gehen, die mehrheitlich gutwilligen Bergarbeiter dem Einfluß der „zechenfremden Elemente“ zu entziehen. Wie freilich die industriellen Beziehungen nach einer Befriedung der Zechen aussehen sollten, darauf verschwendete man nur wenig Gedanken, abgesehen von den gelegentlichen Appellen der Bergbehörden, die die Zechenleitungen zu einer einfühlsamen und verständnisvollen Politik ihren Belegschaften gegenüber aufriefen. Das Betriebsrätegesetz, soviel schien Ende 1923 den Bergbauunternehmen klar zu sein, brachte kaum Vorteile, im Gegenteil ermöglichte es genau jenen "Unruhestiftern“ einen ungehinderten Zugang zum Betrieb, die man für die Ursache allen Übels hielt. Die eigentliche Ursache der eskalierenden Konflikte wurde so recht erfolgreich in den Hintergrund gedrängt: Die Verhandlungs-

396 Ebenda.
397 Ebenda.
${ }^{398}$ Ebenda. 
strukturen auf Branchen- wie auf Betriebsratsebene funktionierten nur bedingt; die jeweiligen Verhandlungen zogen sich in die Länge, rasche Entscheidungen fielen faktisch nie, die Ergebnisse der Verhandlungen waren für die Bergleute zumeist zu gering. Die direkte Aktion schien den Ausweg zu schnellen und materiell zufriedenstellenden Resultaten zu weisen. Diese Aktionsformen stellten wiederum Foren für die Unionisten dar, deren Agitation den Zechen und ihrem Verband, aber auch den staatlichen Bergaufsichtsbehörden als Anlaß diente, die Bergarbeiterbewegung politisch in Mißkredit zu bringen und nach militärischer Repression zu verlangen. Diese offenkundige Haltung der Zechenverwaltungen brachte die Bergarbeiterschaft weiter auf und förderte zumindest ihren symbolischen Radikalismus. Eine Spirale in die Eskalation drehte sich auf diese Weise fast zwangsläufig, die zu beenden einer weitergehenden Bereitschaft der Zechenverwaltungen zum schnellen, materiell spürbaren Kompromiß bedurft hätte. War diese Bereitschaft 1918/19 aus prinzipiellen Gründen nicht vorhanden, so verschlechterte sich nach 1920 sukzessive die betriebswirtschaftliche Lage der Zechen, so daß nunmehr auch objektiv die Bedingungen für einen materiellen Interessenausgleich schlechter wurden. Den Tarifgewerkschaften waren in diesem "Spiel“ die Hände gebunden, da sie auf den Verhandlungsweg setzten, der indes wegen der Obstruktionshaltung der Zechenbesitzer nur schleppend und wenig ergiebig war. Im Ergebnis nahm daher die Konfrontation zwischen allen beteiligten Gruppen immer weiter zu, deren offener Ausbruch lediglich durch die über Kohlenpreiserhöhungen finanzierten Zwischenkompromisse verhindert wurde.

Faßt man die Jahre 1920 bis 1923 zusammen, zeigt sich folgender Eindruck. Das Betriebsrätegesetz und seine Ausführungsbestimmungen brachten dem Ruhrbergbau im Frühjahr und Sommer 1920 eine neue institutionelle Kommunikationsstruktur, die gemessen an den Verhältnissen des Jahres 1919 auf eine effektive Beschränkung der Handlungsmöglichkeiten der Betriebsräte hinauslief. Seit dem Sommer 1920 begann zudem ein Kampf zwischen Zechenverband, Zechenleitungen und Betriebsräten/Gewerkschaften um die Rechte und Handlungsmöglichkeiten der Betriebsvertretungen, den letztere, zumindest soweit eine Erweiterung der Rechte angestrebt wurde, verloren. In der Frage der Rechte der Betriebsräte beim Unfallschutz zeigte sich, daß gegen die große Koalition von Zechen und Bergaufsicht faktisch nur wenig ausgerichtet werden konnte, auch wenn sich auf dem Papier (Verordnung des preuß. Handelsministers) eine Stärkung der Betriebsräte durchgesetzt hatte. Aber nicht einmal im Rahmen der engen Bestimmungen des Betriebsrätegesetzes entwickelte sich eine fruchtbare Zusammenarbeit zwischen Zechenleitungen und Betriebsräten. Es herrschte vielmehr von Anfang an ein Kleinkrieg auf den Zechen, der zwei Ursachen hatte. Einerseits suchten die Zechenleitungen die Betriebsräte durch Erschwerung der Revierbefahrungen, mangelnden Verhandlungswillen und komplizierte Entscheidungsprozesse zu paralysieren, zum anderen versuchten zahlreiche Betriebsräte sich faktisch Kompetenzen im Bereich der Organisationskontrolle, der Arbeitszeiten und der Mehrarbeit zu erstreiten, die auf eine effektive Beschneidung der Handlungsmöglichkeiten der Zechenleitungen hinausliefen. Im Ergebnis versuchten sich beide Seiten gerade dort zu schaden, wo Kooperation möglich und notwendig war. Nachdem der Prozeß der symmetrischen Eskalation einmal eingeleitet war, be- 
schleunigte er sich unter dem Eindruck von Inflation und schlechter Betriebswirtschaft zusehends. Die Kompromißbereitschaft in materieller Hinsicht sank, die Forderungen an die jeweilige Gegenseite nahmen zu. Die zahlreichen unregulierten materiellen Konflikte brachten zudem den Ansatzpunkt für unionistische und syndikalistische Politik, die die Eskalationsspirale weiter drehte, ebenso wie das unverhohlene Eintreten mancher Bergwerksgesellschaften gegen die Republik zur Politisierung und damit zur Eskalation beitrug. Den Hintergrund dieser Eskalationsprozesse bildeten freilich immer materielle, keineswegs politische Konflikte. Erst das Versagen der Regulierungsverfahren machte aus materiellen Konflikten politische Probleme. Hier stellt sich die Frage nach den Ursachen insbesondere der Verweigerungshaltung von Zechenverband und Zechenleitungen, die spätestens 1919/20 hätten einsehen müssen, daß auf dem Wege der Konfrontation nur eine weitere Eskalation der Konflikte eintreten würde.

Eine einfache Antwort auf diese Frage war 1923 kaum möglich. Die betriebswirtschaftlichen Probleme, die Einbrüche in den Leistungen der Bergleute, die Revolutionserfahrung namentlich im westlichen Ruhrgebiet, die Bürgerkriegsszenen des Jahres 1920, das Versagen jeder betrieblichen Kommunikation seit den späten Kriegstagen, die Sozialstruktur des leitenden Zechenpersonals, die besondere Radikalität der Bergleute: all diese Faktoren spielten eine wichtige Rolle bei der Verweigerung von Anpassungsbereitschaft. Entscheidend war, daß die Bergwerksgesellschaften sich schlechterdings nicht vorstellen konnten, die Bergleute würden bei geringerem Leistungsdruck und freundlicherer Umgangsweise das Leistungsniveau steigern. Für sie war der Zusammenhang zwischen Demokratisierung, Tarifsystem und Leistungszusammenbruch derart offensichtlich, daß nur eine Einschränkung der Rechte der Arbeiterschaft die Leistung steigern konnte. Hätte man indes eine differenzierte Kommunikationsstruktur besessen, so wäre der Blick auf die Realität des bergmännischen Lebens zu differenziert gewesen, um an derart einfachen Erklärungen festzuhalten. In der Weigerung, im betrieblichen Alltag die Klagen der Bergleute anzuhören und ernst zu nehmen, lag mithin die tiefere Ursache der Anpassungsverweigerung durch die Zechen. Diese Weigerung war zudem in den Organisationsstrukturen gleichsam institutionalisiert, eine Stelle zur "Selbstbeobachtung" im Organisationsaufbau nicht vorgesehen. Das Betriebsrätegesetz, das in der chemischen Industrie deshalb einigermaßen funktionierte, weil hier die Selbstbeobachtung der Unternehmen ohnehin einen wesentlichen Beitrag zur Ausdifferenzierung der betrieblichen Kommunikation leistete, traf im Bergbau auf ausgesprochen lernunwillige Strukturen. Allerdings waren die Lernbedingungen der frühen zwanziger Jahre auch außerordentlich kompliziert. Die Chancen standen nicht gut, daß die Mitbestimmung im Bergbau nach einer Stabilisierung der deutschen Wirtschaft ein neues qualitatives Niveau erreichen würde.

\section{4 bis 1929}

Zur entscheidenden Determinante der industriellen Beziehungen im Bergbau nach der Währungsstabilisierung wurde die Tatsache, daß sich an die inflationäre Krise des Jahres 1923 fast unmittelbar der Ausbruch der Strukturkrise 1924 an- 
schloß. 1923 war wegen des passiven Widerstandes und der Hyperinflation die Kohlenförderung mit 41 Mio. $t$ faktisch zusammengebrochen. Die Beschäftigung lag mit 507000 angelegten Bergarbeitern aber noch um 100000 über dem Vorkriegsstand. 1924 stieg die Förderung des Ruhrbergbaus zwar wieder auf 94 Mio. $t$ an; die Beschäftigung sank im Jahresdurchschnitt auf knapp 450000 angelegte Bergleute $a b$, jedoch waren die Relationen der Vorkriegszeit (1913: 114 Mio. $t$ Förderung mit 400000 angelegten Bergarbeitern) noch längst nicht wieder erreicht. Der Anstieg der Schichtförderleistung pro Belegschaftsmitglied war daher nur im direkten Vergleich der Jahre 1923 und 1924 eindrucksvoll. Die Leistung lag gleichwohl noch um ein Drittel unter dem Vorkriegsstand, der erst 1927 wieder erreicht wurde und danach bis zur Weltwirtschaftskrise auf dem Vorkriegsniveau stagnierte. ${ }^{399} \mathrm{Da}$ parallel zur steigenden Förderung jedoch der Absatz stagnierte und auf den bestrittenen Märkten kostendeckende Preise nicht erzielt werden konnten, befand sich der Bergbau in einer Zwangslage. Hohe Kosten und geringe Leistungen einerseits, stagnierender Absatz bei unzureichenden Preisen andererseits verlangten zwingend nach einer Bereinigung der Branchenstruktur und einer Senkung der Kosten bei gleichzeitiger Erhöhung der Leistungen. Die geringe Flexibilität der Lohnkosten und die sich nur langsam verbessernden Leistungen wurden zum zentralen Ansatzpunkt der Politik der Zechenverwaltungen, wobei die veränderten gesetzlichen Rahmenbedingungen und das kollektive Arbeitsrecht immer mehr als eigentliche Ursachen des Kostendrucks hingestellt wurden. ${ }^{400}$ Ging es während der Jahre 1919 bis 1923 aus der Sicht der Zechenleitungen vordringlich um die Frage, wer die "Macht" in den Zechen besaß, während die Betriebswirtschaft selbst eine nachgeordnete Rolle spielte, so wurde die Machtfrage, d. h. der Streit um die Kontrolle des Arbeitsprozesses, der Arbeitsbedingungen und der Löhne jetzt in der Sicht der Unternehmensleitungen zur entscheidenden Frage des wirtschaftlichen Überlebens. Eine "gesunde“ Betriebswirtschaft schien den Zechen nur erreichbar, wenn die Anpassung von Kosten und Leistungen an die Marktlage nicht „politisch“ behindert wurde. Obwohl die Bedeutung der Betriebsräte nach der Hyperinflation und der Maiaussperrung 1924 deutlich zurückging, trat daher von Seiten der Zechenleitungen keine Entspannung im Umgang mit den betrieblichen Interessenvertretungen ein. Das Resümee des Alten Verbandes zum vierjährigen Bestehen des Betriebsrätegesetzes war ausgesprochen pessimistisch: „Nachdem das Betriebsrätegesetz vier Jahre in Kraft war, hätte man annehmen können, die Unternehmer würden sich mit ihm abgefunden haben. Das ist aber keineswegs der Fall. Sie benutzten vielmehr die Wirtschaftskrise nach der Marktstabilisierung, welche sich im Bergbau besonders stark bemerkbar machte, dazu, um einen scharfen Kampf gegen die Betriebsräte zu führen. “401 Ein anderer Grund für die weiterhin auf den Zechen vorherrschende Konfrontationshaltung war die politische Radikalität der Belegschaften. Deren Hintergrund bildete die sich rasch verschlechternde materielle Lage der Bergarbeiterschaft während der

${ }^{399}$ Wiel, Wirtschaftsgeschichte des Ruhrgebietes, S. 131.

${ }^{400}$ Zum Verhältnis der Zechen zur staatlichen Wirtschafts- und Sozialpolitik vgl. Mommsen, Der Ruhrbergbau im Spannungsfeld, in: Blätter für deutsche Landesgeschichte 108 (1972), S. 167.

${ }^{401}$ Jahrbuch des Bergarbeiterverbandes 1924, S. 240. 
Hyperinflation ${ }^{402}$ und die sozialen Folgen der Stabilisierung. Anfang 1924 standen sich auf den Zechen eine "durchmarschbereite“ Arbeitgeberschaft und eine zumindest zu großen Teilen noch kampfbereite Bergarbeiterschaft gegenüber, deren Konflikte angesichts des Ausfalles des Preiserhöhungsautomatismus offen ausbrachen. Bereits bei den Stillegungsaktionen im Herbst 1923, vor allem aber im Kontext der Streiks und Aussperrungen im April und Mai $1924^{403}$ stellten sich wilde Konfliktformen ein, in denen die Zechenleitungen angesichts der schlechten Konjunkturlage in die Offensive kamen. Hatten zuvor vor allem die Bergarbeiter versucht, durch Regelverletzungen materielle Vorteile durchzusetzen, so setzten nunmehr die Zechenleitungen gezielt das Instrument der Regelverletzung selbst um den Preis einer Zerstörung der bisherigen Arbeitsgemeinschaft mit den Tarifgewerkschaften ein. Zuerst versuchte man, durch Wiedereinführung der Vorkriegsarbeitszeit aus der Leistungskrise des Bergbaus herauszukommen, des weiteren sollten durch Lohnkürzungen die Kostenstrukturen und damit die Liquidität der Unternehmen verbessert werden. ${ }^{404}$ Nachdem im Herbst 1923 der Versuch der Zechen gescheitert war, einseitig eine Verlängerung der Schichtzeiten (Unnaer Arbeitszeitdiktat) durchzusetzen, ging man zum Bruch des Lohntarifes über, um zumindest die Lohnsätze herabdrücken zu können. Wenn auch die spezifische politische Konstellation von Kohlengemeinwirtschaft und staatlicher Schlichtung einen Durchmarsch der Zechenleitungen verhinderte, so konnten die Lohnsätze dennoch deutlich gesenkt und die Arbeitszeit de facto verlängert werden, da durch einen staatlichen Schiedsspruch im April 1924 die achtstündige Schicht an die Stelle der siebenstündigen trat, die achte Arbeitsstunde mithin nicht mehr als Überstunde galt. ${ }^{405}$ Die Belegschaften gerieten in die Mühle sinkender Löhne und verlängerter Arbeitszeiten, aus denen das Tarifsystem keinen Ausweg mehr wies. Die Betriebsratswahlen im März und April 1924 brachten die Unzufriedenheit der Belegschaften auf den Punkt. Erstmals verloren die freien Gewerkschaften im Ruhrbergbau die relative Mehrheit der Stimmen und Mandate an die Union, die knapp 100000 Stimmen erzielte und damit auf eine Quote von 36,55\% kam. Die freien Gewerkschaften hatten weitere $7 \%$ der Stimmen verloren, behaupteten aber gemeinsam mit den christlichen Gewerkschaften, die gut 20\% der Stimmen erhalten hatten, noch eine tarifgewerkschaftliche Mehrheit in den Betriebsvertretungen. ${ }^{406}$ Für die GBAG-Zechen fehlen Einzelergebnisse. Die vorhandenen Daten für die Phoenix-Zechen zeigen, daß es wegen der knappen Mehrheits- bzw. Stimmverhältnisse in vielen Betriebs- und Arbeiterräten nicht mehr zu klaren Mehrheiten kam. Nur auf der Zeche Nordstern und auf Zollverein 3/7/10 gab es unionistische Mehrheiten. Auf Zollverein 4/5 aber hatte die Union überhaupt kein Mandat errungen, auf Zollverein 6/9 gab es ein Patt zwischen Tarifgewerkschaften und Union. Lediglich der Schacht Holstein des Vereinigten Hoerder Kohlenwerkes behauptete im übrigen 1924 eine deutliche freigewerkschaftliche

${ }^{402}$ Vgl. Hartewig, Das unberechenbare Jahrzehnt, S. $170 \mathrm{ff}$.

${ }^{403}$ Tschirbs, Tarifpolitik im Ruhrbergbau, S. $190 \mathrm{ff}$.

${ }^{404}$ Grundsätzlich hierzu Mommsen, Soziale Kämpfe im Ruhrbergbau, in: Mommsen, Borsdorf (Hg.), Glück auf, Kameraden!, S. 252-254.

${ }^{405}$ Mommsen, Verspielte Freiheit, S. 194.

${ }^{406}$ Jahrbuch des Bergarbeiterverbandes 1924, S. 240. 
Mehrheit. ${ }^{407}$ Die Deutsch-Lux-Zeche Dannenbaum in Bochum bekam 1924 erstmals für ein Jahr lang einen klar unionistisch beherrschten Betriebsrat, nachdem sich hier bis 1922 eine tarifgewerkschaftliche Mehrheit hatte behaupten können. ${ }^{408}$ Auf der Wittener GBAG-Schachtanlage Ver. Hamburg und Franziska, einer reinen Kohlenzeche ohne größeren Übertagebetrieb, behauptete sich hingegen die freigewerkschaftliche Mehrheit. ${ }^{409}$ Kurz: die Mehrheitsverhältnisse auf den Zechen der späteren Abteilung Bergbau der Vereinigten Stahlwerke wurden unübersichtlich. Als Muster zeigte sich lediglich die bekannte Tatsache, daß die Belegschaften der Großzechen der nördlichen und westlichen Reviere radikaler votierten als die Belegschaften der mittleren, südlichen und östlichen Schachtanlagen.

Die Maßnahmen der Zechenleitungen richteten sich in der folgenden Zeit keineswegs nur gegen Unionisten und Syndikalisten. Schon 1922 hatte sich gezeigt, $\mathrm{da} ß$ die Paralysierungspolitik der Zechenleitungen keineswegs nur auf radikale Betriebsräte abzielte. Es sollte vielmehr die Handlungsfähigkeit der Betriebsvertretungen generell eingeschränkt werden. Die Betriebsräte waren nicht zuletzt in der Arbeitszeitfrage ein ernstzunehmender Gegner, da das Überschichtenabkommen den Betriebsräten Mitspracherechte bei der Organisation der Mehrarbeit zugestanden hatte. Zudem verfügten sie über die Möglichkeit, unkontrollierbare Kommunikationsräume in den Belegschaften zu schaffen, die die stete Gefahr direkter Aktionen zu beinhalten schienen. Bereits die Reaktionen auf das Unnaer Arbeitszeitdiktat zeigten, daß zahlreiche Betriebsvertretungen nicht bereit waren, Arbeitszeitverlängerungen mitzutragen. ${ }^{410}$ Diese Widerstände zu brechen und die Handlungsbereitschaft der Belegschaften zu senken, war das eigentliche Ziel der gegen die Betriebsräte gerichteten Maßnahmen der Zechenleitungen. Sie gingen auf zweierlei Weise vor. Einerseits wurde versucht, mißliebige Betriebsvertreter zu entlassen, wobei den Höhepunkt dieser Strategie die Maiaussperrung 1924 darstellte, von der $95 \%$ der Belegschaft betroffen waren. Nach der Wiederaufnahme der Arbeit weigerten sich die Zechenleitungen, die bisherigen Betriebsvertreter anzuerkennen. Sie behaupteten, mit der Aussperrung seien die bisherigen Arbeitsverhältnisse gelöst, bei den notwendigen Neuwahlen könnten nach dem Text des BRG lediglich jene Arbeiter wählen, die länger als ein halbes Jahr beschäftigt waren, was nur noch auf $5 \%$ der Belegschaft zutreffe. Erst auf massiven Druck des Bergarbeiterverbandes beim Reichsarbeitsminister und den preußischen Bergbehörden hin fand man einen Kompromiß. In der Frage der Amtsfortführung wiedereingestellter Betriebsräte wurde eine neutrale Schiedskommission gebildet, deren Spruch sich beide Seiten im vorhinein unterwarfen. Unter der Leitung des Hammer Oberlandesgerichtspräsidenten kam am 11. Juni 1924 ein Schiedsspruch zustande, nach dem zumindest die wiedereingestellten Betriebsvertreter im Amt

407 Wahlergebnisse der Phoenix-Zechen, BgA 41/329.

${ }^{408} \mathrm{BgA} \mathrm{40/226.}$

409 BgA 40/44.

${ }^{410}$ Siehe die Zusammenstellung einzelner Berichte über Betriebsratsreaktionen bei der GBAG auf das Unnaer Arbeitszeitdiktat bei Tschirbs, Tarifpolitik im Ruhrbergbau, S. 203 f. Ferner Reaktion des bereits "gesäuberten“ Dannenbaum-Betriebsrates auf die Arbeitszeitverlängerung Anfang Januar 1924, Betriebsratssitzung, 5. 1. 1924, BgA 40/225. 
bleiben konnten. Flächendeckende Neuwahlen wurden dadurch überflüssig. ${ }^{411}$ Der Versuch, die unionistischen Betriebsräte auf diese Weise „elegant“ loszuwerden und durch wirtschaftsfriedliche Betriebsvertreter zu ersetzen, war damit gescheitert. In den folgenden Monaten betrieben die Zechenverwaltungen daher gezielt die Entlassung radikaler Betriebsräte, so daß der Stimmungsbericht des Dortmunder Oberbergamtes vom 1. Januar 1925 zufrieden feststellen konnte, die kommunistische Agitation im Steinkohlenbezirk sei entscheidend zurückgegangen: „Es hat zur Beruhigung auch wesentlich beigetragen, daß die Verwaltungen in den letzten Monaten ihre Belegschaften und Betriebsräte von den berufsmäßigen Hetzern, Großmäulern und anderen für die Arbeit minderwertigen Elementen gereinigt haben. ${ }^{4412}$

Zugleich unternahmen die Zechen auch wieder öffentliche Kampagnen gegen die Betriebsvertretungen. Ende des Jahres 1924 trat die Deutsche Bergwerks-Zeitung mit den Ergebnissen einer Umfrage zur Arbeit der Betriebsräte, deren Beantwortung der Zechenverband koordiniert hatte ${ }^{413}$, an die Öffentlichkeit. ${ }^{414}$ Das Gesamtergebnis war, wie nicht anders zu erwarten, niederschmetternd; vor allem die Großbetriebe beklagten den politischen Mißbrauch der Betriebsvertretungen. Die Verpflichtung des Betriebsrates auf das Gesamtwohl des Betriebes würde überhaupt nicht beachtet. Die meisten Zechen des rheinisch-westfälischen Industriegebietes plädierten daher für die Beseitigung des Betriebsrätegesetzes, zumindest aber für eine deutliche Einschränkung der Rechte der Betriebsvertretungen, behauptete die Bergwerkszeitung. ${ }^{415}$ Parallel zu dieser politischen Verurteilung der Räte beklagten Zechenverband und Deutsche Bergwerkszeitung die Kosten der Betriebsvertretungen. Ein jährlicher Förderausfall von $400000 \mathrm{t}$ sei durch die Einrichtung der Betriebsräte verursacht worden. ${ }^{416}$ Eine Modellrechung der Bergwerkszeitung kam gar zu dem Ergebnis, alle freigestellten Betriebsräte in Deutschland - im Bergbau beschäftigt - könnten die Kohlenförderung um 17 Mio. $t$ steigern, real entgehe der deutschen Volkswirtschaft durch das Betriebsrätegesetz mithin der Gegenwert von 17 Mio. t Kohle. Der Bergarbeiterverband widersprach energisch: falsche Zahlen aus dem Ruhrbergbau würden unzulässig extrapoliert. Im Ruhrbergbau gebe es keine 12000 Betriebsräte, von denen 1200 freigestellt seien. In Wirklichkeit gäbe es „nur rund 3500 Betriebsräte“. Von diesen würden vielleicht 600 wegen ihres Engagements in der Grubenkontrolle keine produktive Arbeit leisten, also die Hälfte weniger, als die Bergwerkszeitung behauptet hatte..$^{417}$

${ }^{411}$ Der Vorgang ist kurz und präzis dargestellt in: Jahrbuch des Bergarbeiterverbandes 1924, S. $95 \mathrm{f}$.

${ }^{412}$ Stimmungsbericht des Oberbergamtes Dortmund, 1. 1. 1925, StAM OBAD 1864, Bl. 70.

${ }^{413}$ Zechenverband, Bezirksgruppe Gelsenkirchen, an Mitgliedszechen, 20.3. 1924, BgA 41/329

${ }^{414}$ Hat sich das BRG bewährt? Ergebnisse einer Rundfrage, in: Deutsche Bergwerks-Zeitung, 18.11. 1924.

${ }^{415}$ Ebenda. Vgl. Gewerkschaftszeitung 1924, Nr. 50, S. 500 f.

${ }^{416} \mathrm{Vgl}$. Aufstellung der monatlichen Kosten im Bereich der Bergbauverwaltung des Phoenix: $7 \mathrm{Ze}-$ chen mit 14 Schachtanlagen und je einem Betriebsausschuß, Oktober 1924, BgA 41/329. Die Phoenix-Bergwerksverwaltung errechnete monatliche Lohnkosten für ausgefallene Arbeitsschichten der Betriebsausschuß-Mitglieder in Höhe von 15442,- RM sowie einen Förderausfall in Höhe von monatlich $1266 \mathrm{t} / 17850,-\mathrm{RM}$.

${ }^{417}$ Jahrbuch des Bergarbeiterverbandes 1924, S. 94. 
In den erhalten gebliebenen Antworten der einzelnen Phoenix-Zechen auf die Umfrage der Bergwerkszeitung zeigte sich ein plastisches Bild des Verhältnisses der Zechenleitungen zu den Betriebsräten, das zudem mit den Antworten verglichen werden kann, die dieselben Zechen zu Jahresende auf eine ähnliche Anfrage eines holländischen Aufsichtsratsmitgliedes gaben. ${ }^{418}$ Die Antworten auf die Anfrage der Deutschen Bergwerkszeitung erfolgten Mitte/Ende März 1924, zum Zeitpunkt der Betriebsratswahlen, bei denen auf den Phoenix-Schachtanlagen sich ein sehr unterschiedliches Bild ergeben hatte. Die Zeche Nordstern mit zwei Schachtanlagen hatte klare unionistische Mehrheiten in den Arbeiterräten, ein Patt in einem Betriebsrat, eine unionistische Mehrheit in dem anderen. ${ }^{419}$ Auf die Bergwerks-Zeitungs-Umfrage äußerte sich die Zechenleitung in Horst-Emscher am 20. März 1924 in scharf negativen Worten: „Das Zusammenarbeiten zwischen Betriebsrat und Werksverwaltung war durchweg schlecht. Es hat wiederholt Auseinandersetzungen und Unstimmigkeiten gegeben, weil der Betriebsrat seine Hauptaufgabe darin sah, lediglich die Arbeiterinteressen in einseitiger Weise zu vertreten. Mehrere Betriebsräte wurden wegen grober Verfehlungen - Begünstigung von Sprengstoffausgabe an die Rote Armee, Aufforderung zu Streiks, fristlos entlassen. " 420 Eine ähnliche Auffassung vertrat die Zeche Graf Moltke (zwei Schachtanlagen, eine mit unionistischer Mehrheit, eine mit Patt), die am 8. März 1924 nüchtern mitteilte: „Sachen, die ein Zusammenarbeiten mit dem Betriebsrat erforderlich machten, sind von dem Betriebsrat nicht vorgetragen worden. ${ }^{421}$ Die Zeche Westende, die tarifgewerkschaftliche Mehrheiten bei ihren beiden Arbeitervertretungen hatte, war nicht derart nüchtern, sondern äußerte sich grundsätzlich: „Die Durchführung des Betriebsrätegesetzes hat von Anfang an daran gekrankt, daß das Gesetz in einer Zeit politischer Hochspannung eingeführt wurde, und von der Arbeitnehmerseite zweifellos dazu dienen sollte, in wirtschaftlichen Fragen politische Machtansprüche durchzusetzen. Aus dieser Sachlage mußte sich eine Kampfstellung zwischen Verwaltung und Betriebsrat herausbilden, da erstere ihrem ganzen Wesen nach nur wirtschaftliche Ziele im Betrieb verfolgen kann und somit gezwungen war, den politischen Ansprüchen der Betriebsräte entgegenzutreten. " ${ }^{422}$ Für die Westender Zechenleitung war es daher fast zwangsläufig, daß es "nur vereinzelt möglich (war), zu einer wirklichen $\mathrm{Zu}$ sammenarbeit zu gelangen." Alles sei sofort politisch aufgeladen worden: „Selbst die Aufgaben des Betriebsrates, die diesem Gelegenheit geben konnten, wirklich sachlich mit der Verwaltung zusammenzuarbeiten, wie die Bekämpfung von Unfall- und Gesundheitsgefahren, die Weiterleitung und Abstellung von Beschwerden der Arbeiterschaft wurden auf das politische Gebiet gezerrt und konnten dadurch keine vernunftmäßige Regelung finden." Ließ sich die Politisierung hier noch ertragen, so bekam sie in anderen Fragen sehr kontraproduktive Züge: „Viel deutlicher trat dieses noch in die Erscheinung bei den politisch sich auswirkenden Fragen wie Regelung der Arbeitszeit und der Lohnzahlungen, die von den Betei-

\footnotetext{
${ }^{418}$ Phoenix-Hauptverwaltung an die Betriebsabteilungen, 27. 10. 1924, BgA 41/329.

$419 \mathrm{BgA} \mathrm{41/329.}$

420 BgA 41/329.

$421 \mathrm{BgA} \mathrm{41/329.}$

+22 8. 3. $1924, \mathrm{BgA} 41 / 329$.
} 
ligten als Tummelplatz ihrer Ansprüche betrachtet wurden." Die Westender Zechenleitung wollte diese „Verzerrungen" vor allem à conto der Aufgeregtheiten der Zeit schreiben. „Es dürfte nicht ausgeschlossen sein, daß bei weiterer wirtschaftlicher Durchbildung der Betriebsräte das Verhältnis ein besseres werden kann. "423 Vom Hoerder Kohlenwerk schließlich, dessen eine Schachtanlage unionistisch, die andere freigewerkschaftlich votiert hatte, kamen nur einige lakonische Bemerkungen: „Von einem Zusammenarbeiten kann man kaum sprechen. Die Betriebsräte haben der Betriebsleitung - namentlich in der ersten Zeit ihrer Tätigkeit - viel Zeit weggenommen, hatten immer viel Lust zu Sitzungen und langen Reden. Was sie vortrugen, war meist töricht und mußte daher abgelehnt werden. Das galt ihnen dann als Bosheit. Allmählich ist die ganze Tätigkeit des Betriebsrates versandet." ${ }^{24}$ Die Deutsche Bergwerks-Zeitung hatte ebenfalls gefragt, welche Personen in die Betriebsräte gewählt würden. Das Urteil der Phoenix-Zechen war auch hier eindeutig: „In den Betriebsräten waren fast durchweg die schlechtesten Arbeiter vertreten", vermeldete die Zeche Nordstern. Bei Graf Moltke waren die Auswahlkriterien „Organisationszugehörigkeit“ und „Redegewandtheit". Kompetenz spiele keine Rolle. Die Zeche Westende betonte das Überwiegen politischer Kriterienbei der Kandidatenauswahl, wodurch sehr viele junge Leute in die Betriebsvertretungen gekommen seien. „Allerdings scheint von den Organisationen in letzter Zeit mehr Wert darauf gelegt zu werden, daß auch ältere beständigere Leute aufgestellt werden." Die Zechenleitung des Hoerder Kohlenwerkes, die die Ansichten ihrer Arbeiter im wesentlichen "töricht" fand, wunderte sich auch über deren personalpolitische Vorlieben: „Die Leute entwikkeln in der Auswahl ihrer Vertreter vielfach einen komischen Geschmack. Neben einigen guten Arbeitern und verständigen Menschen findet man zahlreiche andere, die sich durch nichts als durch große Worte auszeichnen. Schließlich scheint es auch eine Naturnotwendigkeit zu sein, daß das minderwertigste Belegschaftsmitglied im Betriebsrat nicht fehlen darf."

Auf die Frage nach ihrer wirtschaftlichen Funktion waren sich alle Zechenleitungen einig. Sinnvolle wirtschaftliche Arbeit leisteten die Betriebsvertretungen nicht, im Gegenteil! Sie würden die Zeche schädigen, schrieb die Zechenleitung von Nordstern, „nicht allein dadurch, daß sie produktive Arbeit selbst nicht leisteten, sondern auch einen ungünstigen Einfluß auf die Leistung der Arbeiter ausgeübt und Streiks und Arbeitseinstellungen begünstigt haben." Die Leitung von Graf Moltke störte in dieser Hinsicht, daß die Betriebsausschußmitglieder bei ihren Revierbefahrungen die Leute von der Arbeit abhielten, namentlich „durch lange Besprechungen von Verbandsangelegenheiten“. Überdies würde der Betriebsrat, der die "Gedingesätze stets zu niedrig hinstellt", die „Arbeitsfreude“ zerstören. Auf der Zeche Westende kam man zu dem Schluß, daß wirtschaftlich die Räte keinerlei positive Bedeutung hätten. „In dieser Beziehung waren die Mitglieder viel zu sehr von dem Gedanken beherrscht, daß eine Schwächung des , $\mathrm{Ka}$ pitalismus" zum Vorteil der Arbeiter gereiche." Unverantwortliche Betriebsräte hätten u. a. bei Arbeitseinstellungen und passiver Resistenz eine unheilvolle Rolle

423 Ebenda.

424 12. 3. 1924, , BgA 41/329. 
gespielt. Aus Hoerde war eine ähnliche Beurteilung zu hören. Über ihre Rolle beim Arbeits- und Unfallschutz wußte ebenfalls nicht eine Zechenleitung Positives zu melden. Nach Meinung der Zeche Nordstern hatten die Betriebsräte hier "geradezu versagt“ und sich stattdessen nur darum gekümmert, „zugunsten der Arbeiter das Möglichste herauszuholen." Ähnlich lagen die Dinge nach Ansicht der Zechenleitung von Graf Moltke; die Versuche der Bergbehörde, die Betriebsräte im Unfallschutz heranzuziehen, kamen auf Zeche Westende, so der Bericht, „zu einem völligen Fiasko; brauchbare Vorschläge sind kaum von den Betriebsräten gemacht worden, so daß die Aussprachen nahezu ganz eingestellt worden sind." In Hoerde empfand man die Frage fast schon als unanständig: „Für den Arbeiterschutz hat er nichts geleistet und konnte er auch nichts leisten. Eine Grube, die nachhaltig mit Nutzen betrieben werden soll, kann nicht lodderig geführt werden. Die Baue müssen schon aus Gründen des Geldverdienens - wenn man die Sorge des Unternehmers für die Sicherheit der Arbeiter nicht gelten lassen will in tadellosem Zustande gehalten werden. Tatsächlich haben die Betriebsräte in dieser Richtung auch niemals Klagen vorgebracht, obwohl wir von ihnen Meldungen über bei Befahrungen gefundene Mängel ausdrücklich verlangt haben.“

Vor diesem Hintergrund war es auch kein Wunder, daß die Betriebsräte nach Auffassung der Zechenleitungen einen negativen Einfluß auf das Verhältnis zwischen Belegschaften, Vorgesetzten und Zechenleitungen ausübten. „Die Verschärfung der Gegensätze zwischen Arbeitern und Vorgesetzten ist darauf zurückzuführen“, so die Meinung beim Nordstern, „daß die Betriebsräte vielfach versuchten, die Autorität der Vorgesetzten mit allen Mitteln zu beeinträchtigen. “ Auf der Zeche Graf Moltke wollte man ebenfalls eine massive Verschlechterung der Vorgesetzten-Arbeiter-Beziehung im Kontext des Betriebsrätegesetzes festgestellt haben. Ständig hätten sich die Betriebsvertreter in Lohn- und Tariffragen eingemischt. „Weiter haben sie nur darüber nachgedacht, wie für sie noch irgendwelche Vorteile geldlicher Art oder in Form von nicht zu leistender Arbeit aus dem Betriebsrätegesetz herauszulesen sei." Durch die Art der Forderungen hätten sie zu erheblichen Konflikten beigetragen: „Bei der Vorlage von Wünschen wurde auf deren Erfüllbarkeit keine Rücksicht genommen. Jegliche Schuld an der Ablehnung ihrer unerfüllten Forderungen wurde von dem Betriebsrat dann auf die Werksverwaltung und die Beamten geschoben, wodurch dann besonders junge Leute und auch ältere, frisch angelegte Leute, die die Beamten noch nicht persönlich genügend kannten, letztere als ihre größten Feinde anzusehen lernten.“ Die Zeche Westende beklagte zwar auch die negativen Folgen der bisherigen Rätepraxis, war aber nachdenklicher: „Immerhin muß anerkannt werden, daß durch das Bestehen des Betriebsrätegesetzes als solchem die Möglichkeit gegeben war, mit einer gesetzmäßigen Vertretung der Arbeiterschaft zu verhandeln, wodurch gegebenenfalls Streitigkeiten leichter ausgetragen werden konnten, als es sonst möglich gewesen wäre." Das Hoerder Kohlenwerk meinte schließlich, das Betriebsrätegesetz habe auf die Beziehungen überhaupt keinen Einfluß weder im guten noch im schlechten Sinne gehabt. Auf die abschließenden Fragen nach der Zukunft des Gesetzes fielen die Antworten nuanciert unterschiedlich aus. In Horst-Emscher war man skeptisch; zumindest solange sich die Betriebsräte „politisch“ betätigten, sei nicht mit einer Verbesserung der Verhältnisse zu rechnen. Im Prinzip aber ver- 
langte man eine Einschränkung des Gesetzes: „Die Tätigkeit der Betriebsräte sollte sich lediglich erstrecken auf die Überwachung und Innehaltung der Arbeitsordnung und bei ihren Befahrungen auf die Befolgung der Unfallverhütungsschutzvorschriften. Hierbei müßte insbesondere verlangt werden, daß die Betriebsräte die Betriebspunkte nur in Begleitung der Beamten befahren." Schließlich war man auch der Auffassung, daß die „Anzahl der Betriebsratsmitglieder wesentlich eingeschränkt werden (könnte)“. Die Zechenleitung von Graf Moltke sprach eine deutlichere Sprache: „Es wäre ... im Interesse des Werkes samt der Arbeiterschaft das beste, wenn das Betriebsrätegesetz ganz verschwinden würde, da es den Arbeitern keinen Nutzen und dem Werk nur Schaden gebracht hat." Zeche Westende verlangte, der Betriebsrat müsse zumindest aus dem Einzelarbeitsverhältnis herausgehalten werden, „sei es in Lohnfragen, in Fragen der Beschäftigung und Kündigung." Das Hoerder Kohlenwerk, das zuvor die Betriebsräte bitter kritisiert hatte, war in der Schlußbetrachtung indes sehr moderat. „Ein Betrieb mit einer großen Arbeiterzahl braucht ... eine Arbeitervertretung, die die gemeinsamen Interessen der Arbeiter wahrnimmt. Wenn sie sich auf diesen Pflichtenkreis beschränkt, ist sie ... von Nutzen." In Hoerde bestritt man lediglich den Sinn der häufigen Revierbefahrungen. Diese seien schlicht „überflüssig.“425

Innerhalb der Phoenix-Bergwerksverwaltung wurden diese Stellungnahmen zusammengefaßt und an den Zechenverband weitergeleitet, wobei die Nuancierungen unter den Tisch fielen. Kamen in diesen Berichten vor allem die Erfahrungen der Revolutions- und Inflationszeit zum Ausdruck, in denen in der Tat Kleinkrieg, Kampf und Unverständnis vorgeherrscht hatten, so zeugten sie andererseits von einem engen Selbstverständnis der Zechenleitungen, die nicht wahrnahmen, daß ein Teil des Verhaltens der Betriebsräte lediglich Ausdruck und Folge der Blockadepolitik von Zechenleitungen und Berginspektion war. Wären die Aussagen der Zechenleitungen in der Betonung der "Politisierung“ als Ursache der versagenden Kooperation korrekt gewesen, so hätten die ein knappes dreiviertel Jahr später, nach der „Säuberung“ der meisten Betriebsvertretungen verfaßten Berichte für den holländischen Aufsichtsratsvertreter unterschiedlich ausfallen müssen. In der Tat zeigte sich jetzt eine moderatere Haltung der Zechenleitungen, die es mit "friedlichen“ Belegschaften und tarifgewerkschaftlichen Betriebsräten zu tun hatten. Die Zeche Westende erging sich jetzt gleichwohl noch in Grundsatzanklagen, wobei - für die Zechenleitung von Westende typisch - man sozialpolitische Kompetenz zeigte. ${ }^{426}$ Zunächst legte man dar, daß die Betriebsräte ihrer doppelten Aufgabenstellung kaum gerecht werden könnten und sich lediglich um die Interessen der Arbeiter kümmern würden. Die im März beklagte Tatsache, der Betriebsrat politisiere und schaffe dadurch Konflikte, wurde wiederholt: "Je nach Begabung und Temperament, offen und geheim, mit größerem oder geringerem Geschick und nicht selten mit fragwürdigen Mitteln wird innerhalb der Betriebsorganisation versucht, die Stellung der Arbeitgeber zugunsten des Arbeitnehmers zu schwächen. Die Interessen des Werkes als solchem treten dabei natürlich in den Hintergrund. Auf diese Weise haben sich die Betriebsräte immer mehr zum Tum-

$425 \mathrm{BgA} 41 / 329$.

426 Zeche Westende an Phoenix-Bergwerksverwaltung, 31. 10. 1924, BgA 41/329. 
melplatz politischer Auseinandersetzungen entwickelt, auf dem auch die gegensätzlichen mehr oder minder radikalen Ansichten der Arbeiter unter sich nicht selten heftig aufeinanderprallen." Zwar habe sich eine gewisse Mäßigung breitgemacht, doch: „Alles in allem ist die Organisation der Betriebsräte aber auch jetzt noch, besonders indirekt mit Kosten verknüpft, für die ein Gegenwert in Leistungen für das Werk seitens der Betriebsräte nicht besteht. ${ }^{\text {" } 227}$ Die Zeche Nordstern blies in das gleiche Horn, zumal in ihren Betriebsausschüssen weiterhin Kommunisten saßen. ${ }^{428}$ „Bei den wöchentlichen Befahrungen der einzelnen Betriebsabteilungen, die sie [die Betriebsräte] meistens allein ohne Begleitung von Beamten vornehmen, werden die Arbeiter vielfach in der Arbeit gestört und unnötig aufgehalten, und es ist bestimmt anzunehmen, daß gerade augenblicklich wieder, insbesondere von den kommunistischen Betriebsräten, reichlich für kommunistische Zwecke agitiert wird. ${ }^{* 429}$ Diese Beschreibungen betonten lediglich das Negative und übertrieben ganz zweifellos die von den Betriebsräten ausgehende "Gefahr". Die Antwort des Hoerder Kohlenwerkes auf die Anfrage des holländischen Aufsichtsratsmitgliedes zeigte, daß man die Situation auch nüchtern begreifen konnte: "Während wir in der ersten Zeit des Bestehens der Betriebsräte viel Scherereien mit ihnen hatten, ist ihre Tätigkeit allmählich in ein ruhiges Fahrwasser gekommen. Viel Schaden haben wir heute von den Leuten nicht mehr, abgesehen von dem, daß wir Leute bezahlen müssen, die nicht arbeiten." Das Hoerder Kohlenwerk hatte zwei Schachtanlagen (Holstein, Schleswig): „Auf Zeche Holstein ist seit dem Bestehen des Betriebsrätegesetzes ein recht verständiger Mann an der Spitze des Betriebsrates. Er hält jetzt fast niemals mehr Sitzungen ab, vertritt seine Wünsche allein und hat Autorität genug bei den Leuten, um unberechtigte Forderungen von Arbeitern seinerseits zurückzuweisen, so daß wir in diesem Falle sagen können, daß wir von der Einrichtung sogar einen gewissen Nutzen haben.“ Ganz anders sah es bei der Nachbaranlage aus: „Auf Schleswig hat die Zusammensetzung des Betriebsrates mehrfach gewechselt. Dort steht keine solche überragende Persönlichkeit an der Spitze. Infolgedessen wird dort noch immer viel getagt und viel nutzloses Zeug geredet." In Hoerde war man bereit, sich mit dem Status quo zu arrangieren: „Da irgendeine Arbeitervertretung notwendig ist, kann man sich mit dem gegenwärtigen Zustande abfinden, wenn man den Betriebsrat in den Grenzen hält, die ihm das Gesetz zieht. “430

Der Leiter der Bergwerksverwaltung des Phoenix, Schulze-Buxloh, faßte die Berichte zusammen, strich die weniger schroffen Stellen heraus und übersandte den Bericht an den Phoenix-Vorstandsvorsitzenden Fahrenhorst. ${ }^{431}$ Wie bereits im März wurde erneut ein Bild vermittelt, das nicht den realen Nuancierungen entsprach. Faktisch waren die Zechen in der zweiten Hälfte des Jahres 1924 nicht mehr zu größeren Auseinandersetzungen mit den Betriebsräten gezwungen. Der Vorstand der Bergwerksabteilung der Rheinelbe-Union befaßte sich 1924 ledig-

\footnotetext{
+27 Ebenda.

${ }^{428}$ Zeche Nordstern an Phoenix-Bergwerksverwaltung, 31. 10. 1924, BgA 31/329.

${ }^{429}$ Ebenda.

430 Ver. Hoerder Kohlenwerk an Phoenix-Bergwerksverwaltung, 29. 10. 1924, BgA 41/329.

431 Schulze-Buxloh an Fahrenhorst, 2. 11. 1924, BgA 41/329.
} 
lich ein einziges Mal mit Betriebsrätefragen. ${ }^{432}$ Probleme mit dem Betriebsrätegesetz tauchten nicht auf und auch die wenigen Protokolle von Betriebsratssitzungen aus dem Jahr 1924, etwa der Phoenix-Zeche Holland oder von Dannenbaum, zeigten keine Anzeichen eines groben Radikalismus, sondern signalisierten das Bemühen der Betriebsvertretungen um möglichst konkrete Verbesserungen der sozialen Lage der Bergarbeiter. ${ }^{43}$

Den Bergwerksverwaltungen und der von diesen freilich mitorganisierten Beschäftigungskrise war es Ende 1924 gelungen, den Betriebsräten ihren politischen Stachel zu ziehen. Zwischen Wahlradikalität und betrieblicher Aktion öffnete sich eine zunehmend breiter werdende Kluft. Je gefährdeter der Arbeitsplatz wurde, um so mehr wuchs zwar die Bereitschaft vieler Bergarbeiter, eine radikale Gruppierung zu wählen, an deren radikale Aktionen man aber nicht teilnehmen wollte. Auf diese Weise hielten sich 1924 und 1925 unionistisch-kommunistische Gruppierungen bei den Betriebsratswahlen. ${ }^{44}$ 1925, nach der Auflösung der Union der Hand- und Kopfarbeiter und des mehrheitlichen Übertrittes ihrer Mitglieder zum Alten Verband, ergaben sich schließlich klare freigewerkschaftliche Betriebsratsmehrheiten. ${ }^{435}$ Diese signalisierten aber nicht unbedingt einen Bruch in der Einstellung der Belegschaften. ${ }^{436}$ Die Zechenleitungen trauten daher dem Frieden nicht, der sich in der zweiten Jahreshälfte 1924 eingestellt hatte. Hauptursache für dieses Mißtrauen war der Versuch der KPD, flächendeckend Betriebszellen einzurichten, Belegschaftszeitungen herauszubringen und die Tarifgewerkschaften zu „unterwandern“ ${ }^{437}$ Die Zechenleitungen begannen im Gegenzug gezielt, die noch verbleibenden Handlungsspielräume der ohnehin bereits weitgehend disziplinierten Betriebsräte zu beschneiden. Ihr Hauptaugenmerk konzentrierte sich dabei auf die Revierbefahrungen der Betriebsräte. Das unkontrollierbare Verhalten der Betriebsräte unter Tage war den Zechenleitungen seit langem ein Dorn im Auge. Durch das Recht, die Größe der Steigerreviere und damit der Fahrabteilungen der jeweiligen Betriebsausschußmitglieder festzulegen, hatten die Zechenleitungen ein Mittel in der Hand, die Bewegungsfreiheit der Betriebsräte in den Gruben zu behindern, wobei die beginnende Rationalisierung im Bergbau den Zechenleitungen zu Hilfe kam. Denn die Größe der Steigerreviere war nicht willkürlich festsetzbar, sondern mußte bergtechnische, betriebswirtschaftliche und arbeitsorganisatorische Gesichtspunkte zu berücksichtigen. Die auf den Zechen von 1924 an wegen der Überproduktion und der ungünstigen Kostenstrukturen beginnende Rationalisierung erzwang eine Vergrößerung der Steigerreviere und erlaubte damit, die Befahrungstätigkeit der Betriebsräte wirksam zu beschränken. Gegen diese schleichende Aushöhlung ihrer Arbeitsfähigkeit blieb den Betriebsräten nur der Weg zum Gericht, allerdings ohne Erfolg. Das Berggewerbegericht Aachen

\footnotetext{
+32 Niederschrift der Vorstandssitzung der Bergwerksabteilung, 2. 5. 1924, BgA 55/126.

${ }^{433}$ BgA 41/329; BgA 40/225.

4341924 hatte es eine relative Mehrheit der Stimmen und Mandate gegeben, 1925 erreichte die Union 29\% der Stimmen, die freien Gewerkschaften 40,5\% und dic christlichen 23,3\% der Stimmen. Siehe Martiny, Arbeiterbewegung an Rhein und Ruhr, S. 253. Vgl. auch Zollitsch, Arbeiter zwischen Weltwirtschaftskrise und Nationalsozialismus, S. $190 \mathrm{ff}$.

435 Jahrbuch des Bergarbeiterverbandes 1925, S. $88 \mathrm{f}$.

436 Zollitsch, Arbeiter zwischen Weltwirtschaftskrise und Nationalsozialismus, S. 290.

${ }^{437}$ Bericht des Bergrevierbeamten Buer, 29. 12. 1924, StAM OBAD 1864, Bl. 101.
} 
bestätigte das Recht der Zechenleitungen, die Größe der Steigerreviere allein festzusetzen, was der Zechenverband unmittelbar darauf den Mitgliedszechen bekanntgab. ${ }^{438}$ Im Januar 1925 wies das Berggewerbegericht Dortmund auch eine Klage des Betriebsrates der Rheinelbe-Zeche Minister Stein III gegen die willkürliche Vergrößerung von Steigerrevieren zurück. ${ }^{439}$

\section{Das Grubenunglück auf Minister Stein}

Kurze Zeit nach dem Urteil des Berggewerbegerichts kam es am 11. Februar 1925 auf Minister Stein zu einer Schlagwetterkatastrophe, der 136 Bergleute zum Opfer fielen. Nach der Explosion wurde sehr schnell der Vorwurf großer Arbeitshetze und mangelnder Einhaltung der Sicherheitsbestimmungen laut. Die Bergarbeiterzeitung erinnerte in ihrer Ausgabe vom 21. Februar 1925 an das Dortmunder Urteil: „Diese Betriebsräte protestierten gegen eine Maßnahme der Zechenverwaltung, welche den Betriebsräten die gewissenhafte Befahrung der Grubenbaue zum Zwecke der Prüfung der vorhandenen Sicherheitseinrichtungen erschwerte. Betriebsräte, die bisher ein Revier gründlich befahren konnten, mußten jetzt zwei Reviere befahren, damit sie besser produktive Arbeit leisten konnten " ${ }^{440}$ Für die Bergarbeiterzeitung war die Schuldfrage geklärt: „Die ganze ungeheure Schuld der Zechenherren tritt hier ans Licht. Im gehässigen Kleinkampf sucht man den pflichtbewußten Betriebsräten, die mit der Befahrung der Strecken nur das Leben ihrer Kameraden schützen wollen, die Arbeit möglichst schwer zu machen." Die Bergarbeiterzeitung erkannte System hinter diesen Maßnahmen: „Doch nicht nur auf einer Zeche, im ganzen Kohlenrevier macht sich der reaktionäre Geist der Zechenherren bemerkbar. Aus allen Institutionen sucht man die Arbeitervertreter hinauszuekeln." So habe fast zwei Jahre lang überhaupt keine Sitzung der Gesteinsstaubkommission stattgefunden. ${ }^{441}$ Den Opfern der Schlagwetterkatastrophe, die man jetzt als "brave Knappen“ bezeichne, „haben die Zechenherren in maßlosem Dünkel immer das Recht freier Mitbestimmung abgesprochen." ${ }^{\text {"42 Ins- }}$ besondere aber starke Antreiberei und Arbeitshetze hätten zu einer Beschneidung der Betriebsratsrechte und Vernachlässigung der Sicherheitsbedingungen geführt. Die Vorwürfe waren nicht aus der Luft gegriffen. Minister Stein war neben Rheinelbe/Alma die größte Schachtanlage der alten GBAG und wurde Mitte der zwanziger Jahre gezielt und zügig zur Großschachtanlage ausgebaut. ${ }^{443}$ Die Ausdehnung der Förderung, die Ende 1924 bereits über dem Stand von $1913 \mathrm{lag}$, ging rascher voran als der Ausbau der grubentechnischen Anlagen, der offensichtlich erst nachzog. „Die Werksverwaltung von Minister Stein muß sich jetzt vor der Öffentlichkeit verantworten!“ Die Bergarbeiterzeitung wollte vor allem wissen, warum in dem betreffenden Schacht das "Gesteinsstaubverfahren“ noch nicht

\footnotetext{
${ }^{438}$ Rundschreiben Nr. 22, 27. 1. 1925, des Zechenverbandes, BgA 41/312.

439 Der Vorsitzende der Spruchkammer Dortmund des Berggewerbegerichts an den Herrn Reichsarbeitsminister, 18. 2. 1925, BAP RAM 419, Bll.205-210.

${ }^{440}$ Bergarbeiterzeitung. Organ des Verbandes der Bergarbeiter Deutschlands, 21. 2. 1925.

441 Ebenda.

442 Ebenda.

+43 1913990000 to/Jahr, 19251181000 to/Jahr, 19382066000 to/Jahr, Wiel, Wirtschaftsgeschichte des Ruhrgebietes, S. 181-183.
} 
durchgeführt, warum Gefahrenhinweise aus dem Betriebsausschuß nicht ernst genommen, ja von den zuständigen „Grubenbeamten“ bestritten worden seien.

Das Bergamt hielt sich mit seinem Urteil zurück: „Die Gerüchte, die über die Explosionsursache im Umlauf sind, entbehren der Begründung. Zurzeit kann nur gesagt werden, daß Kohlenstaub bei der Explosion mitgewirkt hat. ${ }^{\text {“444 }}$ Der Unfallausschuß der Grubensicherheitskommission Dortmund kam einige Zeit später, im April 1925, zu dem Ergebnis, auf Minister Stein sei eine Kohlenstaubexplosion erfolgt, bei der technische Probleme (teilweiser Ausbau der Stein- bzw. Kohlenstaubsperren) und menschliches Versagen (Ausführung von Schießarbeiten durch den Ortsältesten statt den Schießmeister) zusammengespielt hätten, konnte sich aber auf eine Stellungnahme zur Bedeutung der Betriebsvorschriften der Zeche für die Explosion nicht einigen. Der Ausschuß hatte aber immerhin festgestellt, das Verhältnis zwischen Zechenleitung und Betriebsvertretung sei so schlecht nicht gewesen. Größere Klagen hätte der Betriebsausschuß in Sicherheitsfragen nicht vorgebracht, kleineren sei abgeholfen worden. „Der Betriebsausschuß anerkennt die Maßnahmen der Verwaltung; Beschuldigungen allgemeiner Art, die mit der Explosion in erheblichem Zusammenhang stehen, hat er gegen die Werksleitung nicht ausgesprochen. ${ }^{445}$ Der Betriebsausschuß hielt jedoch den Vorwurf aufrecht, daß ihm die Zechenleitung zu wenig Gelegenheit zur Befahrung der „Unglücksreviere“ gegeben habe. Dies wurde von Seiten der Arbeitgebervertreter allerdings bestritten, so daß der Unfallausschuß der Grubensicherheitskommission sich selbst ein Bild machte. ${ }^{446}$ Der Untersuchungsausschuß verurteilte schließlich das Verhalten der Zeche in diesen Fragen nicht. Die Arbeitermitglieder im Unfallausschuß sowie ein Vertreter des Oberbergamtes gaben aber ein Sondervotum ab, welches kritisierte, daß „1. die gesetzliche Betriebsvertretung durch willkürliche Festsetzung der Größe der Fahrabteilungen in ihren Befahrungen und ihrer Überwachung der Sicherheit der Betriebe in dem Explosionsfelde beschränkt worden sei.... 2. Das Prämiensystem, d. h. die Gewährung besonderer, von der Förderleistung abhängender Vergütungen an die Aufsichtsbeamten veranlasse diese, die Sicherheit des Betriebes außer acht zu setzen, um einen hohen Effekt und geringe Kosten für Materialien, Holz usw. zu erzielen. Auf der Zeche herrsche ein von der Verwaltung unterstütztes Antreibesystem. Das Abschließen der Gedinge durch den für die Sicherheit des Betriebes nicht verantwortlichen Fahrsteiger bildet einen Grund mehr, daß von der für die „Sicherheit des Reviers erforderlichen Sorgfalt abgewichen werde. “447

Die Arbeitgebervertreter wiesen diese Angaben als unzutreffend zurück, und in der Tat waren allein auf Minister Stein die Abbauverhältnisse so unterschiedlich, daß ein simpler Zusammenhang zwischen einer bestimmten Arbeitsorganisation und der generellen Grubensicherheit nicht hergestellt werden konnte. Eindeutiger waren schon die Hinweise auf die technisch unzureichende Sicherung gegen Wetter durch Staubsperren, spezifische Formen der Bewetterung sowie unzureichende Berieselung und schlecht kontrollierte Schießarbeit in einer als gas- und

${ }^{444}$ Zit. nach Bergarbeiterzeitung, 21. 2. 1925.

${ }^{445}$ Zit. nach Bergarbeiterzeitung, Nr. 13, 6. 4. 1925.

${ }^{446}$ Ebenda.

${ }^{447}$ Ebenda. 
kohlenstaubgefährdet geltenden Flözpartie: „Der Ausschuß kommt daher zu dem Ergebnis, daß der Werksleitung nicht der Vorwurf erspart bleiben kann, nicht alles getan zu haben, was zur wirksamen Bekämpfung der Unfallgefahr hätte geschehen müssen." Aber für die Grubensicherheit war auch die Berg- als Genehmigungsbehörde verantwortlich: „Auch die Bergbehörde hat von dem Recht der Ausnahmegenehmigung sowohl hinsichtlich der Wetterführung als auch der Schießhauer zu reichlich Gebrauch gemacht. ${ }^{* 448}$ Damit stand man vor dem Problem, eine eindeutige Schuldzuweisung nicht vornehmen zu können. Schuldzuweisungen erfolgten daher von den einzelnen beteiligten Gruppen und der Politik, die schnell eine kommunikative Eskalation einleiteten.

Die Schuldzuweisungen begannen unmittelbar nach der Katastrophe bei einer Reichstagsdebatte am 19. Februar 1925, die auf eine Interpellation der SPD-Fraktion hin zustande kam. ${ }^{449}$ Die Reichsregierung verhielt sich jedoch gegenüber sozialdemokratischen und kommunistischen Forderungen nach einer Verbesserung der Grubenkontrolle u. a. durch eine Hinzufügung entsprechender Passagen in das Betriebsrätegesetz ausgesprochen zurückhaltend. Auf die Anfragen der SPD antwortete das Reichsarbeitsministerium: „Das geltende Recht gibt ... den Betriebsräten auf dem Gebiete der Unfallverhütung im Bergbau ein außerordentlich weites Wirkungsfeld. Ein Anlaß zu neuen gesetzgeberischen Maßnahmen seitens des Reiches liegt nicht vor. Vielmehr genügt die tatkräftige Durchführung des geltenden Rechts, um allen berechtigten Wünschen auf Mitwirkung der Betriebsvertretungen an der Unfallverhütung zu genügen." Im übrigen müsse das Ergebnis des Untersuchungsausschusses abgewartet werden ${ }^{450}$ Der Reichstag ließ sich mit derartigen Bemerkungen nicht zufriedenstellen, sondern ersuchte die Reichsregierung, die Mitwirkung der Betriebsräte bei der Grubenkontrolle und Unfallverhütung zu verbessern und „mit möglichster Beschleunigung dem Reichstag den Entwurf eines Reichsberggesetzes vorzulegen. ${ }^{~} 451$ Das Reichsarbeitsministerium erachtete die an der Ruhr geltenden Richtlinien für ausreichend und plädierte statt eines neuen Gesetzes für eine Klarstellung offener Fragen, etwa der Reviereinteilung, durch die Tarifpartner. ${ }^{452}$ Weitere Initiativen zur Verbesserung des Unfallschutzes oder gar die Vorlage eines Reichsberggesetzes unterblieben daher. Als die KPD-Fraktion am 6. April 1925 nachfaßte ${ }^{453}$, wurde sie mit dem Hinweis auf laufende Debatten im Preußischen Landtag beschieden. ${ }^{454}$

Parallel zu ihren Initiativen im Reichstag hatten SPD und KPD im eigentlich zuständigen Preußischen Landtag Anträge eingebracht. ${ }^{455}$ Doch auch hier kam

${ }^{448}$ Ebenda.

${ }^{449}$ Aktennotiz Feig, 25. 2. 1925, BAP RAM 419, Bl. 217.

${ }^{450}$ Auszugsweise Abschrift aus dem Entwurf für die Beantwortung der Interpellationen Nr. 547 und 552, ohne Datum, mit Abzeichnungsvermerk, BAP RAM 419, Bll.218f.

${ }^{451}$ Der Präsident des Reichstages an den Reichsarbeitsminister, 19. 2. 1925, BAP RAM 419, Bl. 220.

${ }^{452}$ Der Staatssekretär im Reichsarbeitsministerium Geib an die Fachgruppe Bergbau des RDI, 14.4. 1925, BAP RAM 419, Bl. $225 \mathrm{f}$.

${ }^{453}$ Reichstag, III. Wahlperiode 1924/25: Interpellation der KPD-Fraktion, 6. 4. 1925, BAP RAM 419, Bl. 229. Die Interpellation griff weitere Grubenunglücke, so auf Matthias Stinnes, auf und verlangte „durchgreifende Maßnahmen zum Schutze des Lebens der gefährdeten Bergarbeiter", insbesondere die Wiedereinführung der Siebenstundenschicht.

${ }^{454}$ Vorschlag zur Beantwortung der Anfrage der KPD-Fraktion, 28. 4. 1925, BAP RAM 419, Bl. 227.

455 Preuß. Landtag, 2. Wahlp., 1.Tagung: Uranträge der SPD-Fraktion (Vermehrung der Bergrevierin- 
man nicht voran. Wiederholt wurde von Länderministerien beim Reichsarbeitsministerium in Berlin angefragt, was denn nun geschehe. Immer erfolgte der Hinweis auf eine mögliche preußische Initiative, doch nichts geschah. ${ }^{456}$ Anfang August 1925 war klar, daß eine Gesetzesinitiative durch die Bürokratie nicht erfolgen würde, sondern man sich um eine Regelung durch die Tarifparteien bemühen wollte. ${ }^{457}$ Der Preußische Handelsminister wies zugleich in Leitsätzen die unteren Bergbehörden an, die Betriebsräte verstärkt zum Unfallschutz heranzuziehen. ${ }^{458}$ Damit war zumindest auf dem Papier ein stärkerer Einfluß der Betriebsräte bei der Grubenkontrolle möglich. Jedoch hatten bereits die Auseinandersetzungen um die Grubensicherheit nach dem Unglück auf der Herner Schachtanlage Mont Cenis 1921 gezeigt, daß die Vorschriften des preußischen Handelsministeriums praktisch wirkungslos blieben, so lange sich die Bergaufsicht nicht kooperativ zeigte. ${ }^{459}$ Auch die Ende 1926 gegen den Willen der Bergaufsicht schließlich in Preußen eingeführten Arbeiterkontrolleure im Bereich der Bergsicherheit scheiterten schließlich hieran sowie an der Haltung der Zechenleitungen, die die Betriebsräte auch im Unfallschutz ablehnten. ${ }^{460}$

Im Dauerfeuer von konjunktueller Krise, politischer Paralysierung und mangelnder Kooperationsbereitschaft der Bergbehörden geriet die Betriebsrätebewegung im Bergbau 1925 in eine schwere Krise. Wie weit die Paralyse reichte, demonstrierte der Bergarbeiterverband an der Tatsache, daß vielfach die Betriebsräte selbst nicht mehr auf ihren gesetzlichen Rechten bestanden, da dies etwa im Falle der Bilanzvorlage doch zwecklos sei. ${ }^{461}$ Der Verband bemühte sich zwar weiterhin für den Gedanken der Betriebsvertretungen zu werben und wies daraufhin, daß 1925 in etwa 400 Fällen Entlassungen hätten rückgängig gemacht werden können. Bei einem effektiven Beschäftigungsabbau von etwa 40000 im Jahr 1925 und einer entsprechend etwa doppelt so hochliegenden Zahl von Entlassungsfällen waren diese „Erfolge“ aber kaum der Rede wert. ${ }^{462}$ Für die Zechenleitungen hingegen war der eingetretene Zustand erträglich: „Die Besprechungen und die in den ersten Jahren nach Einführung des Betriebsrätegesetzes recht zahlreichen Sitzungen nahmen die Beamten sehr in Anspruch. In der letzten Zeit ist darin eine erhebliche Besserung eingetreten. Es finden mit den Betriebsvertretungen jetzt Sitzungen alle zwei Monate statt, und die täglichen Besprechungen mit den Betriebsführern morgens vor der Anfahrt dauern etwa 5-10 Minuten. Die gesetzlichen Vorschriften werden im Verkehr mit den Räten befolgt. “463

spektoren, Verkleinerung der Steigerabteilungen, Versorgung mit Sauerstoffgeräten, Einführung von Grubenkontrolleuren, Einbau von Gesteinsstaubsperren, Belehrung der Bergleute, Erweiterung der Kontrollrechte der Bergämter), 21. 2. 1925; Urantrag der KPD-Fraktion, 24. 2. 1925 (Einführung von Grubenkontrolleuren), BAP RAM 419, Bll.223f.

${ }^{456}$ Anfragen des Thüringischen Ministeriums für Inneres und Wirtschaft beim Reichsarbeitsministerium, 11. 4. 1925, 30.6. 1025, BAP RAM 419, Bl. $242 \mathrm{f}$.

${ }^{457}$ Reichsarbeitsminister an Thüringische Ministerium für Inneres und Wirtschaft, 4. 8. 1925, BAP RAM 419, Bl. 244.

${ }^{458}$ Niederschrift über die Verhandlungen der Preußischen Grubensicherheitskommission (Hauptkommission), 12. 2. 1930, BAP RAM 420, Bll.24-25.

${ }^{459}$ Siehe oben.

${ }^{460}$ Bergrevier Recklinghausen-West, 13. 11. 1926, StAM OBAD 1868, Bl. 73.

461 Jahrbuch des Bergarbeiterverbandes 1925, S. 87.

${ }^{462}$ Beschäftigtenzahlen bei Wiel, Wirtschaftsgeschichte des Ruhrgebietes, S. 131.

${ }^{463}$ Zeche Nordstern an Phoenix-Bergwerksverwaltung, 31. 10. 1924, BgA 41/329. 


\section{Mitbestimmungsalltag während der Strukturkrise}

Die soziale und wirtschaftliche Entwicklung der Branche ${ }^{464}$ zwischen 1925 und 1929 bot ein ambivalentes Bild. Zwischen 1924 und 1929 kam es zu deutlichen Steigerungen bei den realen Schichtlöhnen der Bergleute, wobei die Jahreseinkommen aber mehr oder weniger stagnierten. ${ }^{465}$ Trotz des Belegschaftsabbaus im Kontext der Rationalisierung ging zudem die Arbeitslosigkeit im Ruhrbergbau deutlich zurück. Mit einer Arbeitslosenquote von 2,1\% 1927 und 2,5\% 1928 herrschte in den Jahren vor der Weltwirtschaftskrise faktisch Vollbeschäftigung. ${ }^{466}$ Die Verbesserungen der sozialen Situation der Bergleute korrelierten freilich mit einer Zunahme der Leistungsanforderungen. Zwischen 1924 und 1929 nahm die Pro-Kopf-Förderung der Belegschaft je Schicht an der Ruhr deutlich zu, 1928 wurde der bisherige Höchststand von 1915 erreicht und überschritten. ${ }^{467}$ In diesen Leistungssteigerungen drückte sich die Wirkung verschiedener Faktoren aus, wobei die Arbeitszeitverlängerung auf acht Stunden, die Arbeitsintensivierung sowie eine kontinuierliche Erhöhung der Gedinge sich als direkt spürbare Verschlechterungen der Arbeitsbedingungen der Bergleute erwiesen. Deutlichster Ausdruck der Intensivierung der Arbeit war zunächst ein starkes Anwachsen der Unfälle bis $1926 .^{468}$ Erst mit der Modernisierung des Untertagebetriebes ging auch die Zahl der Unfälle zurück. Bei der Abteilung Bergbau der Vereinigten Stahlwerke sank die Zahl der Unfälle pro 10000 verfahrene Schichten von 7,38 1926/27 auf 6,4 1929/30 und 5,18 1932/33. ${ }^{469}$ In den Augen der Zechenleitungen war die Leistungssteigerung allerdings weniger eine Folge gestiegener Leistungsbereitschaft als das Ergebnis der Konzentration der Förderung auf die rentabelsten Betriebspunkte und umfangreicher Investitionen, deren Schwerpunkt bei der Abteilung Bergbau der Vereinigten Stahlwerke in den Jahren 1926/27 und 1927/28 lag. ${ }^{470}$ Im Ergebnis dieser Rationalisierungsmaßnahmen stiegen Leistungsfähigkeit und Leistung, während die Lohnstückkosten zu sinken begannen. Die deutlichen Produktions- und Umsatzsteigerungen konnten auf diese Weise mit einer zwischen 1926 und 1929 lediglich um etwa 10\% steigenden Belegschaft erzielt werden. Die wichtigsten betriebswirtschaftlichen Kennziffern entwickelten sich nicht ungünstig. Die Arbeitskosten je Tonne gingen ab 1927/28 langsam zurück, während die Arbeitskosten je Schicht bis 1930/31 weiter anstiegen. ${ }^{471}$ Vor allem aber sank, wenn auch nur moderat, der Anteil der Löhne am Umsatz vom 42,1\% 1926/27 auf 40,0\% 1929/30. ${ }^{472}$ Gemessen an den Problemen auf den Märkten und

\footnotetext{
${ }^{464} \mathrm{Vgl}$. hierzu insgesamt Ausschuß zur Untersuchung der Erzeugungs- und Absatzbedingungen der deutschen Wirtschaft, Die deutsche Kohlenwirtschaft. Verhandlungen und Berichte des III. Unterausschusses, Berlin 1929.

${ }^{465}$ Tschirbs, Tarifpolitik im Ruhrbergbau, S. 362. Die nominalen Jahresdurchschnittseinkommen der Bergleute zeigten hingegen nur eine leichte Aufwärtstendenz, was sich aus der niedrigen Zahl verfahrener Schichten pro Jahr erklärte; Monatsbericht der VSt. 9/1933, S. 46.

the Berger, Die Arbeitslosigkeit, in: Saitzew (Hg.), Die Arbeitslosigkeit, S. 1-31.

467 Wiel, Wirtschaftsgeschichte des Ruhrgebietes, S. 131. Wegen der leicht sinkenden Zahl der Schichten stagnierte allerdings die Jahresförderung pro Kopf.

${ }^{468}$ Tschirbs, Tarifpolitik im Ruhrbergbau, S. 255-258.

${ }^{469}$ Monatsbericht der Vereinigten Stahlwerke 9/1933, S. 60, BgA 55/498.

${ }^{470}$ Betriebs- und Wirtschaftlichkeitsverhältnisse der GBAG 1926-1933/34, S. 10 f, BgA 55/1295

471 Ebenda, S. 4

472 Monatsbericht der Vereinigten Stahlwerke 3/1941, S. 99, BgA 55/556.
} 
den erheblichen Rationalisierungsbemühungen waren diese Erfolge für die Abteilung Bergbau der Vereinigten Stahlwerke aber völlig unbefriedigend, da sie die erkennbaren Strukturprobleme der Branche bzw. des Unternehmens nicht beseitigten. Nur eine dauerhafte, deutliche Senkung des Lohn- und Gehaltsanteiles am Umsatz war dazu geeignet, die notwendige Liquidität zu sichern. Die bis in die Weltwirtschaftskrise ansteigenden Schichtlöhne und die in ihrer Höhe stagnierenden Sozialaufwendungen ${ }^{473}$ schienen mithin durchgreifende Rationalisierungserfolge zu verhindern. Daß die Zechenleitungen und der Vorstand der Abteilung Bergbau der Vereinigten Stahlwerke die staatliche Lohn- und Arbeitszeitpolitik und das Tarifsystem mit dem relativ starken Einfluß der Gewerkschaften ablehnten, weil sie einer Besserung der wirtschaftlichen Lage der Zechen im Weg zu stehen schienen, war insofern folgerichtig. Entsprechend änderte sich auch die Einstellung zu den Betriebsräten, die man als gewerkschaftlichen Stoßtrupp auffaßte, nicht.

Die Zahlen vermitteln ein sehr pauschales Bild. Die Jahre zwischen 1925 und 1929, wenn auch im statistischen Rückblick relativ günstige Jahre, waren von extremen Entwicklungsschwankungen und damit korrespondierend heftigen sozialen Konflikten gekennzeichnet. Das Jahr 1924 war von starken Krisenerscheinungen geprägt. Erst im Winter 1924/25 zeigten sich leichte Besserungen der wirtschaftlichen Lage. Im Dezember 1924 mußten lediglich 100000 Feierschichten gegenüber noch 400000 im Oktober 1924 verfahren werden. ${ }^{474} \mathrm{Im}$ ersten Halbjahr 1925 verschlechterte sich die konjunkturelle Lage des Bergbaus erneut. Massenentlassungen und Zechenstillegungen waren an der Tagesordnung. Insbesondere die hohe Zahl der Feierschichten führte zu sinkenden Einkommen, so daß sich die Einstellung der Bergarbeiter zur Mehrarbeit wandelte: „Die Leute drängen sich um Über- und Nebenschichten und bereiten in der Arbeitsdisziplin keine Schwierigkeiten. ${ }^{475}$ Die gestiegene Arbeitsdisziplin hielt freilich nicht lange vor. Der offene Ausbruch der Struktukrise des Kohlenbergbaus 1925 veränderte die Lage. Abwanderungsbewegungen insbesondere jüngerer Bergleute machten sich bemerkbar: „Wenn nicht bald höhere Löhne bewilligt würden, so klagen ... Betriebsvertretungen, würden die guten Elemente aus dem Bezirk verschwinden; der Bergmannsstand sinke dann immer tiefer, weil die schlechten Arbeiter hier blieben." ${ }^{476}$ Das Risiko der Arbeitslosigkeit verlor zugleich seine Schrecken; Bergarbeit wurde, auch wegen Zechenschließungen und Massenentlassungen immer unattraktiver: „Ein ... Ortsältester erkannte an, daß die Leistung in seinem Betriebe zu gering sei, sagte aber ... auf meine Vorhaltungen, daß er mehr verdiene oder mindestens gerade so viel, wenn er bei den Erwerbslosen Notstandsarbeiten verrichte. Seine einzigen Bedenken nach dieser Richtung hin seien nur die, daß er in einem Haus der Bergmannssiedlung wohne. ... Verschiedene Steiger haben

${ }^{473}$ Die Abteilung Bergbau der Vereinigten Stahlwerke zahlte pro 100 RM Lohn noch einmal 14,55 RM an Sozialabgaben 1926/27 und 14,14 1928/29, Monatsbericht der Vereinigten Stahlwerke 9/ 1933 , S. 59, BgA 55/498.

${ }^{474}$ Stimmungsbericht des Oberbergamts Dortmund, 1. 1. 1925, StAM OBAD 1864, Bll.68-73, hier Bl. 71.

${ }^{475}$ Bergrevier Recklinghausen-West, 14. 1. 1925, StAM OBAD 1864, Bl. 117.

${ }^{476}$ Bergrevier Gelsenkirchen, 13. 3. 1925, StAM OBAD 1864, Bl. 259. 
ähnliche Beobachtungen gemacht. “477 Lohnerhöhungen, so der Eindruck vieler Bergleute, verpufften zudem wegen der fast automatisch folgenden Preissteigerungen. „Es wird ... von den Arbeitern ... Klage über die vorzeitige Veröffentlichung der Lohnschiedssprüche geführt. Sofort nach Bekanntwerden von beabsichtigten Lohnerhöhungen werden von den Kaufleuten die Preise in die Höhe gesetzt, so daß die höheren Preise bereits vor stattgehabter Lohnerhöhung zu zahlen seien und die Lohnsteigerungen praktisch wertlos seien. ${ }^{4478}$ Preissteigerungen und Feierschichten trügen, so die Bergbehörde, das Ihre dazu bei, für viele Bergleute die Erwerbslosigkeit attraktiv zu machen: „Die Krise zeitigt jetzt sogar auf den besseren Fettkohlengruben schlimme Folgen. Sie wird verstärkt durch die in Ansehung der vielen Feierschichten verständliche Tatsache, daß die Leistung der Belegschaften zurückgeht. Auch die Zahl der infolge Krankheit und aus anderen Gründen feiernden Arbeiter nimmt ständig zu. Teilweise werden hierüber geradezu erschreckende Tatsachen mitgeteilt. ${ }^{* 479}$ Auf einzelnen Schachtanlagen würden bis zu 20\% der Untertagebelegschaft fehlen. Zudem wanderten in starkem Maße qualifizierte Arbeitskräfte, insbesondere Grubenmaurer in das besser beschäftigte Baugewerbe ab. „Auch sonst findet eine erhebliche Belegschaftsabwanderung in Saison- sowie in landwirtschaftliche Betriebe statt. Die jüngeren Leute geben als Grund für das Ausscheiden aus der Bergarbeit vielfach an, daß ihnen die Knappschaftsgefälle zu hoch seien; es könne ihnen nicht zugemutet werden, daß sie die Mittel für Alterspensionen für solche Arbeiter aufbringen sollten, die mehr als sie selbst verdienten." ${ }^{\text {"480 }}$

Betriebliche Interessenvertretung verlor in diesem Kontext weitgehend ihren Sinn. Zwar fielen 1925 die Wahlergebnisse bei den Betriebsratswahlen keineswegs zur Zufriedenheit der Zechenleitungen und Bergbehörden aus, doch stellte man andererseits auch fest: „Im allgemeinen sind die Auffassungen in den Belegschaften von Jahr zu Jahr gemäßigter geworden. Der Kreis derjenigen Leute, welche eingesehen haben, daß die eigene Lebenshaltung nicht durch Gewalt, sondern nur durch Arbeit eine Verbesserung erfahren kann, ist zweifellos größer geworden.“ Dies, so stellte der Bergrevierbeamte für Recklinghausen fest, schlage sich freilich im Wahlverhalten nicht nieder, „denn die breite Masse wählt nicht nach Erkenntnissen, die mit mehr oder weniger schmerzlicher Erfahrung gewonnen wurden, sondern nach Hoffnungen. Deshalb werden nach wie vor Führer den Vorzug erhalten, die das meiste versprechen. ${ }^{481}$ Bei dem von einer hohen Wahlbeteiligung gekennzeichneten Urnengang 1925 konnten die freien Gewerkschaften einen deutlichen Stimmengewinn verbuchen; der Wählerzuwachs von 30000 schlug sich in Gewinnen des Alten Verbandes nieder, während die Syndikalisten erhebliche Stimmverluste hinzunehmen hatten. Die absolute Zahl der Wähler der Union sank indes nur von 98000 auf 95000.482 Wenn dies auch kaum Aufschluß über die Aktionsbereitschaft der Belegschaften gab, besaß die Union dennoch auch weiter-

\footnotetext{
${ }^{477}$ Bergrevier Recklinghausen-Ost, 31. 3. 1925, StAM OBAD 1864, Bl. 278.

${ }^{478}$ Stimmungsbericht des Oberbergamtes, 15. 4. 1925, StAM OBAD 1864, Bl. 305.

${ }^{479}$ Stimmungsbericht des Oberbergamtes, 1.5. 1925, StAM OBAD 1864, Bl. 337.

${ }^{480}$ Ebenda, Bl. 338.

${ }_{481}$ Bergrevier Recklinghausen-West, 14. 1. 1925, StAM OBAD 1864, Bl. 117.

${ }^{482}$ Martiny, Arbeiterbewegung an Rhein und Ruhr, S. 252.
} 
hin eine starke betriebliche Position. Zu Recht wertete die Bergbehörde dieses Ergebnis allerdings nicht als Ausdruck der Aktionsbereitschaft der Belegschaften.

Man rechnete auch kaum mit großer Bewegung angesichts des Anfang 1925 auslaufenden Überschichtenabkommens, wenngleich die Zechen fürchteten, zu materiellen Zugeständnissen gezwungen zu werden. ${ }^{483}$ Aus Dortmund wurde ein Betriebsratsvorsitzender folgendermaßen zitiert: „Obwohl große Unzufriedenheit darüber herrscht, daß die Löhne in keinem Verhältnis zu den großen Lebenshaltungskosten ständen, sei die Arbeiterschaft sehr ruhig. Es bestehe auch keine Neigung, etwa wegen der Arbeitszeitfrage in einen Streik einzutreten. Wenn allerdings von den Organisationen die Streikparole ausgegeben würde, so würde die Arbeiterschaft derselben geschlossen folgen. “484 Nach Ansicht des Gelsenkirchener Bergrevierbeamten waren die Belegschaften nicht an kürzeren Arbeitszeiten, sondern an Überstundenzuschlägen interessiert. ${ }^{485}$ Die Bewegung ginge vielmehr von den Gewerkschaften aus: „Die Verhandlungen über das Arbeitszeitabkommen finden bei den Belegschaften nur wenig Interesse. Es hat den Anschein, als ob diese ganze Angelegenheit nur von den Führern der christlichen Gewerkschaft eingeleitet ist, um die Bedeutung ihrer Tätigkeit den Arbeitern wieder vorzuführen. " ${ }^{486}$ Die alte Überschichtenregelung wurde im Februar 1925 durch die staatliche Zwangsschlichtung verlängert, so daß die Befürchtungen der Zechenbesitzer nicht eintraten. „Die Verbindlichkeitserklärung des Arbeitszeitschiedsspruches wird trotz kommunistischer Hetze keine Störung des Wirtschaftslebens zur Folge haben", schrieb das Oberbergamt in Dortmund. Die kommunistischen Streikparolen hätten auch deshalb wenig Erfolg, da die Bergleute die Höhe der Halden kennten. ${ }^{487}$ Trotzdem nähme mancher Bergmann die Streikparolen ernst: „Wie stets bei Agitationen zum Streik haben auch jetzt die Bergleute in großer Zahl Krankenscheine genommen, um sich bei einem etwaigen Ausstand das Krankengeld zu sichern. “488 Die Möglichkeiten gewerkschaftlicher oder parteipolitischer Agitation waren entsprechend gering, auch wenn die Bedingungen von Zeche zu Zeche verschieden waren. Die verbreitete kommunistische Agitation fand bestenfalls passive Zustimmung; jedenfalls mußte die KPD ihren Streikaufruf zum 2. März 1925 wegen geringer Erfolgsaussichten zurücknehmen. ${ }^{489}$ Dieses Bild um sich greifender Passivität wurde von den Angaben über die Teilnahme der Arbeiter an den Maifeiern bestätigt. Hatten 1924 wegen des 1 . Mai noch rund $28 \%$ der Bergarbeiter eine Schicht ausfallen lassen, so waren es am 1. Mai 1925 nach Angaben des Oberbergamtes nur mehr 14\%. Der Bergbehörde schien zudem bemerkenswert, „daß der Reichspräsident Hindenburg in den Bergmannsorten vielfach verhältnismäßig hohe Stimmenzahlen erhalten hat, so z. B. in dem ehemals poli-

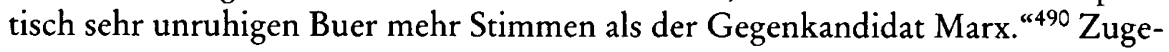

\footnotetext{
${ }^{483}$ Stimmungsbericht des Oberbergamtes Dortmund, 15. 1. 1925, Bl. 103.

4\$+ Stimmungsbericht des Oberbergamtes Dortmund, 15. 1. 1925, Bl. 105.

${ }^{485}$ Bergrevier Gelsenkirchen, 14. 2. 1925, StAM OBAD 1864, Bl. 197.

${ }^{486}$ Bergrevier Buer, 13. 2. 1925, StAM OBAD 1864, Bl. 206.

${ }^{487}$ Stimmungsbericht des Oberbergamtes Dortmund, 2. 3. 1925, StAM OBAD 1864, Bll.208-212, hier Bl. 210.

${ }_{488}$ Ebenda.

${ }^{+89}$ Stimmungsbericht des Oberbergamtes, 14. 3. 1925, StAM OBAD 1864, Bll. 243-247.

${ }^{490}$ Stimmungsbericht des Oberbergamtes, 1. 5. 1925, StAM OBAD 1864, Bl. 338.
} 
spitzt formulierte der Bergrevierbeamte in Gelsenkirchen im Juli 1925: „In Arbeitnehmerkreisen herrscht vollkommene Stille. Jeder, der beschäftigt ist, ist froh, wenn er nicht entlassen wird. “491

Absatzkrise, erste Rationalisierungsmaßnahmen, Massenentlassungen - allein bei den Zechen der Rheinelbe-Union standen im Mai 19258500 Bergleute zur Kündigung an -, Feierschichten und hohe Lebenshaltungskosten wurden im ersten Halbjahr 1925 mithin zu den entscheidenden Determinanten der industriellen Beziehungen im Bergbau. Die Arbeitszeitfrage war vor diesem Hintergrund nur noch im Kontext der Programmatik der Gewerkschaften und der Union vorrangig; die Mehrzahl der Bergarbeiter hätte wahrscheinlich wegen des höheren Verdienstes widerstandslos Mehrarbeit ausgeführt. Die Stellung der Betriebsräte war prekär. Von den Belegschaften nicht mehr unterstützt wie früher, führte eine Anlehnung an Gewerkschaften und politische Parteien sie in den doppelten Konflikt mit Zechenverwaltungen und Belegschaften, so daß auch eine enge Zusammenarbeit mit den Gewerkschaften nicht in Frage kam. Prototypisch kam dies in einem Entlassungskonflikt im Bergrevier Recklinghausen-West zum Ausdruck: "In den mehrfachen Verhandlungen mit dem Vertreter des Demobilmachungskommissars auf verschiedenen Zechen über die Frage der Entlassungen war die Stellungnahme des Betriebsausschusses und der Gewerkschaftsvertreter recht beachtenswert. Stets versuchten die Gewerkschaftsvertreter die Zahl der zur Entlassung angemeldeten Leute zu verkleinern, während der Werksvertreter erklärte, daß die Feierschichten nur bei Entlassung der angemeldeten Zahl aufhören könnten. Die Mitglieder des Betriebsausschusses, die vor Entlassung geschützt sind, gaben kund, daß unter allen Umständen die Feierschichten aufhören müßten, möge sonst kommen, was da wolle. Sie stimmten also ihrem Werksdirektor zu und befanden sich in einem Gegensatz zu den Gewerkschaftsvertretern, der nur aus dem Grunde wenig scharf hervortrat, weil letztere recht bald nachgaben. Die völlige Machtlosigkeit der Gewerkschaften, bei der jetzigen Notlage den Belegschaften im Ganzen helfen zu können, hat ihrem Ansehen unter den Leuten sehr geschadet. ${ }^{492}$ Eigenständiger Handlungsspielraum verblieb den Betriebsräten letztlich kaum, zumal die Betriebsratstätigkeit immer noch hohen moralischen Erwartungen unterlag, wie aus dem Bergrevier Buer der Bergaufsichtsbeamte berichtete, dem ein Betriebsratsmitglied folgende Geschichte erzählt hatte: „,Der einzige vom ganzen Betriebsrat, der seine Aufgabe ernst genommen hat, war Sch. Aber, was haben wir davon?` Der Betriebsführer bestätigte dies und gab an, daß Sch. tatsächlich jede Beschwerde eines Arbeiters persönlich geprüft habe, indem er eine halbe Schicht lang dessen Arbeit übernahm und erst danach sich entschloß, ob er die Beschwerde vertreten wolle oder nicht. Dafür sei er dann bald von anderen Betriebsratsmitgliedern auf dem Grubenhof verprügelt worden und habe sein

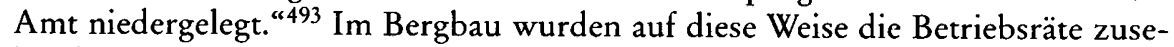
hends zum Anhängsel von Belegschaftsforderungen, die angesichts der Konjunkturlage der gewerkschaftlichen Programmatik fundamental widersprachen. Ver-

${ }^{491}$ Bergrevier Gelsenkirchen, 30. 7. 1925, StAM OBAD 1865, Bl. 144.

${ }^{492}$ Bergrevier Recklinghausen-West, 30. 7. 1925, StAM OBAD 1865, Bl. 138.

${ }^{493}$ Ebenda, Bl. 341. 
suche, aus der engen Bindung an die jeweils aktuellen Belegschaftsinteressen herauszukommen, waren riskant, auch wenn sie im Rahmen der Gewerkschaftstätigkeit der Betriebsräte immer wieder versucht wurden. Spätestens jetzt hätten die Zechenleitungen begreifen müssen, daß eine engere Zusammenarbeit mit den Betriebsräten nicht ohne weiteres nachteilig sein mußte. Jedoch blieb trotz der Kooperationsbereitschaft zahlreicher Betriebsratsmitglieder die kommunistische Agitation erhalten, die eine nüchtern-abwägende Betriebsratsarbeit erschwerte, da sie die schlechte Stimmung in den Bergrevieren gezielt förderte und gegen die „Mehrheitssozialisten“, aus deren Reihen die kooperationsbereiten Betriebsräte stammten, zu steuern suchte: „Am Niederrhein nimmt die kommunistische Partei die Arbeiterentlassungen zum Anlaß, gegen die Arbeitgeber und gegen die Behörden zu hetzen. In den letzten Versammlungen der Zellenobleute der kommunistischen Partei wurden auch Anweisungen zum Vorgehen gegen die Mehrheitssozialisten gegeben, da deren Vertreter die volkswirtschaftliche Notwendigkeit der Einstellung verschiedener Zechen anerkannt hätten." Besonders bedenklich erschien dem Oberbergamt vor allem die Paralyse der alltäglichen betrieblichen Kommunikation durch die Kommunisten: „Die in Betriebsvertretungen sitzenden Zellenobleute sollen den Betriebsvertretungen und den Behörden in jeder Weise, auch in den kleinsten Dingen, Schwierigkeiten bereiten und die Arbeiter immer wieder auf die Arbeiterfeindlichkeit der Zechen und Behörden hinweisen." Auch nehme die kommunistische Bewegung zunehmend militante Züge an: "Auch im Hammer Bezirk fällt auf, daß das Auftreten der linksradikalen Kreise immer schärfer wird. Es werden dort von diesen Exerzier- und Marschübungen, Felddienstübungen, Biwacks usw. abgehalten. “494

Anstatt mit den Betriebsräten und den Gewerkschaften zu kooperieren, gingen Zechenverband und einzelne Zechen ihre „eigenen“ Wege und verständigten sich mit den Betriebsräten nur, wenn es wie im Falle von Entlassungsaktionen nicht anders möglich war. ${ }^{495}$ Die Zechenleitungen versuchten, die Krise zur Hebung der Leistungsbereitschaft zu nutzen und hoffte dabei auf die Kooperationsbereitschaft der noch beschäftigten Bergleute, die aber gerade nicht das Ergebnis einer freiwilligen Entscheidung war, sondern durch die Verhältnisse erzwungen wurde. Im Juli 1925 geisterten Nachrichten durch die Presse, der Zechenverband beabsichtige das Überschichtenabkommen zu kündigen, um zur 8-1/2 Stundenschicht zurückzukehren. Wenn das Oberbergamt auch noch keinen entsprechenden Beschluß des Zechenverbandes kannte, so war die Position des Zechenverbandes doch klar: „Der Zechenverband vertritt ... den Standpunkt, daß durch Verlängerung der Arbeitszeit die Produktionskosten herabgesetzt und dadurch der auf dem Ruhrbergbau schwer lastende Wirtschaftsdruck gemildert werden können." Parallel zu diesen Forderungen forcierte der Zechenverband die Rationalisierung vor allem im Sinne der Schließung unrentabler Anlagen, Reduktion der Förderung bei gleichzeitiger Konzentration der Förderung auf die günstigsten Betriebspunkte, was auch umfangreiche Entlassungen implizierte. Analog zur damit zwangsläufig gegebenen Verminderung der Belegschaft sollte die Leistung der

${ }^{+94}$ Stimmungsbericht des Oberbergamtes, 15.6. 1925, StAM OBAD 1865, Bl. 37.

495 Z.B. Bergrevier Buer, 14. 1. 1926, StAM OBAD 1866, Bl. 191. 
weiterhin angelegten Bergleute planmäßig gesteigert werden. Selbst das Oberbergamt mußte zugeben, daß es sich bei den verschiedenen Programmpunkten des Zechenverbandes um „Dinge“ handele, „die sich nicht leicht miteinander vereinigen lassen. “496

Die Folgen dieser Strukturkrisenmaßnahmen führten zunächst nur deshalb nicht zu größeren sozialen Problemen, weil die freiwillige Abwanderung aus dem Bergbau anhielt. Das Oberbergamt registrierte im Sommer 1925 eine starke Rückwanderung in die Landwirtschaft: „So sind die zur Zeit nach Ostpreußen fahrenden Sonderzüge stets überfüllt. Hierzu dürfte die Annahme berechtigt sein, daß ein großer Teil der von dort eingewanderten Leute, die dem landwirtschaftlichen Berufe entstammen, zur Erntezeit dort Arbeit zu finden hoffen. ${ }^{4}{ }^{97}$ Den Bergbehörden war klar, daß die Arbeitsgelegenheiten im Baugewerbe und in der Landwirtschaft saisonalen Schwankungen unterlagen, so daß im Herbst kaum noch mit einer Entlastung des Arbeitsmarktes gerechnet werden konnte. Große Arbeitslosigkeit stand damit ins Haus. ${ }^{498}$ Bereits Anfang August 1925 spannte sich die Lage am Arbeitsmarkt erkennbar an: „Die Zahl der die Erwerbslosenfürsorge in Anspruch nehmenden Arbeit suchenden Bergleute, welche Mitte Juni nur gegen 6000 betrug, stellte sich Mitte Juli etwa auf 10000 und Ende Juli auf ungefähr 15000 . Ihre Zahl wird sich bis Mitte August auf etwa 25-30000 steigern, da die Unterbringungsmöglichkeiten erheblich zurückgegangen sind. ${ }^{* 499}$ Bis Mitte September waren schließlich allein von Stillegungen und Fördereinschränkungen knapp 46000 Arbeiter und 1400 Angestellte betroffen. ${ }^{500}$ Wegen der anhaltenden Steigerung der Lebensmittelpreise war allerdings trotz des entlassungsbedingten Rückganges der Feierschichten ${ }^{501}$ seit der zweiten Julihälfte auch die Ruhe der noch beschäftigten Bergleute bedroht: „Immer von neuem und immer heftiger wird über das Mißverhältnis zwischen den sehr hohen Lebensmittelpreisen und den durch die Feierschichten empfindlich geschmälerten Löhne geklagt. Sobald die Räumung des Ruhrgebietes durch die Franzosen erfolgt ist, muß damit gerechnet werden, daß stellenweise Lebensmittelkrawalle eintreten. "502

Ende des Jahres 1925 schien der oberen Bergbehörde die Lage derart bedrohlich - nach einer internen Bestandsaufnahme waren bis zum November 1925 fast 75000 Arbeitsplätze im Ruhrbergbau weggefallen -, daß sie von sich aus die Initiative zu einer großen Bergbaukonferenz von Politik und Verbänden ergriff, um durch Verbesserung der Kommunikation zwischen den sozialen Gruppen und ihren Verbänden einer immer wahrscheinlicher werdenden Konflikteskalation zuvorzukommen. Ziel war es, „die Vertreter der Arbeitgeber und der Arbeitnehmer unter Zuziehung der beteiligten drei Regierungspräsidenten, der beiden Oberprä-

\footnotetext{
${ }^{496}$ Stimmungsbericht des Oberbergamtes, 15. 7. 1925, StAM OBAD 1865, Bl. $96 \mathrm{f}$.

${ }^{497}$ Stimmungsbericht des Oberbergamtes, 1. 7. 1925, StAM OBAD 1865, Bl. 67.

${ }^{498}$ Bergrevier Duisburg, 15.7. 1925, StAM OBAD 1865, Bl. 125.

+99 Stimmungsbericht des Oberbergamtes, 1. 8. 1925, StAM OBAD 1865, Bl. 129.

${ }^{500}$ Stimmungsbericht des Oberbergamtes, 15. 9. 1925, StAM OBAD 1865, B1. 227.

${ }^{501}$ Anzahl der Feicrschichten (Werktagsdurchschnitt) im Juli 1925: 16736, im August 1925: 10752, im September 1925: 8322, im Oktober 1925: 7911. Stimmungsbericht des Oberbergamtes, 31. 10. 1925, StAM OBAD 1866, Bl. 2. In den folgenden Monaten bis zum Ausbruch des englischen Bergarbeiterstreiks schwankte die werktägliche Feierschichtenzahl kontinuierlich um 8000 .

${ }^{502}$ Stimmungsbericht des Obcrbergamtes, 15. 7. 1925, StAM OBAD 1865, B1. 100.
} 
sidenten und des Reichs- und Staatskommissars Mehlich zu einer Aussprache über Wünsche, Beschwerden und Vorschläge der Arbeitgeber- und Arbeitnehmerseite einzuladen." Die Ergebnisse einer derartigen Konferenz sollten dem Handelsminister unterbreitet werden. Der Plan stieß indes auf ein geteiltes Echo, da der Zechenverband ihn zwar grundsätzlich begrüßte, aber zunächst nicht realisiert sehen wollte, während die Gewerkschaftsseite dem Plan sofort zustimmte. Die Bergbehörde mußte daher den Plan zunächst auf die lange Bank schieben, wollte aber zu gegebener Zeit darauf zurückkommen. ${ }^{503}$

Im Kontext der Krise des Bergbaus fand auf den Zechen mithin ein Mehrfrontenkrieg mit sich ständig verschiebenden Frontlinien und Bündnissen statt, die eine geregelte Betriebsratstätigkeit erschwerten. Während sich ein Teil der Bergarbeiter in die Krise gefügt hatte und hoffte, die Massenentlassungen würden zumindest den verbleibenden Bergleuten bessere Einkommen bescheren, drang ein anderer Teil auf sozialen und politischen Protest gegen die Folgen der Krise und trat in explizite Kampfstellung zu Zechenleitungen und Behörden, wobei auch gezielt alle Möglichkeiten betrieblichen, arbeitsplatznahen Protestes genutzt wurden. ${ }^{504}$ Die Betriebsräte wurden dabei jeweils als Agenten der eigenen Position, die freilich von Belegschaft zu Belegschaft variieren konnte, genutzt. Im Ergebnis blieb damit die Blockadehaltung der Zechenleitungen erhalten, die fortfuhren, die durch die Rationalisierungsmaßnahmen bedingte Vergrößerung der Steigerreviere zugleich zur Paralysierung der Betriebsratstätigkeit zu nutzen. Sie konnten sich dabei in der Regel der Unterstützung der Bergbehörden sicher sein, die jeweils die neuen Fahrabteilungen überprüften und in der Regel gegen die Betriebsräte entschieden. ${ }^{505}$ Für die Zechenleitungen wie für die Bergbehörden schien ein Zwang zu verbesserter innerbetrieblicher Kooperation nicht zu bestehen, da die angestrebten Ziele zur Verbesserung der Rentabilität der Zechen gegen die Gewerkschaften und radikale Betriebsvertreter durchgesetzt werden mußten. Namentlich die Bergbehörden glaubten überdies, vor allem durch Senkungen der Lebensmittelpreise ließe sich zumindest ein Teil der sozialen Spannungen im Bergbau wirksam bekämpfen. Im übrigen teilten sie die Auffassung der Zechenleitungen in Preis- und Arbeitszeitfragen weitgehend, auch wenn sie deren Politik der Kommunikationsverweigerung nicht akzeptierten. „Ich habe die feste Überzeugung“, schrieb Ende November 1925 der Gelsenkirchener Revierbeamte, „daß die eigentlichen Arbeiter (sämtliche Arbeiter ausschließlich der Betriebsräte und Gewerkschaftssekretäre) gegen die Wiederherstellung der Friedensarbeitszeit nichts einzuwenden haben, wenn dadurch das unglückliche Stillegen und Einschränken von Betrieben aufhören würde. “506 Sein Bueraner Kollege pflichtete ihm bei: „Allem Anscheine nach ist bei dem ganz überwiegenden Teile der Belegschaften das Bestreben, durch möglichst regelmäßige Arbeit sich einen hohen Verdienst zu sichern, jetzt vorhanden. Die Unregelmäßigkeit des Absatzes, welche einerseits leicht zu Feierschichten führt, andererseits viel Gelegenheit zu Überschichten hervorruft, ohne daß es ratsam wäre, mehr Arbeiter einzustellen, zeigt, daß Über-

\footnotetext{
${ }^{503}$ Stimmungsbericht des Oberbergamtes, 1. 12. 1925, StAM OBAD 1866, Bl. 67.

${ }^{504}$ Stimmungsbericht des Oberbergamtes, 15. 7. 1925, StAM OBAD 1865, Bl. 98.

505 Bergrevier Bucr, 26. 2. 1926, StAM OBAD 1866, Bl. 281.

${ }^{506}$ Bergrevier Gelsenkirchen, 30.11. 1925, StAM OBAD 1866, B1. 84.
} 
stunden doch überwiegend gern wahrgenommen werden. Daß die Belegschaften zur Zeit wenig Neigung spüren, sich für politische $Z$ wecke anspannen zu lassen, zeigt der Umstand, daß die Bestrebungen, die Arbeiter zu Demonstrationszwekken gegen die Fürstenabfindung auf die Straße zu locken, erfolglos geblieben sind. “507

Die Krise hielt bis in den Herbst und Winter 1925 hinein an. Die von den Zechenleitungen heftig bekämpfte Lohnerhöhung im Oktober 1925 (durch staatliche $\mathrm{Z}$ wangsschlichtung) ${ }^{508}$ sowie das dauerhaft hohe Beschäftigungsrisiko hielten die Unzufriedenheit der Bergarbeiter über ihre unzureichenden Lebensbedingungen - die Preissenkungsaktionen blieben durchweg erfolglos - unterhalb der Flagranzschwelle. Leistungsbereitschaft und Leistungswille der Belegschaften entwickelten sich indes schlecht; so wurde z. B. die Einführung der planmäßigen Seilfahrt, durch die Verzögerungen bei Arbeitsbeginn und -ende beseitigt werden sollten, von manchen Betriebsräten mit Unterstützung eines Teiles der Belegschaften abgelehnt. ${ }^{509}$ Die Schlichtungsausschüsse entschieden zugunsten der Zechenleitungen, so daß sich die "revierweise Seilfahrt“ immer mehr durchsetzte. ${ }^{510}$ Auch provozierte die mit der systematischen Seilfahrt und der Einführung von Schüttelrutschen verbundene Veränderung der Pausensysteme unter Tage Proteste von Bergarbeitern, die das Wegfallen der freien Pauseneinteilung als Mißtrauen der Zechenleitungen interpretierten und zutreffend eine Verschärfung der Arbeitskontrolle befürchteten; offener Widerstand blieb in diesem Zusammenhang allerdings aus, von gelegentlichen Mißfallenskundgebungen einzelner Betriebsräte abgesehen ${ }^{511}$. Fehlte offener Protest, so gab es andererseits immer wieder Berichte über „unreine Förderung“, die von den Zechenleitungen als passiver Widerstand interpretiert wurde, wofür man die Arbeit der kommunistischen Betriebszellen verantwortlich machte. ${ }^{512}$ Schließlich breitete sich, insbesondere um die Jahreswende 1925/26, das Krankfeiern aus, wobei ganz offensichtlich der Umstand eine Rolle spielte, daß das Krankengeld auch an Sonn- und Feiertagen gezahlt wurde. ${ }^{513}$ Doch nicht nur die Belegschaften dachten über Tarifbruch und illegale Maßnahmen nach bzw. nutzten sie dort, wo es einigermaßen risikofrei möglich war. Fast spiegelbildlich verhielten sich auch die Zechenleitungen, über deren Einstellung der Gelsenkirchener Revierbeamte Mitte Dezember 1925 notierte, daß sie sich angesichts der Steuer-, Abgaben- und Lohnbelastungen von der Rationalisierung keine durchgreifende Verbesserung mehr erhofften. Es würden neue Töne angeschlagen: „Man hat mir im Ernst versichert, nicht nur die letzte Lohnerhöhung rückgängig zu machen, sondern eine noch darüberhinausgehende Lohnverminderung durchzusetzen, weil keine andere Möglichkeit mehr vorhan-

${ }^{507}$ Bergrevier Buer, 29. 1. 1926, StAM OBAD 1866, Bl. 218.

${ }^{508}$ Stimmungsbericht des Oberbergamtes, 15. 11. 1925, StAM OBAD 1866, Bl. 36.

${ }^{509}$ Bergrevier Recklinghausen-West, 14. 1. 1926, StAM OBAD 1866, Bl. 176. Vgl. auch Bergrevier Hamm, 30. 1. 1926, StAM OBAD 1866, Bl. 197.

510 Stimmungsbericht des Oberbergamtes, 1. 12. 1925, StAM OBAD 1866, Bl. 65.

511 Stimmungsbericht des Oberbergamtes, 15. 4. 1926, StAM OBAD 1867, Bl. 35 f. Zum Schüttelrutschenbetrieb vgl. insgesamt Tschirbs, Tarifpolitik im Ruhrbergbau, S. $241 \mathrm{ff}$.

512 Ebenda.

513 Stimmungsbericht des Oberbergamtes, 15. 1. 1926, StAM OBAD 1866, Bl. 169. Das Ansteigen der Krankenziffern war zeitgenössisch unumstritten; heftig umstritten waren die Ursachen dieser Entwicklung. 
den sei, die Selbstkosten zu vermindern. An eine Preiserhöhung der Kohlen ist bei der allgemeinen Weltwirtschaftslage nicht zu denken. Ein anderer Zechenvertreter hielt die Herabsetzung der Löhne nicht für empfehlenswert, forderte dagegen eine Verlängerung der Arbeitszeit. Die letztere Ansicht", so der Gelsenkirchener Beamte, „halte ich für die richtige, weil Lohnverminderung die Arbeitsfreudigkeit schwächt. " 514 Wenn zu Beginn des Jahres 1926 trotzdem die effektiven Leistungsziffern im Untertagebetrieb aus der Sicht der Zechenleitungen sich recht günstig gestalteten, lag dies mit Sicherheit nicht an den Bergleuten selbst: „Die Leistungen sind auf allen Zechen recht befriedigend", notierte der Gelsenkirchener Bergrevierbeamte und fügte hinzu, „was auf die scharfe Beaufsichtigung, die genaue Beobachtung der Arbeitszeit und auf den maschinellen Abbau zurückzuführen ist. " 515

Anfang 1926 verschärfte sich die Strukturkrise weiter, auch wenn im ersten Quartal 1926 die Zahlen der Zechenschließungen und Entlassungen niedriger lagen als in der zweiten Jahreshälfte 1925. Dafür ging die Zahl der Feierschichten in die Höhe. Lagen sie im Dezember 1925 arbeitstäglich zwischen 8000 und 9000, so schwankten sie im Januar 1926 zwischen 10000 und 20000, im Februar 1926 wurden gar Spitzenwerte von über 40000 (22. Februar) erzielt. Das Oberbergamt sprach von einer "geradezu erschreckende(n) Zunahme der Feierschichten infolge des Absatzmangels. "516 Im März 1926 begannen auch wieder umfangreiche Stilllegungs- und Entlassungsmaßnahmen; bei der GBAG waren die Zechen der Gruppe Dortmund besonders betroffen. ${ }^{517}$ Die materielle Lage sowohl der noch angelegten wie der bereits entlassenen Bergleute verschlechterte sich rasch, wodurch auch der Stoff für die Wahlpropaganda für die vor der Tür stehenden Betriebsratswahlen bestimmt wurde. Proteste gegen die schweren Lebensbedingungen, gegen Arbeitshetze und Intensivierung der Kontrolle, perfektionierte Arbeitszeitsysteme und zunehmenden Gedingedruck ${ }^{518}$ konnten aber kaum die Tatsache verdecken, daß die Gewerkschaften auf den Schachtanlagen nur noch über eingeschränkten Einfluß verfügten, vor allem aber, daß sie angesichts der Strukturkrise des Bergbaus letztlich konzeptlos waren. Weder war eine Politik der Arbeitsplatzerhaltung um jeden Preis sinnvoll und durchsetzbar, noch konnte ein Eingehen auf die Rationalisierungspolitik der Zechenleitungen für die Gewerkschaften in Frage kommen. Die Wahlappelle des Bergarbeiterverbandes zur Betriebsratswahl besaßen angesichts dieser Konstellation abstrakte Züge; letztlich beschränkte man sich auf die Aufforderung, die Organisation zu stärken, um die Interessen der Bergleute stärker zur Geltung bringen zu können. Auch wurde der Alte Verband nicht müde, vor den negativen Folgen einer geringer Wahlbeteiligung zu warnen. ${ }^{519}$ Ein im eigentlichen Sinne positives Programm aber konnte er zu den Betriebsratswahlen 1926 nicht vorlegen. Sein nomineller Wahlerfolg war daher auch nur auf den ersten Blick überzeugend, da nach dem Übertritt der Uni-

\footnotetext{
${ }^{514}$ Bergrevier Gelsenkirchen, 14. 12. 1925, StAM OBAD 1866, Bl. 125.

515 Bergrevier Gelsenkirchen, 13. 2. 1926, StAM OBAD 1866, Bl. 239.

516 Stimmungsbericht des Oberbergamtes, 1. 3. 1926, StAM OBAD 1866, Bl. 253.

517 Stimmungsbericht des Oberbergamtes, 15. 3. 1926, StAM OBAD !866, B1. 289.

518 Bergrevier Gelsenkirchen, 13.2. 1926, StAM OBAD 1866, Bl. 239.

519 Stimmungsbericht des Oberbergamtes, 15.2.26, StAM OBAD 1866, Bl. 223.
} 
onsmitglieder in den Alten Verband die wichtigste Organisationskonkurrenz zur Wahl nicht mehr angetreten war. Auf den Alten Verband entfielen mit 183500 Stimmen recht genau zwei Drittel der Wählerstimmen. Jedoch waren von knapp 400000 wahlberechtigten Bergleuten nur 275000 überhaupt zur Wahl gegangen, weniger als zu irgendeinem anderen Zeitpunkt vor $1931 .{ }^{520}$ Die vereinzelt von den Bergrevierbeamten gemeldeten Wahlbeteiligungsziffern einzelner Schachtanlagen zeigten recht klar an, daß die deutlich gesunkene Wahlbeteiligung eng mit Stimmenthaltungen auf zuvor mehrheitlich unionistischen Zechen zusammenhing. ${ }^{521}$

Der Radikalität von Teilen der Belegschaften korrespondierte weiterhin keine Aktionsbereitschaft. ${ }^{522}$ Resignation und ein individualisiertes Streben nach materiellen Verbesserungen blieben dominierend; die Tendenz zur Abwanderung hielt ebenso an wie das Ausnutzen aller Spielräume der Sozialversicherung. Zwei Jahre Strukturkrise, Rationalisierungs- und Leistungsdruck sowie wegen der Vielzahl an Feierschichten stark schwankende, gemessen am Lebensunterhalt zu niedrige Einkommen hatten alle Zukunftshoffnungen aus der Bergarbeiterschaft genommen, die sich noch wenige Jahre zuvor mit der Vision einer sozialisierten Kohlenwirtschaft verbunden hatten. ${ }^{523}$ Hinzutrat das Gefühl der Hilflosigkeit, das auch durch Gewerkschaften und Betriebsvertretungen nicht kompensiert werden konnte. Erstere verloren an Einfluß; letztere waren im betrieblichen Stellungskrieg zwischen verschiedenen Belegschaftsteilen, Zechenleitungen, Gewerkschaften und Bergbehörden längst aufgerieben worden. ${ }^{524}$ Die Kommunikation über die Probleme der Bergarbeit war zusammengebrochen; auch die Tarifauseinandersetzungen verkamen zusehends zu einem ritualisierten Nullsummenspiel, das nur durch jeweilige Staatsintervention aufrecht erhalten wurde. ${ }^{25}$ Gleichwohl war der Bergbau - paradoxerweise - Mitte der zwanziger Jahre zumindest wirtschaftlich auf dem richtigen Weg: Beschäftigungs- und Kapazitätsabbau einerseits, Modernisierung der verbleibenden Anlagen andererseits waren die einzigen Möglichkeiten, die Strukturkrise einigermaßen zu meistern.

\section{Zwischenspiel: Die Auswirkungen des englischen Bergarbeiterstreikes 1926}

Da traten im Mai 1926 die englischen Bergarbeiter in einen Streik, der die englische Kohle für fast ein Jahr vom Weltmarkt nahm. Erst zögerlich, setzte schließlich im Sommer 1926 ein Aufschwung der Kohlenwirtschaft ein, den noch im April 1926 niemand für möglich gehalten hätte. Die Zahl der Feierschichten ging

${ }^{520}$ Martiny, Arbeiterbewegung an Rhein und Ruhr, S. $252 \mathrm{f}$.

${ }^{521}$ Zum Beispiel Bergrevier Recklinghausen-Ost, 31. 3. 1926, StAM OBAD 1867, Bl. 14.

522 Bergrevier Buer, 30. 4. 1926, StAM OBAD 1867, Bl. 97.

${ }^{523}$ Die Bergbehörde beobachtete diese Phänomene recht genau: „Zur Zeit ist die nationalsozialistische Partei mit Werbungen in der hiesigen Gegend sehr tätig. Es läßt sich nicht verkennen, daß sie Erfolge zu verzeichnen hat. Die Resignation über das Fehlschlagen der Hoffnungen, die man ehcmals an die sozialistischen Wirtschaftstheorien knüpfte, ist in den Arbeiterkreisen recht groß. Sie hat sich zum Teil schon in der Entstehung der kommunistischen Bewegung ausgewirkt. Aber recht viele Arbeiter stößt das gewalttätige politische Gebaren der Linksradikalen sowie ihre internationale Einstellung ab. Sie wollen gute Deutsche und Patrioten sein, ohne grundsätzlich auf sozialistische Ideen verzichten zu müssen. Für diese bildet die nationalsozialistische Partei jetzt die $\mathrm{Zu}$ kunftshoffnung." Bergrevier Recklinghausen-West, 30. 7. 1926, StAM OBAD 1867, Bl. 282.

${ }^{524}$ Z.B. Bergrevier Lünen, 29. 4. 1926, StAM OBAD 1867, Bl. 72.

525 Tschirbs, Tarifpolitik im Ruhrbergbau, S. $259 \mathrm{ff}$. 
stark zurück. Im Juni 1926 kamen Feierschichten wegen Absatzmangels nicht mehr vor. Eine noch skeptische Bergbauunternehmerschaft zögerte zwar mit Neueinstellungen und versuchte durch Überschichten und Haldenauflösung die sich bessernde Konjunktur zu nutzen. Ende Juni/Anfang Juli 1926 aber hörte der Beschäftigungsabbau auf; statt dessen konnte die Bergaufsicht von Neueinstellungen infolge der verbesserten Absatzmöglichkeiten berichten. Naheliegenderweise führten die Ausfälle an englischer Kohle zu Nachfrageschüben im sog. bestrittenen Gebiet und im Ausland, also auf jenen Marktsegmenten, auf die die englische Kohle nach dem Streik wieder zurückkehren würde, unter Umständen mit dann sehr viel günstigeren Konkurrenzvoraussetzungen (längere Arbeitszeiten, niedrige Löhne), wie die deutschen Zechenverwaltungen befürchteten. ${ }^{526}$ Der steigende Absatz und die sich bessernde Ertragssituation ${ }^{527}$ nahmen wegen dieser pessimistischen Zukunftserwartungen keineswegs den Druck aus den Verteilungskämpfen; im Gegenteil wurde er durch den Bergarbeiterstreik nur weiter verschärft wie überhaupt die Wirkungen des englischen Bergarbeiterstreiks in jeder Hinsicht verheerend waren, da sie dem Ruhrbergbau die Fortführung seiner internen Blockaden ermöglichten und eine kooperative Verarbeitung der Strukturkrise nur weiter hinausschoben. Vor allem beendete der Streik den weiteren Kapazitätsabbau; wegen der schlechten Zukunftsaussichten versuchten die Zechenleitungen die Fördersteigerung mit nur mäßig wachsenden Belegschaften zu erzielen, wodurch die technische Rationalisierung einerseits, die Mehr- und Überarbeit andererseits stark an Bedeutung gewannen. Insbesondere aber die technische Rationalisierung brachte - nicht zuletzt wegen der Beibehaltung der Kapazitäten auf sog. Grenzzechen - zusätzliche Kapazitätseffekte, die schließlich wiederum die Strukturkrise verschärften.

Im Taumel des Mai und Juni 1926 aber war niemand realistisch genug, die voraussehbaren Folgen der künstlichen Konjunkturbelebung zu sehen. Gewerkschaften und Betriebsräte waren über das Ende von Feierschichten und Entlassungen froh; ihre Unterstützung der streikenden englischen Bergarbeiter fiel lasch aus. Der Aufruf der vier Bergarbeiterverbände vom 6. Mai 1926 zum englischen Streik stellte drei Punkte in den Vordergrund, nämlich die Verhinderung von Kohlenlieferungen nach Großbritannien und - in diesem Zusammenhang - die Forderung nach Unterlassung von Mehrarbeit sowie schließlich eine mehr oder weniger unverhohlene Mahnung vor zu weitreichenden Solidaritätsaktionen, wie sie die Kommunisten forderten. Die Bergbehörde konstatierte zufrieden: „Der Aufruf zeichnet sich durch sehr beachtenswertes Maßhalten aus. " ${ }^{528}$ Versuche, die Bergarbeiterschaft für einen Sympathiegeneralstreik zu gewinnen, registrierten die Bergämter zwar und meldeten sie auch weiter: „Wir betonen jedoch, daß wir diese uns gewordene Nachricht lediglich der Vollständigkeit halber weiter geben, da sie uns völlig unwahrscheinlich erscheint. "529 Die Zurückhaltung der vier Bergarbeiterorganisationen erfolgte mit Unterstützung der Belegschaften: „Wie es scheint, ist doch der überwiegende Teil der Bergarbeiterschaft hinsichtlich des

\footnotetext{
${ }^{526}$ Stimmungsbericht des Oberbergamtes, 17. 7. 1926, StAM OBAD 1867, Bl. 236.

527 GBAG, Betriebs- und Wirtschaftsverhältnisse 1926-1933/34, S. 12, BgA 55/1295.

${ }^{528}$ Sonderbericht des Oberbergamtes, 6. 5. 1926, StAM OBAD 1867, Bl. 99.

${ }^{529}$ Stimmungsbericht des Oberbergamtes, 1. 5. 1926, StAM OBAD 1867, Bi. 63.
} 
englischen Streiks immer noch so eingestellt, daß er die bessere Verdienstmöglichkeit durch Überschichten gern mitnimmt und für die Unterstützung der Engländer nicht viel Wärme übrig hat. ${ }^{\text {"530 }}$

In der ersten Phase des Bergarbeiterstreiks - im Sommer 1926 - trafen daher die Zielsetzungen von Zechenleitungen und noch angelegten Bergarbeitern zusammen. Erstere wollten die Mehrförderung durch Leistungssteigerung und längere Arbeitszeiten erreichen; letztere hatten vor allem ein Interesse an besserem Verdienst. Die Über- und Mehrarbeit griff daher schnell und in einem Maße um sich, daß fast regelmäßig auch die Bestimmungen der Arbeitszeitordnung verletzt wurden, was den Betriebsvertretungen eine effektive Handhabe geben konnte, gegen die Arbeitszeitpolitik der Zechenleitungen vorzugehen. Doch im Wissen um das Interesse der Belegschaft an Überstunden verzichteten die Betriebsvertretungen zunächst fast durchweg darauf, ihre Machtposition zu nutzen: „Die Betriebsräte sind überall gegen das Verfahren von Überschichten. Sie vermögen jedoch ihren ablehnenden Standpunkt auf den einzelnen Schachtanlagen nur in sehr verschiedenem Maße Geltung zu verschaffen, so daß die Zahl der Überschichten bei den einzelnen Gruben sehr verschieden ist. Nach Angabe der Zechen wird niemand zur Überschicht direkt oder indirekt gezwungen. Viele Leute sind froh, daß sie durch die Überschichten den Verdienstausfall der früheren Monate einigermaßen wettmachen können. Die Überschichten dürften, trotz der Freiwilligkeit, der Arbeitszeitverordnung widersprechen. ... Eine Beschwerde wegen des Verfahrens der Überschichten ist mir bisher von keiner Seite, insbesondere auch nicht von Betriebsvertretungen zugegangen. " ${ }^{531}$ Teilweise beobachtete die Bergaufsicht eine regelrechte Überstunden- und Arbeitswut, an der sich auch Betriebsräte beteiligten. ${ }^{532} \mathrm{Da}$ die Zechen auch in den kommenden Monaten nur wenig Neueinstellungen vornahmen ${ }^{533}$, wurde neben der Lohn- und Gedingefrage die Mehrarbeit zu einem vordringlichen Problem, das vor allem Betriebsvertretungen und $\mathrm{Ge}-$ werkschaften aufgriffen. ${ }^{534}$ Dabei bildeten sich in zunehmendem Maße Konfliktlinien nicht nur zwischen Betriebsräten und Zechenleitungen, sondern eben auch zwischen Betriebsräten und Belegschaftsteilen. ${ }^{535}$ Der Kampf verschiedener Betriebsvertretungen galt dabei nicht der „legalen“, sondern der Mehrarbeit, die über die Arbeitszeitordnung hinausging. ${ }^{536}$ Hatten die Proteste der Betriebsvertretungen im Juni und Juli 1926 noch wenig Wirkungen und vor allem wohl „for-

${ }^{530}$ Bergrevier Buer, 28. 6. 1926, StAM OBAD 1867, Bl. 232. Vgl. auch Stimmungsbericht des Oberbergamtes, 1. 11. 1926, StAM OBAD 1868, Bl. 3.

${ }^{53 t}$ Bergrevier Gladbeck, 28. 6. 1926, StAM OBAD 1867, Bl. 233.

532 Bergrevier Buer, 29. 7. 1926, StAM OBAD 1867, Bl. 299a.

${ }^{53}$ Die Belegschaft im Oberbergamtsbezirk Dortmund betrug Ende April 352000, Ende Mai 350000 , Ende Juni 352000, Ende Juli 360000; Stimmungsbericht des Oberbergamtes, 14. 8. 1926, StAM OBAD 1867, Bl. 303. Im August nahm die Zahl der angelegten Bergarbeiter noch einmal um ca 10000 auf insgesamt $371000 \mathrm{zu}$, bis Ende Oktober stieg sie auf 382000 an. Im Oktober 1926 hatte die Förderung den Vorkriegsstand erreicht, jedoch hatte die Belegschaft im Durchschnitt der Vorkriegsmonate Mai/Juni 1914 bei 430000 Mann gelegen.

534 Bergrevier Recklinghausen-West, 14. 7. 1926, StAM OBAD 1867, B1. $249 \mathrm{f}$.

535 Bergrevier Herne, 14. 7. 1926, StAM OBAD 1867, Bl. 255, berichtet von Konflikten zwischen Belegschaften und Betriebsräten, „die auf Veranlassung der Organisationen statt der Überschichten Neuanlegungen wünschen."

${ }^{536}$ Bergrevier Gelsenkirchen, 14. 7. 1926, StAM OBAD 1867, Bl. 256. 
melle Bedeutung"537, so begann sich die Lage im August zu ändern. Parallel zueinander stiegen zuriächst die Zahlen der willkürlich bzw. krankfeiernden Bergleute stark an. Für die Zechenleitungen war diese Entwicklung das Ergebnis der Knappschaftsnovelle vom 1. Juli 1926 und der gewerkschaftlichen Hetze, insbesondere der Kündigung des Lohntarifes zum 31. August 1926. Die Gruppe Hamborn der Abteilung Bergbau der Vereinigten Stahlwerke schrieb: „Durch das Vorgehen der Verbände ist natürlich eine große Unruhe in die Belegschaft hineingetragen worden. Durch radikale Elemente werden alle Bestrebungen, durch erhöhte Leistung bezw. durch Fördersteigerung der durch den englischen Streik gestiegenen Nachfrage sich anzupassen, zu vereiteln gesucht, so daß die Förderung und Leistung je Mann und Schicht darunter leiden. Dazu kommt, daß durch Inkrafttreten des neuen Knappschaftsgesetzes die Zahl der Krankfeiernden im Steigen begriffen ist. Es ist dies darauf zurückzuführen, daß zu den geltenden Krankenhaussätzen für jede zum Haushalt gehörende Person ein Sonderzuschlag von $10 \%$ bis zum Höchstsatz von $50 \%$ gezahlt wird. Danach erhält ein Arbeiter in der höchsten Lohnklasse mit Frau und vier Kindern M 6,48 je Tag (auch für Sonnund Feiertage), so daß es vorkommen kann, daß ein Bergmann beim Krankfeiern ein größeres Einkommen hat als beim Arbeiten. Während Anfang Juli auf unseren Schachtanlagen der Hundertsatz der willkürlich- und krankfeiernden Belegschaft 11,5, derjenige der Krankfeiernden allein 7,4\% betrug, waren die beiden Zahlen Anfang August auf 15 bezw. 10\% gestiegen. Das sind üble Folgen einer gutgemeinten, aber zu weitgehenden Sozialpolitik. " 538 Die Bergleute feierten indes nicht nur häufiger krank; Ende August/Anfang September 1926 gingen auch fast flächendeckend die Leistungen und die Bereitschaft, Überschichten zu verfahren, zurück. Dieses Zusammenfallen von Krankheit, Leistungsrückgang und „Arbeitsunlust“ hatte noch eine weitere Ursache, wie die Bergbehörde im Gegensatz zu den Zechenleitungen vermutete. Es war eben nicht nur der Einfluß von $\mathrm{Ge}-$ werkschaften und radikalen Betriebsräten: „Von den Betriebsvertretern höre ich“, schrieb der Gelsenkirchener Bergrevierbeamte Mitte September 1926, „daß das Nachlassen der Leistungen und die geringere Beteiligung an Überschichten auf die allmähliche Ermüdung der Bergleute zurückzuführen sei. Diese Begründung

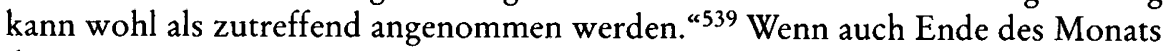
die Leistungen wieder anstiegen, so blieb jedoch in der Folgezeit die Krankenziffer hoch. Die verstärkte Neuanlegung von Bergleuten brachte zusätzliche Probleme, da qualifizierte Hauer kaum zu bekommen waren. ${ }^{50}$ Überdies begannen zahlreiche Bergleute die Arbeitskräfteknappheit durch Stellenwechsel zu nutzen sowie ihre gewachsene Machtstellung im Betrieb auszuspielen: „Verschiedentlich höre ich ..., daß einzelne Leute den Beamten gegenüber dreist und z.T. sogar frech auftreten. Das liegt zweifellos daran, daß sie jetzt leicht überall Arbeit finden können. ${ }^{441}$ Eine rigide Gedingepolitik konnte unangenehme Folgen haben: „Die Pluto-Zechen, die mit ihren Gedingelöhnen gegenüber den Nachbarzechen zu-

\footnotetext{
${ }^{537}$ Bergrevier Gelsenkirchen, 31. 7. 1926, StAM OBAD 1867, Bl. 290.

538 Zitiert nach Stimmungsbericht des Oberbergamtes, 14. 8. 1926, StAM OBAD 1867, Bl. $304 \mathrm{f}$.

${ }^{539}$ Bergrevier Gelsenkirchen, 14. 9. 1926, StAM OBAD 1867, Bl. 395.

${ }^{540}$ Sonderbericht des Oberbergamtes, 5. 10. 1926, StAM OBAD 1867, Bll. 410-413.

${ }^{5+1}$ Bergrevier Gelsenkirchen, 30. 10. 1926, StAM OBAD 1868, B1. 22.
} 
rückgeblieben waren, mußten diese Taktik schwer bereuen; denn es kündigten zahlreiche Hauer ihr Arbeitsverhältnis und wurden mit Freuden von den Nachbarzechen eingestellt. “542 Im vom englischen Bergarbeiterstreik zusätzlich angeheizten Konjunkturaufschwung der zweiten Jahreshälfte 1926 versagte mithin die Disziplinierung durch das Arbeitsmarktrisiko. Das „Konfliktbewältigungsmuster" der Zechenleitungen aus den Jahren 1924 und 1925 brach sukzessive zusammen. Spätestens jetzt war es erforderlich, die innerbetrieblichen Sozialbeziehungen zu überdenken.

Daß dabei mehr herauskommen konnte, als eine Fortsetzung der Blockadepolitik gegenüber den Betriebsräten, zeigte die staatseigene Bergwerks- A.G. Recklinghausen ${ }^{543}$, die bereits zum 1. Juni 1926 für ihre Betriebe die Stelle eines „Sozialinspektors" eingerichtet und mit einem ehemaligen Gewerkschaftssekretär besetzt hatte. Dessen Aufgaben bestanden vor allem in der Kommunikation mit Gesamtbetriebsrat und Einzelbetriebsräten, der Koordinierung der Einstellungsund Entlassungspolitik sowie der Bearbeitung von Beschwerden. ${ }^{544}$ Bei der Abteilung Bergbau der Vereinigten Stahlwerke ging man diesen Weg nicht. Auch hier hätten die Neuorganisation nach der Fusion und die Bildung von vier Regionalgruppen Anlaß sein können, die innerbetrieblichen Kommunikationsstrukturen zu reorganisieren. Stattdessen ergriffen die Einzelbetriebsräte der VSt.-Schachtanlagen von sich aus die Initiative und forderten die Bildung von Gesamtbetriebsräten entsprechend der vier Regionalgruppen, nachdem ein erster Versuch, für die Vereinigten Stahlwerke einen Gesamtbetriebsrat zu schaffen, an der ablehnenden Haltung des Konzernvorstandes gescheitert war. ${ }^{545}$ Das über diese Versuche dem Bergausschuß der Vereinigten Stahlwerke berichtende Vorstandsmitglied Karl Winnacker wußte nicht nur von weit fortgeschrittenen Wahlvorbereitungen in der Gruppe Hamborn zu berichten, er meinte auch das Motiv dieser Versuche zu kennen. „Nach Äußerung der Gegenseite“, sagte er am 14. Oktober 1926 vor dem Bergausschuß, „habe die Rede des Herrn Silverberg die Veranlassung zu diesem Vorgehen gegeben. "Nach Prüfung der Rechtslage könne die Bildung eines derartigen Gremiums nicht verhindert werden, wenn alle Einzelbetriebsräte der Bildung der Gesamtvertretung zustimmten. Genau betrachtet habe ein Gesamtbetriebsrat aber kaum Kompetenzen, da er nicht in Gruppenräte aufgeteilt werden könne und daher nur Angelegenheiten zu beraten habe, die sowohl Arbeiter und Angestellte gleichermaßen wie auch zumindest mehr als eine Schachtanlage einer Gruppe beträfen. „Hieraus ergibt sich“, schlußfolgerte ein Mitglied der Rechtsabteilung, die derartige Fragen bearbeitete, „daß die Zuständigkeit der Gesamtbetriebsräte sehr eng, seine (!) Bedeutung daher praktisch nur sehr gering anzuschlagen ist. " ${ }^{546}$ In der Tat konnte man ein Jahr später, als bei der Gruppe Bochum die Bildung eines Gesamtbetriebsrates erfolgte, feststellen, „daß der Gesamtbetriebsrat der Gruppe Hamborn wegen seiner geringen Zuständigkeit keinerlei Bedeu-

\footnotetext{
${ }^{542}$ Bergrevier Gelsenkirchen, 12. 11. 1926, StAM OBAD 1868, Bl. 79.

${ }^{543} 1925$ vom Preußischen Staat zur Verwaltung seines Zechenbesitzes gegründet, Wiel, Wirtschaftsgeschichte des Ruhrgebietes, S. 163.

${ }^{544}$ Stimmungsbericht des Oberbergamtes, 14. 8. 1926, StAM OBAD 1867, Bl. 306.

${ }^{545}$ Niederschrift der Bergausschußsitzung der VSt., 14. 10. 1926, BgA 55/580.

${ }^{5+6}$ Niederschrift der Bergausschußsitzung der VSt., 14. 10. 1926, BgA 55/580.
} 
tung" erlangt habe. ${ }^{547}$ Auch den gelegentlichen Anfragen der Betriebsratsmitglieder im Aufsichtsrat der Vereinigten Stahlwerke nach Besprechungen unter Hinzuziehung von Betriebsratsmitgliedern aus den Gruppen begegnete man reserviert; Grubenfahrten dieser Aufsichtsratsmitglieder lehnte man ab. ${ }^{548}$

Der Abteilung Bergbau war gleichwohl bewußt, daß durch eine reine Verweigerungshaltung die betrieblichen Probleme nicht zu lösen waren, zumal das Auftreten der Bergarbeiterschaft „aggressivere“ Züge annahm. Zwar half gegenüber radikalen Betriebsvertretungen in der Regel der Gang zum Arbeitsgerich $t^{549}$, doch blieben Unzufriedenheit, Krankfeierei und geringe Leistungsbereitschaft ${ }^{550}$ an der Tagesordnung. Das Krankfeiern nahm bei der Gruppe Hamborn der Abteilung Bergbau der VSt. derartige Ausmaße an: „daß von der Gesamtbelegschaft im ganzen, d. h. wegen Krankheit, wegen Urlaubs und willkürlich, 15 bis $18 \%$ feiern, so daß rd. 3000 bis 4000 Mann der Belegschaft täglich der Arbeit fernbleiben. Derselbe Prozentsatz an Feierschichten wird aus dem Bergrevier Oberhausen gemeldet. “551 Auch begann sich jetzt das Fehlen von qualifizierten Bergleuten immer stärker bemerkbar zu machen, deren Abwanderung man ein Jahr zuvor zwar beklagt, aber tatenlos hingenommen hatte. Die Antwort auf Verweigerungshaltung und Nachwuchsmangel, die die Abteilung Bergbau der VSt. präsentierte, bestand aus Werksgemeinschaft und Lehrlingsausbildung. Insbesondere in der Gruppe Hamborn begann man mit einer systematischeren Nachwuchsförderung und Lehrlingsausbildung. ${ }^{552}$ Zugleich eröffnete man eine bissige Polemik gegen die staatliche Sozialpolitik, insbesondere gegen die Auswirkungen der letzten Knappschaftsnovelle. ${ }^{53}$ Die Leistungen der Krankenversicherung und der Erwerbslosenfürsorge seien derart hoch, daß sie einen wirklichen Anreiz zur Arbeit ausschlössen. ${ }^{554} \mathrm{Zwar}$ waren derartige Angaben übertrieben, da ein im Leistungslohn bezahlter Hauer besser verdiente als ein Kranker oder Arbeitsloser; jedoch war die Zahl der Feierschichten allein in Hamborn so hoch, daß durch Mehrarbeit gerade die Normalauslastung der Gruben, keineswegs aber Spitzenförderleistungen erreicht werden konnten. Die Verweigerungshaltung gegenüber den Betriebsräten und der Beginn einer systematischeren Förderung des bergmännischen Nach-

${ }^{547}$ Bergausschußsitzung, 3. 11. 1927, BgA 55/581.

${ }^{548}$ Bergausschußsitzung, 3. 11. 1927, BgA 55/581, Bergausschußsitzung, 2. 8. 1929, BgA 55/583.

${ }^{549}$ Bergrevier Duisburg, 12.11. 1926, StAM OBAD 1868, B1. 87.

550 Nach der Statistik des Zechenverbandes entfielen im September 1926 auf einen angelegten Bergmann 3,28 Feierschichten (davon 2,03 wegen Krankheit) gegenüber 1,73 Über- und Nebenschichten; vgl. Stimmungsbericht des Oberbergamtes, 15. 10. 1926, StAM OBAD 1867, Bl. $442 \mathrm{f}$.

551 Sonderbericht des Oberbergamtes, 5. 10.1926, StAM OBAD 1867, Bl. 410. Der Krankenstand der gesamten Abteilung Bergbau der VSt lag im Geschäftsjahr 1926/27 allerdings nur bei 7,51\%, vgl. Monatsbericht der VSt 9/1933, S. 63.

552. Siehe die Beschreibung der insgesamt vierjährigen Ausbildung in: Stimmungsbericht des Oberbergamtes, 15. 3. 1927, StAM OBAD 1868, Bl. $322 \mathrm{f}$.

553 Im Geschäftsjahr 1926 betrugen die gesetzlichen sozialen Aufwendungen 13,68\% der Lohnsumme, 1926/27 14,55\%, 13,94\% im Geschäftsjahr 1929/39. In der Weltwirtschaftskrise stiegen die Aufwendungen wiederum stark auf schließlich 17,85\% 1931/32 an - allerdings wegen eines statistischen Basiseffektes. Vgl. Monatsbericht der VSt 9/1933, S. 59. Im Bergbau lag die Belastung mit Sozialabgaben wegen des hohen Knappschaftsgefälles deutlich über dem Durchschnitt der Sozialaufwendungen der gesamten Vereinigten Stahlwerke. Sie waren im Durchschnitt im Arbeiterbereich ctwa doppelt so hoch wie bei den Hüttenbetrieben, Monatsbericht der VSt 9/1933, S.59.

${ }^{554}$ Stimmungsbericht des Oberbergamtes, 1.9. 1926, StAM OBAD 1867, Bl. 337. 
wuchses brachten indes nicht die gewünschten Ergebnisse. ${ }^{55} \mathrm{Da}$ auch eine nennenswerte freiwillige Sozialpolitik unterblieb - im Jahresdurchschnitt 1926/27 wurden gerade $25 \mathrm{RM}$ pro Belegschaftsmitglied an freiwilligen sozialen Aufwendungen gezahlt ${ }^{556}$-, waren die materiellen Möglichkeiten der Abteilung Bergbau der Vereinigten Stahlwerke zur besseren Integration der Arbeiterschaft und zur Erhöhung der Attraktivität der Bergarbeit schnell ausgeschöpft. Daß vor diesem Hintergrund der Werksgemeinschaftsgedanke eine gewisse Faszination ausübte, da er weder mit materiellen Leistungen der Zechen noch mit anderen Zugeständnissen an die Bergarbeiterschaft verknüpft war, ist verständlich. Im Rahmen des Konjunkturaufschwunges 1926 war allerdings der Problemdruck noch nicht so groß, daß man derartige Konzepte vorrangig betrieb.

Denn die genannten Probleme waren eine Folge der guten Konjunktur: „Insgesamt übersteigt die Nachfrage die Lieferungsmöglichkeiten“, berichtete das Oberbergamt im Oktober 1926. Letztere würden neben Problemen beim Kohlentransport vor allem durch „das Nachlasen der freiwilligen Überarbeit" begrenzt. Erstmals (August 1926) überträfen die Feierschichten (wild, wegen Krankheit) auch das Volumen der Mehrarbeit, schrieb die Bergaufsichtsbehörde und wiederholte damit bereits seit längerem bekannte Klagen des Zechenverbandes. ${ }^{57}$ Der Arbeitskräftemangel wurde daher mehr und mehr zu einer Engpaßgröße der Kohlenförderung und zur entscheidenden Frage der Nutzung der günstigen Konjunktur. ${ }^{558}$ Das Landesarbeitsamt zählte Anfang November 1926 nur noch knapp 9000 arbeitsuchende Hauer, von denen lediglich 4500 Kohlenhauer waren. Von diesen waren wiederum nur 1800 voll einsatzfähig. ${ }^{559}$ Von der guten Konjunktur profitierten nicht nur die Zechen. Die Arbeitskräfteknappheit verschaffte auch den Bergleuten wieder größere Handlungsspielräume, die sie zunächst individuell nutzten. Erstmals gab es Berichte über wegen Desinteresses ausgefallene Belegschaftsversammlungen, und der Berginspektor in Recklinghausen wußte von schlechter Stimmung bei den Gewerkschaften zu berichten: „Da Löhne und Arbeitsverhältnisse zufriedenstellend sind, so läßt das Interesse der Belegschaften an den Beitragszahlungen nach." Durch das Schüren von Unzufriedenheit und die Aufstellung von Forderungen suchten die Bergarbeiterorganisationen ihre Existenzberechtigung nachzuweisen. ${ }^{560}$

Daß im Dezember 1926 Forderungen nach höheren Löhnen, kürzeren Arbeitszeiten und Einschränkung der Mehrarbeit auf den Tisch kamen, war aber nicht allein eine Folge der gewerkschaftlichen Interessen; die Forderungen zeigten die gewachsene Stärke der Bergarbeiterschaft. Angesichts der schwierigen Arbeitsmarktverhältnisse - ausreichend leistungsfähige Kohlenhauer waren weiterhin "Mangelware" - schien den Zechenleitungen aber gerade in der Arbeitszeitfrage ein Kompromiß ausgeschlossen. Wäre man gezwungen, argumentierte die Gruppe Hamborn der Abteilung Bergbau der Vereinigten Stahlwerke im Dezem-

\footnotetext{
${ }^{555}$ Stimmungsbericht des Oberbergamtes, 15.3. 1927, StAM OBAD 1868, Bl. $322 \mathrm{f}$.

${ }_{556}$ Berechnet nach den Angaben in: Monatsbericht der VSt 9/1933.

${ }^{557}$ Stimmungsbericht des Oberbergamtes 15. 10. 1926, StAM OBAD 1867, Bl. 442.

${ }^{558}$ Stimmungsbericht des Oberbergamtes 1.11. 1926, StAM OBAD 1868, Bl. $2 \mathrm{f}$.

${ }^{559}$ Stimmungsbericht des Oberbergamtes 15.11. 1926, StAM OBAD 1868, Bl. 45.

560 13. 11. 1926, StAM OBAD 1868, Bl. 73.
} 
ber 1926, eine durchaus mögliche höhere Förderung durch Einstellung nicht leistungsfähiger Arbeiter zu realisieren, so würde sich die Kostenbelastung der Zechen dramatisch verschlechtern. Es müsse deshalb die Einführung des schematischen Achtstundentages, die im Bergbau zu einer Untertagearbeitszeit von sieben Stunden führe, wie ein zu weitgehendes Mehrarbeitsverbot in der bevorstehenden Arbeitszeitgesetzgebung auf jeden Fall vermieden werden. ${ }^{561}$ Die Hamborner Leitung der Zechen der Vereinigten Stahlwerke hatte mit ihrer Argumentation ökonomisch recht. Eine starke Ausdehnung der Beschäftigung im Ruhrbergbau wäre nicht nur kostentreibend; angesichts der Strukturkrisenerfahrung der Jahre 1924 und 1925 würde auf diese Weise zudem das Problempotential der Branche stark erhöht. Den Vereinigten Stahlwerken aber ging es vor allem um die Ausnutzung der aktuell guten Konjunktur: „Soll eine auftretende günstige Konjunktur nicht allein für den Unternehmer, sondern für die gesamte Wirtschaft vorteilhaft ausgenutzt werden können, so muß die Möglichkeit gegeben sein, den gesamten Betrieb bis zur Höchstleistung anzuspannen. Falls die bisher zulässige Mehrarbeit in Zukunft eingeschränkt werden sollte, ist gegebenenfalls mit Fehlmengen in der deutschen Kohlenwirtschaft zu rechnen. ${ }^{\text {"562 }}$ Angesichts der bisherigen Zahlenverhältnisse - der Zechenverband hatte für die Jahre 1924 bis 1926 ein deutliches Überwiegen der Feierschichten gegenüber der Mehrarbeit festgestellt - schien Mehrarbeit zudem unbedenklich. ${ }^{563}$

Der eigentliche Hintergrund der Befürchtungen der Zechen vor einer neuen Arbeitszeitauseinandersetzung war dabei recht einfach. Im Jahr 1926 war der Anstieg der Kohlenförderung um 8 Mio. t gegenüber 1925 mit einer weiter sinkenden Belegschaft erreicht worden. Der Belegschaftsabbau bis zum Juni 1926 hatte die Zahl der angelegten Bergarbeiter auf fast 350000 gedrückt (Jahresdurchschnitt 1925 410000) und auch nach dem Umschwung der Absatzlage waren die Belegschaftszuwächse moderat geblieben (etwa 400000 zur Jahreswende 1926/27). Durch umfangreiche Rationalisierungsmaßnahmen war die Pro-Kopf-Leistung je Schicht von 255 auf $308 \mathrm{t}$ angestiegen. ${ }^{564}$ Für den Fall von Arbeitszeitverkürzungen drohte konkret ein Verlust der bisherigen Produktivitätsgewinne und ein deutlicher Anstieg der Lohnkosten. Daß man daher darauf setzte, die Konjunkturspitzen durch Mehrarbeit und nicht durch Mehrbeschäftigung bei gleichzeitiger Arbeitszeitverkürzung abzudecken, war nur folgerichtig. Da die Arbeitszeitfrage in der Programmatik der Bergarbeiterverbände und der Kommunisten eine zentrale Rolle spielte, war für die bevorstehenden Verhandlungen über das gekündigte Arbeitszeitabkommen und den ebenfalls gekündigten Manteltarifvertrag eine schwere Auseinandersetzung zwischen den Tarifparteien zu erwarten. Ange-

561 Stellungnahme der Gruppe Hamborn, wiedergegeben in Bericht des Bergreviers Oberhausen, 14. 12. 1926, StAM OBAD 1868, Bl. 150-155.

562 Ebenda, Bl. $154 \mathrm{f}$.

${ }^{563}$ In der Tat ermittelte auch die Bergaufsicht für 1926 ein deutliches Überwiegen der Feier- über die Neben- und Überschichten. Im ersten Quartal 1926 entfielen bei 65,7 Schichten je angelegten Bergmann auf jedes Belegschaftsmitglied 2,35 Über- und Neben-, aber 12,09 Feierschichten. Im letzten Quartal 1926 betrugen die Zahlen entsprechend 73,04 Schichten insgesamt, 5,47 Nebenund Überschichten, 8,51 Feierschichten, Stimmungsbericht des Oberbergamtes 1.7. 1927, StAM OBAD 1869, Bl. 148.

${ }^{564}$ Zahlen nach Wiel, Wirtschaftsgeschichte des Ruhrgebietes, S. 131. 
sichts der Ende 1926 noch günstigen konjunkturellen Lage der Schachtanlagen war allerdings eine eigenständige Handlungsweise der Belegschaften für den Fall sich hinziehender bzw. schließlich scheiternder Verhandlungen unwahrscheinlich. Anders als bis 1923 war der materielle Druck der Belegschaften zu Ende des englischen Bergarbeiterstreikes gering. Und selbst bei einer Verschlechterung der Konjunktur würden Entlassungsrisiko und Feierschichten dafür sorgen, daß die Bergarbeiterschaft nicht kampfbereit wäre.

\section{Mitbestimmung in der Schwebe 1927 bis 1929}

1927 schien sich die gute Konjunkturlage weiter fortzusetzen. Die Kohlenförderung, die 1925104 Mio. $t$ betragen hatte und 1926 auf 112 Mio $t$ angestiegen war, erhöhte sich 1927 zunächst noch weiter. Im Jahresschnitt erreichte sie 118 Mio. t, stieg also um etwa 5\%, jedoch nahm die Zahl der Beschäftigten im gleichen Umfang zu, so daß sich die Schichtproduktivität im Jahresdurchschnitt nicht mehr erhöhte. ${ }^{565}$ Nicht allein diese Entwicklung machte den Zechenleitungen Sorgen. Mit dem Ende der guten Konjunktur im Frühjahr verschärfte sich der Preiswettkampf in erheblichem Maße, wobei wiederum die Konkurrenzsituation im bestrittenen Gebiet keine kostendeckenden Preise mehr zuließ. Bereits im März zeichnete sich das Ende der Massenkonjunktur ab. Angesichts der nur geringen Möglichkeiten, die Mehr- und Überarbeit effektiv auszudehnen, stiegen bis zum März noch die Beschäftigtenzahlen. Im Ruhrbergbau lagen sie im März 1927 bei 403000 , also deutlich über dem Jahresdurchschnitt von 1926, der bei 365000 gelegen hatte. ${ }^{566}$ Die Stagnation der Förderung, der zurückgehende und preislich unbefriedigende Absatz sowie die weiter vorangetriebene Rationalisierung übten aber bereits vom März 1927 an wieder einen erheblichen Entlassungsdruck aus. Wie einschneidend der Wandel war, zeigte sich daran, daß noch Anfang Januar 1927 über Arbeitermangel und dadurch bedingte Förderausfälle geklagt wurde, jedoch bereits Mitte Januar sich erste Krisenzeichen zeigten. Betraf der Absatzmangel zunächst vor allem die reinen Zechen und hier insbesondere zahlreiche Südrandzechen ${ }^{567}$, so waren die Wirkungen erster Entlassungen und Feierschichten kaum zu überschätzen. ${ }^{568}$ Vielen Belegschaften, aber auch zahlreichen Zechenleitungen und den Bergbehörden kamen jetzt zudem Zweifel, ob die Absatzpolitik des RWKS während des englischen Streikes sich langfristig als vorteilhaft erweisen würde: „Der Verlauf des Absatzes im Frühjahr und Sommer wird zeigen müssen, ob die Handelspolitik des Kohlensyndikats richtig war, die Arbeitsstreitigkeiten bei dem englischen Steinkohlenbergbau geldlich nicht auszunützen und dafür langfristige Abschlüsse zu tätigen. Es wird nunmehr darauf ankommen, ob in genügendem Maße Abschlüsse hereingeholt worden sind und insbesondere auch darauf, ob die ausländischen Abnehmer die eingegangenen Verpflichtungen erfüllen. Wenn dies nicht geschieht, wird in absehbarer Zeit wieder mit Absatzschwierigkeiten zu

\footnotetext{
565 Ebenda.

566 Stimmungsbericht des Oberbergamtes, 15. 3. 1927, StAM OBAD 1868, Bl. 321.

567 Stimmungsbericht des Oberbergamtes, 15. 1. 1927, StAM OBAD 1868, Bl. $194 \mathrm{f}$.

${ }^{568}$ Mitte Februar berichtete der Berginspektor des Reviers Buer, daß Befürchtungen über den Fortgang der Konjunktur laut würden, 12. 2. 1927, StAM OBAD 1868, Bl. 287.
} 
rechnen sein, da das Inland die stark gestiegene Förderung trotz der etwas gebesserten wirtschaftlichen Lage nicht aufnehmen kann. ${ }^{“ 569}$

Die Verhandlungen über einen neuen Lohn- und Manteltarifvertrag fielen damit in eine Zeit wirtschaftlicher Unsicherheit. Namentlich für die Gewerkschaften stellte diese Konstellation eine erhebliche Behinderung dar. Ein Aufruf der ADGB-Gewerkschaften vom 30. Januar 1927 an die Arbeiterschaft des Industriebezirks, „dem Überschichtenwesen ein Ende zu machen“, traf auf wenig Resonanz, da die Überschichten ohnehin konjunkturbedingt zurückgingen. ${ }^{570}$ Auch die Überschichtenpraxis selbst hatte sich während der guten Konjunktur einigermaßen eingespielt: „Für Leute, welche gern Über- oder Nebenschichten verfahren, findet sich Gelegenheit genug.; die anderen werden dazu nicht gedrängt. Man möchte sagen, daß sich hierin eine gewisse Gewohnheit herausgebildet hätte. “571

Die sich hinziehenden Tarifverhandlungen ${ }^{572}$ stießen in der Bergarbeiterschaft zunächst auf wenig Interesse. Hatte schon im Februar der Bueraner Bergaufsichtsbeamte betont, „ein einheitliches Bild über die Stimmung der Arbeitnehmerschaft ist nicht zu erlangen" ${ }^{273}$, so brachten auch Arbeitszeit- und Lohnkonflikt keine Stimmungsänderungen. Zwar befürchteten manche Arbeiter, mit der Bildung der neuen Reichsregierung ${ }^{574}$ würden die Schwerindustriellen einen Generalangriff auf ihre sozialen Rechte verbinden, doch war insgesamt die Stimmung ruhig. Die Versuche der Tarifgewerkschaften zur Mobilisierung der Belegschaften erschöpften sich vor diesem Hintergrund in Appellen. Der Bergarbeiterverband verteilte Flugblätter, die die ungerechten Folgen der Rationalisierung kritisierten, als Handlungsangebot allerdings lediglich den Organisationsbeitritt empfahlen: „Einer 80 bis $90 \%$ organisierten Bergarbeiterschaft würde man nicht bieten, was die Unternehmer mit ihrem Standpunkt und die Reichsregierung mit ihrem Arbeitszeitnotgesetz den Bergleuten zu bieten wagen. In letzter Stunde rufen wir den Bergleuten zu: Steht nicht teilnahmslos und nörgelnd beiseite! Organisiert Euch! Schließt Euch dem Bergarbeiterverband an!" 575 Am 18. März 1927 wurde ein neuer Rahmentarif durch Schlichtungsspruch verkündet, der die bisherige Arbeitszeit ${ }^{576}$ beibehielt (Siebenstündige Regelarbeitszeit unter Tage bei gleichzeitiger Möglichkeit ihrer Verlängerung um 1 Überstunde). Wenig später erklärte der Reichsarbeitsminister mit Zustimmung der christlichen Bergarbeitergewerkschaften den Schiedsspruch für verbindlich. Die kommunistischen Versuche, den Schiedsspruch zu unterlaufen, stießen allerdings auch bei den freien Gewerkschaften auf massiven Widerspruch. Nicht zuletzt wegen dieser traiftreuen Haltung des Alten Verbandes, aber auch weil verschiedene Zechenverwaltungen auf die Folgen

${ }^{569}$ Stimmungsbericht des Oberbergamtes, 1.2. 1927, StAM OBAD 1868, B1 225.

${ }^{570}$ Der Aufruf ebenda, Bl. 228.

571 Bergrevier Buer, 12. 2. 1927, StAM OBAD 1868, Bl. 287.

${ }^{572} \mathrm{Im}$ März scheiterten die Verhandlungen der Tarifparteien sowie eine erste Schlichtungsrunde, so daß eine staatliche Schlichterkammer unter Leitung des Schlichters für die Rheinprovinz gebildet wurde, vgl. Stimmungsbericht des Oberbergamtes, 15. 3. 1927, StAM OBAD 1868, B1. 321.

${ }^{573}$ Ebenda.

${ }^{574}$ Zur Bürgerblockregierung unter dem Reichskanzler Wilhelm Marx, die ab dem Februar 1927 amtierte, vgl. Mommsen, Verspielte Freiheit, S. 254. Die Befürchtungen bezogen sich auf das bevorstehende Arbeitszeitnotgesetz.

575 Zitiert nach ebenda.

${ }^{576}$ Zum größeren Zusammenhang Tschirbs, Tarifpolitik im Ruhrbergbau, S. 280. 
von Tarifbrüchen hinwiesen, unterblieben größere Proteste der Belegschaften gegen den neuen Rahmentarifvertrag. In den einzelnen Revieren war die Lage unterschiedlich; so hatten die kommunistischen Aufrufe in Essen und Recklinghausen zeitweilig Erfolg. Auf der Zeche Mathias Stinnes kam es zum einzigen größeren Versuch, die Arbeitszeitregelung durch direkte Aktionen der Belegschaft zu unterlaufen. ${ }^{577}$ Dabei zeigte sich sehr rasch wieder das aus den frühen zwanziger Jahren bekannte Bild. Eine Belegschaftsversammlung beschloß am 31. März 1927 in einer Karnaper Wirtschaft, nur die siebenstündige Schicht zu verfahren und bildete zur Durchführung dieses Beschlusses einen Aktionsausschuß. Der Aktionsausschuß organisierte am 1. April in der Waschkaue eine erneute Belegschaftsversammlung, die beschloß, erst eine Stunde nach dem offiziellen Schichtbeginn einzufahren. Der Betriebsratsvorsitzende, der sich gegen den Beschluß wandte, wurde, so die Bergaufsicht, am Reden gehindert. Entsprechend des Beschlusses fuhren nur 400 von 1000 Bergleuten der Morgenschicht pünktlich an, von der Mittagsschicht nur 50\%. Nach massiven Drohungen der Zechenleitung lag die Verweigerungsquote bei der Nachtschicht nur noch bei $14 \%$. Trotz erneuter Mobilisierungsversuche durch den Aktionsausschuß verweigerten am 2. April nur noch zwischen 12 und 15\% der Belegschaft die reguläre Anfahrt. Die Zechenverwaltung kürzte daraufhin insgesamt 800 Arbeitern den Lohn und entließ 304 fristlos. Verhandlungen zwischen Arbeiterrat und Zechenleitung, bei denen das Bergamt als Schlichter vermitteln wollte, scheiterten. ${ }^{578}$ Der Zeche kamen der Streik und die Entlassungen nicht ungelegen, da „sich die Z.echenverwaltung durch den in den letzten Tagen immer schärfer auftretenden Absatzmangel ohnehin gezwungen sehe, die Frage einer Belegschaftsverringerung in Erwägung zu ziehen. Die Verwaltung wolle deshalb die Kündigungen auch aus dem Grunde nicht zurücknehmen, weil dann später möglicherweise arbeitswillige Bergarbeiter zur Entlassung gelangen müßten. ${ }^{\text {579 }}$ Der Recklinghäuser Berginspektor erwartete für die kommende Zeit folgerichtig: „Inzwischen ist die Kündigung der Lohntarife erfolgt. Man kann annehmen, daß die Verhandlungen nach dem Wiedereintritt von Feierschichten in gemäßigter Weise verlaufen werden. ${ }^{\text {"580 }}$

Die Bestimmungen der Arbeitszeitverordnung vom 14. April $1927^{581}$, die im Grundsatz die bisherige Regelung bestätigten, allerdings für die neunte Arbeitsstunde einen Überstundenzuschlag von $25 \%$ vorschrieben, sowie die steigende Anzahl der Feierschichten bei gleichzeitigem deutlichen Rückgang der Überschichten nahmen der Arbeitszeitfrage schließlich ihre Brisanz. Die Betriebsräte hatten nun auch formal kaum noch Einflußmöglichkeiten in der Überstundenfrage, nachdem bereits 1925 und 1926 die jeweilige konjunkturelle Situation das Verhalten der Bergleute stärker bestimmt hatte als programmatische Überlegungen. Der Versuch in der „regulierten“ Arbeitszeitfrage Änderungen durchzusetzen, implizierte nach dem März 1927 zudem den Tarifbruch, so daß sich ein eigenständiges Handlungsfeld in dieser Frage den Betriebsräten nicht bot. Ohnehin

\footnotetext{
577 Vgl. hierzu auch Tschirbs, Tarifpolitik im Ruhrbergbau, S. 281.

578 Bericht des Bergreviers Essen III, 13. 4. 1927, StAM OBAD 1869, Bl. 65.

${ }^{579}$ Stimmungsbericht des Oberbergamtes, 14. 4. 1927, StAM OBAD 1869, Bl. 41.

580 Ebenda.

${ }^{581}$ Tschirbs, Tarifpolitik im Ruhrbergbau, S. 281.
} 
hätten radikale, tarifbrechende Arbeiter im Zweifelsfall kaum auf die Betriebsräte gesetzt, wie das Beispiel Mathias Stinnes zeigte. Der Arbeiterrat in Essen wurde lediglich benötigt, um die Folgen der direkten Aktion - erfolglos - in Grenzen zu halten. Zudem änderten sich nach dem neuen Tarifvertrag und der Arbeitszeitverordnung die Fronten. Nicht zuletzt aus konjunkturellen Gründen, aber auch um teuere Mehrarbeit einzusparen, verweigerten einige Zechen ihren Belegschaften Mehrarbeit und verhielten sich bei der Organisation der Arbeitszeit außerordentlich unkooperativ: „Die Bestimmung der A.Z.V. [Arbeitszeitverordnung], daß jegliche, auch freiwillige Überarbeit verboten ist [was unzutreffend von manchen Zechenleitungen behauptet wurde], wird von den Arbeitern vielfach als Härte empfunden, weil ein Schichtausfall nicht mehr durch Überarbeit an einem der folgenden Wochentage herausgeholt werden kann, ja sogar ein Verlegen von der Nachtschicht auf eine Tagschicht für die Arbeiter jedesmal den Ausfall einer Schicht bedeutet." 582 Durch den Wegfall der Über- und Nebenschichten sank in der Tat die Lohnsumme ab, was die Belegschaften zum Teil stark belastete. ${ }^{583}$ Von der durch Feierschichten und Mehrarbeitsausfall verkürzten Arbeitszeit wurden vor allem die Untertagearbeiter, namentlich die im Gedinge bezahlten Kohlenhauer stark betroffen, deren Einkommenszuwächse 1927 deutlich hinter denen der Tagesarbeiter zurückblieben. ${ }^{584}$ Der Ende April 1927 in der Lohnfrage gefällte Schiedspruch stellte zwar die Untertagearbeiter etwas besser als die Tagesarbeiter, die arbeitszeitbedingten Lohnausfälle konnte er jedoch nicht ausgleichen. ${ }^{585}$ Vor diesem Hintergrund plädierten zahlreiche Betriebsräte nunmehr für eine Verlängerung der Arbeitszeit und waren bei anhaltender konjunktureller Flaute, sofern hierdurch die Zahl der Feierschichten gesenkt werden konnte, auch wieder bereit, Entlassungen zuzustimmen. Eine klare Linie in der Arbeitszeitpolitik der Betriebsvertretungen war jedenfalls nicht mehr erkennbar. Während manche Betriebsräte, insbesondere jene bei den Hüttenzechen, die noch voll ausgelastet waren, weiterhin der Mehrarbeit skeptisch bis ablehnend gegenüberstanden, setzten sich andererseits Betriebsvertretungen reiner bzw. von Absatzmangel besonders betroffener Südrandzechen für eine Verlängerung der Arbeitszeiten ein, um auf diese Weise drohende Stillegungen zu verhindern. Die Frage, wie sich die Betriebsräte in der Arbeitszeitfrage verhalten würden, war generell nicht mehr vorhersehbar.

Die Kompromißlosigkeit in der Arbeitszeitfrage, zu der die enge Auslegung der Arbeitszeitverordnung zählte, beherrschte auch in anderen Feldern den gegenseitigen Umgang von Zechenleitungen und Betriebsräten. Nach der Einführung von Arbeiterkontrolleuren waren die Auseinandersetzungen um die Rolle der Betriebsräte in der Frage der Grubensicherheit keineswegs abgerissen. ${ }^{586} \mathrm{Ze}$ chenleitungen und Bergaufsicht gingen nunmehr freilich auf andere Weise als bisher gegen die Kontrollansprüche der Betriebsräte vor. Zwar wurden auch weiter-

\footnotetext{
582 Bergrevier Lünen, 11. 6. 1927, StAM OBAD 1869, Bl. 185.

${ }^{583}$ Bergrevier Herne, 14. 6. 1927, StAM OBAD 1869, Bl. 196.

${ }^{584} \mathrm{Zu}$ den Jahresverdiensten Tschirbs, Tarifpolitik im Ruhrbergbau, S. 296. Vgl. auch Monatsbericht der VSt 9/1933, S. 46.

${ }^{585} \mathrm{Zu}$ den Bestimmungen des Schiedsspruches Stimmungsbericht des Oberbergamtes, 30.4. 1927, StAM OBAD 1869, Bl. 79. Vgl. auch Tschirbs, Tarifpolitik im Ruhrbergbau, S. 283.

${ }^{586}$ Bergrevier Buer, 29. 1. 1927, StAM OBAD 1868, Bl. 257.
} 
hin die Befahrungsrechte der Betriebsräte, wo es ging, beschnitten, und die Konflikte über die Bezahlung der Ausfallschichten von Betriebsausschußmitgliedern hielten $\mathrm{an}^{587}$, jedoch wurden jetzt in zunehmendem Maße Belegschaften und Betriebsräte gegeneinander ausgespielt. Unter anderem wegen des vorherrschenden Drucks auf die Gedinge betrieben manche Bergleute den Grubenausbau und die Verfüllung von Hohlräumen nur nachlässig, um die Arbeitszeit möglichst weitgehend zur Kohlenförderung nutzen zu können. Die Versuche der Betriebsräte, durch Änderung der Gedingestellung diesen Druck zu mindern, waren durchweg gescheitert, so daß bei korrekter Auslegung der Bergpolizeivorschriften die $\mathrm{Be}$ triebsräte in Konflikte mit den Kameradschaften kommen mußten. Diesen latenten Konflikt nutzte die Bergbehörde gezielt: „Als aber neulich bei einer Befahrung durch einen höheren Beamten in Gegenwart eines Betriebsausschußmitgliedes festgestellte recht auffallende Übertretung von Anordnungen zur Bestrafung des Steigers als auch der gesamten Belegschaft eines Rutschen-Abbau-Stoßes führte und führen mußte, sah sich der Betriebsausschuß in einer sehr unangenehmen Lage und suchte sich derselben dadurch zu entziehen, daß er auf die Teilnahme an der nächsten Befahrung verzichtete. ${ }^{\text {" }} 88$ Dieses Vorgehen war kein Einzelfall. „Die Verwaltung der Zeche Minister Achenbach hat ihre Betriebsführer angewiesen, alle Fälle, in denen Hohlräume im Versatz festgestellt werden oder ungenügend verbaut sind, dem Bergrevierbeamten zur Anzeige zu bringen, so daß dieser gezwungen ist, Strafverfahren einzuleiten. Sie tut dies, um 1.) nicht aus den angegebenen Gründen Strafen auf Grund der Arbeitsordnung verhängen zu müssen, weil die Arbeiterorganisationen vielfach über zu große Zahl der Bestrafungen Beschwerde führen und 2.) der Behörde den Nachweis zu erbringen, daß vielfach von den Arbeitern die Vorschriften und Anordnungen nicht befolgt werden, also die Unfälle im Bergbau zum großen Teil auf diese, der Behörde vielleicht gar nicht bekannten Zuwiderhandlungen zurückzuführen sind. “589 Auf diese Weise konnte das Verhältnis der Belegschaften zu den Betriebsräten gezielt unterminiert werden, da erstere im Zweifelsfall gezwungen waren, gegen die materiellen Interessen der Belegschaften zu votieren. Die zurückgehende Akzeptanz der Betriebsräte bei den Belegschaften wurde von der Bergaufsicht entsprechend mit einer unübersehbaren Schadenfreude notiert, zumal deren Versuche, ihre Bedeutung zu unterstreichen, durchweg untauglich seien und daher auch von den Behörden nicht unterstützt würden: „Man hört ... gelegentlich, daß in Belegschaftskreisen z.T. geringschätzig über die Betriebsvertretungen gedacht wird. Jedenfalls ist dies dort richtig, wo vernünftige Betriebsführer bestrebt sind, Beschwerden von Arbeitern verständnisvoll entgegenzunehmen und Mängel abzustellen, bevor berechtigter Unmut Platz gegriffen hat. ${ }^{~} 590$ Steckte bereits in dieser Bemerkung jenseits ihres „Körnchens Wahrheit“ die Vorstellung, ein verständnisvolles Verhalten der Vorgesetzten mache die Betriebsvertretung überflüssig, so drückte die nachfolgende Einlassung des Bueraner Berginspektors seine Blasiertheit gegenüber den realen Interaktionsprozessen auf den Zechen aus: „Das Bestreben mancher Betriebsaus-

\footnotetext{
${ }^{587}$ Bergrevier Buer, 28. 2. 1927, StAM OBAD 1868, Bl. $317 \mathrm{f}$.

${ }^{588}$ Bergrevier Buer, 29. 1. 1927, StAM OBAD 1868, Bl. 257.

${ }^{589}$ Stimmungsbericht des Oberbergamtes, 15. 3. 1927, StAM OBAD 1868, Bl. 322.

${ }^{590}$ Bergrevier Buer, 31. 5. 1927, StAM OBAD 1869, Bl. 176.
} 
schüsse, Beschwerden an die Behörde zu geben, bevor selbst der Betriebsführer von den behaupteten Mängeln Mitteilung durch den Betriebsausschuß erhalten hat, ist ein Mittel desselben, von sich reden zu machen und um zu verhindern, daß ihm der Wind aus den Segeln genommen wird. Die Zahl derjenigen Betriebsausschußmitglieder, die auch den tüchtigen Belegschaftsmitgliedern Achtung abnötigen, ist nicht zu groß “" ${ }^{\circ 91}$ Die „blockierten“ Betriebsräte fanden in den Bergbehörden keine Stütze; im betrieblichen Alltag standen sie zusehends allein und ohne große Einflußmöglichkeiten dar, wurden von den Belegschaften aber gleichwohl weiterhin nach ihren Erfolgen beurteilt.

Die Berichte des Bergarbeiterverbandes über die Tätigkeit der Betriebsräte spiegelten diese Situation wider, wenngleich sich ab 1927 wegen der freigewerkschaftlichen Dominanz bei den Wahlen Zufriedenheit in den Reihen des Alten Verbandes einstellte. Erfolge in der Bildungs- und Schulungsarbeit traten hinzu. ${ }^{592}$ Berichte über praktische Erfolge der Betriebsräte in der betrieblichen Mitbestimmung waren indes nicht zu vermelden. Zwar versuchten einige Betriebsräte sich gegen die neuen Arbeits- und Pausenregelungen nach dem Arbeitszeitnotgesetz, die endgültig zum Wegfall der freien Pauseneinteilung geführt hatten, zu wehren. Derartigen Versuchen blieb der Erfolg versagt. ${ }^{53}$ Proteste gegen das sog. Gedingeköpfen, einseitige Akkordverschärfungen durch die Zechenleitungen ${ }^{594}$, waren ebenfalls wirkungslos. Die geringen Aktivitäten der Betriebsräte führte die Bergaufsicht darauf zurück, daß sich auf den Schachtanlagen zufriedenstellende Bedingungen ergeben hätten: „Vor Anfertigung meiner Stimmungsberichte“, notierte der Gelsenkirchener Bergaufsichtsbeamte am 31. Mai 1927, "pflege ich mich mit einigen Direktoren und mit einigen Betriebsvertretern zu unterhalten. Kennzeichnend ist, daß schon seit langer Zeit aus den Äußerungen der Direktoren Unzufriedenheit, aus den Äußerungen der Betriebsvertreter Zufriedenheit spricht. ${ }^{\text {} 595}$ Und auch zwei Monate später war sein Urteil nicht anders: „Verschiedene Betriebsratsvorsitzende, die ich über die allgemeine Lage gefragt habe, wissen nichts besonderes vorzubringen, sondern erklären zum Teil offen, daß man im allgemeinen zufrieden sei. “596

Diese vermeintliche Zufriedenheit war ein Ausdruck der mit Wiederausbruch der Strukturkrise zurückgekehrten Resignation. Eine Rolle spielte auch, daß die gute Industriekonjunktur Ausweichmöglichkeiten schuf, der Problemdruck auf den Schachtanlagen also durch Fluktuation gemindert wurde. Junge und qualifizierte Arbeitskräfte verließen im Sommer 1927 in Scharen den Bergbau ${ }^{597}$; allein die Gruppe Hamborn der Abteilung Bergbau der Vereinigten Stahlwerke verlor zwischen Mai und Juli 1927 bei einer Gesamtbelegschaft von 20000 Bergleuten

\footnotetext{
591 Ebenda. Der selbe Bergrevierbeamte berichtete am 29. 7. 1927, das Verhältnis zwischen Zechenleitungen und Betriebsräten sei bis auf Ausnahmen akzeptabel, StAM OBAD 1869, B1.299.

592 Jahrbuch des Bergarbeiterverbandes für 1927, S. 286-290.

${ }^{593}$ Arbeiterratssitzung Zeche Dannenbaum 16. 4. 1927, BgA 40/226. Protokoll der Bergausschußsitzung, 3.6. 1927, BgA 55/581.

594 Tschirbs, Tarifpolitik im Ruhrbergbau, S.

595 Bergrevier Gelsenkirchen, 31. 5. 1927, StAM OBAD 1869, Bl. 167.

596 Bergrevier Gelsenkirchen, 30. 7. 1927, StAM OBAD 1869, Bl. 289.

597 Beispielhaft Bergrevier Wattenscheid, 31. 5. 1927, StAM OBAD 1869, Bl. 168.
} 
1300 Bergarbeiter durch freiwillige Abkehr. ${ }^{598}$ Dabei kam es auch häufig zu Kontraktbrüchen, da viele Bergarbeiter kurzfristig bessere Verdienst- und Beschäftigungsmöglichkeiten in der Hüttenindustrie oder im Baugewerbe wahrnahmen. ${ }^{599}$ Die Bergleute nutzten auch gezielt zwischen den Zechen bestehende Unterschiede etwa bei der Zahl der Feierschichten. ${ }^{600}$ Der Abwanderungsdruck war das gesamte Jahr 1927 so hoch, daß trotz zahlreicher Entlassungen die Quote arbeitsloser Bergarbeiter niedrig blieb. ${ }^{601}$ Verschiedene Zechenleitungen versuchten erfolglos, die Gunst der Stunde zu einer erneuten „Säuberung“ der Belegschaften zu nutzen: „Ich beobachte, daß man auf einzelnen Schachtanlagen die faulen und unzuverlässigen Leute aussiebt", schrieb der Gelsenkirchener Bergrevierbeamte, doch stieß die Selektion an Grenzen: „An guten Bergarbeitern und namentlich an Hauern herrscht auf verschiedenen Zechen Mangel."602 Angesichts der Abwanderungstendenzen verstärkte die Gruppe Hamborn ihre Nachwuchsförderung, insbesondere bildete man in Sechsmonatskursen Ortsälteste und Hauer aus, ohne den Verlust qualifizierter Arbeitskräfte ausgleichen zu können. ${ }^{603}$

Die betriebliche Machtposition insbesondere der Hauer wuchs in der zweiten Hälfte des Jahres 1927 an, zumal die Hüttenzechen keine Absatzproblemen hatten, also gut beschäftigt und auf qualifizierte Arbeitskräfte angewiesen waren. Die Hüttenzechen litten unter den zu niedrigen Preisen im Fremdabsatz. Die Klagen über schmale Erlöse nahmen stark zu. ${ }^{604}$ Diese Klagen waren nicht völlig unberechtigt. Die erkennbaren Gewinneinbrüche bei der Abteilung Bergbau der Vereinigten Stahlwerke 1927/28 waren das Ergebnis eines leichten Absatzrückganges bei zugleich steigenden Selbstkosten und sinkenden Erlösen. ${ }^{605}$ Abhilfe konnte aus eigener Initiative nur eine deutliche Steigerung der Förderung und damit eine bessere Ausnutzung der Anlagen oder eine durchgreifende Kostensenkung bieten. Durchgreifende Preiserhöhungen waren ausgeschlossen ${ }^{606}$; die Kostenfrage wurde dadurch stark aufgewertet. Dadurch gerieten die Zechen in eine immer schärfere Frontstellung gegen das Tarifsystem, wobei, so Rudolf Tschirbs, die leitenden Personen der Abteilung Bergbau der Vereinigten Stahlwerke „Pionierrollen“ übernahmen ${ }^{607}$ Für materielle Zugeständnisse glaubte man wegen der Erlöskrise keinerlei Spielräume zu besitzen. Die Zechen forcierten vielmehr die Rationalisierung, deren mögliche Auswirkungen man zugleich als politisches und soziales Druckmittel verwandte, stellten die Absatzprobleme größer dar, als sie zumindest bei den Hüttenzechen waren ${ }^{608}$, und suchten zugleich, durch schärfere

${ }^{598}$ Bergrevier Duisburg, 14. 7. 1927, StAM OBAD 1869, Bl. 265.

${ }^{599}$ Bergrevier Essen I, 11. 6. 1927, StAM OBAD 1869, Bl. 199. Monatsbericht der VSt 9/1933, S. 46.

${ }^{600}$ Stimmungsbericht des Oberbergamtes, 15. 8. 1927, StAM OBAD 1869, Bl. 304.

601 Stimmungsbericht des Oberbergamtes, 15. 7. 1927, StAM OBAD 1869, Bl. 242.

602 Bergrevier Gelsenkirchen, 31. 10. 1927, StAM OBAD, Bl. 482.

${ }^{603}$ Die Halbjahreskurse absolvierten im ersten Halbjahr 1927 etwa 1000 Bergleute, allein von Mai bis Juli 1927 aber kehrten etwa 1300 Bergarbeiter bei der Gruppe Hamborn freiwillig ab; Stimmungsbericht des Oberbergamtes, 15. 7. 1927, StAM OBAD 1869, Bl. 242.

${ }^{604}$ Bergrevier Gelsenkirchen, 11.6. 1927, StAM OBAD 1869, Bl. 229: „Selbst die guten Zechen können unter den jetzigen Verhältnissen nicht mit Gewinn arbeiten.“

605 Zahlen nach ebenda.

606 Oberbergamt 1. 7. 1927, StAM OBAD 1869, Bl. 279.

607 Tschirbs, Tarifpolitik im Ruhrbergbau, S. 308.

${ }^{608}$ Bereits im Mai 1927 hatte der Herner Bergrevierbeamte Zweifel, ob die Absatzprobleme zumindest teilweise nicht vorgeschoben seien, 31.5. 1927, StAM OBAD 1869, B1. 166. 
Gedingestellung die individuellen Produktionsleistungen $z u$ erhöhen und dadurch die relativen Kosten zu senken. ${ }^{609}$ Eine Bereitschaft zum Entgegenkommen gegenüber den Betriebsräten war ausgeschlossen, zumal sich verschiedene Betriebsräte gegen die Rationalisierungsfolgen wandten und damit scheinbar den Rationalisierungserfolg in Frage stellten. Ein typisches Beispiel hierfür war die Auseinandersetzung um die Beschleunigung der Transportprozesse unter Tage. Als sich auf verschiedenen Schachtanlagen im Kontext beschleunigter Waggontransporte unter Tage die Transportverluste häuften, die Mindermaßkontrolle über Tage den betroffenen Kameradschaften Verluste ankreidete und die Betriebsräte dieses Problem, das vielen Bergleuten Ärger bereitete, ansprachen, kamen ihnen die Zechenleitungen in keiner Hinsicht entgegen. Die Forderung der Betriebsräte nach Mindermaßkontrolle am Abfüllort wurde strikt zurückgewiesen, obwohl den Bergleuten so einseitig die Folgen der Transportrationalisierung angelastet wurden. ${ }^{610}$

Ließen sich die Betriebsratsproteste gegen die Rationalisierungsfolgen noch einigermaßen erfolgreich abwehren, so drohte im September 1927 den Zechen eine andere Gefahr. Bereits die nur moderate Lohnerhöhung vom Frühjahr 1927 hatten die Zechen für die Erlöskrise mitverantwortlich gemacht und wohl auch deshalb scharf kritisiert, weil die Kosten der Lohnerhöhung nicht über die Preise abgewälzt werden konnten. ${ }^{611}$ Weitere Lohnforderungen erachtete man als unbezahlbar. In den Revieren aber machte sich bei den noch angelegten Bergleuten erhebliche Mißstimmung wegen der zahlreicher werdenden Feierschichten und der in ihren Augen unangemessen hohen Lebensmittelpreise breit. Ein Ende der Feierschichten war nicht absehbar, im Gegenteil: Die Absatzmengen im bestrittenen Gebiet gingen unter der heftigen englischen Konkurrenz zurück; ein französisches Kohlenimportverbot im Juli 1927 verschärfte die Lage weiter. Ende Juli 1927 schnellten die Zahlen der Feierschichten stark nach oben: wegen Absatzmangel mußten in der vorletzten Juliwoche 37000 , in der letzten sogar $66000 \mathrm{Fei}$ erschichten eingelegt werden. ${ }^{612}$ In den folgenden Wochen entspannte sich die Situation kaum. Vielmehr verstärkte sich jetzt auch bei den Hüttenzechen der Absatzmangel; Betriebsstillegungen, Zusammenlegungen und entsprechende Entlassungen bzw. Verlegungen größerer Belegschaftsteile waren an der Tagesordnung. Bei den Vereinigten Stahlwerken stand die Zusammenlegung der Förderung von Rheinelbe und Alma, Pluto, Bonifacius und Holland auf der Tagesordnung, in Hamborn, Bochum und Dortmund kam es zu größeren Belegschaftsverschiebungen. ${ }^{613}$ Massenentlassungen, bei denen die Betriebsvertretungen nur geringen Einfluß auf die Zusammensetzung der zu Entlassenden nehmen konnten, häuften sich. Besonders zermürbend wirkten die zahlreichen kleineren Belegschaftsverringerungen, bei denen die Zechen überdies gezielt „faule“ Arbeiter entließen.

\footnotetext{
${ }^{609}$ Tschirbs, Tarifpolitik im Ruhrbergbau, S. 297.

${ }^{61 C}$ Siche den Konflikt auf der Bochumer Zeche Prinzregent im September 1929, BgA 40/481.

611 Tschirbs, Tarifpolitik im Ruhrbergbau, S. $306 \mathrm{f}$.

${ }^{612}$ Stimmungsbericht des Oberbergamtes, 1.8. 1927, StAM OBAD 1869, Bl. 270.

${ }^{613}$ Stimmungsbericht des Oberbergamtes, 15. 9. 1927, StAM OBAD 1869, Bll.368f. Zu den Rationalisierungsmaßnahmen der Gruppe Hamborn vgl. Bergrevier Duisburg, 14. 9. 192.7, StAM OBAD 1869, Bl. 391.
} 
War die Stimmung im Frühsommer 1927 scheinbar noch zufriedenstellend, so war sie jetzt gereizt.

Die sich im September abzeichnende Erhöhung der Beamtenbesoldung brachte schließlich den Anlaß zur offenen Artikulation der Befürchtungen der Bergleute, die Preise würden weiterhin steigen, die Bergarbeiterlöhne real aber sinken. „Auf der Zeche Zollverein fand eine Belegschaftsversammlung statt, die sich dem Vernehmen nach mit der durch die zu erwartende Gehaltserhöhung der Beamten geschaffenen Lage beschäftigen soll. In Arbeiterkreisen wird die Angelegenheit so dargestellt, daß durch die Gehaltserhöhung Lohnforderungen der Arbeiterschaft notwendig würden. Dieser Auffassung begegnet man fortwährend. " ${ }^{14}$ Die Forderungen blieben nicht auf Zollverein beschränkt. Die Bergarbeiterverbände kündigten zum 30. September 1927 erfolglos das Mehrarbeitsabkommen; Lohnforderungen, von den Kommunisten gefördert, breiteten sich immer weiter aus. ${ }^{615}$ Mitte Oktober 1927 machte sich „Kampfstimmung“ an der Ruhr breit. ${ }^{616}$ Ausgehend von dieser Stimmungslage verlangten auch die Tarifgewerkschaften nun „eine zwischentarifliche Lohnerhöhung“. Die Forderung wurde vom Zechenverband unter Hinweis auf den gültigen Lohntarifvertrag zurückgewiesen. ${ }^{617}$ Die Organisation der Zechenbesitzer konterte, angesichts der wirtschaftlichen Not des Bergbaus müßte eigentlich über Lohnsenkungen verhandelt werden, was den Alten Verband unter Hinweis auf die Tarifauseinandersetzung im Frühjahr 1928 zu einer scharfen Reaktion veranlaßte. „Auch aus Betriebsratskreisen ist geäußert worden, daß im kommenden Frühjahr der Kampf um die Lohnerhöhung mit größter Schärfe begonnen werden solle. " ${ }^{618}$

Eine Konflikteskalation im Herbst 1927 wurde indes durch die leicht anziehende Konjunktur verhindert, wobei sich besonders eine verstärkte Kohlennachfrage aus dem unbestrittenen Gebiet positiv bemerkbar machte. Die Zahl der Feierschichten ging im November und Dezember 1927 deutlich zurück. Die Zahl der beschäftigungssuchenden Bergleute nahm allerdings leicht $\mathrm{zu}$, da die Abwanderungsmöglichkeit in Saisongewerbe jahreszeitlich bedingt geringer wurde. Erhöhtes Arbeitsmarktrisiko und deutlich höhere Verdienste durch eine Mehrzahl an geleisteten Schichten entschärften mithin kurzfristig die soziale Konfrontation im Ruhrbergbau. Hinzukam das bevorstehende Weihnachtsfest: „Wie alljährlich, so ist auch in diesem November mit Rücksicht auf das Weihnachtsfest, zu dem die Novemberlöhne ausgezahlt werden, die Leistung je Mann und Schicht und damit auch die Förderleistung gestiegen. “619

Die ständig schwankende Absatzlage der Zechen und die niedrigen Kohlenpreise im bestrittenen Gebiet bedingten allerdings eine weitere Zunahme der Rationalisierungs- und Stillegungspolitik. Während insbesondere die Hüttenzechen über stabile wirtschaftliche Verhältnisse verfügten, gerieten zahlreiche reine Zechen unter den Druck niedriger Kohlenpreise. Vor diesem Hintergrund war ein

\footnotetext{
614 Bergrevier Essen II, 26. 9. 1927, StAM OBAD 1869, Bl. 415.

615 Bergrevier Duisburg, 14. 9. 1927, StAM OBAD 1869, Bl. 391.

616 Bergrevier Recklinghausen-West, 13. 10. 1927, StAM OBAD 1869, Bl. 437.

617 Stimmungsbericht des Oberbergamtes, 15. 10. 1927, StAM OBAD 1869, Bll.425ff.

${ }^{618}$ Stimmungsbericht des Oberbergamtes, 1. 11. 1927, Bl. 463.

${ }^{619}$ Stimmungsbericht des Oberbergamtes, 1. 12. 1927, StAM OBAD 1869, Bl. 536.
} 
einheitliche Auftreten der Betriebsräte im Revier faktisch ausgeschlossen. Während die Betriebsräte der gut ausgelasteten Zechen die Lohn- und Arbeitszeitforderungen der Gewerkschaften unterstützten, wenn sie nicht im Namen der Belegschaften sogar über diese Forderungen hinausgingen, waren auf anderen Schachtanlagen die Betriebsräte bereit, durch Betriebsvereinbarungen selbst gültige Tarifverträge zu durchbrechen, um durch Mehrarbeit und Lohnverzicht das wirtschaftliche Überleben „ihrer" Zechen zu ermöglichen. Derartige Kompromißbereitschaft führte zu erheblichen Konflikten zwischen Betriebsräten und Gewerkschaften. ${ }^{620}$ Die ohnehin labile Einheit in der Betriebsrätebewegung des Ruhrgebietes zerbrach unter dem Druck niedriger Preise und zechenseitiger Rationalisierungs- und Stillegungsmaßnahmen Ende 1927 daher weitgehend; auch die Tarifgewerkschaften waren nicht mehr dazu in der Lage, eine geschlossene Haltung der Betriebsvertretungen herbeizuführen, zumal von den noch etwa 370000 Bergleuten an der Ruhr überhaupt nur noch ein gutes Drittel organisiert war. ${ }^{621}$

Mit dem nachlassenden sozialen Druck auf den Schachtanlagen waren aber die Lohnforderungen keineswegs vom Tisch. Die Beamtenbesoldungsanpassung vom 1. Oktober 1927 wirkte im übrigen nicht nur bei den Bergarbeitern wie ein Fanal, sondern löste insgesamt Unruhe in der deutschen Tariflandschaft aus, da zahlreiche Arbeitergruppen Sonderlohnbewegungen auch gegen laufende Tarifverträge allerdings zumeist erfolglos - durchzusetzen versuchten. ${ }^{622}$ Die Gewerkschaften konnten sich diesen Bewegungen nicht verschließen, zumindest wurden für die Lohnrunden des Frühjahres 1928 deutliche Lohnverbesserungen angemahnt. Im Bergbau trugen neben den Lohnforderungen der Belegschaften auch die Erfahrung einer nur noch begrenzten Reichweite gewerkschaftlicher Solidarität und das Bild zersplitterter Belegschaften dazu bei, daß die gewerkschaftlichen Töne in den Auseinandersetzungen schärfer wurden: „Das reaktionäre Unternehmertum und seine Trabanten will (!) uns zurückwerfen in die frühere Rechtlosigkeit. Aus dem sozialen Volksstaat will man einen Klassen- und Beamtenstaat machen. Die produktiv tätige Arbeiterschaft soll niedergerungen werden. Den Bergarbeitern werden gegenwärtig ausreichende Löhne verweigert, für die öffentlichen Beamten aber sind große Gehaltserhöhungen in Aussicht gestellt." Mit der staatlichen Schlichtung waren die christlichen Gewerkschafter nicht mehr zufrieden, im Gegenteil: „Auch die Staatshilfe versagt in der Lohnfrage. ... Aber für die Beamten ist ausreichend Geld da. Sie sollen mehr haben, als ursprünglich überhaupt gefordert wurde. Auf 1,5 Milliarden Mark wird die jährliche Summe für die Besoldungserhöhung geschätzt." Die christlichen Gewerkschaften schürten in ihrem Flugblatt ${ }^{623}$ die Stimmung der Bergleute, die ohnehin Angst um ihre relative Lohnposition hatten, gegen die Beamten: „Diese Milliarden müssen natürlich auch wieder in der Hauptsache von den ärmeren Volksschichten aufgebracht werden. ... In vielen Bezirken müssen die Bergarbeiter buchstäblich am Hungertuch

${ }^{620}$ Vgl. das Beispiel der Verhandlungen auf den Zechen der Adler AG, Zentrum und Johann Deimelsberg, Stimmungsbericht des Obcrbergamtes, 15. 12. 1927, StAM OBAD 1869, Bl. 567.

621 Tschirbs, Tarifpolitik im Ruhrbergbau, S. 326.

622 Zum Hintergrund der Besoldungsanpassung zum 1. 10. 1927 vgl. Preller, Sozialpolitik in der Weimarer Republik, S. 359.

623 Zitiert nach Stimmungsbericht des Oberbergamtes, 15. 12. 1927, StAM OBAD 1869, Bl. 571. 
nagen. Das ist ein Hohn auf die Gerechtigkeit.... Wir wollen keine Beamtenrepublik, d. h. eine zu große Anzahl öffentlicher Beamten, die auf Kosten anderer leben. Wir wollen den sozialen Volksstaat." Das Flugblatt schloß mit einem dramatischen Appell, sich in den christlichen Gewerkschaften zu organisieren.

Die Hoffnungen, in der Lohnrunde Anfang 1928 entscheidende Verbesserungen durchsetzen zu können, wurden allerdings enttäuscht. Die zeitweilige Besserung der Absatzverhältnisse im Winter 1927/28 erwies sich nur als kurzfristige Belebung des Kohlenmarktes. 1928 sank die Förderung kontinuierlich, die Zahl der angelegten Bergarbeiter ging parallel, durch den Rationalisierungsprozeß verstärkt ebenfalls deutlich zurück. Rationalisierungsbedingte Stillegungen und Schachtzusammenlegungen, mit denen in der Regel größere Arbeiterentlassungen bzw. -verlegungen verbunden waren, beherrschten das gesamte Jahr 1928. Die Kampfposition der Bergarbeiter war nicht gut. Trotzdem waren die Tarifverhandlungen mit hohen Erwartungen besetzt, die nicht zuletzt von den Bergarbeiterverbänden genährt wurden. Auf der anderen Seite hatte der Zechenverband angesichts der geringen Gewinnmargen bzw. der Verluste zahlreicher Zechen gegen die bisherige tarifliche Lohnpolitik in bislang unbekannter Schärfe polemisiert. Der Schlichterspruch schließlich enttäuschte sowohl Zechenleitungen wie Gewerkschaften und Belegschaften. Einerseits behielt er die bisherigen Untertagearbeitszeiten bei, andererseits wurden deutliche Arbeitszeitverkürzungen für die Übertagearbeiter dekretiert. Die Löhne sollten durchweg um $8 \%$ angehoben werden. Sowohl Gewerkschaften als auch Zechenverband lehnten den Schiedsspruch ab. Reichsarbeitsminister Brauns erklärte ihn trotz der Widerstände für verbindlich. Damit war de facto eine Situation erreicht, in der der Staat die Lohn- und Arbeitsbedingungen im Bergbau festlegte; das Tarifsystem war endgültig gescheitert. ${ }^{624} 1929$ wiederholte sich eine ähnliche Konstellation, nur wurden die Kosten des Schiedsspruches, der die Löhne moderat anhob und die Arbeitszeitregelung faktisch unverändert ließ, über die Subventionierung der Knappschaft nunmehr teilweise direkt vom Reich übernommen. ${ }^{625}$

Die Unzufriedenheit der Belegschaften auf den Schachtanlagen führte gleichwohl nicht zu spontanen Bewegungen. Kommunistische Streikaufrufe verhallten wirkungslos. Dafür nahmen die Konflikte in den Gewerkschaften einerseits, im Kohlensyndikat andererseits zu. Der Konflikt zwischen den reinen und den Hüttenzechen spitzte sich deutlich zu „Wirtschaftskrisen pflegen zumeist die Syndikatsgebilde der betreffenden Industrien in ihren Grundfesten mehr oder weniger zu erschüttern. So hat auch die jetzige schwierige Lage auf dem Kohlenmarkt im Rheinisch-Westfälischen Kohlen-Syndikat größere Unstimmigkeiten hervorgerufen. Der alte Gegensatz: Hüttenzechen - reine Zechen ist auf der letzten Mitgliederversammlung verschärft in Erscheinung getreten, indem 4 große Hüttenkonzerne [u. a. die Abteilung Bergbau der VSt.] eine Neugestaltung der jetzigen Umlageberechnung verlangten, um den bisher an der Umlage beteiligten Selbstverbrauch der Hütten auf Kosten der reinen nur am Verkauf beteiligten Zechen zu

${ }^{624}$ Ausführlich hierzu Tschirbs, Tarifpolitik im Ruhrbergbau, S. $314 \mathrm{ff}$.

625 Ebenda, S. 338. 
entlasten." ${ }^{\text {26 }}$ Die im Sommer 1928 weiter steigende Syndikatsumlage belastete den Selbstverbrauch der Hüttenkonzerne und ließ eine strenge Wirtschaftlichkeitsrechnung der Zechen kaum zu, da die Erlöse nicht entsprechend der geförderten Kohlensorten variierten. ${ }^{627}$ Der Hintergrund der Auseinandersetzungen war die Angst der Hüttenzechen, die reinen Zechen de facto zu subventionieren und die erstmals wieder deutlich steigenden Umsatzerlöse den wachsenden Syndikatsumlagen opfern zu müssen. Auf ihren Druck hin wurde zeitweilig der nicht kostendeckende Absatz im Ausland gedrosselt, was jedoch auf den massiven W1derstand nicht nur der reinen Zechen, sondern auch der Gewerkschaften stieß: „In der ersten Juli-Woche haben Pressemeldungen zufolge verschiedene Konferenzen des Gewerkvereins christlicher Bergarbeiter Deutschlands stattgefunden, in denen man sich entschieden gegen die derzeitige Absatzpolitik des Kohlensyndikats aussprach. In der Versammlung wurde gefordert, daß der Kampf in der wichtigen Frage der Erhaltung des Auslandsabsatzes in voller Öffentlichkeit fortgeführt werden müsse. Für die jetzige Absatzdrosselung der Ruhrkohle, die sowohl die Bergarbeiter als auch die gesamte deutsche Volkswirtschaft außerordentlich schädige, habe man kein Verständnis. " ${ }^{628} \mathrm{Um}$ aus der schwierigen Lage herauszukommen, wurden im RWKS jetzt erstmals Rufe nach direkten Subventionen laut. ${ }^{629}$

Die betriebswirtschaftlichen Daten der Abteilung Bergbau machten ihren Schritt gegen weitere Erhöhungen der Syndikatsumlagen, die angesichts internationaler Billigkonkurrenz wegen der durchschnittlich hohen deutschen Förderungskosten zwangsläufig folgen mußten, verständlich. Nach der Kohlenpreiserhöhung im Anschluß an die Lohnerhöhung, der ersten im übrigen seit 1924, und in Folge des gesicherten Hüttenabsatzes und des einigermaßen stabilen Absatzes im unbestrittenen Gebiet stiegen die Umsatzerlöse bei der Abteilung Bergbau der Vereinigten Stahlwerke pro Tonne Kohlenverkauf von 14,57 RM 1927/28 auf 15,46 RM 1927/23 und 15,38 RM 1929/30. Das Ergebnis pro Tonne Kohle vor Abschreibungen stieg entsprechend von 1,62 RM auf 2,80 RM bzw. 2,25 RM, da neben den höheren Preisen zugleich auch die gesamten Selbstkosten stagnierten, die Arbeitskosten sogar 1928/29 um knapp 3\% sanken. Weil die Arbeitskosten je Schicht bis 1930/31 weiter anstiegen, gingen die Kostensenkungen auf die Rationalisierungserfolge zurück. ${ }^{630}$ Die Abteilung Bergbau lief bei weiteren Steigerungen der Syndikatsumlage daher Gefahr, ihre Überschüsse deutlich verringern zu müssen, zumal sie als ein kostengünstig produzierendes Unternehmen im Export nicht einen entsprechend hohen Preissubventionsbedarf hatte.

Bei der Abteilung Bergbau der Vereinigten Stahlwerke machten sich spätestens seit dem Sommer 1928 jedenfalls die Rationalisierungserfolge deutlich bemerkbar. Alle betriebswirtschaftlichen Kennziffern entwickelten sich positiv, lediglich die Arbeitskosten je Schicht stiegen bis 1931 weiter an. Auch der Anteil der Löhne am Umsatz begann langsam zu sinken, wenn es auch zu einer durchgreifenden Verbesserung erst in der Weltwirtschaftskrise kam. Die Arbeitsproduktivität stieg

${ }^{626}$ Stimmungsbericht des Oberbergamtes, 30.6. 1928, StAM OBAD 1870, Bl. 2.
${ }^{627}$ Ebenda.
${ }^{628}$ Stimmungsbericht des Oberbergamtes, 15. 8. 1928, StAM OBAD 1870, Bl. 105.
${ }^{629}$ Stimmungsbericht des Oberbergamtes, 1. 8. 1928, StAM OBAD 1870, Bl. 74.
630 Zahlen nach GBAG, Betriebs- und Wirtschaftsverhältnisse 1926-1933/34, BgA 55/1295. 
1928/29 deutlich an; die Rationalisierung begann sich bezahlt zu machen. Die von der Abteilung Bergbau der VSt. mitverursachte Krise im RWKS war daher zugleich ein Ausdruck dafür, daß die Abteilung Bergbau sich nicht wegen der wirtschaftlich schwierigen Lage der Rand- und reinen Zechen weiter in die ökonomischen Folgen der Strukturkrise hineinziehen lassen wollte. Dies implizierte zugleich auch die schärfere Frontstellung gegen das Tarifsystem und die Betriebsräte, deren Aktivitäten ebenfalls die Rationalisierungserfolge in Frage zu stellen geeignet waren. Die harte Haltung der Abteilung Bergbau im Jahre 1928/29 war daher weniger eine Folge der Strukturkrise als vielmehr Ausdruck für den relativen Erfolg des Bergbauunternehmens, den man weder durch das RWKS noch durch das Tarifsystem gefährden lassen wollte. So sprach sich Ernst Brandi, der Chef der Abteilung Bergbau, auch nachdrücklich gegen weitere Steigerungen der Syndikatsumlagen aus. ${ }^{631}$ Diese Rechnung ging 1929 weitgehend auf. Die Abteilung Bergbau der Vereinigten Stahlwerke steigerte ihre Förderung auf 27,2 Mio. t, womit $70 \%$ der Syndikatsbeteiligung ausgenutzt wurden. Angesichts des verbreiteten Quotenkaufes mußte dies nicht auf eine Kapazitätsauslastung von lediglich $70 \%$ hindeuten, jedoch war die Abteilung Bergbau leistungsfähiger, als in der Förderzahl von 27,2 Mio. t zum Ausdruck kam. Die Arbeiterbelegschaft der Abteilung Bergbau sank von Oktober 1927 auf den Oktober 1928 um mehr als 6000, um während der günstigen Konjunktur 1929 noch einmal um etwa die gleiche Ziffer anzusteigen. ${ }^{632}$ 1928/29 jedenfalls zeigte sich, daß die Abteilung Bergbau die Strukturkrise vergleichsweise gut gemeistert hatte; nicht zuletzt deshalb versprach man sich von einer Änderung der Syndikatspolitik und einer Intensivierung der Konkurrenz nur Vorteile, vorausgesetzt die sich günstig entwickelnden Kostenund Leistungsverhältnisse würden nicht erneut durch Belegschaftsdruck oder politisch in Frage gestellt. ${ }^{633} \mathrm{Im}$ Kontext des Ruhreisenstreites im November 1928 kritisierten daher auch Vertreter des Bergbaus, voran der Abteilung Bergbau der VSt. das Tarifsystem grundsätzlich und ließen keinen Zweifel daran, daß ihnen wirtschaftlich die Beseitigung des Tarifsystems das sinnvollste erschien. Eine Alternative zum Tarifsystem hatten sie freilich nicht zu bieten; offensichtlich wurde an eine Rückkehr zur Vorweltkriegszeit gedacht.

Der Leistungsdruck und das Arbeitsmarktrisiko waren im Frühjahr 1928 hoch. Sie verhinderten trotz verbreiteter Unzufriedenheit eine erkennbare Widerstandsbewegung der Bergarbeiter gegen den Tarifabschluß vom April $1928 .{ }^{634}$ Im Verlaufe des Jahres 1928 blieb die unübersichtliche Situation erhalten. 1929 besserten sich wegen der vergleichsweise günstigen Absatzlage noch einmal die betrieblichen Positionen der Arbeiterschaft, doch blieb das Arbeitsmarktrisiko wegen der fortschreitenden Rationalisierung durchweg spürbar. Im Sommer 1928 häuften sich Berichte der Bergaufsichtsbehörden über Mißmut, Unruhen und Widersetzlichkeiten: „Zusammengefaßt ergibt sich ein weiteres bedenkliches Schwinden der

${ }^{631}$ Stimmungsbericht des Oberbergamtes, 1. 8. 1928, StAM OBAD 1870, Bl. 73.

${ }^{632}$ Monatsbericht der Vereinigten Stahlwerke 9/1933, S. 50.

${ }^{633} \mathrm{Daß}$ der Bergbau daher die Haltung der Arbeitgeber im Ruhreisenstreit stützte, bedarf keiner weiteren Erläuterung, Stimmungsbericht des Oberbergamtes, 15.11. 1928, StAM OBAD 1870, Bl. 320.

${ }^{634}$ Stimmungsbericht des Oberbergamtes, 14. 7. 1928, StAM OBAD 1870, Bl. 40. 
Arbeitsfreudigkeit, eine Neigung zum Nichtstun unter dem Schutze der Erwerbslosenunterstützung. Dazu tritt eine wesentliche Verschärfung des radikalen Elements in der Belegschaft, die in immer steigendem Umfang sich von den linksradikalen Hetzern beeinflussen läßt. ${ }^{* 635}$ Resignation einerseits, Proteststimmung andererseits griffen mithin im Bergbau Platz. Das alte Bild gespaltener Belegschaften bestätigte sich erneut, diesmal indes in verschärfter Form: „Der Bergrevierbeamte von Lünen teilt mit, daß in der Arbeiterschaft wegen der zahlreichen Feierschichten vielfach der Wunsch bestehe, die jüngeren Belegschaftsmitglieder in andere Berufe zu überführen und sie bei auskömmlichem Lohne bei Kanalbauten und beim Urbarmachen von Ödland zu beschäftigen. "636 Im Kontext des Ruhreisenstreites zerbrach, nach den Bemerkungen der Bergaufsicht, gar die Solidarität der Arbeiter untereinander, da die Belegschaften der Fettkohlenzechen wegen der geringeren Koksnachfrage zusätzliche Feierschichten, z.T. bis zu drei pro Woche, einlegen mußten: „Über die Stimmung der Arbeitnehmer wird berichtet, daß sie wegen des großen Verdienstausfalles, besonders auch im Hinblick auf die kommende Weihnachtszeit, ... sehr gedrückt sei. Die teilweise gereizte Stimmung, die sich ursprünglich nur gegen die Arbeitgeberschaft gerichtet habe, sei auf einzelnen Zechen umgeschlagen und richte sich nun auch gegen die Metallarbeiter selbst, die keinen Grund gehabt hätten, neue Lohnforderungen zu stellen. Ein großer Teil der Arbeiterschaft erkenne die Führerschaft der Gewerkschaften nicht an. ${ }^{1637}$ Die Tarifgewerkschaften nutzten zwar den Ruhreisenstreit, um für das kommende Frühjahr eigene Lohnforderungen anzukündigen, jedoch ließ sich der Vertrauensverlust bei den Belegschaften nicht mehr ausgleichen. Vier Jahre Strukturkrise mit ihren zermürbenden Wirkungen sowie die Hilflosigkeit von Gewerkschaften und Betriebsräten gegenüber den Rationalisierungsfolgen hatten eine mißtrauische, resignierte und kampfesmüde, über die eigene Zukunft zutiefst verunsicherte und in wichtigen sozialen und politischen Fragen gespaltene Bergarbeiterschaft hinterlassen.

Die Betriebsratswahlen der Jahre 1928 und 1929 bestätigten die Spaltung der Belegschaften. Während 1928 wegen des Fehlens einer kommunistischen Liste noch klare Mehrheiten für die Tarifgewerkschaften heraussprangen, erreichte die RGO 1929 auf Anhieb 10\% der abgegebenen Stimmen, also die Unterstützung von etwa 30000 Bergleuten. ${ }^{638}$ Im September 1928 waren die kommunistischen Bergleute aus der Front des Alten Verbandes ausgebrochen, nachdem dieser zuvor scharf gegen kommunistische Wortführer vorgegangen war, die nicht nur den Tarifspruch vom April, sondern zugleich auch die Verbandsführung kritisiert hatten. ${ }^{639}$ Das Oberbergamt berichtete am 15. September 1928: „Diejenigen kommunistisch eingestellten Teile der Ruhrbelegschaften, welche es sich bisher angelegen sein ließen, in den Bergarbeiterverbänden, insbesondere dem Verband der Bergarbeiter Deutschlands, als ,Zellenbauer' verbandszersetzend tätig zu sein, fordern nunmehr offen zur ,revolutionären Arbeit' in den Gewerkschaften auf." In Bot-

\footnotetext{
635 Bergrevier Recklinghausen-West, 29. 8. 1928, StAM OBAD 1870, Bl. 147.

${ }^{636}$ Ebenda.

${ }^{637}$ Stimmungsbericht des Oberbergamtes, 15. 11. 1928, StAM OBAD 1870, Bl. 321.

${ }^{638}$ Martiny, Arbeiterbewegung an Rhein und Ruhr, S. 253.

${ }^{639}$ Tschirbs, Tarifpolitik im Ruhrbergbau, S. $320 \mathrm{ff}$.
} 
trop sei ein Flugblatt erschienen mit der Schlagzeile: „Oppositionelle Gewerkschafter vor die Front!“ Nach dem Bericht des Oberbergamtes solle „der Kampf ...gehen, gegen Wirtschaftsdemokratie und Industriefrieden, gegen Schlichtungswesen und Arbeitsgemeinschaft, für den revolutionären Klassenkampf, für volles Streikrecht, gegen die kapitalistische Rationalisierung, für verkürzte Arbeitszeit und Lohnerhöhung, gegen die Gewerkschaftsspalter national wie international, für die revolutionäre Gewerkschaftseinheit der Arbeiter aller Länder, gegen die imperialistischen Kriegsrüstungen und Panzerkreuzerbauerei, für Ausbau und Erhöhung der Sozialversicherung und Renten' " ${ }^{640}$ Die Stoßrichtung der KPD ging eindeutig gegen die Tarifgewerkschaften und gegen die neue, sozialdemokratisch geführte Reichsregierung. Der Alte Verband beklagte sich entsprechend über die "Hundsgemeinheiten“ der KPD, die „anläßlich der Betriebsratswahlen eine beispiellose Gift- und Dreckoffensive" geführt hätten. ${ }^{641}$ War so im RWKS aufgrund der unterschiedlichen wirtschaftlichen Lage der Zechen die Einheit der Arbeitgeber zerbrochen, so traten zu den sozialen Spaltungen der Belegschaften nun auch wiederum verstärkt politische Differenzen hinzu.

Vor diesem Hintergrund hatte 1928 und 1929 die Tätigkeit der Betriebsräte zu erfolgen. Trotz der Schwäche der Belegschaften waren die Zechenleitungen keineswegs kooperationsbereit. Der Alltag der Betriebsräte der Abteilung Bergbau der VSt. war weiter von Konfrontation gekennzeichnet; selbst Ende der zwanziger Jahre kam es noch zu Geschäftsführungsstreitereien, die in anderen Unternehmen schon lange zurücklagen. Der Betriebsrat der Bochumer Zeche Prinzregent, dem im übrigen noch Anfang 1930 der Telephon-Anschluß für sein Büro verweigert wurde ${ }^{642}$, mußte noch im Juni 1929 vor dem Arbeitsgericht um seine Ausstattung klagen. Er verlangte von der Zeche je ein Exemplar der Reichsversicherungsordnung, der Gewerbeordnung, des Betriebsrätegesetzes mit Kommentar und als laufende Lieferung das Reichsarbeitsblatt. Das Arbeitsgericht entschied zu Gunsten der Zeche. Ein Exemplar des Betriebsrätegesetzes mußte allerdings gestellt werden.${ }^{643}$ Die Hauptstreitpunkte auf den Sitzungen der Betriebsvertretungen bezogen sich vor allem auf Fragen der Ausstattung der Bergleute mit Lampen und Gezähe, der Regelung der Löhnungszeitpunkte oder der Qualität der gelieferten Deputatkohlen. ${ }^{644}$ Gelegentlich wurden auch Fragen der Wohnungsmieten, der Geldstrafen und der Hygiene in den Kauen angesprochen. ${ }^{645}$ Die Betriebsausschußmitglieder versuchten zugleich, ihre Revierbefahrungen und damit ihre Funktionen bei Grubenkontrolle und Unfallschutz voll wahrzunehmen. Der Rationalisierungsprozeß konfrontierte viele Betriebsräte allerdings mit Veränderungen der Steigerreviere und zunehmend vorsichtig werdenden Belegschaften. Deutlich zurückgehende Krankenziffern waren hierfür ein signifikanter Beleg. Die Krankenquote der Arbeiterschaft der Abteilung Bergbau sank von 7,5\% im Monatsdurchschnitt 1926/27 kontinuierlich auf 4,29\% 1929/30, um in der Krise

${ }_{640}^{64 t i m m u n g s b e r i c h t ~ d e s ~ O b e r b e r g a m t e s, ~ 15 . ~ 9 . ~ 1928, ~ S t A M ~ O B A D ~ 1870, ~ B l . ~} 171$.

${ }^{6+1}$ Jahrbuch des Bergarbeiterverbandes für 1928, S. 341f; für 1929, S. 311-315 mit Abdruck der kommunistischen Richtlinien zu den Betriebsratswahlen.

${ }^{642}$ Betriebsratssitzung Prinzregent, 15. 5. 1930, BgA 40/481.

${ }^{6+3}$ Urteil des Arbeitsgerichts Bochum, 8. 7. 1929, BgA 40/481

${ }^{644}$ Zum Beispiel Betriebsratssitzung Dannenbaum, 20. 8. 1929, BgA 40/226.

${ }^{645}$ Z.B. Betriebsratssitzung auf der Zeche Prinzregent, 13. 10. 1928, BgA 40/481. 
noch weiter herunterzugehen. ${ }^{646}$ Proteste gegen die Rationalisierungsfolgen scheiterten entweder an der nichtvorhandenen Kooperationsbereitschaft der Zechenleitungen oder bei den Arbeitsgerichten, die etwa in Konflikten um die Mindermaßkontrolle regelmäßig zugunsten der Zechenleitungen entschieden. ${ }^{647}$

Die Rationalisierung und ihre Folgen bescherten den Betriebsräten allerdings auch ein völlig neues Arbeitsfeld. Nach dem Betriebsrätegesetz waren Massenentlassung und Stillegungen anmeldepflichtig; bei ihrer Durchführung mußte der betreffende Betriebsrat gehört werden. In zunehmender Zahl erfolgten derartige Stillegungsmeldungen und Ankündigungen von Massenentlassungen bei den Bergbehörden, die daraufhin jeweils gemeinsame Besprechungen von Zechenleitungen, Betriebsräten und Bergaufsichtsbehörden ansetzten. ${ }^{648}$ Derartige Besprechunge häuften sich 1928 und 1929. Der Betriebsrat wurde darin faktisch zum "Gehilfen“ der Zechenleitungen bei der sozial verträglichen Auswahl der zu Entlassenden, doch stieß selbst diese "Gehilfenfunktion“ an die Grenze jener „Erfordernisse des Betriebes“, die etwa eine Verjüngung der Belegschaften verlangten. Soziale Kriterien spielten höchstens in zweiter Hinsicht eine Rolle bei der Entlassungselektion. ${ }^{649}$ Erfolgreich tätig sein im Interesse der Belegschaft konnte der Betriebsrat bei Massenentlassungen kaum. Die notwendige Kooperation mit der Werksleitung schürte eher noch das Mißtrauen der Belegschaften, die Bereitschaft zu „betriebsegoistischen“ Verstößen gegen geltendes Tarifrecht entfremdete Betriebsräte und Gewerkschaften. Als für die Abteilung Bergbau der Vereinigten Stahlwerke typisches Beispiel sei die Stillegungsverhandlung der Zeche Rheinelbe geschildert. Die ehemals bedeutendste Schachtanlage der GBAG stellte Anfang 1928 die Förderung ein. Von der Untertagebelegschaft kamen 60 Bergleute zur Entlassung, von den Tagesarbeitern rund 190. Die Betriebsvertretung erhob bei der Stillegungsbesprechung mit der Werksleitung „keine grundsätzlichen Einwände gegen die Stillegung der Schachtanlage Rheinelbe als Förderschachtanlage." Die Betriebsräte akzeptierten die angegebenen Gründe der Gruppe Gelsenkirchen der Vereinigten Stahlwerke, nach denen die Stillegung wegen der Rationalisierung erfolgte und "letzten Endes auch im Interesse der Arbeitnehmer" liege. ${ }^{650}$ Die zu entlassenden Belegschaftsangehörigen wurden einzeln durchgesprochen, „um Härten möglichst zu vermeiden. “ Der Betriebsrat konnte sich dabei mit seinen Vorstellungen nicht durchsetzen, sondern klagte, „daß nicht alle Wünsche zur Vermeidung von Härten berücksichtigt worden seien." Die Vertreter der Gruppe Gelsenkirchen der Bergbauabteilung der Vereinigten Stahlwerke machten hierfür, ohne Widerspruch von Seiten der Bergbehörde zu erhalten, die „Erfordernisse des Betriebes“ verantwortlich. Das „Verhandlungsergebnis“, das tatsächlich keines war, da die Betriebsräte lediglich auf die Zusammensetzung der Entlassungsliste, nicht aber auf deren Größe Einfluß nehmen konnten - von der Stillegung selbst ganz zu schweigen -, wurde protokolliert und den Belegschaften

\footnotetext{
${ }^{646}$ Monatsberichte der Vereinigten Stahlwerke 9/1933, S. 131, BgA 55/498.

${ }^{647}$ Stimmungsbericht des Oberbergamtes, 1. 10. 1928, StAM OBAD 1870, Bl. 216.

${ }^{648}$ Siehe hierzu den Ordner Massenentlassungen bei der GBAG, Mai 1925ff., BgA 41/710.

${ }^{649}$ Siehe die Protokolle von Stillegungs-/Entlassungsverhandlungen, in: BgA 41/710.

${ }^{650}$ Abschrift der Verhandlung zwischen Werksleitung und Betriebsvertretung von Rheinelbe, 22.3.

$1928, \mathrm{BgA} 41 / 710$.
} 
mitgeteilt, die auf diese Weise fast den Eindruck erhalten mußten, ihre Vertreter würden an den Entlassungsmaßnahmen im Interesse der Gegenseite mitwirken.

Für die Abteilung Bergbau der Vereinigten Stahlwerke war der erreichte $\mathrm{Zu}$ stand gleichwohl nicht zufriedenstellend. Fluktuation und Abwanderung aus dem Bergbau bedingten einen latenten, teilweise sogar offenen Mangel an qualifizierten Hauern, der durch die Intensivierung der Nachwuchsförderung bisher nicht hatte ausgeglichen werden können. Die Stimmung unter den Beschäftigten war erkennbar schlecht; wachsende kommunistische Stimmanteile signalisierten zukünftige Konflikte. Die schlechte Stimmung und die Verärgerung über die Gedingestellung führten zudem zu Leistungszurückhaltung, die trotz Rationalisierung und verbesserter Leistungskontrolle nicht grundsätzlich verhindert werden konnte. Wenn man nicht bereit war, Zugeständnisse im Rahmen des Tarifsystems und der Betriebsverfassung zu machen, so mußten, wollte man nicht die Erfolge der Rationalisierung in einem zukünftigen Konjunkturaufschwung mit verbesserten Kampfpositionen der Arbeiterschaft auf das Spiel setzen, Alternativen zur Integration der Arbeiterschaft in den Betrieb gesucht werden. Bei dieser Suche nach Alternativen spielte die fragwürdige Gewißheit eine Rolle, die Bergarbeiterschaft bestehe aus einer "gesunden" und "arbeitsfreudigen" Mehrheit und einer rebellischen Minderheit, die bereits bei den Säuberungsaktionen 1924/5 Pate gestanden hatte. Diese Belegschaftssäuberungen hatten aber das gewünschte Ziel nicht erreicht; vielmehr hatte das Arbeitsmarktrisiko die Disziplinierungsfunktion übernommen. Gleichwohl war man bei der Abteilung Bergbau der VSt. nicht bereit, den Grundfehler des Disziplinierungsansatzes zuzugestehen, weil jede kompromißorientierte Alternative zu kostenträchtig erschien. Aus diesem Grund kam auch eine Intensivierung der betrieblichen Sozialpolitik nicht in Frage. Nicht zuletzt auch angesichts des spezifischen Gesellschaftsbildes der führenden Bergbauindustriellen lag es daher nahe, den zuletzt 1917 erwogenen „Werksgemeinschaftsgedanken“ als kostengünstige Integrationsmaßnahme erneut aufzugreifen. Die Abteilung Bergbau der VSt. konnte dabei von der Arbeit des seit 1925 bestehenden DINTA ${ }^{651}$, mit dem bereits in der Nachwuchsförderung zusammengearbeitet wurde, und einiger "führender" Arbeitswissenschaftler profitieren. 1928/29 begannen Bemühungen, die Arbeiter ideologisch für eine engere Zusammenarbeit jenseits der "Konfliktpartnerschaft" des kollektiven Arbeitsrechtes zu gewinnen. ${ }^{652}$ Dabei ging es offensichtlich auch darum, das Verhältnis zwischen Vorgesetzten und Arbeitern zu verbessern, das sich während der Rationalisierung wegen des Leistungsdruckes verschlechtert hatte. ${ }^{653} \mathrm{Im}$ Vorstand der Abteilung Bergbau der Vereinigten Stahlwerke wurde jedenfalls im September 1929 festgestellt, daß das Verhältnis zwischen Arbeiterschaft und Vorgesetzten häufig nicht so gut war, wie es eigentlich sein sollte. Man beschloß daher zunächst, aufklärend auf die „Beamten“ einzuwirken, indem man für alle Angestellten bis hinunter

${ }^{651}$ Zum DINTA vgl. Zollitsch, Arbeiter zwischen Weltwirtschaftskrise und Nationalsozialismus, S. $137 \mathrm{ff}$. Die These, der Bergbau sei ein Hort des DINTA gewesen, trifft freilich nur für die Abteilung Bergbau der Vereinigten Stahlwerke zu. Trischler, Steiger im deutschen Bergbau, S. $297 \mathrm{ff}$.

${ }^{652}$ Zum Ansatz des DINTA und der es stützenden Schwerindustrie siehe Hinrichs, Peter, Industrieller Friede?, S. 70-74.

${ }^{653}$ Zum Phänomen des sog. Gedingeköpfens und der Scheingedinge, mit denen die Arbeiter zu vermehrter Leistung angetrieben werden sollten, siehe Tschirbs, Tarifpolitik im Ruhrbergbau, S. 297 f. 
zum Fahrsteiger die Schrift: „Frevel am deutschen Volk. Gedanken zur deutschen Sozialpolitik" von E. Horneffer beschaffen ließ. ${ }^{654}$ Bereits im Oktober 1928 hatte man an alle Angehörigen des Managements bis hinunter zum Betriebsdirektor Horneffers Schrift „Der Weg zur Arbeitsfreude“ verteilen lassen ${ }^{655}$, damit aber offensichtlich nicht den gewünschten Erfolg erzielt. Während man auf diese Weise die betriebs- und wirtschaftsfriedlichen Gedanken des DINTA ${ }^{656}$, das ja unter tätiger Mithilfe des eigenen Vorstandsvorsitzenden Albert Vögler zustandegekommen war, den Angehörigen des Managements nahebringen wollte, befaßte man sich zugleich mit der Idee der Werksgemeinschaft, um die Arbeiter für eine wirtschaftsfriedliche Kooperation zu gewinnen. Gustav Knepper, der Leiter des Bergausschusses, hatte erstmalig Anfang 1929 wohlwollend auf das Konzept der Werksgemeinschaft aufmerksam gemacht; im Mai 1929 wurde es zum Tagesordnungspunkt der Bergausschußsitzung. ${ }^{657}$ Eigene Konzepte aus der Abteilung Bergbau wurden dabei naheliegenderweise nicht verhandelt. Man griff Überlegungen aus dem Umfeld des DINTA auf und beschloß, den Werksgemeinschaftsgedanken im Kontext der Abteilung Bergbau zu fördern. Die Gruppen wurden durch Bergausschußbeschluß aufgefordert, ebenfalls im Sinne des Werksgemeinschaftskonzeptes tätig zu werden. ${ }^{658}$

Praktisch konzentrierten sich alle Überlegungen, für die Bergwerksdirektor Wilke mit Kneppers Unterstützung die Federführung übernahm, einerseits auf das direkte Ansprechen der Bergbauangestellten, die häufig sozialdemokratischen Angestelltenorganisationen angehörten, um sie für eine autoritär-patriarchalische Betriebsführung zu gewinnen. ${ }^{659}$ Andererseits suchte man ganz im Sinne des DINTA, die Werkszeitungen zu Sprachrohren an die Belegschaften umzugestalten, kam damit aber vor Ausbruch der Weltwirtschaftskrise nicht einmal konzeptionell voran. Auf der Bergausschußsitzung am 10. Dezember 1929 jedenfalls wurde zwar Vöglers Leitlinie, durch „behutsame Umgestaltung des Inhalts“ der Werkszeitungen Einfluß auf die Belegschaften zu nehmen, bekanntgegeben, doch war völlig unklar, wie die Werkszeitungen in Zukunft aussehen und wer sie herausgeben sollte. ${ }^{660}$

Werksgemeinschaftskonzepte und Einbeziehung der Angestellten in autoritäre Führungsstrukturen waren daher letztlich ideologische Selbsttäuschung, da sie mit keinerlei praktischen Veränderungen in den industriellen Beziehungen im Werk verbunden waren. Sie waren gleichwohl Ausdruck der Vorstellung, daß unter günstigen Umständen und bei richtigen Maßnahmen ein Zustand harmonischer Kooperation im Bergbau erreichbar sein müßte. Diese Vorstellung basierte

\footnotetext{
${ }^{654}$ Sitzung des Bergausschusses der VSt., 23. 9. 1929, BgA 55/583.

${ }^{655}$ Bergausschußsitzung, 26. 10. 1928, BgA 55/582.

${ }^{656}$ Während das DINTA sich eine stärkere Flexibilisierung der Führungspolitik vorstellen konnte, plädierte der führende Kopf des Werksgemeinschaftsgedankens bei der Abteilung Bergbau der VSt., Wilke, für eine Rückkehr zu Vorkriegsverhältnissen, BgA 55/1453. Zur Kritik von Bergbauvertretern am DINTA Trischler, Steiger, S. $279 \mathrm{ff}$. Die Abteilung Bergbau des VSt. gehörtc naheliegenderweise nicht zu den prominenten Kritikern des DINTA.

657 15. 5. 1929, BgA 55/583.

${ }^{658}$ Bergausschußsitzung, 15. 5. 1929, BgA 55/583.

${ }^{659} \mathrm{Vgl}$. hierzu Trischler, Steiger, S. $279 \mathrm{ff}$. Vgl. im einzclnen die Stimmungsberichte des Oberbergamtes, StAM OBAD 1864-1870.

${ }^{660}$ Bergausschußsitzung, 10.12. 1929, BgA 55/583.
} 
dabei auf der Grundüberzeugung, Gewerkschaften, Tarifsystem und Betriebsräte würden nicht nur die Beziehungen zur Belegschaft „vergiften“, sondern im Konzert mit der staatlichen Schlichtung auch den Erfolg der Rationalisierung in Frage stellen. Daß die Rationalisierung und die Strukturkrise selbst, unabhängig von der Form ihrer Kommunikation, konfliktgenerierend waren, nahm die Abteilung Bergbau nicht zur Kenntnis, da es dem Selbstkostendenken zwangsläufig widersprochen hätte. Einen Ausweg aus der Strukturkrise in Kooperation mit Belegschaften und Gewerkschaften zu suchen, konnte man sich in Essen 1929 ebenso wenig vorstellen wie 1918. So blieb letztlich nur die Flucht in den autoritären Ausweg, der bei der Abteilung Bergbau der VSt. bewußt unter Verweis auf die Verhältnisse im Kaiserreich, als der noch nicht in Frage gestellte Autoritarismus der Garant eines beispiellosen Aufstiegs gewesen zu sein schien, gewählt wurde. Die autoritäre Werksgemeinschaft war kein Zeichen von Stärke, sie war die ultima ratio einer industriellen und Unternehmensorganisation, die betriebswirtschaftlich bedrängt und sozial phantasielos war. Im Bergbau zeigte sich, daß die Bestimmungen des Betriebsrätegesetzes zumindest insoweit unzureichend waren, als sie keine differenzierenden Eingriffe in die Unternehmensorganisation etwa im Sinne der Gründung von Sozialabteilungen für den Fall vorschrieben, daß sich Unternehmen chronisch lernunfähig oder lernunwillig zeigten. Ob sich die Probleme, die die Weltwirtschaftskrise schließlich brachte, dadurch hätten leichter bewältigen lassen, ist schwer zu beantworten. Im Ruhrbergbau, konkret bei der Abteilung Bergbau der Vereinigten Stahlwerke aber wäre eine Situation der Paralyse der Betriebsratsarbeit und schließlich der fast notwendigen Flucht in die autoritäre Gemeinschaftlichkeit zumindest zum innerbetrieblichen Diskussionsgegenstand geworden.

\section{9 bis 1934}

\section{Die Weltwirtschaftskrise als Sanierungsphase}

Der Verlauf der Weltwirtschaftskrise, die in den Augen des Vereins für die bergbaulichen Interessen nichts anderes als die Folge der Weimarer Wirtschaftsfeindlichkeit darstellte ${ }^{661}$, wies für die Abteilung Bergbau der Vereinigten Stahlwerke ein janusköpfiges Gesicht auf. ${ }^{662}$ Einerseits brach der Umsatz zusammen und betrug im Geschäftsjahr 1931/32 gerade noch $40 \%$ des Volumens von 1928/29, als er mit knapp 580 Mio. RM den Höhepunkt während der Weimarer Republik erreicht hatte. Dabei entwickelte sich die konzerninterne Nachfrage deutlich schlechter als der Fremdumsatz. Insbesondere der Export wurde für die Abteilung Bergbau der Vereinigten Stahlwerke zu einem relativen Stabilisator. ${ }^{663}$ Parallel zum Umsatzrückgang sank die Kohlenförderung von 27,2 Mio. t 1928/29 auf 18,4 Mio. t 1930/31 und 14,3 Mio.t 1931/32. Im Geschäftsjahr 1932/33 begann ein langsamer Wiederanstieg der Förderung. ${ }^{664}$ Ab 1929 wuchsen die Halden. Am

${ }^{661}$ Der Ruhrbergbau im Wechsel der Zeiten, S. 173.

662 Siehe aus Konzernsicht zur Gesamtentwicklung 10 Jahre Steinkohlenbergbau der Vereinigte Stahlwerke AG. Ferner GBAG (Hg.), 25 Jahre Bergbau der Vereinigten Stahlwerke AG.

${ }^{663}$ Zahlen nach Monatsbericht der Vereinigten Stahlwerke 9/1933, S. 40, BgA 55/498.

${ }^{664}$ GBAG, Betriebs- und Wirtschaftlichkeitsverhältnisse 1926-1933/34, S. 3, BgA 55/1295. 
1. Oktober 1930 lagen 1 Mio. t Kohlen und 1,2 Mio. t Koks auf Halde. Wenn auch die Haldenbestände bei Kohle in den folgenden Jahren auf einen Durchschnitt von etwa $500000 \mathrm{t}$ gesenkt werden konnten, so stiegen die Haldenbestände in Koks bis zum 1.Oktober 1933 kontinuierlich auf schließlich 1,85 Mio.t weiter an, obwohl die Koksproduktion von 8,7 Mio. t 1928/29 auf 3,6 Mio. t 1931/32 zurückgenommen wurde. Die hohen Haldenbestände und die geringe Ausnutzung der Anlagen trieben die Abschreibungssätze nach oben, die 1928/29 bei 1,27 RM je t Förderung, 1931/32 allerdings bei 2,96 RM je t Förderung lagen. Das Abschreibungsvolumen stieg daher trotz des Rückganges der Förderung in der Weltwirtschaftskrise zunächst weiter an und hielt sich dann mit etwa 40 Mio. RM auf hohem Niveau. Hierdurch geriet auch das Geschäftsergebnis der Abteilung Bergbau ab 1930/31 in die roten Zahlen. Während das Bilanzergebnis vor Abschreibungen je $t$ Förderung 1928-1930 mit etwa 2,25-2,50 RM am höchsten war, sank es auch in der Weltwirtschaftskrise mit durchschnittlich 1,87 RM nicht unter das Niveau von 1926/27. Lediglich die sehr hohen Abschreibungssätze führten schließlich 1930/31 zu Bilanzverlusten von 5,5 Mio. RM, 1931/32 15,7 Mio. RM und schließlich 1932/33 2,5 Mio. RM. .65 $^{6}$

Über die Berechtigung der hohen Abschreibungssätze im Bergbau wurde in den zwanziger Jahren heftig gestritten. ${ }^{666}$ Auffällig in den internen Berichten der Abteilung Bergbau von 1934 war allerdings nicht so sehr der möglicherweise überhöhte Abschreibungssatz während der Weltwirtschaftskrise, sondern die Tatsache, daß sich das Kohlenunternehmen betriebswirtschaftlich während der Weltwirtschaftskrise endgültig saniert hatte. Parallel zu den Arbeitskosten je t Förderung gingen ab 1930/31 mit der faktischen Durchbrechung des Tarifsystems auch die Arbeitskosten je Schicht um fast 16\% bis Anfang 1934 zurück. Die Arbeitskosten je t Förderung sanken von ihren Höhepunkt 1927/28 bis Anfang 1934 um mehr als 40\%, wobei der Großteil der Schrumpfung (35\%) auf die eigentlichen Krisenjahre entfiel. ${ }^{667}$ Zugrunde lag dieser Entwicklung ein Anstieg des Förderanteils je Mann und Schicht von $1327 \mathrm{~kg}$ Anfang 1929 auf $1956 \mathrm{~kg}$ Ende $1933 .{ }^{668}$ Während die Kohlenförderung von ihrem Höhepunkt 1928/29 um maximal 47,6\% bis 1931/32 sank, ging die Zahl der Bergarbeiter sehr viel deutlicher zurück. Waren am 1. Oktober 1929 noch etwa 87000 Bergarbeiter bei der Abteilung Bergbau beschäftigt, so ein Jahr später nur noch 65000 . Am 1. Oktober 1931 waren es nur 45000. Der Tiefstand wurde im Herbst 1932 mit gut 37000 angelegten Bergarbeitern erreicht. Der Rückgang betrug bei der Arbeiterbelegschaft also etwa $60 \%$. Bei den Angestellten fiel er mit 30\% erheblich geringer aus. ${ }^{669}$

Zentrale betriebswirtschaftliche Kennziffern konnten auf diese Weise verbessert werden. Zunächst ging - nach den obigen Zahlen zwangsläufig - der Umsatz je Arbeiter nicht zurück, sondern konnte sich trotz deflationärer Entwicklungen die Kohlenpreise sanken durchschnittlich von 1928 bis 1933 um etwa 10\% - auf

${ }^{665}$ Zahlen nach ebenda, laufend.

${ }^{666}$ Ausschuß zur Untersuchung der Erzeugungs- und Absatzbedingungen der deutschen Wirtschaft,

Die deutsche Kohlenwirtschaft. Verhandlungen und Berichte des III. Unterausschusses, Berlin 1929 , S. $139 \mathrm{ff} ., 172 \mathrm{ff} .$, S. $347 \mathrm{ff}$.

${ }^{667}$ GBAG, Betriebs- und Wirtschaftlichkeitsverhältnisse 1926-1933/34, S. 4, BgA 55/1295.

${ }^{668}$ Ebenda.

${ }^{669}$ Monatsbericht der Vereinigten Stahlwerke 9/1933, S. 50, BgA 55/498. 
Vorkrisenniveau halten. Da die weiterhin beschäftigten Bergarbeiter zudem jährlich weniger Schichten verfuhren - im Durchschnitt des Ruhrgebietes lag die jährliche Schichtenzahl 1929 bei $275,1930-1933$ bei ca. $240^{670}$-, stieg der Umsatz je verfahrene Schicht während der Weltwirtschaftskrise weiter an, und zwar um etwa 10\%. Im Ergebnis dieser Entwicklungen sank damit der Anteil des Lohnes am Umsatz von $40 \%$ Ende 1929 auf 26,3\% im Geschäftsjahr 1933/34. ${ }^{671}$ Sollte es in der Weimarer Republik eine überhöhte Lohnbelastung der Bergwerke gegeben haben, so wurde sie bereits in der Weltwirtschaftskrise abgebaut, und zwar in einer Weise, die nicht allein mit den Tarifkürzungen erklärt werden kann, die zweifellos von großer Bedeutung waren. Die Abteilung Bergbau der Vereinigten Stahlwerke erreichte eine Verbesserung ihrer Liquiditätskennziffern bei sinkender Produktion, obwohl die Skalenerträge durch Kostendegression bei hoher Anlagenausnutzung ausblieben. ${ }^{672} \mathrm{Ganz}$ offensichtlich wurde von den verbleibenden Bergleuten bei sinkender Jahresarbeitszeit und deutlich zurückgehenden Löhnen gleichwohl sehr viel mehr geleistet als vor der Krise. Was alle mehr oder minder brachiale Akkord- und Gedingepolitik nicht bewirkt hatte, brachte die Weltwirtschaftskrise gleichsam von selbst: die Steigerung der Leistungsbereitschaft der Arbeiterschaft. Dies war der Hintergrund, der Knepper im März 1935 die wirtschaftliche Lage der jetzt neuen GBAG ausgesprochen positiv einschätzen ließ. Alle Rationalisierungs- und Kostensenkungsmaßnahmen zusammengenommen hätten eine „gute Grundlage für günstige Selbstkosten“ geschaffen. Es sei zu erwarten, daß mit zunehmender Nachfrage die wirtschaftliche Lage der GBAG „schnell günstig“" wird. ${ }^{673}$ Sie war nicht einmal in der Weltwirtschaftskrise so ungünstig, denn hätte sich die Abteilung Bergbau mit geringeren Abschreibungssätzen zufrieden gegeben, so wäre sie selbst 1931/32 nicht in die roten Zahlen gerutscht. Von der Betriebswirtschaft her war jedenfalls die GBAG bei ihrer förmlichen Neugründung 1934 ein gesundes Unternehmen.

Dieses Ergebnis war die Folge einer gezielten Politik des Beschäftigungsabbaues, der Konzentration der Förderung auf die günstigsten Standorte und Betriebspunkte, der Lohnsenkung und der Erhöhung des Leistungsdrucks. Es war klar, daß diese ausgesprochen "leistungsfördernden“ Momente im Wiederaufschwung nicht voll beibehalten werden konnten, doch war gerade die Konsolidierung dieser betriebswirtschaftlichen Kennziffern ein ausdrückliches Ziel der Politik der GBAG nach 1933/34. Daß es ihr gelang, die Daten, insbesondere das Lohn-/Umsatzverhältnis auf dem niedrigen Krisensatz zu stabilisieren, den Umsatz je Beschäftigten sogar deutlich zu steigern, lag daran, daß wegen der anhaltenden Arbeitslosigkeit im Bergbau das Disziplinierungsinstrument der Beschäftigungspolitik wirksam blieb. Wegen der nicht zuletzt hierüber gesicherten hohen Leistungsbereitschaft konnte die GBAG den Aufschwung nach 1934 mit nur unterdurchschnittlich wachsenden Arbeiterzahlen bewerkstelligen. Mit Erreichen der Vollbeschäftigung 1937 aber änderten sich die Verhältnisse und die betriebs-

\footnotetext{
${ }^{670}$ Günther Hegermann, Die Entwicklung des Montansektors, Ms., Bochum 1991, Zahlentafel 1.

671 Daten nach Monatsbericht der Vereinigten Stahlwerke 3/1941, S. 99, BgA 55/556.

${ }^{672}$ Die Konzentration der Förderung auf die rentabelsten Betriebspunkte dürfte zu einem Teil den Rückgang der Skalenerträge allerdings ausgeglichen haben.

${ }^{673}$ GBAG, Betriebs- und Wirtschaftlichkeitsverhältnisse 1926-1933/34, S. 13f., BgA 55/1295.
} 
wirtschaftlichen Kennziffern begannen sich zu verschlechtern, allerdings nicht in einem Maße, das an die Vorkrisenzeit erinnert hätte. ${ }^{674}$

Für die Bergleute stellte sich der Krisenverlauf daher als eine komplexe Verschlechterung der Lebens- und Arbeitsbedingungen bei gleichzeitiger, durch das Beschäftigungsrisiko bedingter Verunmöglichung von arbeitsplatznahem Protest dar. Während die Arbeiterbelegschaft der Abteilung Bergbau von 87085 im Oktober 1929 auf 37420 im Oktober 1932, also um etwa 60\% sank, ging die Lohnsumme von 209 Mio. RM 1928/29 auf knapp 70 Mio. RM 1931/32 herunter, also um exakt zwei Drittel. ${ }^{675}$ Das Durchschnittsjahreseinkommen eines Arbeiters im Bergbau der Vereinigten Stahlwerke, das 1928/29 mit 2483 RM seinen Höhepunkt in der Weimarer Republik erreicht hatte, schrumpfte in den kommenden Jahren kontinuierlich zusammen auf schließlich 1753 RM 1931/32. ${ }^{676}$ Zwar mußte der jeweilige Bergmann für das gesunkene Einkommen etwa 30 Schichten pro Jahr weniger verfahren, seine Jahresarbeitsleistung aber sank keineswegs, da er während der verbleibenden Schichten pro Schicht im Schnitt um die 50\% mehr Kohlen förderte. Der Leistungszuwachs pro Mann und Schicht war dabei bei der Abteilung Bergbau der Vereinigten Stahlwerke besonders ausgeprägt. Während im Schnitt die bergmännische Belegschaft auf den Ruhrgebietszechen 19291271 kg Kohle förderte, lag dieser Satz bei der Abteilung Bergbau bei $1327 \mathrm{~kg}$ im Geschäftsjahr 1928/29. Der Ruhrgebietsdurchschnitt hatte $19321628 \mathrm{~kg}$ erreicht, in der Abteilung Bergbau wurden indes $1956 \mathrm{~kg}$ Kohlen von jedem Mitglied der bergmännischen Belegschaft gefördert. ${ }^{677}$ Proteste gegen diese Entwicklung blieben die Ausnahme. Die stark sinkenden Unfall- und Krankheitsmeldungen waren hierfür ein deutliches Indiz. Die Krankenquote unter den Bergleuten ging in der Weltwirtschaftskrise immer weiter zurück; $1931 / 32$ lag sie mit 3,35\% um mehr als die Hälfte unter dem Stand von 1927. Auch die Zahl der Unfälle mit über dreitägiger Arbeitsunfähigkeit wies eine Schrumpfungsrate von fast $70 \%$ zwischen 1928 und 1932 auf, obwohl im gleichen Zeitraum die Arbeitsleistung pro Bergmann um deutlich mehr als 50\% zunahm. ${ }^{678}$ Mochte der Rückgang der Unfälle auch mit der Konzentration der Förderung auf die modernsten Anlagen und der deutlichen Erhöhung des Aufsichtspersonals im Grubenbetrieb - kamen vor der Krise 18 Arbeiter auf einen Angestellten, so waren es 1932 nur noch elf ${ }^{679}$ - zusammenhängen, so war eine derartig durchgreifende Anhebung der Betriebssicherheit doch unwahrscheinlich. Wahrscheinlicher war, daß kleinere Unfälle nicht oder kaum noch gemeldet wurden, und die Bergleute sich bei größeren Unfällen bemühten, so schnell wie möglich zur Arbeit zurückzukehren. Angst machte sich breit. Zwei beschäftigten Bergleuten stand Anfang 1932 ein arbeitssuchender Bergmann gegenüber; niemand, nicht einmal voll leistungsfähige Kohlenhauer waren vor der

\footnotetext{
${ }^{674}$ Daten nach Monatsbericht der Vereinigten Stahlwerke 3/1941, laufend, BgA 55/556. Zur Entwicklung insyesamt vgl. Wisotzky, Der Ruhrbergbau im Dritten Reich.

${ }^{675}$ Monatsbericht der Vereinigten Stahlwerke 9/1933, S. 48, BgA 55/498.

${ }_{676}$ Monatsbericht der Vereinigten Stahlwerke 9/1933, S. 46, BgA 55/498.

677 Zahlen nach Wiel, Wirtschaftsgeschichte des Ruhrgebietes, S. 137 sowie GBAG, Betriebs- und Wirtschaftlichkeitsverhältnisse 1926-1933/34, S. 4, BgA 55/1295.

${ }^{678}$ Daten nach Monatsbericht der Vereinigten Stahlwerke 9/193, S. 60, 63, BgA 55/498.

${ }^{679}$ Monatsbericht der Vercinigten Stahlwerke 9/1933, S. 50, BgA 55/498.
} 
Arbeitslosigkeit sicher. Kommunistische, in zunehmendem Maße aber auch nationalsozialistische Agitation traf an der Ruhr auf gut vorbereiteten Boden.

\section{Endgültige Unterhöhlung der betrieblichen Mitbestimmung}

Die Betriebsratswahlen im Ruhrbergbau seit 1930 wurden so insbesondere für den Alten Verband zum Desaster. Nicht zuletzt er und seine Politik wurden von den Bergleuten mit dem Status quo identifiziert, ihm wurden das Tarifsystem und sein Versagen angelastet. Die symbolische Protestwelle der noch beschäftigten und daher wahlberechtigten Bergleute schwappte zunächst zu den Kommunisten, die 1930 23,3\% und 1931 29\% der Stimmen erringen konnten, während der Stimmanteil der freien Gewerkschaften, der 1929 immerhin noch knapp 58\% ausgemacht hatte, zunächst auf $43,6 \%$ und dann auf $36,4 \%$ sank. Die Nationalsozialisten erzielten 1931 lediglich 4,2\% der Stimmen, hatten aber dafür 1933, als im Ruhrbergbau noch fast alle Schachtanlagen die Betriebsrätewahlen durchführten, mit 30,9\% und knapp 50000 Stimmen den freien Gewerkschaften den ersten Rang abgenommen. Während sich die christlichen Gewerkschaften 1933 mit 23\% der Stimmen noch einigermaßen behaupten konnten, brachen die Kommunisten, die nur noch 9,3\% der Stimmen erhielten, stark ein. ${ }^{680}$ Die Bergleute nahmen dabei den Protestcharakter der Wahlen offensichtlich ernst, da alle verfügbaren Daten auf jeweils hohe Wahlbeteiligungsquoten von ca. $80 \%$ hinwiesen. ${ }^{681}$

Das Klima bei den Betriebsratswahlen, ja überhaupt die Auseinandersetzungen $z$ wischen den verschiedenen politischen und gewerkschaftlichen Richtungen in der Bergarbeiterbewegung verschlechterte sich dabei proportional zu ihren realen Handlungsmöglichkeiten. ${ }^{62}$ Eine Streikaktion von 1931 blieb ergebnislos. Die Bergleute waren weder zu radikalen noch zu gewerkschaftlichen Aktionen zu bewegen; auch wenn sich manche RGO- und KPD-Funktionäre dies wünschten, bestand zwischen Wahlentscheidungen und Handlungsbereitschaft kein Zusammenhang. ${ }^{683}$ Auf der Ebene der Betriebsräte führten die Wahlverschiebungen ohnehin nicht zu entscheidenden Änderungen, da die tarifgewerkschaftlichen Mehrheiten, wenn auch in geringerem Ausmaß, erhalten blieben, von einzelnen Schachtanlagen des westlichen Reviers abgesehen, wo sich kommunistische Mehrheiten durchsetzen konnten. Deren alltägliche Arbeit war bereits seit 1928 durch die kontinuierlich erfolgenden Massenentlassungen geprägt. Nunmehr wurde der Belegschaftsabbau zu einer flächendeckenden und dauerhaften Massenerscheinung. Der Belegschaftsabbau erfolgte allerdings keineswegs auf einmal, sondern je nach Markt- und Absatzlage in Schüben, wobei die Entlassungen bei der Gruppe Gelsenkirchen der Abteilung Bergbau der Vereinigten Stahlwerke maximal jeweils Arbeitergruppen von etwa 300 bis 500 Mann betrafen. ${ }^{684}$ Häufiger aber standen Gruppen von 40 bis 50 Bergleuten zur Entlassung an, wobei

\footnotetext{
${ }^{680}$ Martiny, Arbeiterbewegung an Rhein und Ruhr, S. 253.

681 Vgl. Wahlergebnisse von Prinz Regent, Gruppe Bochum der GBAG, BgA 40/481. Das Jahrbuch des Bergarbeiterverbandes gab für 1930 reichsweit eine Wahlbeteiligung von $84,22 \%$ (Jahrbuch 1930, S. 145) und für 1931 von $86,63 \%$ (Jahrbuch 1931, S. 205) an.

682 Jahrbuch des Bergarbeiterverbandes 1929, S. 311-316, 1930, S. 144-148, 1931, S. 205-207.

683 Vgl. Zollitsch, Arbeiter zwischen Weltwirtschaftskrise und Nationalsozialismus, S. $179 \mathrm{ff}$.

${ }^{684}$ BgA 41/710.
} 
nicht zuletzt die Politik der Zechenleitungen eine Rolle spielte, durch Entlassungen von weniger als 50 Beschäftigten die Mitwirkungsrechte der Betriebsvertretungen auszuhebeln. Die Wirkung dieser kontinuierlichen Ausdünnung war offensichtlich verheerend, wie ein Betriebsausschußmitglied der inzwischen neu gebildeten Schachtanlage Vereinigte Rheinelbe/Alma anläßlich von Entlassungsverhandlungen für Rheinelbe/Alma und Bonifacius im Juni 1930 erläuterte. Nachdem er die aktuelle Entlassungsaktion von 480 Bergleuten als unvermeidbar akzeptiert hatte, klagte er über die vergangenen Monate: „Es sei bedauerlich,“ vermerkte das Protokoll, „daß die Belegschaften bereits seit vier Monaten verdünnt worden seien. An jedem Kündigungstermin seien etwa 40 bis 50 Leute abgebaut worden. Darüber herrsche in der Belegschaft Mißstimmung und Angst.“ Diese wurde aber offensichtlich von der Zechenleitung ausgenutzt, wie der Betriebsrat weiter berichtete: „Diese Angst werde noch verschärft durch das Vorgehen einiger Beamten, die ihren Untergebenen ständig mit Entlassung drohten. Kein Belegschaftsmitglied habe mehr den Mut, sich in irgendeiner Angelegenheit zu beschweren. So sei z. B. im letzten Monat keine Beschwerde mehr eingegangen. " ${ }^{" 685}$ Der Betriebsratsvorsitzende sah daher die jetzige umfangreiche Entlassungsaktion sogar mit einer gewissen Genugtuung. Man könne sie nicht verhindern, „aber es sei besser, durch eine durchgreifende Maßnahme endlich geregelte Verhältnisse herbeizuführen."

Diese Hoffnung blieb unerfüllt. Die Entlassungsaktionen des ersten Halbjahres 1930 brachten kein Ende des Personalabbaues; sie waren lediglich seine erste Etappe. Die Entlassungen gingen weiter. Der Druck auf die noch beschäftigten Bergarbeiter nahm also nicht $\mathrm{ab}$, sondern wurde noch größer, da man tagtäglich das Elend der Arbeitslosen vor Augen hatte. Bereits bei den zuvor erwähnten Entlassungsverhandlungen wurde diese Tendenz zur sozialen Verelendung angesprochen, als der Betriebsratsvorsitzende betonte, "die wirtschaftliche Not unter den Belegschaftsmitgliedern sei so groß, daß man keine Worte dafür habe. ${ }^{\text {686 }}$ Zudem versagte auch zunehmend der Mechanismus sozialer Selektion bei der Zusammenstellung der Entlassungslisten, da bald nur noch „soziale Härtefälle“ in Lohn und Brot standen. Hatten die Bergleute die durch die Betriebsräte sozial sekundierten Stillegungen in der zweiten Hälfte der zwanziger Jahre zumeist noch hingenommen, so lösten 1930/31 die Veröffentlichungen selbst von zuvor mit den Betriebsräten abgestimmten Entlassungslisten Bestürzung, Empörung und Beschwerdefluten wegen "unbilliger Härten“ aus. Die Entlassungsliste der Schachtanlage Ver. Rheinelbe/Alma im Juni 1930 war gemeinsam mit dem Betriebsrat unter eingehender Berücksichtigung der „sozialen Verhältnisse“ aufgestellt worden. „So seien z. B. Väter mehrerer Kinder nicht zur Entlassung vorgemerkt. Trotzdem habe der Betriebsausschuß noch 40 Einsprüche gemäß $\$ 84$ BRG erhalten“, der Arbeiterrat hatte also der Entlassung von 40 Bergleuten wegen besagter „unbilliger Härten“ nicht zugestimmt. ${ }^{687}$

${ }^{685}$ Preußisches Oberbergamt, Niederschrift über die Verhandlung am 18.6. 1930 in der Steigerstube der Schachtanlage Alma in Gelsenkirchen, betr. Betriebseinschränkung, BgA 41/710.

${ }^{686}$ Ebenda.

${ }^{687}$ Ebenda. In solchen Fällen wurde die Sache arbeitsgerichtsanhängig, doch hatten die Arbeiter hier kaum Chancen, da die Gerichte jewcils „Arbeitsmangel“ als Entlassungsgrund akzeptierten. 
Wie bereits Ende der zwanziger Jahre wurden die Betriebsvertretungen auf diese Weise zu Sekundanten der Entlassungsaktionen, während die eigentliche $\mathrm{Be}$ triebsratsarbeit wegen der Zwangsdisziplinierung der Belegschaften immer mehr zum Formalismus noch abgehaltener, aber unbedeutender Sitzungen erstarrte. ${ }^{688}$ Die Leitung der Abteilung Bergbau der Vereinigten Stahlwerke, die sich im Kontext des Zechenverbandes zum Vorreiter des Kampfes gegen den Tarif aufschwang und die Krise zur Senkung der Löhne und zur Durchbrechung des Tarifsystems zu nutzen gedachte ${ }^{689}$, sowie die einzelnen Gruppenleitungen in Hamborn, Gelsenkirchen, Bochum und Dortmund nahmen aber selbst die Sekundantenrolle der Betriebsräte nur noch widerwillig hin und hätten auf die Mitarbeit der Betriebsräte am liebsten ganz verzichtet. Als es im Juli 1930 zu umfangreichen Entlassungen bei der Zeche Zollverein in Essen-Katernberg kam, akzeptierte der bei der Besprechung in der Steigerstube ebenfalls anwesende Vertreter des Alten Verbandes zwar die Ausführungen von Bergwerksdirektor Springorum über die Notwendigkeit der Entlassungen, merkte aber an, daß er der Ansicht sei, daß „dem Sinne des $\$ 74$ BRG nach nicht nur die Kündigungslisten mit den Betriebsvertretern zu besprechen seien, es sollen vielmehr auch schon die geplanten Maßnahmen und die Art ihrer Durchführung vorher mit den Betriebsräten besprochen werden. Die Betriebsvertretungen seien dann in der Lage, auch ihrerseits Vorschläge zur Behebung von Krisen und sonstigen Schwierigkeiten zu machen." ${ }^{\circ 90}$ Trampmann, so hieß der Vertreter des Alten Verbandes, beschwor die Vertreter der Gruppe Gelsenkirchen regelrecht, die Chancen der Kooperation zu nutzen: „Es liege doch ganz und gar im Interesse der Zeche, wenn solche Vorschläge unterbreitet würden. Im übrigen seien die Vorbesprechungen geeignet, das Einvernehmen zwischen Betriebsleitung und Betriebsvertretung zu heben." Und wohl eher an den anwesenden Vertreter der Bergbehörde gerichtet bemerkte Trampmann weiter, daß „die Erfahrung gelehrt (habe), daß diese Vorbesprechungen meistens nur bei den kleineren Gesellschaften stattfinden. Die größeren Gesellschaften, insbesondere die Ver. Stahlwerke würden aber durchweg eine Zusammenarbeit mit den Betriebsräten ablehnen. Natürlich seien dann die Mitglieder der Betriebsvertretungen nicht mehr in der Lage, bei den Stillegungsverhandlungen entsprechende Vorschläge zu machen. "691 Springorum wollte die Kooperationsbereitschaft des Alten Verbandes und seiner Betriebsvertreter vor den Augen der Behörde nicht völlig barsch zurückweisen, war aber unmißverständlich in seiner Anmerkung, „die Verwaltung habe die Maßnahmen bis in alle Einzelheiten überlegt. Sie seien unvermeidbar. Eine Besprechung mit den Betriebsvertretungen sei nach seiner Ansicht zwecklos gewesen, da seitens der Betriebsräte doch keine durchgreifenden Vorschläge zur Vermeidung der Maßnahmen gemacht würden." Beim letzten Mal habe man den Betriebsrat sogar zwei Wochen vor der Verhandlung informiert. „Die Betriebsräte hätten damals keine Vorschläge gemacht. Auch im vorliegenden

\footnotetext{
${ }^{688}$ Siehe die Betriebsratsprotokolle der Schachtanlage Dannenbaum, BgA 40/226.

${ }^{689}$ Tschirbs, Tarifpolitik im Ruhrbergbau, S. $379 \mathrm{ff}$.

${ }^{690}$ Niederschrift über die Verhandlung am 29.7. 1930 auf der Zeche Zollverein 4/5 in KaternbergNord, betr. die Anzeige der Ver. Stahlwerke, Abteilung Bergbau-Gruppe Gelsenkirchen, vom 16. 7. 1930 über Betriebseinschränkung und Entlassung von 350 Arbeitern, BgA 41/710.

${ }^{691}$ Ebenda.
} 
Fall sei er der Überzeugung, daß die Betriebsvertretungen bereits geraume Zeit über die Maßnahmen der Verwaltung unterrichtet seien. Falls irgendwie Vorschläge zur Vermeidung der Maßnahmen hätten gemacht werden können, so sei der Weg zur Verwaltung offen gewesen." ${ }^{\text {692 }}$

Nach Auffassung der Gruppenleitung in Gelsenkirchen war die Mitarbeit des Betriebsrates also nicht besonders sinnvoll. Produktive Ergebnisse erwartete man sich hiervon nicht. Daß aber selbst die von Springorum vorgegebene Bereitschaft, Vorschläge der Betriebsvertretungen entgegenzunehmen, offensichtlich nur aus taktischen Gründen eingeräumt wurde, machten zur gleichen Zeit die Auseinandersetzungen in der Gruppe Bochum deutlich, wo die Betriebsräte für Arbeitszeitverkürzungen plädierten, um die Massenentlassungen zumindest zu begrenzen, damit aber bei der Gruppenleitung auf taube Ohren stießen. Sie wandten sich daraufhin an den Reichsarbeitsminister. Die Gruppenleitung in Bochum verhandelte über die Vorschläge nicht, sondern wies sie in der Deutschen Bergwerkszeitung als unhaltbar („Auf falschem Wege“) zurück. ${ }^{693}$ Der Bergausschuß, also das Leitungsorgan der Abteilung Bergbau der Vereinigten Stahlwerke, erfuhr von den Initiativen der Bochumer Betriebsräte im übrigen aus der Zeitung. Eine Initiative des Bergarbeitermitgliedes im Aufsichtsrat der Vereinigten Stahlwerke, im Zusammenhang der Bochumer Vorschläge, eine Aufsichtsratssitzung zum Thema der Massenentlassungen einzuberufen, wollte der Bergausschuß darüber hinaus auch nicht. „Die Einberufung erübrige sich aber nach Mitteilung des Herrn Vögler um so mehr", notierte das Protokoll der Bergausschußsitzung vom 15. Mai 1930, „als dieser bereits vor einiger Zeit mit Dieckmann [so bie $\beta$ das betreffende Aufsichtsratsmitglied der Bergleute] und zwei weiteren Betriebsratsmitgliedern sehr eingehend die ganze Wirtschaftslage durchgesprochen habe. “694

Die Abteilung Bergbau der Vereinigten Stahlwerke lehnte auch in der Weltwirtschaftskrise jede Zusammenarbeit mit den Betriebsräten ab, und seien sie noch so gemäßigt. Als im Februar 1930 zwischen dem Zechenverband und den Tarifgewerkschaften über eine neue Arbeitsordnung verhandelt wurde, sprach sich der Bergausschuß der Vereinigten Stahlwerke nachdrücklich gegen jede Änderung der bisherigen Arbeitsordnung aus; insbesondere wünschte man keinerlei Vorschriften in dem Sinne, daß etwa vor Feierschichten mit dem Betriebsrat „Fühlung genommen" werden müsse. ${ }^{695} \mathrm{Im}$ Gegenteil hielt man auch weiterhin daran fest, die Betriebsvertretungen in ihrer Arbeit zu behindern und Betriebsratsmitglieder zu entlassen, sobald sich irgendeine Handhabe hierzu bot. Im Kontext der Massenentlassungen war dies nicht so einfach wie bei Stillegungen, es boten sich aber weiterhin genügend Gelegenheiten. Im Oktober 1930 wurde zum Beispiel der Vorsitzende des Betriebsrates von Dannenbaum fristlos entlassen, da er eine Befahrung durchgeführt, dabei aber keine Lampe benutzt hatte; seine Ein- und Ausfahrt war mithin nicht registriert worden. Der Betriebsratsvorsitzende gab auf Nachfrage „keine Auskunft“. Der Betriebsrat lehnte die fristlose Entlassung ab, das Bochu-

\footnotetext{
692 Ebenda.

${ }^{693}$ Bergausschuß der Vereinigten Stahlwerke, 15. 5. 1930, BgA 55/584.

${ }^{694} \mathrm{BgA} 55 / 584$.

${ }^{695}$ Bergausschuß, 27. 2. 1930, BgA 55/584.
} 
mer Arbeitsgericht stimmte ihr am 6. November $1930 \mathrm{zu} .{ }^{696}$ Kommunisten auf den Ruhrzechen trafen die Entlassungen, zumal wenn sie im Betriebsrat vertreten waren, in der Regel noch schneller, da sie den Zechenleitungen die leichtere Kündigungshandhabe boten.

Die Politik der Zerstörung des Weimarer Arbeits- und Tarifrechtes paßte als Eckstein in die Rationalisierung- und Kosteneinsparungspolitik des Hauses hinein. Als man Ende 1930 im Bergausschuß die betriebswirtschaftlichen Kennziffern des Unternehmens, insbesondere die Daten zu Löhnen und Lohnnebenkosten debattierte, wurden nachgerade bestürzende Zahlen über die Explosion der Lohn- und Lohnnebenkosten vorgelegt, die seit 1924 zwischen $40 \%$ und $50 \%$ gestiegen seien: „Unsere Belastung durch soziale Lasten, Löhne und Gehälter betrug bei Zugrundelegung von 60000 Arbeitnehmern in 1929/3060 Mio. M. mehr als 1923/24, mithin je Arbeitnehmer 1000,- M. mehr. ${ }^{“ 697} \mathrm{Daß}$ die Vorschläge von Gewerkschaften und Betriebsräten, die auf Arbeitszeitverkürzungen mit einem gewissen Lohnausgleich hinausliefen, vor diesem Hintergrund strikt zurückgewiesen wurden, war naheliegend. Die konkrete Bekämpfung derartiger Vorschläge und Forderungen überließ die Abteilung Bergbau allerdings dem Zechenverband, ebenso wie sie durch dessen Aktionen endlich wieder freie Hand bei den Löhnen und Lohnnebenkosten bekommen wollte, um insbesondere die eigene Kohle im Ausland stärker konkurrenzfähig machen zu können. ${ }^{698}$ Das Scheitern der Tarifverhandlungen Ende 1930 nahm man daher genauso dankbar auf wie den damit zusammenhängenden Aussperrungsbeschluß, nach dem am 2. Januar 1931 alle Bergleute zum 15. Januar 1931 gekündigt werden sollten. ${ }^{699}$ Der Aussperrung kam eine letzte Streikaktion der Bergarbeiter zuvor, die jedoch bald in sich zusammenbrach. Von dem Lohnstreik waren bei der Abteilung Bergbau der VSt. ohnehin nur Zechen der Gruppe Hamborn betroffen, während die anderen Gruppen weiterarbeiteten. Der Leiter der Gruppe Hamborn, Karl Winnacker, konnte dem Bergausschuß überdies bereits in der Sitzung vom 8. Januar 1931 berichten, „der Betriebsratsvorsitzende von Friedrich Thyssen 4/8 sei gestern wieder Erwarten bei ihm vorstellig geworden mit der Erklärung, daß die Belegschaft bereit sei, sofort vollständig die Arbeit wieder aufzunehmen, sofern von Strafentlassungen abgesehen würde." Der Bergausschuß erklärte sich hiermit einverstanden, da man glaubte, auf diese Weise eine Bresche in die Hamborner Streikfront schlagen zu können. Ansonsten sollten aber weiterhin "Streikhetzer", insbesondere dann, wenn es sich um Betriebsratsmitglieder handelte, rücksichtslos entlassen werden. ${ }^{700}$ Konnten sich Zechenverband und Einzelunternehmen Anfang 1931 gegen die Gewerkschaften mit Tariflohnsenkungen durchsetzen und brachten auch die Papenschen Notverordnungen und Änderungen im Reichsknappschaftsgesetz sowie bei der Arbeitslosenversicherung der Bergleute weitere Entlastungen bei Löhnen und Lohnnebenkosten, so ging das der Abteilung Bergbau immer noch nicht

${ }^{696} \mathrm{BgA} \mathrm{40/226.}$

${ }^{697}$ Bergausschußsitzung, 5. 12. 1930, BgA 55/584. Die Zahlen waren freilich nicht ganz korrekt, da die Abteilung Bergbau 1929 etwa 90000 Beschäftigte hatte.

${ }^{698}$ Beschlüsse hierzu gefaßt auf der Bergausschußsitzung, 28. 10. 1930, BgA 55/584.

${ }^{699}$ Bergausschußsitzung, 30. 12. 1930, BgA 55/584. Zum Hintergrund Tschirbs, Tarifpolitik im Ruhrbergbau, S. $382 \mathrm{ff}$.

700 Bergausschußsitzung, 8. 1. 1931, BgA 55/584. 
weit genug. Im Oktober 1932 diskutierte man im Bergausschuß die Auflösung des bzw. den Austritt aus dem Zechenverband, um ganz aus dem Tarifsystem herauszukommen. Man nahm davon schließlich Abstand, da man selbst nach einem Austritt wohl Einzeltarifverhandlungen auf den Zechen nicht aus dem Weg gehen könnte, ein Austritt die Schwierigkeiten mit dem Tarifvertrag also nicht beseitigen würde. ${ }^{701}$ Dennoch war klar, daß die Abteilung Bergbau strikt eine Rückkehr zu den Vorkriegsverhältnissen ansteuerte.

Denn eine Alternative zur Lohnfestsetzung und Regelung der industriellen $\mathrm{Be}$ ziehungen im Betrieb hatte man nicht anzubieten. Knepper und der in der Werksgemeinschaftsfrage federführende Bergwerksdirektor Wilke verschickten zwar ständig Druckschriften aus dem Umfeld des DINTA an das höhere und mittlere Management; Ende 1931 machten sie auch einen Sonderbericht der Dortmunder Zentralstelle für Arbeiterangelegenheiten ${ }^{702}$ zum Thema "Träger der Betriebspolitik“ bei den „Werksbeamten“ bekannt ${ }^{703}$, doch brachten all diese Traktate wenig praktische Lösungsvorschläge für aktuell anstehende Fragen, zumal sie - für Arnhold und das DINTA typisch - auch stets Kritik an den eher traditionalistisch-autokratischen Führungsmethoden im Bergbau übten. ${ }^{704}$ Aus dem Mitte Mai 1929 gefaßten Beschluß, die Durchsetzung der Werksgemeinschaftsidee auf den Zechen $\mathrm{zu}$ unterstützen, war bislang nicht viel geworden. Selbst die Nutzung der Werkszeitschriften etwa zur „verstärkten wirtschaftlichen Schulung der Belegschaften“, denen man gleichzeitig ja nicht nur die Mitsprache, sondern jedes Gespräch über Sinn und Unsinn der Massenentlassungen regelrecht verweigerte, war 1931 nicht wirklich vorangekommen. ${ }^{705}$ Verstärkte Bemühungen richtete Bergwerksdirektor Wilke im Herbst 1931 auf die nationale Angestelltenbewegung, doch stellte man bei einer Besprechung im Dezember 1931 fest, daß man auch mit den nationalen Angestelltenverbänden nicht das erreichen könne, was man wolle, nämlich eine "Werksgemeinschaft ohne Zwischenglied“. ${ }^{706}$ Dies sei eine Arbeit von Jahrzehnten, die aber nur von den Werksleitungen selbst, ohne fremde Hilfe, geleistet werden könne. Die nationale Angestelltenbewegung habe zwar positive Züge, doch bleibe mit ihr ein fremdes Element im Werk. Der Bergausschuß beschloß daher am 23. Dezember 1931, die nationale Angestelltenbewegung wohlwollend zu behandeln, sie aber nicht gesondert zu unterstützen. ${ }^{707}$

Die Werksgemeinschaftspolitik der Vereinigten Stahlwerke blieb damit lediglich Stückwerk, die die zugrundeliegende Strategie kaum bemänteln konnte. Im Kern ging es dem Bergausschuß und den Gruppenleitungen nicht um die Ersetzung der Weimarer Tarif- und Betriebsverfassung durch ein neues Modell, sondern um die Wiederherstellung der unbeschränkten Handlungsautonomie der Zechenleitungen und die autoritäre Integration der Bergarbeiter in den Zechenbe-

${ }^{701}$ Bergausschußsitzung, 6. 10. 1932, BgA 55/585.

702 5. Jahrgang, Bcricht Nr. 5, BgA 55/1453.

${ }^{703}$ Schreiben Knepper/Wilke an die "Werksbeamten“, 15. 10. 1931, BgA 55/1453.

${ }^{70+}$ Helmuth Trischler, Steiger im deutschen Bergbau, S. $279 \mathrm{ff}$.

${ }^{705}$ Im Februar 1931 faßte der Bergausschuß wieder einmal einen programmatischen Beschluß, daß die Werkszeitschriften in Zukunft zu diesem Zweck besser genutzt werden sollten, Bergausschußsitzung, 9. 2. 1931, BgA 55/584.

${ }^{706}$ Besprechung der Bergbaugruppen der Vereinigten Stahlwerke, 11. 12. 1931, BgA 55/1453.

${ }^{707}$ Bergausschußsitzung, 23. 12. 1931, BgA 55/1453. 
trieb, wobei der Fixpunkt des Denkens bei nicht wenigen Männern der Bergbauverwaltungen das Kaiserreich war. Werksgemeinschaft war die wolkige Chiffre für einen erhofften Zukunftszustand, in dem die Belegschaften die unbeschränkte Herrschaft der Zechenleitungen freiwillig akzeptieren würden, mehr nicht, auch wenn es zweifellos einige überzeugte Vertreter von Gemeinschaftskonzepten in der Spitze der Bergbauverwaltung geben mochte. Die öffentliche Werksgemeinschaftsdebatte hatte innerhalb der Abteilung Bergbau der Vereinigten Stahlwerke nur eine ausgesprochen begrenzte Resonanz, und diese Resonanz war rein taktischer, gleichsam etikettenhafter Art für einen letztlich brutalen Machtstandpunkt. Die Bergbauverwaltungen in Essen und in den Gruppen unterstützten alles, was ihnen irgendwie in das Konzept der Wiederherstellung widerspruchsfreier Machtpolitik zu passen schien; so heuerte man unter anderem im Oktober 1932 auch den freiwilligen Reichsarbeitsdienst zu Erdarbeiten auf den Zechen Rheinelbe und Holland an. ${ }^{708}$ Explizit nationalsozialistische oder faschistische Überzeugungen lagen den verschiedenen Maßnahmen nicht zugrunde, auch wenn der Bergbau und seine Organisationen früher und radikaler gegen die Weimarer Republik und für eine Regierungsbeteiligung der NSDAP votierten und wohl auch zahlten, als dies für andere Branchen oder Unternehmergruppen galt. ${ }^{709}$

\section{Auf dem Weg in die autoritäre Werksgemeinschaft 1933/34}

Die nationalsozialistische Machtergreifung ${ }^{710}$ fand in der Unternehmensleitung der Abteilung Bergbau zunächst so gut wie gar nicht statt; auf den Bergausschußsitzungen im Februar und März 1933 gab es keine erkennbare politische Meinungsäußerung, zumindest nicht eine, die vom Protokoll festgehalten worden wäre. ${ }^{711}$ Bei den Belegschaften, die im März 1933 zur Wahl der Betriebsräte aufgerufen wurden, waren die Folgen der Machtergreifung hingegen direkt und deutlich durch den fast schlagartig einsetzenden Terror gegen "marxistische" Arbeiter zu spüren. Die Politisierung wuchs durch derartige Maßnahmen offensichtlich noch weiter an, und zwar mit positiven Auswirkungen für die NSBO. Die Wahlbeteiligung bei den Betriebsratswahlen im März 1933 lag über dem langfristig ohnehin hohen Durchschnitt; bei der Zeche Dannenbaum erreichte sie $93 \%$. Die NSBO erzielte hier die absolute Mehrheit der Stimmen und Mandate in Betriebsund Arbeiterrat, und das auf einer Zeche, die eine tarifgewerkschaftliche Hochburg war. Die Kommunisten hatten hier 1931 keinen durchschlagenden Erfolg wie etwa in Hamborn erzielen können, wo sie auf verschiedenen Schachtanlagen bis zu 70\% der Stimmen errungen hatten. ${ }^{712}$ In Bochum Laer standen Ende März 1933 fünf NSBO-Betriebsräten zwei Frei- und ein christlicher Gewerkschafter gegenüber, die bereits auf der konstituierenden Sitzung am 7. April 1933 als

\footnotetext{
${ }^{708}$ Bergausschußsitzung, 6. 10. 1932, BgA 55/585.

709 Turner jun., Die Großunternehmer, S. 221-231. Vgl. auch Neebe, Großindustrie, Staat und NSDAP, u. a. S. 80-89. Die Vorwürfe gegen den Bergbau im einzelnen bei Stegmann, Kapitalismus und Faschismus, in: Gesellschaft. Beiträge zur marxistischen Theorie, Bd. 6, S. 19-91.

710 Wisotzky, Der Ruhrbergbau im Dritten Reich, S. $26 \mathrm{ff}$.

711 BgA 55/585.

712 Dannenbaum-Wahlergebnisse in: BgA 40/225. Zu Hamborn vgl. Zollitsch, Arbeiter zwischen Weltwirtschaftskrise und Nationalsozialismus, S. $172 \mathrm{ff}$.
} 
„Staats- und Volksfeinde“ zum Rücktritt gezwungen wurden. ${ }^{713}$ Bei der Zeche Adolf von Hansemann der Gruppe Dortmund der Abteilung Bergbau der Vereinigten Stahlwerke verlief das Verfahren ähnlich. Bei der Neuwahl am 28. März 1933 - auf den Ruhrzechen wurde einheitlich an einem Tag gewählt - erhielten die NSBO und „Nationale Einheitsliste" zwar eine Mehrheit der Stimmen und Mandate, doch störten die ebenfalls gewählten Vertreter der Tarifgewerkschaften und der RGO. Der nazifizierte Wahlvorstand teilte dem Reichsarbeitsministerium am 4. April 1933 mit, man habe eine „kommissarische Betriebsvertretung ... aus Kandidaten der Nationalen Organisationen bestellt. Die Mitglieder des Bergbau-Industriearbeiterverbandes wurden aus dem Grunde nicht berücksichtigt, weil alle Mitglieder der Sozialdemokratischen Partei, des Reichsbanners und der Eisernen Front sind. Die Mitglieder des christlichen Gewerkvereins konnten deshalb nicht berücksichtigt werden, weil von diesen Flugblätter, trotz Beschlagnahme durch die Polizei, am Tage der Wahl noch verbreitet wurden. Die Mitglieder der Kommunisten konnten aus allgemein bekannten Gründen nicht in Frage kommen. Das Mitglied des Angestelltenrats, als einzigstes (!) gewählt vom Butab, wurde durch ein Mitglied der nationalen Angestellten ersetzt, weil bei einer Haussuchung bei ihm Schriften, die gegen die jetzige Regierung gerichtet waren, gefunden wurden. ${ }^{\text {" }}$ (14

Wie auf den Zechen Dannenbaum und Adolf von Hansemann ging es auf allen Ruhrzechen zu. Mit mehr oder weniger stillschweigender Duldung der Zechenverwaltungen „säuberten“ die NSBO und ihre Verbündeten die Betriebsräte von Tarifgewerkschaftern und Kommunisten und setzten an deren Stelle Parteigänger in die freigewordenen Ämter ein. Die abgesetzten Betriebsräte, aber auch als "staats- und wirtschaftsfeindlich" bekannte Arbeiter, schlug man daraufhin den Zechenleitungen zur Entlassung vor, die diesen Vorschlägen auch regelmäßig nachkamen. Spätestens seit dem 4. April 1933 waren derartige Aktionen allerdings illegal, da Absetzungen und Neuinstallierungen von Betriebsvertretungen nur noch durch die zuständigen Gewerbeaufsichtsbehörden mit dem Regierungspräsidenten als Beschwerdeinstanz durchgeführt werden durften. Auf den Zechen hielt sich an diese Vorschriften niemand, so daß zunehmend illegale Betriebsräte bestanden, die von den Behörden nicht anerkannt wurden. Der Zechenverband beschrieb die Entwicklung Mitte Mai 1933 folgendermaßen: „Im Rahmen der Säuberungsaktionen in den Betriebsräten sind auf fast sämtlichen Schachtanlagen des Ruhrreviers Betriebsratsmitglieder sowohl kommunistischer wie gewerkschaftlicher Richtung aus ihren Ämtern entfernt und durch nationale Belegschaftsmitglieder ersetzt worden. Hierbei wurde von dem ... amtlichen Abberufungsverfahren regelmäßig Abstand genommen. Die Absetzung der früheren und die Amtsübernahme der neuen nationalen Betriebsratsmitglieder erfolgte vielmehr durch revolutionäre Maßnahmen.... Um die Möglichkeit zur Rückkehr zu geordneten Rechtszuständen im Betriebsverfassungsrecht zu gewinnen, bleibt

713 Betriebsratssitzung Dannenbaum 7. 4. 1933, BgA 40/226.

${ }^{714}$ Der kommissarische Wahlvorstand an den Reichsarbeitsminister, BAP RAM 394, Bll.35f. 
nichts anderes übrig, als eine generelle nachträgliche Legalisierung aller diesen Maßnahmen." 715

Der Oberpräsident der Provinz Westfalen schloß sich dieser Auffassung an, doch der preußische Innen- und der Reichsarbeitsminister bestanden auf einer Einzelfallprüfung, betonten aber zugleich, daß die Landespolizei- und die Gewerbeaufsichtsbehörden ja alle Rechte hätten, die einmal eingetretenen Zustände zu sanktionieren, wenn sie es denn wollten. ${ }^{716}$ De facto spielte daher der Verzicht auf eine Generalermächtigung der bestehenden Betriebsvertretungen auch keine Rolle, zumal Gerichte und Beschwerdeinstanzen unter Nazi-Druck regelmäßig gegen beschwerdeführende oder klagende Tarifgewerkschafter entschieden. Bezeichnender war vielmehr die sich auf den Zechen im Mai 1933 breit machende Angst, was passieren würde, wenn die Änderung bei den Betriebsvertretungen nicht sanktioniert werden würde. Der Zechenverband begründete seinen Wunsch nach Generalpardon für die illegal ins Amt gekommenen Betriebsräte damit, daß es „zu einer verhängnisvollen Verwirrung der Verhältnisse führen“ würde, „wenn man die Absetzung der früheren Betriebsräte als ungesetzlich bezeichnen wollte. Das würde nämlich zur Folge haben, daß alle Maßnahmen, die inzwischen der neue nationale Betriebsrat getroffen hat, ebenfalls unwirksam wären. Tatsächlich haben aber die Zechenverwaltungen den neuen Betriebsrat von sich aus, vielleicht auch teilweise unter dem Druck der Verhältnisse - als gesetzlich, rechtswirksame Betriebsvertretung anerkannt, und mit diesem Betriebsrat verhandelt. Sie haben den neuen Betriebsratsmitgliedern die gleichen Rechte eingeräumt, die Mitgliedern des Betriebsrates zustehen..." Die Arbeiterschaft habe sich überdies auf die neuen Vertretungen ebenfalls verlassen und dort ihre Beschwerden und Einsprüche vorgebracht, die dann unter Umständen ungültig würden. Auch seien zahlreiche Klagen von ehemaligen Betriebsräten gegen ihre Absetzung anhängig. „Es besteht die Gefahr, daß die Gerichte auf Drängen der betroffenen Betriebsratsmitglieder und der hinter ihnen stehenden Organisationen in Kürze über jene Klagen entscheiden und die Absetzung als ungesetzlich bezeichnen", wobei sie sich gerade auf die Gesetzeslage nach dem 4. April 1933 stützen könnten. Allein um derartigen Gerichtsentscheidungen vorzubeugen, brauche man den Generalpardon. Ein Weiteres kam aus der Sicht des Zechenverbandes hinzu: „Besonders augenfällig wird die Notwendigkeit einer möglichst baldigen Klarstellung durch den Umstand, daß bei zahlreichen Zechenverwaltungen Vertreter der NSBO vorstellig geworden sind mit dem Ersuchen, die früheren Betriebsratsmitglieder gewerkschaftlicher Richtung alsbald zu entlassen. Diesem Verlangen haben die Zechenverwaltungen in den meisten Fällen entsprochen und entsprechen müssen." Diese Betriebsräte hätten nun nicht nur gegen ihre Amtsenthebung, sondern auch gegen die Entlassung geklagt und Regreßforderungen gestellt. Wegen der inzwischen verstrichenen anderthalb Monate seit der Entlassung seien die Lohnforderungen der entlassenen Betriebsräte sehr hoch, und es bestehe die Gefahr, daß bei einer

715 Zechenverband an den Herrn Reg.Ass. Dr. Graf von Stosch, Polizeipräsidium Recklinghausen, 15. 5. 1933, BAP RAM 505, Bl. 170.

716 Oberpräsident Westfalen an Preußischen Innenminister, 26. 5. 1933; Preußischer Innen- an Reichsarbeitsminister, 23. 7. 1933; Reichsarbeitsminister an den Oberpräsidenten der Provinz Westfalen, 3. 8. 1933, BAP RAM 505, Bll.167-169, 176. 
Nichtanerkennung der Absetzung die Zechen zahlen müßten. „Hierin liegt einerseits eine unerträgliche Belastung für die Betriebe, die, ohne daß die früheren Betriebsratsmitglieder irgendeine Tätigkeit verrichtet haben, mit sehr hohen Lohnnachzahlungen in Anspruch genommen werden. Andererseits würde sich eine Wiedereinstellung der früheren Betriebsratsmitglieder sehr nachteilig auf die dringend notwendige Erhaltung des innerbetrieblichen Friedens und der Zusammenarbeit der Belegschaft auswirken." Um diese Probleme zu lösen, gebe es nur einen Ausweg, nämlich die nachträgliche Legalisierung aller Maßnahmen. „Hiermit steht es im Einklang, daß der Herr Minister in dem erwähnten Erlaß [Runderla 3 zur Durchf. des Gesetzes vom 4. April 1933] besonders darauf Bedacht zu nehmen anordnet, daß eine national gesinnte und arbeitsfähige Betriebsvertretung eingesetzt wird, dem Gesetz widerspricht es nach dem Runderlaß nicht, wenn marxistische Betriebsvertretungsmitglieder abgesetzt werden, selbst wenn eine Betätigung im staats- oder wirtschaftsfeindlichen Sinne im einzelnen nicht nachweisbar ist. Hier wird also eine Gesetzesauslegung vorgenommen, die im Interesse der Rechtssicherheit und des Wirtschaftsfriedens sehr weit geht." Die Zechenverwaltungen hatten offensichtlich ebenfalls die gesetzlichen Vorgaben weit interpretiert, die Gelegenheit beim Schopf ergriffen und sich in Kooperation mit der NSBO von „politisch bedenklichen“ Belegschaftsmitgliedern getrennt. Diese Radikalität wollte man sich jetzt nicht vorwerfen lassen, zumal ja offensichtlich auch dem Preußischen Innenminister Ähnliches vorgeschwebt habe, als er bei der Anordnung der Einzelfallprüfung die „ausführenden Polizeibehörden“ verpflichtete, „in möglichst weitem Umfange die rev. Maßnahmen zu sanktionieren.“ Die Zechenverwaltungen aber waren anscheinend so weit gegangen, daß sie selbst eine Einzelfallprüfung wohlwollender Behörden für gefährlich hielten. Einerseits dauerten derartige Überprüfungen wegen der Überlastung der Behörden ohnehin zu lange. Andererseits würden sie bei ihren Überprüfungen „oft widersprechende Angaben von den Zechenverwaltungen, der NSBO, den früheren Gewerkschaften und den Bergrevierbeamten erhalten." Kurz und gut: nur eine nachträgliche Pauschallösung sei daher allen legitimen Interessen dienlich. ${ }^{717}$

NSBO und Zechenleitungen nutzten also ganz offensichtlich die Gunst der Stunde und trennten sich von unliebsamen Belegschaftsangehörigen. Die Initiative ging dabei von der NSBO aus, an die sich die Zechenverwaltungen anhängten. Die neuen Betriebsräte machten in ihren ersten Sitzungen gar kein Hehl daraus, daß sie die Entlassung „staats- und wirtschaftsfeindlicher" Arbeiter und stattdessen die Einstellung „national zuverlässiger" Bergleute mit allem nur erdenklichen Druck durchzusetzen gedachten. Die Zechenverwaltungen gingen auf dieses Ansinnen im eigenen Interesse bereitwillig ein. ${ }^{718}$ Die Art und Weise, wie zahlreiche der neuen Betriebsvertretungen dabei vorgingen, dürfte indes den Zechendirektoren nicht unbedingt akzeptabel erschienen sein. Die neuen, kommissarischen $\mathrm{Be}-$ triebsvertretungen verstanden sich keineswegs, so zumindest die NSBO nach den Betriebsratswahlen im Nazi-Organ „Rote Erde“, als „bessere Gelbe ..., die den

717 Zechenverband an den Herrn Reg.Ass. Dr. Graf von Stosch, Polizeipräsidium Recklinghausen, 15. 5. 1933, BAP RAM 505, Bll.170-175.

${ }^{718}$ Betriebsratssitzung Zeche Dannenbaum, 4. 7. 1933, BgA 40/226. 
Rücken schön zu krümmen verstehen." Wer Derartiges erwarte, für den werde es „ein böses Erwachen geben. "719 Viele Nazi-Betriebsräte nahmen derartige Ankündigungen offenbar ernst und setzten daher die Betriebsratsarbeit so weiter fort, wie man es aus der Zeit vor der Machtergreifung kannte. ${ }^{720}$ Auf den Zechen stellte wegen der brachialen Macht- und Leistungslohnpolitik der Bergwerksverwaltungen, die wie gezeigt bis in die Kommunikationsverweigerung hinein reichte, selbst der „linke“ Interessenvertretungsansatz der NSBO, der nun keineswegs mehr vom Klassenkampf geprägt war, noch eine Herausforderung der traditionellen und nach der Machtergreifung wieder selbstbewußteren Führungsattitüden der Bergwerksdirektoren dar. Die NSBO-Betriebsräte hatten durchaus wirre, aber doch entschiedene Vorstellungen von einer Änderung des Tons und der Umgangsformen auf den Zechen und gerieten daher mit den Zechenverwaltungen und den auf Ruhe und Ordnung bedachten Behörden, Partei- und DAF-Stellen in Konflikt. ${ }^{721}$ Die Durchsetzung des Arbeitsordnungsgesetzes und die Beseitigung der Betriebsräte hatten im Bergbau daher eine völlig andere Bedeutung als in der chemischen Industrie, wurde doch hier ein institutioneller Ansatzpunkt zur Bekämpfung der Betriebsführungsautokratie beseitigt. Diese Autokratie und das hinter ihr stehende Führungskonzept verlangten die völlige Beseitigung aller Handlungsmöglichkeiten der Gegenseite. ${ }^{722}$ Dies war indes ein Zeichen der Schwäche, da es der Bergbau nicht vermochte, aus eigener Kraft innerbetriebliche Arbeitsbeziehungen herzustellen, die zu eigenständiger Konfliktregulierung in der Lage waren. Es ist kein Zufall, daß es in den fünfziger Jahren erst der politisch durchgesetzten Institutionalisierung eines Arbeitsdirektors bedurfte, um die binnenorganisatorische Selbstbeobachtungsfähigkeit und damit die Lernfähigkeit in den Bergbauunternehmen an der Ruhr auf ein Niveau zu bringen, das der Komplexität der Aufgaben und der Arbeitsprozesse entsprach. ${ }^{723}$

${ }_{719}$ Zitiert nach „Die Bergbau-Industrie“, 15. 4. 1933, BAP RAM 387, Bl. 127.

${ }^{720}$ Siehe Betriebsratssitzung Dannenbaum, 4. 7. 1933, BgA 40/226, auf der scharf gegen das Antreibersystem protestiert, eine Verbesserung der Kohlenversorgung der Invaliden und eine Senkung der Koloniemieten - alles vergeblich - gefordert wurden.

${ }^{721}$ Wisotzky, Der Ruhrbergbau im Dritten Reich, S. $40 \mathrm{ff}$.

722 Ohne dies hier im einzelnen nachzeichnen zu können, bestimmte diese Schwäche der Zechenverwaltungen selbst noch ihren Umgang mit den vom Arbeitsordnungsgesetz vorgesehenen Institutionen, wie etwa den Unternehmensbeiräten, und der zahlreichen Ansätze von DAF und KdF, auf das Betriebsklima einzuwirken. Mit der Einrichtung eines Unternehmensbeirates taten sich die Vereinigten Stahlwerke im Gegensatz zur I.G.Farbenindustrie AG ausgesprochen schwer, gegenüber der KdF blieb man sehr skeptisch und zurückhaltend, wahrscheinlich auch deshalb, weil man wegen der nicht sehr ausdifferenzierten Strukturen betrieblicher Sozialpolitik kaum Möglichkeiten der reibungslosen Integration der KdF-Konzepte in die eigene Praxis sah. Vgl. hierzu im einzelnen die Besprechungen der Sozialpolitischen Abteilung/Hauptverwaltung der Vereinigten Stahlwerke 1933/34, BgA 55/1402. Auch mit den Vertrauensräten gab es keine derartige Zusammenarbeit wie in Leverkusen, wo sie als Akkordpropagandisten genutzt werden sollten. Die Vertrauensratswahlergebnisse liegen für die neue GBAG leider nur sehr unvollständig vor; Zu- oder Ablehnungsquoten sind nicht bekannt. Lediglich die Zahl der aufgestellten und gebilligten Kandidaten ist bekannt. Hier fällt eine vergleichsweise niedrige Ablehnungsquote auf, doch sagt dies nichts über die Stimmverhältnisse aus. Die Beteiligung an den Abstimmungen schwankte hingegen stark (1934 Minimum 63\%, Maximum 96\%; 1935 Minimum 87\%, Maximum 98,7\%), was für 1934 als ein Beleg für noch verbreitete Ablehnung der nationalsozialistischen Vertrauensleute angesehen werden mag, Abstimmungsergebnisse in: ThA VSt 448, 450. Für den gesamten Ruhrbergbau siehe Wisotzky, Der Ruhrbergbau im Dritten Reich, S. 273-281.

${ }^{723}$ Thum, Mitbestimmung in der Montanindustrie. 


\section{Zusammenfassung}

Die Entwicklung der industriellen Beziehungen im Ruhrbergbau zwischen 1916 und 1934 kann man grob in fünf Phasen gliedern. In der zweiten Kriegshälfte 1916 bis 1918 ging wegen langer Arbeitszeiten und schlechter Lebensmittelversorgung die Leistungsfähigkeit der Belegschaften zurück, während andererseits die Zechenleitungen darum bemüht waren, die Leistungsfähigkeit um jeden Preis aufrechtzuerhalten, wenn nicht zu steigern. Zwar waren die Zechenleitungen zu kontinuierlichen Lohnanpassungen bereit, doch reichten diese Erhöhungen den Belegschaften nicht aus. Die aus dieser Konstellation resultierenden Konflikte besaßen aber keine legitimen Artikulations- und Regelungsstrukturen, da sich die Zechenleitungen weigerten, mit den Gewerkschaften zu verhandeln, und die Arbeiterausschüsse bekämpften. Erst „direkte Aktionen“ der Belegschaften brachten daher Bewegung in die starren Fronten. Da weder die Gewerkschaften noch die Militärbehörden eine Konflikteskalation wünschten, reagierten sie auf die Aktionen der Bergarbeiter einerseits repressiv, andererseits drangen sie gemeinsam bei den Zechen auf Zugeständnisse, die diese zumeist widerwillig zugestanden, über den Preismechanismus aber an die Kohlenverbraucher weitergaben, wobei der Staat seit 1917 bereit war, diese Abwälzungspolitik zu tolerieren und zu unterstützen.

De facto entstand damit seit 1917 ein System indirekter, politisch vermittelter Tarifverhandlungen, das allerdings jeweils erst nach erkennbaren Konflikteskalationen auf den Zechen in Gang gesetzt wurde. Dieses eigentümliche Spiel setzte sich auch nach der Revolution 1918 weiter fort, jetzt allerdings unter erheblich veränderten politischen Rahmenbedingungen. Die nur indirekten Tarifverhandlungen wurden zwar durch direkte Gespräche zwischen Zechenverband und Tarifgewerkschaften ersetzt; zu materiellen Ergebnissen führte aber das neue Tarifsystem nicht oder nur schleppend, zumal die Zechenleitungen auf den Schachtanlagen den Achtstundentag nur zögernd umsetzten. Die Funktionsprobleme des Tarifsystems wurden auch nach dem November 1918 nicht durch eine veränderte betriebliche Kommunikationsstruktur ergänzt und kompensiert. Vielmehr schien den Belegschaften erneut nur die "direkte Aktion“ der Weg, materielle Forderungen durchzusetzen und die Blockaden des Tarifsystems zu durchbrechen. Zwischen der geregelten Konfliktstruktur (Tarifsystem, Arbeiterausschüsse) mit ihren nur schleppend zustandekommenden und materiell unzureichenden Ergebnissen und den Erwartungen der Bergarbeiterschaft öffnete sich ein immer breiterer Graben, den unionistische und syndikalistische Arbeiter durch eine programmatische Aufwertung der "direkten Aktion“ auszufüllen gedachten. Die Bergleute namentlich des Hamborner Reviers waren für derartige Konfliktformen anfällig, nicht weil sie sie politisch mehrheitlich unterstützten, sondern weil sie der einzige Weg schienen, die eigenen materiellen Forderungen durchzusetzen.

Nicht zuletzt die "direkten Aktionen“ der Hamborner Bergarbeiter bedingten auch eine Aufwertung der "Rätefrage“. Im Rahmen der "direkten Aktionen“ war es nicht nur zu Streiks, sondern auch zu Vorgesetztenabsetzungen gekommen, hatten verschiedene Belegschaft versucht, die wirtschaftliche Kontrolle auf den 
Zechen zu erreichen. Die Sozialisierungsoffensive des Frühjahrs 1919 und die Aufwertung der Rätefrage stellten eine eigentümliche Form dar, den Bergarbeiterradikalismus in politische Formen zu gießen und ihn durch materielle Zugeständnisse in der Lohn- und Arbeitszeitfrage zu disziplinieren. Das Scheitern dieser Offensive und die Rückkehr zur militärisch-politischen Repression der Bergarbeiterschaft, deren Streiks die Energieversorgung Deutschlands ernsthaft in Frage stellten, brachten aber keine Rückkehr zu den alten Verhältnissen. Vielmehr wurden auf den Schachtanlagen bereits im Frühjahr 1919 Betriebsräte installiert, deren Rechte gemessen am späteren Betriebsräterecht vergleichsweise weit bemessen waren.

Nach der äußerlichen Beruhigung der Lage im Mai 1919 begann auf den Schachtanlagen ein Kleinkrieg, allerdings nicht in materiellen Fragen, sondern über die konkreten Rechte der neuen Betriebsräte. Die alten, ebenfalls noch bestehenden Arbeiterausschüsse führten nur noch ein Schattendasein. Durch diesen Kleinkrieg wurde verhindert, daß auf den Zechen eine funktionierende betriebliche Kommunikationsstruktur entstand, die das nur schleppende Funktionieren des Tarifsystems hätte zumindest teilweise kompensieren können. Im Gegenteil machte sich als Folge und im Rahmen des Kleinkrieges eine Konfrontationshaltung breit, die für beide Seiten nachteilig war.

Durch die Verabschiedung des Betriebsrätegesetzes wurde 1920 die dritte Phase in der Entwicklung der industriellen Beziehungen im Bergbau eingeleitet, für die die Wirkungen der Inflation entscheidend waren. Die Zechenleitungen nutzten die neue Gesetzesvorlage, um die Rechte der Belegschaftsvertreter einzuschränken, was ihnen auch weitgehend gelang. Die Handlungsmöglichkeiten der Betriebsräte sanken und konnten auch mit politischer Unterstützung etwa im Bereich des Unfallschutzes gegen den Widerstand von Zechenleitungen und Bergaufsicht praktisch nicht wieder erweitert werden. Gleichwohl tobte der Kleinkrieg um die Verfahrensstrukturen weiter.

Das Fehlen einer erfolgreichen betrieblichen Mitbestimmung förderte auch weiterhin die Neigung der Bergarbeiter zu "direkten Aktionen“. Die Arbeitszeitzugeständnisse des Frühjahres 1919 sowie die im Rahmen der Inflation einigermaßen funktionierende Lohnanpassung bei gleichzeitig niedrigem Leistungsdruck bedingte nach 1920 einen Rückgang des Aktionsdrucks auf den Zechen, der allerdings 1923 im Rahmen der Hyperinflation sofort wieder da war und sich in drastischen Formen äußerte. Für die Zechenleitungen war die offene bzw. latent vorhandene Eskalationsbereitschaft Anlaß, eine Paralysierung der Betriebsvertretungen anzustreben, was ihnen durch die alltäglichen Konflikte um die Mitbestimmungsverfahren auch weitgehend gelang. Da zugleich die Betriebsvertretungen für die Verweigerung von Mehrarbeit, damit für die geringe Leistungsbereitschaft der Belegschaften mitverantwortlich schienen, kam zu der politischen Ablehnung der Betriebsräte auch ihre ökonomische hinzu. Die Alternative, Leistungssteigerungen gemeinsam mit den Belegschaftsvertretungen anzustreben und auf diese Weise neue Lohn- und Gedingesysteme akzeptabler zu machen, kam den Zechenleitungen nicht in den Sinn, da letzteres politisch aussichtslos und ökonomisch fragwürdig schien. Zudem besaßen die Zechen keinerlei Kompetenz in Fragen einer differenzierten Arbeits- und Lohnpolitik. Eine Ausdifferenzierung und 
Professionalisierung von Sozialabteilungen erfolgte auf den Schachtanlagen nach 1920 nicht.

Die Stabilisierungsphase und die sich anschließende Strukturkrise des Bergbaus bestätigte die Zechenleitungen in ihrer harten Haltung. Als Reaktion auf die schlechten Lebensbedingungen nach der Währungsumstellung, die Verlängerung der Arbeitszeiten und das offensichtliche Versagen des Tarifsystems und damit der Tarifgewerkschaften in den Augen der Bergleute nahmen die Stimmanteile der Unionisten und Syndikalisten bei den Betriebsratswahlen weiterhin zu; die Strukturkrise beschnitt zugleich die Möglichkeiten für materielle Kompromisse. Die Zechenleitungen strebten nach 1924 daher die Disziplinierung der Belegschaften an, die politisch und ökonomisch der naheliegendste Weg zu sein schien. Die in der Tat eintretende Beruhigung auf den Schachtanlagen folgte aber vor allem dem wachsenden Arbeitsmarktrisiko und den sinkenden Einkommen der Bergleute, die nach 1924 in ihrer überwiegenden Mehrzahl zu Unterordnung und Mehrarbeit bereit waren. Eine wirkliche Integration der Bergleute in den Zechenbetrieb war damit aber nicht verbunden; vielmehr individualisierte sich das Konfliktverhalten durch zunehmende Fluktuation, stark schwankende Leistungsbereitschaft, Abwanderung aus dem Bergbau und Ausnutzung der Spielräume der gesetzlichen Sozialversicherung. Spätestens in der zweiten Jahreshälfte 1926 während des englischen Bergarbeiterstreikes wurde dieses individualisierte Konfliktverhalten für die Zechen erneut zum Problem, da eine Ausdehnung der Mehrarbeit im gewünschten Umfang unmöglich war - die Zahl der Kranken- und „wilden" Feierschichten lag durchweg über der Zahl der Neben- und Überschichten und sich bei qualifizierten Bergarbeitern eine Situation des Mangels einstellte. Anfang 1927 konnte die gute Konjunktur wegen des Engpasses „Arbeitskraft" nicht voll ausgenutzt werden. Versuche, durch scharfe Gedingestellung die individuelle Leistung zu erhöhen, riefen jetzt zudem Abwanderungsbewegungen gerade der qualifizierten Hauer zu anderen Schachtanlagen hervor.

Anstatt sich aber in dieser Konstellation mit den Betriebsräten zu verständigen und durch Kooperation mit den Tarifgewerkschaften die unerwünschte Fluktuation zu bekämpfen, reagierten die Zechenleitungen weiterhin ablehnend gegenüber jeder Form kooperativer Konfliktaustragung, da sie zu teuer und politisch bedenklich erschien. Stattdessen wurde die Rationalisierung der Unter- und Übertageanlagen forciert, zumal im Frühjahr 1927 die Streikkonjunktur nachließ und die Absatzlage sich wiederum verschlechterte. 1928 machte sich zumindest im Rahmen der Abteilung Bergbau der VSt. der Erfolg der Rationalisierungsmaßnahmen bemerkbar. Die betriebswirtschaftliche Lage begann sich zu entspannen, man konnte jetzt sogar das RWKS und seine Umlagepolitik, die sich an den minderleistungsfähigen Zechen orientierte, scharf angreifen. Widerstände der Betriebsräte gegen die Rationalisierung wurden zurückgewiesen, da man deren Erfolg nicht in Frage stellen lassen wollte. 1929 war die Abteilung Bergbau zumindest von der betriebswirtschaftlichen Seite her auf dem richtigen Weg.

Für die Belegschaften brachte die forcierte Rationalisierung nach 1926 eine Steigerung des Leistungsdrucks und eine Erhöhung des Arbeitsmarktrisikos. Diese Erfahrungen sowie das relative Zurückbleiben der Bergleute im Tarifgefüge verstärkte erneut den Abwanderungsdruck; qualifizierte Hauer waren trotz des suk- 
zessiven Beschäftigungsabbaus weiterhin knapp. Die verbleibenden Bergleute waren erkennbar unzufrieden, doch fehlte ihnen faktisch jeder Handlungsspielraum. Die Kluft zwischen den Ergebnissen von Tarifsystem und betrieblicher Mitbestimmung einerseits, den materiellen Erwartungen der Bergleute andererseits konnte jetzt auch nicht mehr durch die kollektive "direkte Aktion“ geschlossen werden, auch wenn die Kommunisten regelmäßig zu jedem Tarifschiedsspruch darauf drangen. Es blieb den Bergleuten lediglich radikales Wahlverhalten und individuelles Anpassungsverhalten. Bei den Bergleuten traten zudem die Differenzierungen nach sozialen und politischen Kriterien stärker in den Vordergrund. Damit war auch für die Betriebsräte jeder Rückhalt innerhalb der Belegschaft verloren, da kaum noch erkennbar war, in welche Richtung das Belegschaftsverhalten sich entwickeln würde. Den Betriebsräten blieb Ende der zwanziger Jahre im Bergbau lediglich das Geschäft der Mitwirkung bei Massenentlassungen, und selbst diese Aufgabe erwuchs ihnen nur durch die Notwendigkeit von behördlich initiierten und überwachten Verhandlungen, die zahlreiche Zechenleitungen durch Beschränkung der Entlassungen auf weniger als 50 Bergleute ebenfalls noch zu umgehen suchten.

Trotz der Paralysierung der Betriebsräte und der Disziplinierung der Belegschaften war die Stimmung im Bergbau schlecht. In dieser Situation ergriff die Abteilung Bergbau der VSt. mit dem Konzept der Werksgemeinschaft die Flucht zurück in das Kaiserreich. Nur die dauerhafte Integration der Arbeiterschaft in den Zechenbetrieb schien auch eine dauerhafte Sicherung der Rationalisierungserfolge zu sichern. Diese Auffassung verschärfte sich in der Weltwirtschaftskrise, da sich die betriebswirtschaftlichen Daten der Abteilung Bergbau günstig entwickelten, und man verhindern wollte, daß im Aufschwung erneut die Spielräume für Gewerkschaften und Betriebsräte wachsen würden. Da zugleich mit individuellem Konfliktverhalten gerechnet werden mußte, schienen die Beseitigung des Tarifsystems und die autoritäre Werksgemeinschaft die Wünsche der Zechenleitungen weitgehend zu erfüllen. Damit bestätigte man 1933/34 erneut jene Haltung, die 1918/19 ganz offensichtlich ihr Ziel nicht erreicht hatte. Der Bergbau mußte daher auf die Hilfe der Politik setzen, die ihm nach 1918 scheinbar versagt geblieben war; den Herausforderungen der demokratischen Republik, in denen eine Kompensation betrieblicher Integrationsfähigkeit durch politische Repression nur sehr beschränkt möglich war, hatte er sich nicht gewachsen gezeigt.

Die Entwicklung der industriellen Beziehungen im Bergbau wurde von der wirtschaftlichen Lage des Steinkohlenbergbaus entscheidend determiniert. Die wirtschaftliche Lage bedingte in hohem Maße das Verhalten und die Interessendefinition der betrieblichen Akteure. Die sich aus diesen „Basisinteressen“ ergebenden Konflikte wurden aber nicht kooperativ reguliert, sondern konfrontativ gegeneinander gestellt und durch Machteinsatz zu entscheiden gesucht. Die Folgen dieses Machteinsatzes verschärften wiederum die materielle Situation der Akteure, deren Interessenartikulierungen daher immer konträrer wurden. Einen Ausweg aus dieser Konflikteskalation bot jeweils nur die politische Intervention, die eine Konflikteskalation vermeiden wollte, durch ihre Neigung zur Konfliktmoderation indes wiederum keine der beiden Seiten zufriedenstellte. Sie konnte nur scheitern, ebenso wie die vom Gesetz vermittelnd gedachte Funktion des Be- 
triebsrates zu keiner Zeit ihre Wirkung entfalten konnte. In dieser Konstellation der permanenten Konfrontation wurden Betriebsräte, die um vermittelnde Konfliktregulierung bemüht waren, fast zwangsläufig aufgerieben.

Die eigentliche Frage im Bergbau war daher, warum es zu keiner Verständigung über die Konfliktaustragungsformen kam. Die Gründe hierfür waren komplex und ergeben sich zu einem großen Teil nur aus der Art und Weise des Konfliktverlaufes selbst. Einige Punkte waren gleichwohl auffällig. Hierzu zählt vor allem die Betriebsführungstradition des Bergbaus, die bereits vor 1914 institutionell verfestigt worden war. Sie verhinderte nach 1916 ein Eindringen der betrieblichen Mitbestimmung in die Organisationsstrukturen des Bergbaus, die zu einer inneren Differenzierung der Organisation und zu einer Infragestellung der bisherigen Betriebsführungstraditionen hätte beitragen können. Die Organisationsstrukturen des Bergbaus und seine Führungstraditionen erwiesen sich als hermetisch gegenüber jeder Innovation, da sie interne Differenzierungen verhinderten, durch die Innovationen sich in die Organisationen hätten einschreiben können. Diese Hermetik provozierte wiederum Reaktionen der Bergarbeiterschaft, die sie nur bestätigte, zumal seit 1924 die Strukturkrise jedes sozial- und arbeitspolitische Experiment zu verbieten schien. In Anlehnung an Klaus Eder läßt sich für den Bergbau daher von "pathologischen Lernprozessen" Handlungsfähigkeit der Bergbauunternehmen in sozialen Fragen ständig zurückging. Das Werksgemeinschaftskonzept war der Versuch, Handlungsfähigkeit zurückzugewinnen, ohne in der eigenen Organisation und bei den eigenen Traditionen Veränderungen vornehmen zu müssen. Es blieb völlig erfolglos, abgesehen davon, daß es zur Zerstörung der Weimarer Betriebsverfassung beitrug und dem Nationalsozialismus den Weg ebnen half. Die Kehrseite der eigenen Handlungsunfähigkeit war der Ruf nach dem Staat bzw. die Bekämpfung der parlamentarischen Republik. $\mathrm{Zu}$ eigenen differenzierten Antworten auf die sozialen Probleme des Bergbaus unfähig, belastete man das politische System mit Erwartungshaltungen und Forderungen, die es während der Weimarer Zeit schlechterdings nicht erfüllen konnte. Die Wende zur Unterstützung des Nationalsozialismus war mithin Ausdruck eigener Anpassungs- und Handlungsunfähigkeit im sozialen und arbeitspolitischen Feld.

Da zumindest die Abteilung Bergbau der VSt. allerdings zugleich die Strukturkrise einigermaßen erfolgreich gemeistert hatte, schien ihr andererseits diese Handlungsunfähigkeit nicht als problematisch. Sie war der Preis, der für eine streng betriebswirtschaftlich konzipierte Sanierung der Schachtanlagen zu zahlen war, deren soziale Folgen vielleicht bedenklich waren, das Konzept aber keinesfalls in Frage stellen durften. Der betriebswirtschaftliche Erfolg wurde mit Maßnahmen erkauft, deren soziale Konsequenzen in einer parlamentarischen Republik, die auf Massenzustimmung angewiesen ist, dauerhaft nicht erträglich waren. Das Plädoyer für die autoritäre Diktatur war daher zugleich Zeichen der sozialen Handlungsunfähigkeit wie der scheinbaren ökonomischen Stärke. Eine Alternative hierzu hätte einen Bruch mit den Traditionen und Organisationsstrukturen der Vorkriegszeit zu einer Zeit verlangt, als Experimente riskant erschienen, zu-

${ }^{724}$ Eder, Geschichte als Lernprozeß, S. $17 \mathrm{ff}$. 
mal nicht sicher war, daß Änderungen innerhalb der Bergbauunternehmen mit wirtschaftlichem Erfolg prämiiert worden wären. Das Beispiel der Abteilung Bergbau der VSt. scheint das Gegenteil zu belegen. Betriebswirtschaftlich war der Bergbau nur noch mit massiven sozialen Folgeproblemen zu sanieren, zumindest solange der Staat nicht zu einer umfangreichen Subventionierung der Branche oder zu Strukturpolitik im heutigen Sinne fähig und bereit war.

Insgesamt ergibt sich für den Kohlenbergbau damit das Phänomen einer strukturellen Überlastung durch wirtschaftliche Krisen und organisatorische Unbeweglichkeit, die sich gegenseitig jeweils aufs Neue bestätigten. Die Reichweite der betrieblichen Mitbestimmung war daher von Anfang an begrenzt, da sie die Grundprobleme des Bergbaus nicht lösen konnte. Im Bergbau zeigte sich letztlich das ganze Dilemma der Mitbestimmung, die nur funktionieren kann, wenn sie erfolgreich ist. Daß indes nicht einmal der Versuch zur kooperativen Konfliktbewältigung gemacht wurde, lag an einem durch die sozialpolitische Starrheit und organisatorische Unbeweglichkeit der Zechen ausgelösten Eskalationsprozeß, der schließlich sowohl bei der Bergarbeiterschaft wie bei den Zechen in gegenseitiger Konfrontation endete. 